Portland State University

PDXScholar

$1-1-1979$

\title{
Group painting as a means of self-expression and communication for mentally retarded persons: three case histories (volumes I and II)
}

Yaeko Steidel

Portland State University

Follow this and additional works at: https://pdxscholar.library.pdx.edu/open_access_etds Let us know how access to this document benefits you.

Recommended Citation

Steidel, Yaeko, "Group painting as a means of self-expression and communication for mentally retarded persons: three case histories (volumes I and II)" (1979). Dissertations and Theses. Paper 848.

https://doi.org/10.15760/etd.848

This Thesis is brought to you for free and open access. It has been accepted for inclusion in Dissertations and Theses by an authorized administrator of PDXScholar. Please contact us if we can make this document more accessible: pdxscholar@pdx.edu. 
GROUP PAINTING AS A MEANS OF SELF-EXPRESSION AND COMMUNICATION FOR MENTALLY RETARDED PERSONS:

THREE CASE HISTORIES

VOLUNE I

by

YAEKO STEIDEL

A thesis submitted in partial fulfillment of the requirements for the degree of

MASTER OF SCIENCE

in

PSYCHOLOGY

Portland State University

1979

(C) Yaelo steicel 1979 
TO THE OFFICE OF GRADUATE STUDIES AND RESEARCH:

The members of the Committee approve the thesis of Yaeko Steidel presented December 13, 1978.

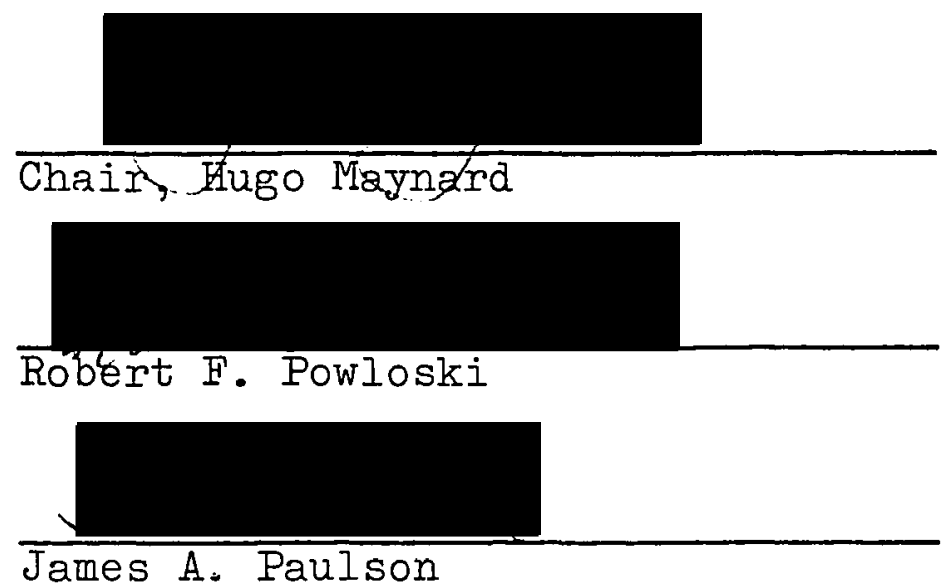

APPROVED :

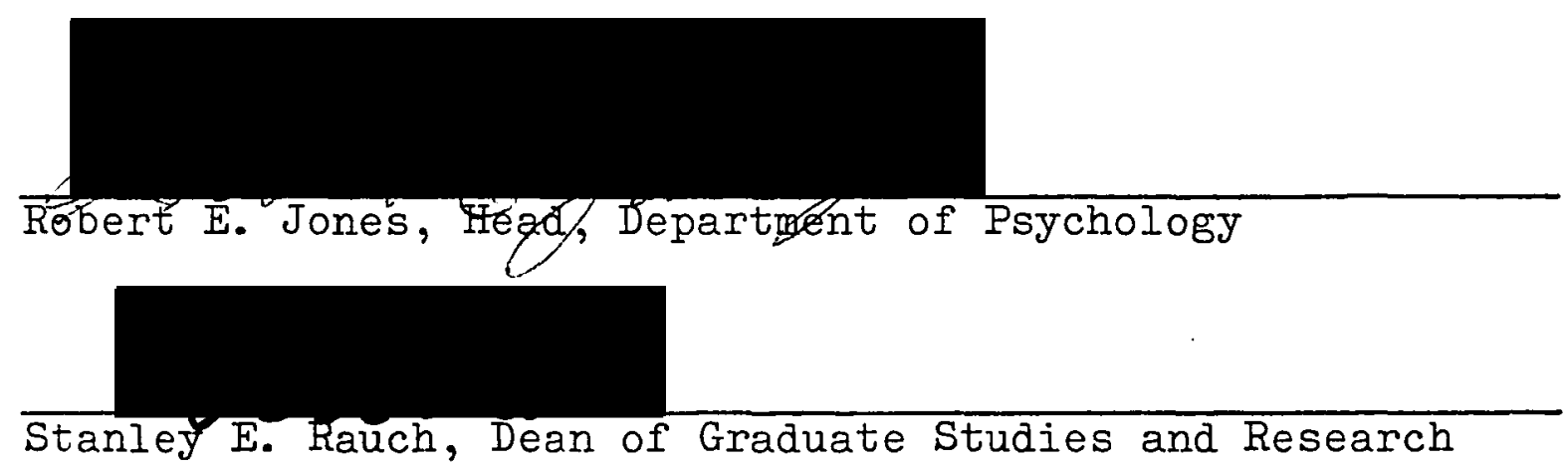


AN ABSTRACT OF THE THESIS OF Yaeko Steidel for the Master of Science in Psychology presented December 13, 1978.

Title: Group Painting as a Means of Self-Expression and Communication for Mentally Retarded Persons: Three Case Histories.

APPROVED BY MEMBERS OF THE THESIS COMMITTEE:

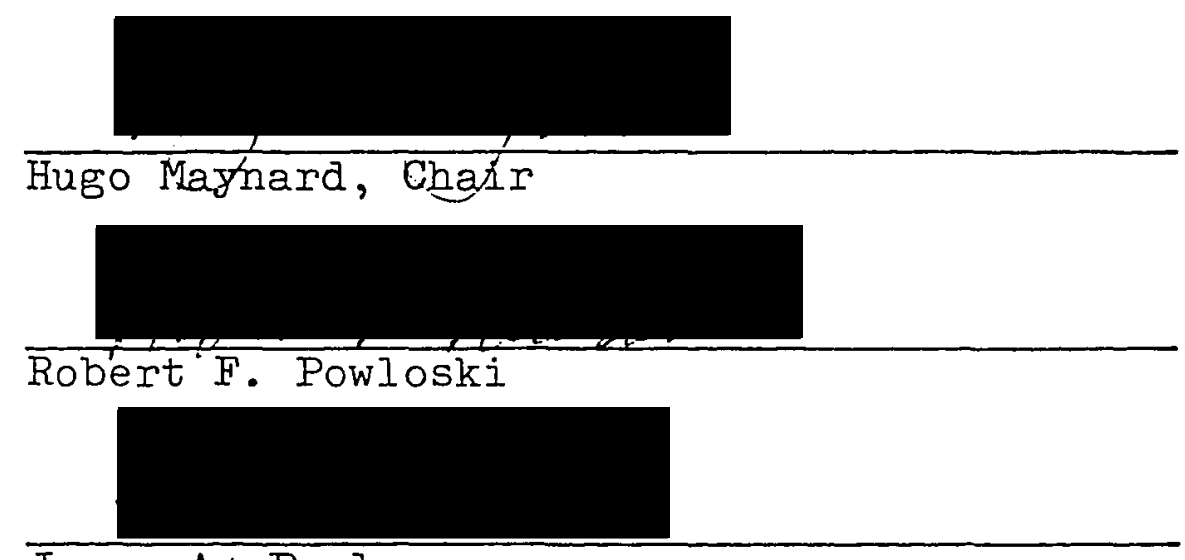

James A: Paulson

This thesis presents the results of a longitudinal study of a painting class for a sroup of rentally retaraed anci physically hanaicapped youns adults. The author's observational joumal and the students' peintinss provioded the basis of the thesis.

The author gave maximum freedom to her students and the students fully exercised creativity through their paintins activity. Eventually each student created his ow style in his painting. This experience brought a new laentity to the group. The stuaients evolved from a collection of 
separate people into a cohesive social unit.

The author tries to show, in this developmental process, how intellectual and emotional events ano problems were met and solved by the studerts in their painting activity. Paintins is seen as a powerful medium of co:munication and expression for the students. In order to emphasize this point, the author used three case histories which incluae 132 pictures presentea in VOI. II. 


\section{PREFACE}

This thesis is a report of experiences in my painting class for a group of mentally retarded young adults. How did I get to know this group and how did I get the idea of teaching them painting? In spring term, 1971, I was taking a Community Psychology class taught by Dr. Hugo Maynard at Portland State University. The course required a practicum experience in a community setting. I asked one of my classmates for advice about my practicum. She introduced me to a group of mentally retarded young adults in a special education program where she was working on her class project with a young woman afflicted withcerebral palsy.

When I first met these mentally retarded people, I did not have any idea what to do with them for my practicum. I had never had any experience with mentally retarded people, nor had I any knowledge about them. At that time my classmate was trying to teach verbal communication to the cerebral palsy woman. This woman was nearly deaf in addition to her severe vocal deficiency, and both my classmate and she were struggling pitifully in order to communicate verbally. I suggested to my classmate the idea of using drawing or painting as an aid for communication. At that time I was taking painting rlasses at Portland State 
University, and I experienced the highly communicitive nature of painting.

My classmate accepted my suggestion but did not know how to teach drawing or painting to the woman when verbal instruction was impossible. I decided to try. I first brought two sketchbooks and a box of crayons to class. I gave the woman a sketchbook and I sat next to her and began drawing in the other sketchbook. She watched me draw for a while and then started drawing with crayon by herself. Fortunately she had good eyesight and was able to hold the crayon. Soon she began enthusiastically drawing many subjects such as birds, dogs, and flowers that were dear to her in her daily life. Her teachers, classmates, my classmate, and myself were charmed by her drawings and heartily cheered her on. For the first time this cerebral palsy woman experienced an active communication with the people around her. She quickly became a cheerful and happy person. This first success made me decide to work with the group of mentally retarded people through the teaching of drawing and painting. Most of them had speech difficulties along with emotional disturbances and suffered from lack of communication with the people around them.

I gave my painting class maximum freedom in order to encourage them to express themselves freely. Each student in the class truly enjoyed self-expression through art and urgently worked to create their own style. Through their 
art they also created communication among themselves and with the people around them. This experience brought them a new and positive self-identity. Each of them became stronger, and then finally they formed their own peer group.

Participating in their dynamic learning and growing process was one of the most significant experiences in my life. This experience gave me a firm belief in human creativity which allows us to search limitlessly in every direction for our survival. What I learned from these mentally retarded people is so precious that I decided to share my experience with other people. The result is this thesis.

I wish to thank the people who helped make this project possible. I truly thank my students who treated me as their friend and openly expressed themselves in their art. I thank the student's families who gave me their full cooperation in my working with their children. I thank the administrator of the special education program who allowed me to work with her students. I thank the teachers in the program who kindly cooperated with me in my paintine class. I thank the American and Japanese college students and classmates at Portland State University who assisted in my painting class.

My sincere appreciation goes out to Mr. Craig G. Choshire and Mr. Melvin Katz who helped me understand the 
art work of my students. My sincere appreciation also goes to Dr. Robert F. Powloski and Dr. James A. Paulson who warmly supported my activity.

My special appreciation goes to Dr. Hugo Maynard, my advisor in my master's program in Psychology, who gave me complete freedom in my practicum. Without his support I could not comfortably have given such freedom to my students in the painting class.

At last my utmost appreciation goes to my husband who continuously. supported us with painting materials, lunches, and transportation along with silent but compassionate good cheer. 
TABLE OF CONTENTS

PAGE

PREFACE ...........................

CHAPTER

I INTRODUCTION • • . . . . . . . . . . . . 1

II CASE HISTORY: DAVID . . . . . . . . 13

The First Stage . . . . . . . 16

III DAVID: THE SECOND STAGE . • . . . • . 27

IV DAVID: THE THIRD STAGE . . . . . . . 50

V CASE HISTORY: EVE . . . . . . . . . 70

The First Stage . . . . . . . 74

The Second Stage . . . . . . 80

The Third Stage . . . . . . . 81

The Fourth Stage . . . . . . . 83

VI CASE HISTORY: KAY • • • . . . . . . 94

VII DAVID: THE FOURTH STAGE • • • • • • . 127

VIII CONCLUSION . . . . . . . . . . 161 


\section{CHAPTER I}

\section{INTRODUCTION}

My thesis is a report of my own experiences in my painting class for mentally retarded young adults. In this introduction, I would like to state briefly what happened in the class and why I think it is important.

From April 1971 to March 1974 I taught painting to a group of mentally retarded young adults. During this period of time the class number varied from ten to fifteen students. They were seventeen to twenty-three years of age and their I.Q.'s ranged up to 55. Some students had certain visible physical defects. Two women were confined to wheelchairs with cerebral palsy and one man was blind in one eye. Two women had Down's Syndrome. One woman suffered from stunted growth. One man had suffered brain damage at birth and had a visual defect.

I taught painting to the group in their regular classroom in a private special education program from April 1971 to June 1973. I met with them once or twice a week. Their class in the special program was canceled after spring term 1973, and thereafter I continued the painting class in my home. We met once a week or once every two weeks during this period. 
When I first began working with the group, I noticed that there was no real companionship or group coherence. I wondered about this situation. Many of these students had been together for a long time. Some of the oldest members had been in this program together for over ten years. Why was there no close relationship among the long time acquaintances? After associating with the students, their teachers, and their parents for some time, the answer began to reveal itself.

The uncooperative attitudes of these students toward each other seemed to be nurtured by the negative feelings of their parents toward the other students plus certain teaching ideals of their class instructors. Through talking with the parents, I realized that our society is not really very kind to the mentally retarded people and their families. The state government is responsible for their education until they reach the age of seventeen, so most of them attend various public and private special education programs.

But assistance programs for the mentally retarded over the age of eighteen have not been well developed. Some job training programs are available, but not nearly enough. And once these people do get a job such as a janitor or dishwasher, they find little understanding from their co-workers. In many cases they have difficulty in holding a permanent job. Consequently they give up trying 
to provide for themselves and end up living out their lives on welfare. They are treated as persons who are not capable in addition to being harmless. They live their lives quietly in a corner of our society, isolated and left out. We are not yet understanding and kind enough toward these people.

The parents receive little understanding and help from society in dealing with their mentally retarded children. They have to cope with most of their problems by themselves. The parents feel alienated and do not trust people or society. This situation breeds the negative attitudes of the parents, which are then transferred to their children. The children are not open to each other. They don't feel free with people. These feelings cause conflict in the classrooms.

Certain teaching goals of the instructors in special education also present problems for the mentally retarded. These goals involve teaching the student to think, behave, and act as similar to normal people as possible. Consequently, the less retarded students with no physical handicaps are treated as superior, good students while the more retarded and severely handicapped ones are treated in opposite fashion.

In the program where I taught, the teacher's value system influenced the class atmosphere, divided the students, and stopped class intercommunication. The less 
retarded students lookeo. down on the other members. They did not help the severely retarded. Rather, they felt superior and didn't want to associate with the others. The combination of parents' and teachers' influence on the students created an uncooperative atmosphere in the class. Although these students are all gentle people, they never actively interacted with each other. There was no cohesiveness. The group was not happy.

As I mentioned earlier, I immediately felt these unhappy relations. In addition to the unfavorable group atmosphere, each student seemed to have his or her own personal problem. These people were very different from normal students, with special needs and abilities. I had to be very careful in deciding what and how to teach them through painting.

First of all, I wanted to teach them the joys of painting. If they could find enjoyment in painting my goal would be almost completed. How could I introduce them to this joy? In order to be a conscientious instructor, I should know each student's individual emotional problems and his or her special needs. But understanding each one's problems and needs and teaching each one individually according to his or her own unique situation would take a very long time. Without knowing each student's special situation, how could I start to teach this group of mentally retarded, emotionally disturbed people? 
I decided to be very, very patient. I set up one rule or basic attitude for my class. Anyone could paint anything he wanted to, anytime he wanted to, anyway he wanted to. I knew from my own experience that only when we really want to paint can we really enjoy painting. We need to have our own strong feeling in order to paint something and enjoy it. When we are forced to paint, it becomes a torture rather than a pleasure. We should paint only when we feel like it:

Ever since these people were very young, they had been treated as mentally retarded and had been in special education programs. They could have quite a different image of the world than normal people have. I thought it would be meaningless for me to tell them what to paint. They should paint whatever they wanted to paint:

Concerning technique, or how to paint, they should be allowed to paint as they please. We should not be concerned with the so-called technical standards of painting. People differ in their color perception. In each individual, color perception changes as his emotional state changes. Usually, there is a strong preference in the use of individual brush strokes. One's brush stroke changes also as one's emotional state changes. Some people prefer to paint objectively; others prefer to paint subjectively. I believe that it is very important to exercise one's own unique technique. 
In short, I wanted my students to be completely free in my painting class. They had been what I call "don't" conditioned. Since early childhood they had been told by their parents and teachers to don't say that, don't do this, don't think or be that way. I wanted them to break away from this "don't complex," to express themselves openly. Even just a dot or a line must be significant to an individual, as long as it is his own. He will see himself in whatever is expressed on his paper. He will enjoy this experience and will continue painting.

My painting class began as one which was completely student-oriented with the students painting freely. I placed paper, paint, brushes, and water on the table and waited. Students would approach the table and say, "Yaeko, I want to paint!" I would then prepare the painting material for them, and they would sit down at the table and paint. Some students painted all day long. Others would paint for one or two hours. Another student would paint only twenty to thirty minutes at a time several times a day. Some students took considerable time to carefully finish one painting. Others made many quick paintings within a short time.

Some students painted many different objects while others kept with the same object for many months. For example, one girl painted squares only. And a boy just scribbled for a long time. Some people preferred water 
color. Others liked crayon, and still others preferred pencil drawings.

Visitors to my painting class were surprised at the undisciplined and noisy atmosphere. Some class members would be dancing to music by the record player while others were looking at comic books. One boy was constantly running around the room cleaning, dusting, and sweeping. Someone would be sitting in a chair daydreaming. Several students would be eagerly painting at the table in the midst of all the other activities. These excited and. inspired painters would shout continually, "Yaeko, I need more color," or "I need clean water."

The class seemed to be a disorganized mess to the random visitor. But to me it was an important and meaningful class. All the students were doing different things, but there was one thing in common: they were each doing what they wanted to do. They were, one and all, relaxed and contented. I could feel a peaceful and warm atmosphere in this noisy class. I would sit by the painting table, feeling very satisfied and pleased with myself. As the painting class progressed it became more and more apparent that the freedom that the students experienced in the class was very important. They were free from the "don't conditions" and were allowed to express themselves through painting. 
Another important aspect of my teaching philosophy centered on how I looked at and evaluated each student's work. At the beginning of the class I realized that their paintings were on the same level as those of normal children five, six, or even two or three years old. But I also saw that they had, in their childish paintings, something more. I saw an expression of deep adult-like emotional energy. In their work I could see and feel deep sorrow, anger, and joy. I understood that by our normal intellectual standards these people were retarded, but they were not retarded in their emotion. Many of them were very sensitive and their paintings showed their suffering hearts. They wanted to grow as human beings with rich souls, yet, this yearning was constantly suppressed in this society. This revealing of their inner personal world in their paintings impressed me, and I felt a deep sympathy for them.

There were two young women who painted only squares. When I gazed at these paintings of squares, I could feel the girls' fear and suffering. There was a young man who only scribbled as a normal two or three year old child would do. But his use of strong colors and strong brush strokes conveyed to me this young man's outbursting energy. When I saw the students' paintings, I was struck by their spirit and strength. My voice, coming naturally from my heart, would say to each student, "Oh, it's 
beautiful," or "How nice it is," or "It is so interesting." I began to understand their world very well. No longer did the details of their paintings seem so important to me. I wanted to see them as whole human beings in their paintings.

As I began to understand them better, I began to feel a very deep friendship and respect toward them. To me, they were not mentally retarded people, but good painting friends whose hearts were gentle and sensitive. This loving feeling and respect toward them grew naturally. All my students well understood my feelings, and they treated me as a painting friend rather than a painting teacher. During the three years of our association these students continued proudly to paint more and more with increasing freedom and abandon. Through painting activity they developed a deep, natural friendship with me. As this activity continued, each student became a stronger and happier person. Some changed slowly; others changed quickly. But all of them improved and became more stable. These students' mental growth was reflected clearly in their paintings.

The women who drew only squares started arranging many squares in many different ways, using a great variety of colors. They created a beautiful world of squares. Afterward, they began to draw other objects such as rainbows and flowers in addition to their squares. 
One woman with cerebral palsy was almost deaf and was confined to a wheelchair all the time. Until she was twenty-one years old, no one thought she could do anything. She was left alone in the classroom most of the time. She looked very pale and never spoke up. She always sat in her wheelchair in a corner of the room in silence.

This severely handicapped woman showed extremely good and sensitive color perception. She was one of the best and most eager students in the class. Her painting improved so much in twenty months that she received a scholarship from Portland State University. She painted in the university in a college-level class with normal college students. By the time she began this college course, she was no longer a quiet, shy girl. She had become a very happy young woman, laughing and shouting whenever she became excited about her paintings.

The whole group changed as each person became stronger and happier. While painting together they exchanged ideas and showed their paintings to each other. They seemed to understand each other better and feel a natural friendship among themselves. They began to care about and heıp each other. The more capable students began to take care of the more disabled ones who were in wheelchairs. When a newcomer came into the class, they got together, helped him, and made him feel welcome. The newcomer quickly became a member of the group. Finally the 
whole class emerged into a happy, beautiful association. Through painting they freely expressed themselves to each other, and each one warmly accepted the other's world. This painting atmosphere bred a very healthy and cheerful environment in the group. When I first began to teach painting to these young people, my goal was to teach each one the joy of painting. It seems they achieved much more than I expected. Through this group painting experience, the whole class achieved mutual understanding, companionship, and happiness.

In my thesis, I would like to emphasize the effect of painting as a self-expressive and communicative medium. I want to reveal how it was possible for a person to change and improve his way of life through painting in the group. To make my point clear, I will choose three persons in my painting class who showed remarkable progress and write their case histories. These three are David, Eve, and Kay. The names "Eve" and "Kay" are pseudonyms which I will use to protect the privacy of these two students. I cannot use another name for David since his name is an important part of many of his pictures, so I have obtained permission from him and his mother to use David's name in this thesis. There was a very important relationship among these three classmates. By the time David had painted with me for a year and a half, Eve and Kay, both severely retarded, entered our class. David voluntarily helped both girls 
and persuaded them to begin painting. Through painting activity these two girls became happier and stronger, and eventually more capable in their daily lives. Assisting the two girls was an important experience for David, which facilitated his socializing and maturing process.

I kept a daily diary of the class from beginning to end. I would like to choose relevant material from this diary to explain the progress of these three people. Included in this report will be photographs of their paintings which show each person's improvement. These photographs appear in Volume II of this thesis. 
CASE HISTORY: DAVID

When I first began my painting class, David was twenty years old and held the longest membership in the class. He had attended the special education program longer than anyone else in the class. At the age of eight David achieved an I.Q. rating of 44 on the Stanford Binet Intelligence Scale. The following quote was taken from a report written by the Psychological Services, Portland Public Schools, in September, 1958.

David still has a moderately severe speech difficulty and rarely uses more than single words or two word phrases. Comprehension of direction often seemed poor and the attention span is extremely limited. Insight into success and failure was also limited. He established a basal age at two years, six months, then passed a few items at each age level up to the six year group at which time he failed all subtests. Moreover, successes were few beyond the four year level. On the Goodenough Draw A Man Test, David reached a mental age level of only four years, six months, which again suggests that this is a severely retarded child. It seems unlikely that this child will ever reach a mental age beyond the six and one-half to seven year level.

David had certain physical defects. He was blind in the left eye. His chest cavity was deformed, and there was a large protruding lump on his chest. He had a walking and coordination problem. With all of these handicaps in addition to being a very tall boy, David looked and acted quite awkward. 
David had a nice, warm and loving home life, but in spite of this good home environment, he was not happy at school when I first met him. He was frustrated and very moody. He often became upset and angry over the slightest incident. The instructors were afraid of him and would not go near him when he became furious.

I wondered why David was so frustrated. I soon found out that his more capable younger brother, who was also in our class, was the main reason. David's brother was a handsome young man with no visible physical defects and less speech difficulty than David. Consequently, the teachers favored him and neglected David. In the classroom, David's brother was always with his own friend who was also one of the more capable members of the group. They did not associate often with David. This situation humiliated David very much. His teacher told me that David did almost nothing in class. No one could make him do anything.

When I first began teaching painting at the special education program, David did not join the group immediately. He started drawing with us several weeks later and kept working for three years. His art improved remarkably. $\mathrm{He}$ also showed beautiful personality growth along with his progress in art. There are four distinct stages in David's development during these years. 
The first stage was a sort of initiation period in which David began painting with the class and rather timidly laid out several painting themes of his own. Figures 1 through 11 belong to this first stage. David and I gradually began to know each other during this time through art activity. But mostly he maintained a shy and quiet attitude during this period.

The second stage was an exploring period. David explored more drawing themes and techniques of his own and elaborated on them up to a certain level. Figures 12 through 59 belong to this period. We began to know each other more and our friendship deepened. David became cheerful, active, and relaxed. He put more trust in me. The third stage was an integrating and unifying process. David combined all of his self-taught techniques and drawing themes, and he developed more sophisticated drawing skills. Figures 60 through 70 are included in this period. David and I became close friends. He began to voluntarily help me in the painting class. He also took care of the severely retarded students who needed help. He cared about the group's welfare and did his best to keep everyone happy. The other students and teachers loved him and depended on him.

David used painting as a powerful self-expressive medium with much awareness in the fourth stage. Painting became a very important activity for him. Figures 114 
through 132 belong to this stage. He matured greatly and became very independent. Toward the end of this stage he joined a workshop program and became even more independent. Now I would like to follow David's development in detail stage by stage.

\section{THE FIRST STAGE}

The first stage was from the beginning of my painting class at the special education program, April 1971, to December 1971. As I mentioned before, David did not work with us at first. It took several weeks before he began drawing. During these weeks there were several incidents in which David and I began to know each other. I happened to meet David for the first time one day in April 1971, when I visited his class in a large church building. This first meeting was an important incident which helped a natural friendship to grow between us.

I had no preconceptions about David before meeting him, and our first meeting was very natural. It was a very windy spring day. The cherry trees in front of the church were in full bloom. The wind was making the cherry blossoms fall like snow. David was standing under a cherry tree with one of his classmates, a young girl. He was picking some blossoms from the tree for her. She already had a handful of blossoms and was smelling them. It was such a peaceful and beautiful scene. I wanted to say 
hello, but I did not want to disturb them. I walked away to the other cherry tree and began to play with cherry blossoms on the ground. The two young people came over and the girl introduced herself and David to me. David looked at me shyly and gave me a very nice warm smile. I felt that he was a warm, gentle young man. David was a frustrated and difficult student for many teachers in that educational program, but my first impression of him was a very nice one.

Several days later while I was standing at the church door looking outside, David came up, stood beside me and gave me a big smile. I wanted to talk with him, but could not remember his name. So I asked him, "Excuse me, but could you tell me your name again?" His smiling face immediately disappeared, and he put on a very frustrated facial expression. He replied in a low voice, "Dave." The change in his facial expression was so quick and definite. I realized that I had hurt his feelings because I did not remember his name. I promised myself not to make this kind of mistake again. But this incident also made me aware of David and drew my attention to him more than to the other students.

There was another incident several days later that made me feel close to David. One afternoon the regular class teacher took half of the students out for a walk. I had to take care of the others. It was the first time that 
I was responsible for taking care of the class by myself. David stayed with us. While we were painting, two young girls went out after I had asked them not to leave. I could not go after them because I had a student who was in a wheelchair and other severely retarded students. I sat there hoping the two girls would come back soon. David was looking at me very seriously. He asked, "Are you worried?" I said, "Yes, very much." David said, "Don't worry, I will follow them. I will hide behind bushes and trees and follow them." He stood up, ready to go. I did not want David to get lost. So I said, "Thank you, David. But I think we should all stay here and wait for the teacher to come back." I then understood that David was a very kind, gentle, young man. I felt much closer to him after this incident.

All these incidents made David and me aware of each other. I often wanted to talk with David but refrained from doing so. David seemed to be too shy and I decided to give us more time. Our painting class had already been in session for several weeks, but David had never yet painted. Whenever I was supervising the painting class, David stayed near me, looking at the other students' work or occasionally bringing out a sheet of art paper for his favorite classmates. I felt that he wanted to paint but was too shy. Although it was against my policy of noninterference, one day I asked him if he wanted to paint. 
He replied, "I don't know" and walked away. I thought that I should not have asked him. I then went back to the other students and forgot about him. After a very short time, the regular instructor shouted to me and exclaimed, "David is drawing a tree! This is the first time he ever drew anything." David was standing in front of a large blackboard. He had drawn a tiny two-inch tree at one edge of the blackboard with chalk. It was such a tiny tree, but I noticed that it was very carefully drawn. I told David that it was beautiful and asked him to draw it on paper. I put paper on the table and gave him a crayon. He sat there and began to draw the same tiny tree on the paper. He looked quite excited. He drew the same tree many times on several sheets of paper.

David drew this tiny tree, one or two inches in size, in every painting class until the term ended. He kept drawing it repeatedly and seemed very satisfied with his drawing activity. I sensed that this tiny tree seemed to be an important symbol for David. I named it, "David's tree." (Figure 1; David's regular class teacher collected all the drawings of David's at this period, and I could keep none of "David's tree" from the earlier stage. The "David's tree" shown in Figure 1 is a detail of one of his later drawings.) Soon the term ended and there was no painting class during the summer vacation. 
At the first painting class of fall term David showed sudden progress. He drew "David's tree" again but he also drew many other objects such as houses, pumpkins, Christmas trees, sun, stars, and moon. From this productive beginning, David's drawings steadily improved. As he drew with his class he became less moody and frustrated. Thus in this initiation period, David showed quite an improvement in both drawing and attitude. I would like to choose relevant material from my class diary to document his improvement.

\section{October 1971}

The first painting class of fall term began today. I did not meet with my painting students during the long summer vacation. When I entered the classroom today, the students ran up to me and welcomed me. The woman teacher who taught the class last year had resigned and the class now had a new male teacher who cooperated well with me in my painting class.

David drew nothing but "David's tree" during the last term. In the very first drawing of today, he drew many more new objects including a Christmas tree, house, rainbow, moon, stars, and people (Figure 2). I was quite surprised and wondered if David had practiced drawing at home during the summer vacation. There is organization in this drawing. The Christmas tree, house, "David's tree," and people are placed on the same level or plane in the lower half of the drawing and not just randomly placed. A rainbow and stars are aptly placed in the upper half. There is much attention paid to the placement of objects and a plan of construction is apparent. This new work is a jump in progress when compared to the previous stage in which David was repeatedly drawing his small "David's tree." While he was drawing this new piece he looked very eager and studious.

Although my basic rule for teaching painting to the class is giving them complete freedom with no interference, I made a suggestion to David at this time. I told David that all of his objects were beautifully done and I would like him to try drawing them 
in a large size. He tried to draw a large tree but his hand did not move smoothly in a big motion and he hesitated. I sat by him, took a piece of paper and drew a big tree. Encouraged by looking at my big tree, David drew a big tree similar to what I had drawn. He took another piece of paper and began to draw a large "David's tree." I encouraged him by saying, "That's it, keep going. You can draw big beautiful leaves too." He drew the leaves with many different colors (Figure 3 ). $\mathrm{He}$ seemed to like the big "David's tree" very much. As he kept drawing he sometimes cried out, "heehee, ho-ho" in joy. David next drew a large Christmas tree (Figure 4). This is a happy and beautiful tree. I said, "David, you are such a sweet person. That is why you can draw such a happy Christmas tree." He smiled happily and kept drawing big objects one after another.

David's enthusiasm made me suggest another idea to him. I showed him how to draw a conventional five-pointed star in one movement without stopping. I drew it only once but David memorized it right away. He drew a whole paper full of these starshaped figures and then added this star shape to the Christmas tree (Figure 4). When I saw David adding this newly learned conventional star shape to his original drawings, I regretted my careless suggestion. I thought, "David doesn't need to know this kind of conventional star. His own stars are more unique and charming. Now I don't know if my suggestion of drawing the objects in large size was right or not." In spite of my annoyed feeling toward myself, David next drew a big orange star and looked at it very proudly (Figure 5). David must have truly enjoyed drawing his objects in large size today. He kept drawing continuously for two hours. He looked very different than he usually did. He usually wore a half smiling facial expression that gave an impression of a very unsure person. Today, while he was drawing, his half smiling expression gave way to a very different expression. He looked quiet, serious, and alert. When I asked him how he liked to draw big trees, he replied, "Fun!" In that simple answer I felt David's enthusiasm and excitement toward drawing. He seemed to discover a new world of art. After two hours of drawing activity, I and David looked at all of the pieces he had done today. He seemed very pleased with his production. I was also very impressed by his new achievement. As we looked at 
his work together, we felt a very natural friendship beginning to flow between us. Today David was not a retarded youngster for me. He was a young man who began to explore the new world of creativity.

\section{October 1971}

Today the regular class teacher asked me to help him in preparing for the Halloween party. We painted several Halloween decorations such as pumpkins, skeletons, and witches. David was shy and quiet. He spent some time at first making some decorations with us. After that he sat in a corner of the room all by himself and drew a house and "David's trees" (Figure 6). The theme of this drawing is very similar to Figure 2, but this latest one was drawn carefully and in more detail. David first drew outlines of the objects and then colored them. David also drew lines to indicate the sky and ground which did not appear in Figure 2. The house is small but stands firmly, and a mass of red smoke is belching out into the air. Many "David's trees" are there, varying in size. David connected the tips of the leaves with a curved line. There are many stars of different colors twinkling in the sky. The Christmas tree has a cross on it. The house and trees are small in size but they express David's happy and loving feeling toward his home life and the Christmas season.

This last work is a better drawing than Figure 2. David isolated himself from the group when he did Figure 6 and worked quietly by himself. Once in a while he looked at me shyly. I felt as if David was writing a letter to me because he was too shy to speak to me directly. I left him alone.

\section{November 1971}

Today the class visited an exhibit of Christmas decorations in the church building that also houses our classrooms. So in our painting class, everyone naturally drew Christmas trees and many other Christmas decorations. David drew a large, beautiful Christmas tree which covered the whole paper (Figure 7). Compared to David's previous Christmas trees (Figures 2 and 4 ), this one has a more definite, determined shape and stands firmly on the tree trunk. David drew a zigzag line around the tree which looked like a net. Although I thought I should not, I 
couldn't resist asking him what that net-like thing was. He said it was a "beehive." He told me that bees made a nest in his home's chimney one time. When his father took the bee nest away, a lot of bees flew out and stung his father and brother. I wondered why David drew a Christmas tree surrounded by a beehive. I also noticed that the "beehive" was taking an important role in this drawing.

David is showing his awareness of the entire paper surface in Figure 7. He first drew a tall Christmas tree in the center of the paper. He then drew many zigzag lines at the bottom of the tree which could be an indication of a decorative covering material around the base of the tree. He then painted stars in the sky above the tree. Then he filled the space around the tree with the "beehive." The whole drawing has a well-unified and balanced composition in respect to the entire surface. This awareness of the entire surface of the paper is a very important sign of improvement. The "beehive" is important because it is something that is from David's life experience and is used as a tool to achieve a harmonious construction in his drawing.

\section{November 1971}

David drew three simple drawings today. One is a drawing of a house (Figure 8). He also drew a new shape (Figure 9). Although Figure 8 is a very simple line drawing of a house, it has several good signs of improvement in it when compared to previous house drawings such as in Figures 2 and 6 . David drew a very big house in Figure 8 in a more determined way. He drew it first with light green crayon. Then he traced it again with dark blue crayon. He is now beginning to be aware of shapes and he tried to draw a more accurate shape of a house. The map-like shape in Figure 9 seems to be a clear indication of David's awareness and search for shapes. David first drew many dots on the paper and then connected these dots with straight or curved lines. Then he added more dots with different colors.

\section{December 1971}

One of the students brought a gingerbread man pattern made out of cardboard to class today. He was tracing it on a piece of paper and coloring it in class. David imitated him and made several gingerbread man drawings. He enjoyed creating the wellbalanced shape of the pattern by tracing it. I left 
him alone and he practiced the pattern drafting repeatedly. David also painted Christmas trees and Santa Clauses today. His heart was full of joy in waiting for Christmas.

9 December 1971

David has been drawing Christmas trees ever since the beginning of this term. Today he drew a very spiritual and symbolic Christmas tree (Figure 10). He placed a red Christmas tree in the center of the paper and drew a beehive with light green, dark green and purple. A red sun is drawn beside the tree. The sun has a cross in it. David framed the whole drawing with a line around the edge of the paper.

This Christmas tree drawing has a feeling of spatial depth. The beehive stretches out from lower right to upper left of the paper just like clouds spread in the sky. The Christmas tree is floating in the clouds and the sun is in the space beyond the tree and the clouds.

The frame-like red line around the edge of the paper is very effective. It gives a boundary to the expanding clouds and integrates every element in the drawing, creating a visually well-balanced composition. This drawing also shows David's good color coordination.

Here David succeeded in expressing his emotional attachment to his Christmas tree in Figure 7; this tree is even more human-like and has a symbolic element. This Christmas tree is floating solemnly in the air as if it was religious David, himself. This is a good drawing with an intellectual element and rich, deep emotion.

David next drew a shape that is very similar to Figure 9 (Figure 11). Before starting to draw this shape, he drew a small beehive in the upper left corner of the same paper. He then drew the shape over the whole paper. As he did for Figure 9 , he first drew many dots and connected these dots with straight and curved lines. This time he started to color each small section of the shape with different colors, but he could not finish it during class time. The drawings of Figures 9 and 11 are very much like maps. Here David seemed to have become interested in intellectual interpretation of space. David first used his beehive for a rather aesthetic expression of space as seen in Figures 7 and 8 . The shapes of Figures 9 and 11 seem to be an extension of his 
beehive. It is like a more sophisticated beehive. I might call this new shape "beehive plus."

David also drew a Santa Claus today. At first I did not understand that it was a drawing of Santa. I asked David what it was. David said it was a "Ho Ho." I asked him what a "Ho Ho" was. David replied, "Ho Ho is a Ho Ho." I asked him again what was a "Ho Ho." David then told me that it was Santa. I replied, "Is that so? They why do you call Santa a Ho Ho?" He said, "Because Santa says Ho Ho." I then said, "Oh, Santa says Ho Ho. I didn't know that." David gave me a very puzzled look for a moment and started laughing. I said, "David, we don't have many Santa Clauses in Japan." I, too, started laughing.

Afterward, I realized the importance of this short conversation about Santa Claus. I did not know about "Ho Ho," so I listened to David's explanation about it. Throughout the conversation we were both friends at the same level. When David and I laughed at our conversation, we felt a very natural friendship. I felt a very natural closeness toward him. Today we had the last painting class of the term. I was very glad that I could share this warm friendly feeling with David.

During the first stage, David created his own themes of "David's tree," "Christmas tree," "house and trees," "beehive," "beehive plus," and repeatedly drew them. All of these themes, except "beehive plus," are subjects which are very close to him in his daily life. He drew these dear objects over and over with great love. At first his general attitude was one of direct emotional appeal. For instance, he expressed a loving, happy feeling in his "Christmas tree" drawing in Figure 7. In the "Christmas tree" drawing in Figure 10, he expressed his religious and serious emotion. After satisfying his emotional appeal, toward the end of the first stage, David began to search in an intellectual direction. The "beehive plus" drawings 
in Figures 9 and 11 are examples of this intellectual searching.

David's rapid mental growth can be traced by following Figures 1 through 11 . This point becomes clearer if one follows the development of his Christmas tree in Figures 2, 4, 7, and 10. There is a great change in his "Christmas tree" between Figure 2 and Figure 10. His Christmas tree in Figure 2 has an infant-like feeling whereas the one in Figure 10 has a deep, mature emotion. David had done nothing constructive in class before drawing his first "David's tree." "David's tree" was his first creation and a very significant achievement. David was very shy and timid throughout the first stage and I generally left him alone. Occasionally, when I was truly impressed by his drawings, I complimented him. He seemed very pleased with these compliments. David and I did not talk to each other much, but through the art activity, a very natural friendship began to grow between us. 


\section{DAVID: THE SECOND STAGE}

The second stage in David's improvement took place between January and August 1972. Friendship between David and me deepened during this period. He became much more relaxed in the painting class. He created new drawing themes and learned new techniques of his own. Toward the end of spring term 1972, David used all of his self-taught techniques to draw many new objects.

During the summer vacation of 1972 we did not have a regular painting class. One day David and two other classmates gathered at my home to paint together. David enjoyed our gathering and painted eagerly. On another day that summer I took all my painting students on a picnic. David was extremely happy about the picnic. He presented me with a sketchbook which contained his own drawings and paintings on the morning of the picnic. The works in that sketchbook are very free and clearly show that David began to draw with much confidence and skill.

Along with improvement in his art work, David's attitude toward his classmates changed greatly. He had always isolated himself from his male classmates. During this period he overcame his shyness and became a very 
cheerful, fricndly person. He began to draw with his classmates in addition to working with them. He also began voluntarily helping me in the painting class.

I would like to present a detailed account of David's improvement during this second stage. Since I gave him freedom from the very beginning, he had learned his drawing and painting through self-teaching. He often showed important improvement within one day. I want to emphasize his self-learning process and present drawings and paintings to illustrate this process in detail. Figures 12 through 59 are David's representative works for this second stage. 6 January 1972

Today we had our first painting class of the term. David's general classroom was moved from the school's basement to ground level. The new room is smaller than the former one, but it has more windows and daylight. It also has a small kitchen in one corner. David seemed happy to meet me after vacation, but he was still shy. One of the students brought a toy cat to class today and she suggested that everyone draw it. David drew the toy along with the other students, but he seemed to be unable to concentrate on the drawing. Maybe it was because he hadn't drawn during vacation. I left him alone.

\section{January 1972}

David sat down beside me and drew one drawing (Figure 12). After that he watched his brother and other young male classmates who were sitting together and drawing. He said, "I want to sit with them." He went there and sat with them and drew. He had always kept himself isolated from these male classmates. Today he voluntarily wanted to draw with them. I thought it was a very good sign. I was also very glad because for the first time David expressed his intention so clearly. David sat with his male classmates and drew his "house and trees." 
He drew a yellow house and a sun and then added a large blue "David's tree" (Figure 13). The classmates around David seemed to be stimulated by David's drawing. They all drew a house and a sun. The young men had never drawn the sun before. So apparently they got the idea from David. David seemed to be very pleased at sharing his idea with them. The two drawings which David drew today, Figures 12 and 13, have a very free and happy feeling. He called the first drawing "a rain" (Figure 12). The colorful rain, red, green, blue, and black, is falling in many directions. It has a rhythmical movement just as if a warm happy feeling was flowing through David while he drew. The next drawing of a yellow house, the sun, and a blue "David's tree," in Figure 13, was drawn with much freedom. David's Cray-pas (an oil-base art crayon) moved freely over the paper. The combination of yellow and blue is very pleasing. He finished the drawing by adding two round objects, a moon or stars, in the upper corners and wrote his name in the right lower corner, He used red for these moon or starlike objects and his name. By doing so, he gave the drawing a structure which brings a feeling of vast space surrounding the house and tree. Compared to David's previous drawing of "house and trees," this one has a more direct, strong emotional approach.

After David drew with his classmates, he played a game with them. I was very surprised to see David participating and sharing in the game. He seemed to realiy enjoy this first companionship with his classmates.

I made a Japanese lunch for the class today, using the small kitchen in the classroom. Everyone was excited about cooking together. They helped me by cutting vegetables and setting tables. David was especially happy and excited, and helped me a lot. He kept saying, "It's fun." When we needed to take down the dishes and cups from a high shelf, David said, "I am tall, that's my job." He took care of everything. Today I could clearly see that David had become a much happier and active person.

\section{February 1972}

David drew two drawings today (Figures 14 and 15). The first drawing contains David's important themes from the previous term including: "house and trees" 
and "beehive." He drew a large, colorful "David's tree." At the bottom of the "David's tree" is an irregular circle which looks like roots. In the circle is a "Christmas tree" which seems to be a part of the roots of the "David's tree."

Ever since David began drawing his "David's tree," I have thought that it could be a very important symbol of himself. The same thought applies to David's "Christmas tree" theme. He rirst drew his "Christmas tree" last term and gradually improved it. It finally began to wear a symbolic atmosphere, such as in the drawing in Figure 10. Therefore, I have begun to think that the "Christmas tree" is another important symbol of David.

Here in Figure 14, David unified the two symbolic trees into one and created a well-balanced and wel1-shaped tree. The tiny house was drawn in the center of the paper beside the "David's tree" with a red and blue "beehive" surrounding it. The "beehive" creates a sort of spatial depth which is very similar to that done in Figure 10. The red "beehive" can be seen as a spatial indication of foreground, and the blue "beehive" can be seen as a spatial indication of background. The red house is placed between the foreground and background. Compared to the large "David's tree" the house seems to stand far away.

There is a tiny flower drawn at the right side of the paper in Figure 14. David drew this after he had finished the main figures. The central figures occupied the left side of the surface and left the right side blank. David achieved a wellbalanced placement by adding this tiny flower. It shows how accurately David was aware of the entire surface and how he attempted to achieve a balanced and pleasing composition.

After David drew Figure 14 he became very free and drew a large valentine heart (Figure 15). An egg-shaped blue circle in the center of the paper is surrounded by a brown circle. Around the brown circle is a large, red heart. There is a single blue line circling the red heart and many short blue lines connecting the blue line and heart. The use of the cool, dark blue color at the center and outer edge of the red heart creates a strong color effect.

It has been ten months since David first drew his tiny "David's tree." Today he combined his important themes which he developed during the past ten months and created a drawing, Figure 14, with a 
harmonious, loving atmosphere. David also expressed his love through the dynamic drawing of the heart. At the previous painting class David showed freedom in his drawings (Figures 12 and 13). Today he became even more free and bold in his expression. I think this direct expression of emotion in Figure 15 is a very good sign.

By looking at today's two drawings, I understood that David is a warm and gentle young man with a strong personality. Some teachers are still afraid of David because they think he is frustrated and can become violent at any time. But to me David is a young man who has such a beautiful world within himself.

\section{February 1972}

David was quiet this morning and thinking seriously about something. He drew five drawings, Figures 16 through 20, and then went back to his desk to do some math problems. Looking at these five drawings, I found that David tried something important.

In Figure 16 David drew his usual themes "house and trees" and "beehive," and then added yellow rain. He next drew a new figure (Figure 17). David said it was a bird. The two top lines of the spread wings are similar to the top curved lines of his valentine heart in Figure 15. The short lines on the wings are similar to the short connecting lines on the outer lines of the heart. David drew this piece quite freely, just as he did in the valentine heart drawing, but there is something different in this new drawing. Compared to the direct, emotional approach that is seen in his valentine heart, this bird drawing has an intellectual element. David attempted to express the force or power of the bird's wing motion in flight by constructing a complicated shape and line. There is an idea of planned structure in this drawing. David drew only the outline of a valentine heart in his next drawing (Figure 18). Then he drew a "house" again (Figure 19). There are some random lines floating through and around the house as if David attempted to draw something more. At last he drew the outline of a valentine heart with a cross shape inside of it (Figure 20). While he drew the first four drawings, he was deep in thought and seemed to try to put on paper what was in his mind. He tried one by one but could not 
satisfy himself. After he finished the fifth drawing he quit and returned to his own desk.

I would like now to follow David's learning process which lies behind these five drawings. He first warmed up by drawing his old theme "house and tree." Next he drew a very complicated shape of a bird. He must have been stimulated by this success. He gained much confidence and attempted to draw something new. He drew the outline of a heart but could not go further. He could not grasp his own idea clearly. He returned to his old theme of "house." After that he tried again to draw a heart shape, and this time he put a cross in it. He became satisfied at this point and quit.

The well-balanced and symmetrical bird shape drawing in Figure 17 could be seen as the result of all David's learning gained till then. By drawing this shapely bird, he became aware of the art of well-balanced lines, shapes, and dividing space. He wanted to express his awareness of the beauty in a symmetrical and balanced structure. He succeeded in expressing his intention when he drew the drawing in Figure 20. Figure 20 is a simple but very important drawing in the development of David's self-teaching process. It shows that David intended to put an inteliectual element into his drawing. David accomplished a very free, emotional expression in Figures 12 through 15. After that his need of emotional outlet must have been satisfied. Then he felt a need of an intellectual element in his drawing. David told me that Figure 20 was a drawing of a car tire.

\section{February 1972}

Today David was in a very good mood, smiling all the time. He drew seven simple drawings. He drew the first one carefully, but after that he drew fast and free as if he wanted to lay out all the ideas in his mind before he forgot them. These seven drawings, Figures 21 through 27 , are simple but have significant meaning.

Among the seven drawings, Figure 26 is a new theme. Figure 27 is an elaborated drawing of the "tire" which he introduced for the first time in the last painting class. When I looked at these latest seven pieces, I could see the process by which David created his new theme in Figure 26.

David first drew the old theme of "house and tree" and rain (Figure 2l). Next he drew a "house" again 
and an extra linear structure to the right side of it (Figure 22). It seems as if for the first time he tried to express a sort of three-dimensional aspect of a house.

David's next drawing, Figure 23, is similar to Figures 9 and 11 from fall term. He began with some dots on the paper and then connected them with a line, just as he had done in Figures 9 and 11. He then drew a line freehand, without dots, at the bottom.

Figure 23 seems basically to be "beehive plus" as in Figures 9 and 11 . But it is much more complicated. I think it is an extension of Figure 22, although there seems to be little connection between them. In Figure 22 David drew a conventional two-dimensional house and then he tried to express the three-dimensional aspect by adding a linear extension. But he could not succeed, so he quit. In Figure 23 he drew straight lines freely and created a figure compacted with many small units. This figure expresses the three-dimensional quality of a house with its height, width, and depth clearly shown.

David said Figure 24 was a drawing of a car. $\mathrm{He}$ apparently tried to express the movement of a speeding car. After I looked at Figure 24 and felt the movement in it, I understood why David expressed the three-dimensional aspect of a house in such a way as in Figure 23. David perceived height, width, and depth of a rectangular mass, a house, in terms of movement.

David's next drawing is a rainbow (Figure 25). It seems as if he did not plan to draw a rainbow at first. Rather, he began to draw a long, curved line to express a kind of movement and then continued to draw more curved lines. He seemed to enjoy the physical sensation of his arm movement as he drew these lines. He then saw a rainbowlike object created on paper and named it "rainbow." Therefore, in its nature, Figure 25 is an extension of Figure 24.

Figure 26 is a drawing of snow. David first drew a long curved line with blue Cray-pas just as he had done in the previous drawing. Then he changed his mind, picked up a red Cray-pas, and went into a free circular scribble. He called his creation "snow."

David loves snow. Whenever he feels good, even if it is summertime, he says it is snowing outside. Snow is a symbol of happiness for David. A rainbow is another symbol of happiness for him. Because of 
this connection between snow and rainbow, David might have drawn his snow after the rainbow. The "snow" drawing resulting from circular scribbling is very new for him. He had never drawn it before.

Figure 27 is a more complicated "tire." Compared to the first "tire," Figure 20, this one was drawn with more confidence; the lines and shapes were more firmly drawn.

Today David drew two drawings of a "house" and then he went to "beehive plus," which has a much more complicated element than his previous "beehive plus" drawings. Then he drew a "car," a "rainbow," and finally the new subject, "snow." After that, with much sureness, he drew the improved "tire."

Seeing this process unfold, I understood the important meaning of David's old drawing theme such as "house and trees," and why he so repeatedly drew this old theme. "House and trees" seems to be a symbol of his happy home life. Today David expressed his love toward people and life by drawing the "house and trees" treme and encouraged himself. Then he elaborated on his "beehive plus" which basically is his intellectual interpretation of space.

The success of achieving a more cornplicated, intellectually involved work might have satisfied David. He became free and drew a running car, a Iarge rainbow, and the new object "snow." After he created his new "snow," he drew a more complicated "tire," which is his symbol of well-balanced form. As I analyzed the meaning of the series of drawings done by David today, I recognized that every simple drawing by him held meaning which allowed the to understand his process of self instruction in art.

9 March 1972

David has been working in a workshop program at the school for the past three weeks. Therefore he could not attend my painting class. Today, for a very short time before he had to go to the workshop, he drew three pictures. At first he drew a free circular scribble, Figure 28, which resembled the "snow" in Figure 26. He drew Figure 28 spontaneously and with more confidence than Figure 26. The circular motion became smoother and larger. This circular scribbling could reappear frequently in the future. If so, I would like to name this circular scribble "snow," as David originally called it. 
David next dreww three big "David's trees" (Figure 29). At the first class of fall term in 1971, I suggested to David that he draw a big tree and he drew a large "David's tree" at that time (Figure 3). After that he kept drawing his "David"s tree" fairly large in size such as in Figures 13 and 14. Today David drew "David's tree" with great confidence and strength. These three "David's trees" are placed side by side and used up all of the space on the paper.

David began in February to participate in activities with his male classmates. This was quite an improvement compared to his previous isolated condition. David is becoming even closer to his male classmates through working with them in the workshop program. Consequently he is becoming even more friendly and confident. The three large "David's trees" standing in a row seem to be an expression of David's recent positive feeling.

Next, David arew a "beehive plus" (Figure 30). This piece is very interesting when understood as an activity that has been going on in the series of "beehive plus" drawings. Compared to the "beehive plus" drawing in Figure 23, today's "beehive plus" shows further improvement. When David drew Figure 23, I perceived that he tried to express the three-dimensional quality of the house, a large rectangular mass. Today's "beehive plus" clearly shows that direction. It seems that David's mind perceives the form of the house as a rectangular mass and that it is gradually developing into a definite form. The three simple arawings which David did today are all important. They show that his self-teaching process was actively progressing in his mind even though he had not drawn during the past three weeks.

\section{March 1972}

Everyone in class was very happy today because spring vacation would soon be here. David drew a "house and trees" (Figure 31). He drew a shape very much like the "tire" underneath the house. He also drew another rectangular-shaped "tire" beside the house. This combination of a "house" and "tire" is a new feature. 
30 March 1972

Today I had the first painting class after spring vacation. David gave me a drawing of "house and trees" (Figure 32) that he had drawn during vacation. In this drawing a "house" is placed in the center and two large "David's trees" are standing on each side of the house. Red and blue rain is falling from the sky. This drawing is David's usual old theme, but there is one important feature. David connected the two "David's trees" with a curved line that looks like a pathway.

In his earlier "house and trees" drawing (Figure 6) David expressed his awareness of spatial relation in rather a conventional way. He drew the ground with a person and a tree standing on it, and connected $a$ house and the ground by a pathway. Compared to Figure 6, Figure 32 showed more sophisticated and free perception of spatial relation. He made more drawings of "house and trees" in class today.

\section{April 1972}

For the past month David has been drawing his old theme "house and trees." He even drew the same theme at home. Today he brought three such drawings to class. Figure 33 is one of them. In this drawing David expressed a foreground with blue and red lines horizontally across the paper. These lines seem to be tentative; David was not sure of them. He was aware of the foreground as a plane, but he really did not know how to express it. In Figure 34, also done at home, these foreground lines have become bolder and seem to represent a road or sidewalk in front of the houses.

There are also three "David's trees" in Figure 33, and one of them is large and improved. David added several branches and a flower or berry to it. This is a drawing of his usual old theme which he has been drawing repeatedly, especially during the past month. But here in this piece, he succeeded in expressing a happy feeling through his old theme. A tall, red house is surrounded by small and large trees. The improved "David's tree" has movement, a kind of swinging motion in the air. The yellow sun between the house and tree is shining in the sky. David drew other objects such as "beehive plus," stars, and rainbows for the first time in a month 
in class today. He has been working hard in the workshop program. David is the biggest boy in class, and he can work hard. At the workshop, David is becoming an important worker. People treat him as a dependable, good worker, and he seems to enjoy his reputation.

\section{April 1972}

Today I cooked a Japanese lunch for my students and their teachers. David was so pleased and made all the students help me. He guided them in helping me prepare the food. We worked together at cleaning, cutting, and cooking the vegetables and meat. David made everyone work in setting up the tables and chairs. When we ate, David was concerned that everyone received enough to eat. After lunch, he made sure everyone helped clean up and put everything away. Afterward, we all sat together and enjoyed tea.

David enjoyed this lunch. He was extremely happy. As he drank his tea, he took a piece of paper and drew a colorful "tire" (Figure 35). This "tire" is more advanced than his previous "tire" drawings. He drew two circles; one is yellow and small and inside of the larger black circle. He next drew several different colored spokes through the circles. David's first "tire" drawing did not look much like a real tire. He achieved an excellent reproduction of a tire today. He drew this "tire" while he was extremely happy. David's "tire" is becoming another important symbol for him. He called the shape beside the "tire" in Figure 35 a "moon."

\section{May 1972}

The regular class teacher quit and a replacement has not arrived yet. Several different teachers from other classes have been taking care of David's class.

Today David again explored a new idea. He drew a new shape, a bird, out of his "snow" theme

(Figure 36). The process that he went through to achieve this new shape from his "snow" theme is interesting. At first he drew a "snow" with many different colors: black, blue, green, pink and yellow ochre. It is very freely drawn compared to the previous "snow" drawings in Figures 26 and 28. David moved his Cray-pas in many different directions, which showed his improvement in motor skills. He drew a large figure " 8 " in the center and over 
the "snow" drawing. At the last painting class David almost drew a complete "tire" (Figure 35). This achievement must have given him confidence in balancing various shapes. In Figure 36 he might have drawn this figure " 8 " over a rather random, carefree, linear "snow" figure in order to achieve a well-balanced structure.

In Figure 37 David took a yellow ochre Cray-pas and drew a large curved line and then added several small curved lines. The large curved line has a rather definite planned nature. It seems as if David received some idea from the "snow" drawing and tried to draw something new using the free curved line in the "snow" drawing. But he could not express what he wanted to, or he did not know what he wanted to draw. Therefore, he just added a few small curved lines.

David next drew another simple "beehive plus" (Figure 38). Then he took another sheet of paper and drew two large "David's trees" (Figure 39). On another sheet of paper he drew a bird-like shape (Figure 40). This could be the result of a learning process that went through Figures 36 and 37.

After David drew Figure 40, he drew another piece, Figure 4l, and said, "This is a bird." This piece is clearly a continued learning process from Figures 37 and 40 . Figure 41 is freely drawn with simple lines, but it has very charming characteristics. The yellow curved lines stretching out from each side seem to be the bird's wings and it has distinct bird feet. After David drew this bird, he drew two large "David's trees" (Figure 42), and looked very contented with himself. He varied the tree on the left by crowning it with a circle drawn with great boldness and freedom.

I want to go over all the drawings David did today and observe his learning process behind these drawings. He first drew "snow" with confidence. The success in achieving this better "snow" might have stimulated and freed him. So he tried to create a new shape, a bird, in Figure 37. But he couldn't achieve it at that time. He went to his old theme of "beehive plus" (Figure 38), and "David's trees" (Figure 39). He might have gained more confidence after drawing his old themes. He tried again to achieve the new bird shape which was in his mind. This time he accomplished his goal, Figure 40, to his great satisfaction. He drew another bird, Figure 41, and exclaimed, "This is a bird." David was very happy about his achievement in creating a new figure. He drew two 
big "David's trees" again, Figure 42, and expressed his joy and satisfaction about his achievement. One of his trees he varied by crowning it with a circle which might represent a flower, a fruit or a decoration; perhaps even a bird's nest.

Recently David has been creating original ideas and themes out of his old drawing themes. What especially drew my attention today was that he drew large "David's trees" before and after his achieving a new figure. When he tried something new, he drew his "David's trees" and gained selfconfidence. After succeeding, he again drew his "David's trees" and expressed his ever gaining selfconfidence with a bold new variation. "David's tree" is his own very first theme. It began as a very tiny tree, one or two inches high. It has grown into a large size tree now and is becoming an important symbol that gives David powerful psychological support in exploring new ideas.

4 May 1972

Today David drew a shape that seemed to be a combination of "beehive plus," "snow," and "tire" (Figure 43). David can now draw complicated curved lines which he developed from his "snow" theme. In Figure 43 he used complicated curved lines to draw the "beehive plus." The lines and shapes are well-planned. He then added a big diagonal cross or " $\mathrm{X}$ " over the entire shape.

In the last painting class four days ago, David created a new shape, a bird, out of his old theme of "snow" (Figure 41). Today he combined three of his themes into a new piece. There was planning and thinking involved. He used his old themes as his own language in order to express his world. In this piece, I could clearly see his need of intellectual exploration, and that he began meeting this need with his own language.

8 May 1972

A new male instructor took charge of David's class today. David drew a submarine in class (Figure 44). It has a well-balanced symmetrical shape, which is obviously the result of a continued learning process from Figure 43. In Figure 43 he combined three old drawing themes and created a well-balanced figure. Today he drew his symmetrically shaped submarine with even more sureness and the same strong cross dominating the figure. 
Ever since the beginning of this year David has gradually become happier and more friendly. Today an incident took place that shows how rapidly he has grown. This morning a student's mother wished to talk with me for awhile. Therefore we could not begin the painting class immediately. When we finished talking, I was in a hurry to get ready for class. I put out the painting tools on the table and brought everyone to their seats. A severely retarded girl who had entered the class a few weeks ago refused to join the group. I thought that she was not enthusiastic this morning for some reason or other. I left her alone and began instructing the others. David had watched the proceedings and voluntarily went to her saying, "Let's paint together." He held her shoulders in his arms, brought her to the painting table and found her a chair. She was very obedient to David. He gave her paper and Cray-pas and she began drawing.

I was very grateful for David's help. I knew David liked tea very much, so I offered him a cup. He brought enough cups for the whole class. I was worried that the girl might burn her mouth with the hot tea. When I was going to get some water to cool her tea, David guessed my intentions, quickly brought the water, and cooled her tea. When she had a second cup of tea, David stopped his drawing and asked me if I had cooled her tea. All of David's actions today made me realize that now he is eagerly helping my painting class.

David had to go to the workshop this morning. Before he left, he helped my painting class begin smoothly and then he drew three pieces. There is, among them, a beautiful "snow" drawing (Figure 45). This is David's fourth "snow" drawing. He drew his first "snow" in the middle of February and he has gradually improved it. Today's "snow" expresses strong and free emotion. The lines are bolder and the use of two opposite colors, orange and black, is very effective. There is a joyous poetic rhythm in this drawing. David's very friendly attitude toward his classmates and this beautiful, warm drawing convinced me that he has become a happier and stronger person.

\section{May 1972}

David didn't have to go to the workshop today; therefore he had plenty of time for drawing. He was 
involved in and enjoying his drawing this morning. He first drew Indian teepees (Figure 46). He used mostly blue with some orange, red, yellow, and green. This color coordination is good. It shows his good perception of color. His overall otganization, or structure, shows an intellectual element.

Spatial dimension becomes even clearer in the drawing in Figure 46. David showed his awareness of spatial dimension in his "house and trees" drawings in Figures 32, 33, and 34, by drawing a simple foreground impression. Today he drew two teepees, and a pathway stretches into the foreground from each teepee. His awareness of space was shown by his orange dots and dashes which are scattered over the whole paper. Here he also expressed his awareness of size difference in terms of spatial relation. He drew one teepee much larger than the other one and placed it slightly forward of the small one. This sets one teepee closer and the other one further back. This size difference in a spatial dimension is a new discovery for David.

25 May 1972

Today we made objects from pipe cleaners. David came to class before anyone else. He drew one piece before class began (Figure 47). He drew many "Christmas trees" in various sizes over the whole paper and connected them with a "beehive" line. He used plenty of warm colors such as orange, red, pink, yellow, and a little bit of cool color such as green and blue. This use of cool color is very effective in giving structure to this free and random drawing. The dots and dashes which run horizontally, vertically, and diagonally among the curved lines of the "Christmas trees" give a crisp and pleasant movement to the drawing. This colorful drawing has harmonious movement which creates a poetic image.

\section{June 1972}

We had a male visitor in our class today. Everyone welcomed him, especially David. David kept saying, "It's fun!" He drew two drawings, both of a very charming three-legged bird (Figures 48 and 49). Both drawings have a lot of happy feeling. At the end of the painting class David drew a large "Christmas tree," Figure 50, and presented it to the visitor, saying, "It's for you!" I realized that David liked this visitor and presented to the visitor 
one of his own most important symbolic objects. David never gave his art work to anyone but me before, so I was quite surprised.

David has continued to draw his "Christmas tree" since the beginning of fall term. He has developed it into his own personal tree. I realize now that his "Christmas tree" has become a symbol of himself. I think he arew this big "Christmas tree" today to express his strong self-confidence and presented it to the male visitor.

It is interesting to compare this symbol of selfexpression to David's other symbol, "David's tree." "David's tree" was his first drawing, and it is apparent that this is his original self-expressive symbol. It seems to be an indication of the gentle and humble David. On the other hand, his big "Christmas tree," in Figure 50, seems to indicate his manliness and strong self-confidence.

\section{June 1972}

This term is nearing its end and the students are excited about the upcoming vacation. David drew a beautiful "snow" again (Figure 5l). He only used the warm colors, orange and red. The now familiar (Figures 43 and 44) big diagonal cross in the center is very effective and structual.

David voluntarily helped another classmate with her drawing today. A girl drew a big Christmas bell. David looked at it and said to her, "You should put a face on it." He then drew a face above the bell and turned the bell into a dress. He has never paid much attention to other people's work or given advice to other students. But today, all of a sudden, he even added his idea to a classmate's drawing. He is really confident in his drawing ability. He believes that he is a good artist now. I looked at the face he had drawn and noticed that it's features, eyes, nose, ears, and eyebrows, were well drawn. I asked David, "Why don't you draw a big face of your own?" Without any hesitation he took Cray-pas and drew a big face that covered the whole paper (Figure 52). I looked at this drawing of a big face and understood what strong feelings David has of himself now.

\section{June 1972}

Today, David first drew his "snow" theme with five different colors, orange, dark blue, light blue, brown, and black. He wrote his name in 
green (Figure 53). I thought that it was a very colorful beginning. After he drew this piece he took a rest. At that time a young man who was a volunteer worker at the school visited our painting class and drew with the students. This young man's participation in our painting class greatly stimulated David. He came back to the painting table and drew two pieces (Figures 54 and 55). David said that the drawing in Figure 54 was the scene of a snake eating people and the drawing in Figure 55 was the scene of a snake eating a bird. There two drawings are unique and charming. David used all of his selftaught drawing themes and techniques. He used various colors effectively and, using both straight and curved lines, he created complicated shapes. In both drawings he drew his "tire" in a decisive way.

For the past month David has been creating new figures in his drawings, one by one. Today he drew complicated yet very rhythmical and beautiful objects. I thought it was a sure sign of his selfconfidence in drawing. The snake in Figure 54 resembles the shape of the bird which David drew from his "snow" theme on 1 May (Figure 40). It seems as if what he learned by drawing the bird figure had been preserved in his memory all this time, being nursed and polished into the new shapes he drew today. All of the drawings David has done during the past month (Figures 44 to 55 ) have a poetic beauty. Today's drawings especially show excellent quality in his work. I am deeply convinced that David is a highly perceptive and artistic young man.

Today was the last painting class of the spring term. As I look at the drawings done by David today I clearly see his improvement. I admire him because he has reached this stage mainly through his own self-taught process. Although I have kept companionship with him all of the time, it was David who courageously explored new themes and techniques. I truly wanted to give him a cheer.

26 June 1972

We are now in summer vacation and there is no painting class. My husband and I took David and two other young men, his classmates, on an outing today to visit a Japanese sailing ship in the Portland harbor. After visiting the ship we stopped at an ice cream parlor. David was calm 
and quiet all day and seemed to have no special activity planned for summer vacation, staying home all the time. I thought I should take him out as much as possible during summer vacation.

\section{July 1972}

We took the whole class on a picnic to the Clackamas River today. Everybody really enjoyed this outing. David was especially happy about the picnic. He began calling the class members by phone one week ahead of time to make sure everybody would join the picnic. He even memorized a list of his favorite classmates' phone numbers. At the picnic David took care of the whole class all day long. At lunch he served food and drink to everyone. And, when someone wandered off, David went looking for them even before I noticed they were gone.

David presented a sketchbook to me this morning which included drawings done during the past several days at home. These drawings are of his themes: "David's tree," "house and trees," "beehive plus," "tire," and "snow." In addition to the old themes, he drew human figures and large human faces. Figures 56, 57, and 58 are selected from this sketchbook.

His "beehive plus" in Figure 56 has emotional projection. He must have been very happy about the upcoming group picnic and expressed his joyous feeling through this "beehive plus." He placed green dots on the paper and connected these dots with warm orange and yellow lines. It seems as if his happy feeling is radiating out all over the paper.

Figure 57 could be David's self-portrait. There is a "David's tree" on the right side of the paper and a sun on the left. In the center a big face is either smiling or uttering the voice of joy.

Figure 58 is David's "snow." Interestingly, this "snow" is very much like David's first "snow" drawing in Figure 26. There is the same single stroke of blue accompanied by other lines in warmer tones, and a simplicity of the whole drawing which is unlike the complex examples in Figures 36,45 , 51, and 53. At first David drew "snow" to express the movement of snow and he gradually developed it into a more abstract style. In this piece he expressed his happy and light feeling with this original style "snow" drawing. The difference is that this "snow" has stronger feeling than his first "snow." The firm 
flowing lines and varied colors of Figure 58 show their strength when compared with the earlier picture. I was very happy to see this beautiful piece of "snow." By looking at it I could really feel how happy David was about the picnic.

\section{July 1972}

I thought some of my students might like to keep painting during summer vacation. Today I had my painting class at my home. This first trial in the new setting turned out to be successful. From the beginning of our association our relationship has been one of mutual friendship rather than one based on a teacher-student relation. Meeting at my home made us even closer.

David was very much stimulated by the change in environment and painted eagerly. I introduced him to acrylic paint. He tried very hard to use this new medium. He painted his first brush painting thoughtfully and slowly (Figure 59). He painted a small house in the center of the paper. The house has a "tire" in it. On the right and the left of the house he painted shapes that look like combinations of his "tire" and "beehive plus" themes.

I have always been convinced that David's "house and trees" theme is a symbol of happy home life, and he paints this theme in my painting class to express his loving friendship toward me. Today at my home, he also combined two of his themes, "beehive plus," and "tire," which are expressions of his intellectual search, with his "house and trees" theme.

This combination of "house and trees" and "tire" appeared tentatively in David's earlier drawing (Figure 31). But in today's painting these two themes are well integrated and express David's new message. David is saying that he is very pleased and encouraged to paint at my home. He is now determined to study harder and learn a lot more.

David showed some interest toward an intellectual direction along with an emotional approach in his first stage. He drew Figure 15 in the beginning of his second stage, which is emotionally rich and has an intellectual element. He gained more self-confidence in his 
work and eagerly searched for both an emotional approach and intellectual direction. While searching for intellectual direction, he tried to achieve well-balanced symmetrical shapes in his work. He created his "tire" and succeeded in improving this theme. Figures 20, 27, and 35 reveal the process in which David searched for the wellbalanced symmetrical shape in his "tire."

Another search for intellectual direction by David appears in his trial of three-dimensional expression. He could not be satisfied with a simple two-dimensional house drawing, and so he attempted to express the threedimensional features of the house. This begins in Figure 22. He wanted to express the house as a rectangular mass. He perceived the rectangular mass as a kind of movement and he used the "beehive plus" to express what he felt about this mass. Figures 23 and 30 show the process developing.

Another search for three-dimensional effect was David's attempt to express spatial relationships in his "house and trees" drawings. He expressed certain spatial relationships in his work in the first stage. He developed more sophisticated spatial perception in the second stage. Figures 13, 14, 16, 32, 33, 34, and 46 show the developmental process of his perception and expression of spatial relationships. 
David expressed his awareness of vast air space in Figure 13. He used the "beehive" to express foreground and background in Figure 14. He drew many short yellow dashes which look like rain falling in the space around the house in Figure 16. He especially attempted to express a foreground in Figures 32, 33, and 34. In Figure 46, David drew a large teepee, and a small teepee. He attempted to express perspective through size difference of the two teepees combined with their position in space.

David seriously searched for freedom of emotional expression in addition to his study in the intellectual element. He succeeded in expressing his feelings by drawing the free circular line in his new "snow" theme. The series of "snow" drawings in Figures 26, 28, 36, 45, 51, 53, and 58 show that he uses this new theme mainly in expressing his joyous, happy feelings.

David also drew many new objects during this second stage. These include: rain (Figure 12), rainbow (Figure 25), birds (Figures 17, 40, 41, 48, and 49), valentine heart (Figure 15), submarine (Figure 44), teepee (Figure 46), snake (Figures 54 and 55), and his self-portrait (Figure 52). His interest in symmetrical shape is clearly seen in some of these new objects. He also succeeded in expressing strong emotion through these drawings. The valentine heart in Figure 15 is an example of him expressing passionate feeling. His bird and snake drawings have 
a poetic effect. These objects were much more complicated than those drawn in the first stage. Toward the end of the second stage, he developed more complicated shapes. The snake drawing in Figure 54 is a good example.

David succeeded in his search for new drawing possibilities in the second stage. His technique improved and the content of his drawings showed marked improvement in maturity. Along with these activities, he continued to polish his two self-symbolic figures, "David's tree" and "Christmas tree." His continuous arawing of "David's tree" brought him important psychological support. He often drew "David's tree" whenever he struggled to create a new subject. When he finally succeeded in his endeavor he drew large "David's trees" to express his satisfaction. Figures 39 and 42 are good examples. He created a more colorful and lively "David's tree" in Figure 33 by adding branches and flowers to his original little tree. He again varied his tree in Figure 42, when expressing his satisfaction at drawing his first "bira." David gained more confidence toward the end of the second stage and began drawing complicated subjects one after another. He revealed a lyrical and beautiful world with the "Christmas trees" in Figure 47. He expressed his strong positive self-image with the "Christmas tree" in Figure 50. At this point, David firmly established his "Christmas tree" as his important masculinity symbol. 
David became much friendier in the second stage along with the improvement in his drawing. He often sat and drew with the other male students in the class. He even encouraged the other students to take more interest in their art. He began to enjoy his art very much and he wanted his classmates to enjoy their art also.

David also became more active outside of the painting class. He became cooperative and worked hard in his workshop program. It was clear that his overall attitude had begun to change in a very positive way. He also became much friendlier toward me. He demonstrated this new friendliness by helping the other students in my painting class. Yet he was still very shy toward me and could not talk freely to me face to face. I left him alone just as I did in the first stage. But once in a while, when I was truly impressed by his work, I could not refrain from uttering a compliment, "This is good, really good:" He would smile contently and I could feel a growing friendship between us. 


\section{CHAPTER IV}

\section{DAVID: THE THIRD STAGE}

David's third stage was from September 1972 to early June 1973. During this period David voluntarily took care of the students in the painting class and did very few works of his own. Although he drew only a small number of pieces, he showed important progress.

David's mental growth was rapid and his attitude changed tremendously during this period. He willingly helped everyone in my painting class. He gently took care of the severely retarded students and encouraged his classmates to help each other. David not only helped his classmates but also aided an inexperienced woman teacher who was newly assigned to his class in the middle of fall term. Figures 60 through 70 are David's representative works during the third stage.

11 September 1972

Today I visited David's class for the first time this fall term. We did not have painting class today, but had lunch together and talked. This morning when I entered the school building and walked down the hall toward the classroom, David saw me and walked up to me. He said, "Hello, dear," bent his tall body over me, and hugged me gentiy. It was a big surprise for me. This was the first time he had hugged me during the past year and a half of our association.

David's greeting made me very happy. He was wearing a new shirt and his hair was neatly 
combed. He acted like a perfect grown-up man. I had never seen David like this. I knew he had been growing steadily, but today I felt something spectacular had happened to him. All of a sudden he was a grown-up man. He looked like a totally different person.

There were several new students entered in the class. Among them were an exceptionally smallbuilt black woman and a young cerebral palsy woman confined to a wheelchair. That now makes two cerebral palsy victims in class with wheelchairs. The same male teacher of last term continued teaching this term. He had two young women as assistants helping him with the class. The whole class atmosphere was generally happy and good.

\section{September 1972}

We had the first painting class of this term today. The new students have not yet been assimilated into the group. I had to give so much attention to them because they were not familiar with painting. Class went slow but at least everybody worked together.

David presented me with a sketchbook which contained drawings he had done during the past several days. These drawings were mostly his old themes; but I noticed that he had improved on them and really enjoyed drawing them repeatedly.

Figures 60 through 64 are drawings from David's sketchbook. Figure 60 is one of several big faces which appear in the book. At the end of last spring term he drew his first big face in another sketchbook he gave me during summer vacation. The big faces in the latest sketchbook were drawn very boldly and freely. They seem to be David's self-portrait. He suffers from pimples on his own face and he usually draws pimples on his big faces.

Figure 61 is a combination of "Christmas tree" and "tire" themes. Unlike his previous "Christmas tree," David also drew a tree trunk under his "Christmas tree" in the same way he draws legs for human beings. In the past David created his

"Christmas tree" as the symbolic figure with which he seemed to identify himself (Figures 10 and 50). Now his "Christmas tree" has legs. Over the "Christmas trees" David drew his "tire." This new "Christmas tree" has become a more humanlike figure, and combined with his "tire," has 
become a symbolic figure searching for a wellbalanced pleasing shape. This drawing is a very significant symbolic figure that expresses David's unifying, integrating growth within himself. Figures 62, 63, and 64 are all very elaborate "snow" themes. David became very free here. He boldly explored many different circular lines and created very attractive shapes. Each of these "snow" drawings are different. Each has its own unique lines and shapes which create a pleasing movement. It seems as if each piece is singing a different song; yet there is a harmonious choruslike rhythm among the three. Now David has really developed his "snow" theme into his own language. He uses this theme to express his feelings as we would use words.

The first thing David did this morning was to present the sketchbook to me. After that he brought all the new students to the painting table and gave them some painting materials. He did all this work voluntarily. When the other students had begun working, David sat with a group of young male classmates and started drawing with them. These boys were using a ruler to draw geometrical shapes. David used a ruler and pencil to draw a symmetrical geometric shape (Figure 65). He worked carefully to achieve accurate lines. He then added some color to it. It is the first time David worked with a ruler and pencil to draw a neat geometrical shape.

In the past David often created a combination of many geometrical shapes in his own theme of "beehive plus." He also attempted to draw a wellbalanced symmetrical shape in his "tire" theme. Therefore his intention of achieving a balanced, geometrical shape has been clearly shown in the past. But today for the first time he used a ruler and pencil to draw accurate symmetrical shapes.

David had always felt inferior to the other male students and seldom tried to work or do the same things that they did in class. Today he voluntarily joined them and eagerly imitated their work. David seemed to be free from the feelings of inferiority he usually had toward them. He acted as if he knew he would do anything with his classmates and he seemed very much to enjoy working with them.

After David arew Figure 65, he did another drawing similar to it and then left the table for a rest break. Soon David's regular teacher came 
into the classroom and looked at his drawings. He was pleased with them, and David was very happy to hear this comment. He began to draw again. This time he went back to his old themes of "David's tree," "house and trees," "Christmas tree," and "snow," etc. He drew them one by one, in a bold manner. The instructor was quite amazed by David's enthusiasm and productivity.

From the very beginning of my painting class, David had kept drawing the same tiny "David's tree" for many weeks. Today in front of his instructor he drew all of his themes with great confidence and openness. Although David has become much happier lately, he still seldom talks to people. One reason could be his speech difficulty. Also he still does not feel comfortable in meeting people. This condition is a remnant of his previous emotional disturbance.

When David drew his themes today, I felt that he was truly expressing himself through his own media. These themes are significant symbolic figures which express David's inner world. David does not talk, but instead he creates his own language and uses it very proudly to communicate with other people.

After lunch we all went into the court and played in the sunshine. I was surprised to see David so watchful of his classmates. The tiny black girl was pushing one of the cerebral palsy girls in a wheelchair with great difficulty. When she began pushing it up an incline to the playground, David ran over and helped her push. When they reached the top, David told her, "It is o.k. now; you do it." He then let her continue on by herself. He acted just like a big brother encouraging his sister to help her handicapped friend.

A young male volunteer worker began wrestling one of the students. He won and pushed the student to the ground. David jumped into action and started wrestling with the volunteer worker. He played so hard and aggressively that I had to tell him to quit. David really is taking the big brother's role. All of his classmates seem to be treating him as such. It is apparent that David is becoming the central figure in class.

\section{September 1972}

We have been mainly using crayons and Cray-pas for our painting class up to now, but today I gave the class acrylic paint and brushes. All the 
students enjoy brush painting. David painted a very significant painting today (Figure 66). He first placed everybody at the painting table, and after everyone had begun painting, he began. He really concentrated on his work and painted very slowly. He painted a red "David's tree" in the center of the paper. He then painted his "beehive plus" and "tire" around the "David's tree." In the left corner there is a yellow sun, and in the right corner is a yellow moon. David painted a red dot at the left side of the red tree and a blue dot on the other side. The whole painting is very symmetrically composed. David drew symmetrical geometric shapes in the last painting class.

Today David used two complementary colors, red and blue, to create a very symmetrical and pleasant shape. Both "beehive plus" and "tire" are a sort of symbolic expression of David's intellectual exploration. David combined these intellectual themes with his rather emotional symbolic figures, "David's tree," sun, and moon, in Figure 66. The red "David's tree," the symbol of himself, is surrounded by blue "beehive plus," "tire," and the yellow sun and moon in a very balanced and structured way. Both the intellectual element and emotion are well integrated in this painting.

21 September 1972 to Middle of January 1973

After David completed Figure 66 on 21 September 1972, he drew very little until the middle of January 1973. Instead, he voluntarily became my assistant teacher and took care of the painting class. He believed that was more important than his own painting. Once in a while he sat by the table and did some casual drawings which were just very simple geometrical shapes.

The class moved to a new location in the city in October 1972. The new space was in the basement of a group home for the retarded and disabled. None of the original class members lived in this home, but some older students 
who lived at the new home joined my painting class and David's job as assistant teacher increased. He became very busy, but enjoyed it. Each morning he sat everybody down to the painting table and put out paint and paper. $\mathrm{He}$ constantly watched everybody and took care of their needs. When class was over, he put everything away and cleaned the table and room. He always worked diligently, setting an example for the others. They began to help him clean up. The class became very happy. They painted together around the big table and everybody truly enjoyed this togetherness. In November 1972, the male teacher quit and was replaced by one of the young woman assistants. She was anxious, and worried about handling her first teaching job. At this time David became very helpful. He voluntarily helped the new teacher. He truly cared about the group's welfare and worked very hard to keep the class happy. The group depended on David. Those students who would not listen to the regular teacher would follow and obey David. There were about fifteen students in the class. Half of them were either severely retarded or had severe physical handicaps. It was apparent that one teacher could not take care of this many people. David controlled the class by devoting himself to its welfare. He preserved the group's cohesion and integrated the new members. He was very proud of himself in helping the new teacher to keep the class happily functioning. Finally, not only the students, but 
the new teacher and myself truly depended on him. He became the central figure in class. David had been so frustrated and moody in the past. People had been afraid of him. He now became a leader and everyone needed him. At about this time a severely retarded young woman named Eve joined the class. She did not speak at all or eat or walk by herself. She just sat silently in a chair all day long. David voluntarily took care of her. His attitude toward her was very gentle, as if he was her brother or father. Eve lived at the group home. David commuted daily. As soon as he arrived each morning, he fed her breakfast, patiently taking a whole hour to feed her one bowl of cereal, spoonful by spoonful. He fed her lunch in the same manner. Sometimes he held her shoulders and let her exercise by walking around the room.

Gradually Eve's behavior changed. Up to this point she had sat and stared into space, never saying one word or showing any reaction to anything around her. She finally began to react to stimuli around her. During painting class I sometimes had Eve sit between David and me. She would sit quietly with a smile on her face and watch her classmates. She finally began walking without help by bracing herself on the walls and furniture. In late November 1972, with David's help, Eve began to paint. About this time a thirty-four year old woman with Down's Syndrome entered the group house. She was very 
frightened, staying in a corner of the room all day with tears constantly falling from her eyes. No one, including the teacher and I, could do anything with her. David voluntarily took care of her also and eventually got her to paint with Eve. Details of these events will appear later in this thesis in the case histories of the two women. Thus David became extremely busy in class, but was thoroughly enjoying his new role.

David was so busy taking care of his classmates that he had no time to paint. Once in a while he sat by Eve and Kay and casually painted, sometimes even imitating their paintings (Figure 67).

With David's constant devotion to the class, the class became a cohesive and friendly group, each member enjoying each other. I was so grateful for his work that I decided to have a big party for the class one day just before Christmas vacation. I brought plenty of food and drink and the whole class had such a good time. This event furthered the group cohesion. David's affection and devotion to his classmates deepened. During the two weeks of Christmas vacation, David often called me and said he missed everyone and could not wait until school began again.

When class began after vacation there was a change in the group home personnel. The former housemother was replaced by a new couple. They became very actively involved with the retarded people in the home. A very warm 
family-type atmosphere developed. The husband especially showed great interest in the students and worked hard to keep them happy.

The people in the home loved the new housefather. He became the central figure. Until then David had been the central figure because there had been no other active male. This new situation made him very anxious and sad. He just stayed close by me during each painting class, and called me at home many times a day after class. He had matured during the past twenty months. His attitude, manner, and facial expression had become that of a young adult rather than a young boy. As a young adult David had a deeper emotion. I saw his deep loneliness and fear of losing the role which had become his important selfidentification.

I had deep sympathy for David, but I did not worry about the situation. The excitement of having new home parents would calm down soon. I knew that there were many things that only David could do for the group. The new house parents would eventually discover and understand David's role in the group and would even depend on him as we did.

One day during this period David called me five or six times in a row and said very excitedly that he had done a drawing at home. He brought this drawing to the next class on January 16, and presented it to me (Figure 68). 
This drawing is very significant in that it shows David's new development. David drew his old theme "house and trees" on a large piece of paper; but there is an additional important element. David tried very hard to express the three-dimensional aspect of the entire scene. The drawing was planned and carefully composed in order to express this three-diemsnional aspect. David drew a long horizontal line to divide the foreground and background. $\mathrm{He}$ drew the front yard on top of this line. Beyond the front yard, there is a swimming pool. The house stands beyond the swimming pool and several trees surround the house. Above the house there is a red thick line drawn horizontally to indicate the sky. Stars and the sun are drawn in the sky. David attempted definitely to express dimensional order in space.

Beside his awareness of spatial dimension, David tried very hard to express the perspective view of the house. He tried to give depth to the rectangular house. For the first time he used the conventional method of drawing three-dimensional perspective of a house. Although he made a mistake in the house lines, David succeeded in conveying the perspective view of a house.

Ever since his early stage, David had shown the urge to express his awareness of the dimensions in his drawings. He had attempted in various ways to satisfy this urge. Figure 68 is the first drawing in which he succeeded. He 
achieved the skill to express the three-dimensional quility in his "house and trees" painting. He had learned and achieved this skill by himself, by searching in his own way during the twenty months. At this point I would like to review briefly his attempts at three-dimensional expression. David already showed a certain awareness of spatial order in his first "house and trees" drawing (Figure 2). Near the lower edge of the drawing a house and tree are placed on a horizontal plane and a human figure is placed on a horizontal plane very close to the upper edge of the paper.

In Figure 6 David expressed his spatial order more clearly than he did in Figure 2. He drew a blue horizontal line near the upper edge of the paper which expresses the sky. Underneath this line he drew a sun, moon, and stars on another horizontal plane. He next drew a blue horizontal line near the lower edge of the paper which symbolizes the ground. His "Christmas tree" and a human figure are standing on that line. He drew a house and several "David's trees" a little above the ground line. By doing this he tried to show the house and "David's trees" as standing a little further away. The house is connected by a path to the blue ground line.

In Figure 7 David expressed his spatial awareness by drawing a "beehive" around a "Christmas tree." In Figure 10 he expressed depth of space by surrounding his "Christmas 
tree" with a "beehive." In Figure 14 he combined a house and "beehive" and succeeded in expressing spatial depth. David searched for spatial expression in a more intellectual way in the drawings in Figures 9, 11, and 23. Here, he used "beehive plus" in order to express twodimensionally expanding space. In Figure 30 he succeeded in expressing a three-dimensional figure of a house; a house as a rectangular mass. When he drew the drawing in Figure 30, David might have been satisfied in his search for three-dimensional expression. After that he began drawing rather freely and did not worry about expressing the three-dimensional aspect.

During this period of free expression David seemed to enjoy drawing one of his most important themes, "house and trees." In Figures 32, 33, and 34 he drew lines casually to show front space. There is no intentional explanation of spatial order such as the one shown in Figure 6. Yet these three "house and trees" drawings, Figures 32, 33, and 34, have a very natural perspective expression of space. There is airy movement in the space as if a breeze were blowing through. In Figure 46 David showed size difference of the object in relation to spatial order. He drew the forward teepee much larger than the one behind.

Looking through the above process in which David learned to express the three-dimensional aspect, it is 
clear that the drawing in Figure 68 is an accumulation of all his self-taught drawing knowledge up to that time. A human figure is standing definitely in the center foreground. A "Christmas tree" is drawn much larger than several "David's trees" behind it. These are not just accidental results on paper. They are the planned placing of objects in the drawing to show the three-dimensional quality. When he made the drawing in Figure 68, David realized its significance and he was very proud of his work. He called me at once with the news, and he brought it to the next meeting of the class. His teachers and classmates praised it. The experience was a very significant one in bringing further development to David's selftaught art work.

Middle of January 1973

to Early June 1973

David began to have a very firm self-confidence in his own drawing after he had completed the drawing in Figure 68. He began to draw at home and bring his work to class to show me. I offered to give him art supplies, but he refused my help. He bought many canvas foundation boards and usually drew on them with Cray-pas. He became quite independent, buying his own material and drawing at home. He presented most of these drawings to me. Figures 69 and 70 are two examples. 
David drew Figure 69 on 27 February 1973. The threedimensional aspect is again emphasized here. David first defined the foreground by drawing the green lawn. Then he divided the remaining space into two parts, blue sky and a purple grove of trees. He clearly defined foreground, middleground, and background. He then put in details such as trees and the house. Compared to Figure 68, this division of space became more complicated in Figure 69. In Figure 69 he put in the middleground, purple tree grove, and cut the horizontal line that divides the sky and earth. The entire division of space became more complicated. In drawing the details as he did in Figure 68, David again tried to describe dimensional order; the lawn in the foreground, path next, and the house standing behind the path.

Another noticeable feature in this drawing is that "David's tree" has roots. "David's trees" in Figure 68 has roots also. But here, in Figure 69, "David's trees" start expressing human-like movement with their roots. The tiny dark green "David's tree," near the left edge of the paper, looks like a human being standing and stretching both arms into the sky. The purple "David's tree" looks like a person who is walking with big steps.

David presented the drawing in Figure 70 to me on March 1. He had begun it in our painting class on February 27. That day the whole class worked in a room upstairs in the group home. When I went down to the basement for 
more paper, I found David sitting and drawing in a corner of the basement by himself. He had been drawing at home for some time and drew very little at class. Therefore I was surprised to see David drawing in the basement. I also was surprised to see his very serious and involved manner. I went near him and asked what he was drawing. He had first drawn an outline of the central object and then divided it just like his "beehive plus." Then he colored each section carefully. He said that it was a "snake." He had chosen the subject of a snake and then planned carefully to express his subject. He then worked steadily and carefully on it. He had drawn half of the snake's body when I saw it that morning. I saw that David had sat there and drawn for a long time. I was quite surprised at his lengthy attention span. When he had drawn Figure 68 at home, I had also realized that his attention span had increased when compared to his earlier stage when I first met him.

When I saw David choosing his own subject, planning and working patiently, I understood that he was enjoying drawing very much. Drawing had become his important selfexpressive medium. I asked David, "This one takes a lot of time, doesn't it?" He said, "Yes, it is hard work." David eventually finished this painting at home and then gave it to me. This snake has a sort of charm about it, which we may find in primitive art. 
David was very busy taking care of the class from fall term 1972 to the middle of January 1973, and drew very little. After finishing the drawing in Figure 68, he started drawing a lot at home and bringing his finished work to class. We all praised his drawings, and he was very proud of himself. He believed that he had become a good artist.

One day during this period David asked me if he could present one of his drawings to his regular teacher. Since the beginning of his art activity he had drawn for me. In my painting class I gave him almost complete freedom. He drew whatever he wanted in whatever way he pleased. Through drawing he enjoyed the freedom of self-expression. I accepted his work whole-heartedly and encouraged him. His art activity continued on this kind of basic relationship between us. David drew to communicate with me. He drew as another person would write a letter to communicate to someone. Therefore he always gave all of his work to me. Now David wanted to give one of his drawings to another teacher and asked my permission. He had gained a strong confidence in his own work, and, by giving his work to others, he wanted to express his friendship toward them. Using drawings as a communication medium with many people would be a very good thing for him. I told David it would be a very good idea for him to give his drawings to other people. He began presenting his drawings to other teachers who accepted them gratefully. 
When the new house parents took over the group home in January, David had felt lost because his role was assumed by the husband. But David even presented his drawings to the husband. He actively communicated with people through his drawing. By doing this he gained his self-confidence back. He gracefully freed himself of the fear of losing his class leadership role. Before the winter term of 1973 was over, the new house parents were replaced. By then David had matured so much that he was very calm in meeting new people and new situations.

Spring term soon began and I had two Japanese college students, a young woman and a young man, to help me with the class. At the time there were two women in wheelchairs and a severely retarded young man in class who all needed much attention. I needed extra hands. These two Japanese students were inexperienced in working with mentally retarded people, and at the beginning they seemed to be lost. They did not know how to handle the job or situation. But the class, including David, welcomed them. David presented his drawings to both of them immediately, and he helped them in their work and to assimilate smoothly into the class.

During this period David would quietly sit in a corner of the room during the painting class, watching everyone. If anyone needed something, he would get up and take care of it. If someone made too much noise, he stopped it 
in a gentle manner. There was a heavily retarded young man, named Drexil, who sat next to me, painting and calling my name out all day long. I sometimes had to spend the majority of my time with him and could do nothing with the other students. David understood the situation very well and worked hard in class to help me. On the school days when I was not present between the weekly painting classes, David often called me and said, "Drexil calls your name all the time. He wants you!" David called me whenever he needed to talk with me. He even called me to report on this severely retarded young man.

David voluntarily worked very hard for the class welfare. Toward the end of spring term 1973, he became very independent. He didn't need any more psychological support from me. He was acting as a very capable assistant teacher in my painting class. From the time he finished the drawing in Figure 68 in the middle of January, his drawing steadily improved. This situation gave him a firm selfconfidence as a good artist and assistant teacher. In fact, he was the best assistant teacher I could have hoped for.

A very deep friendship grew between David and me. I did not need to tell him what to do in class. Without a word he understood all the needs of the students and took care of them. His love for his classmates was strong and sincere. I was often deeply impressed by his devotion to the group. 
David's drawing improvement was remarkable during the third stage. He took a big step forward in searching for intellectual direction. Yet at the same time he managed to keep an emotional freedom in his work. At the beginning of this period, David drew a "tire" over his "Christmas tree" and expressed his very positive self-image (Figure 6l). Soon after that he drew a red "David's tree" surrounded by "beehive plus" (Figure 66) and again expressed an ever growing positive feeling about himself. Both Figures 61 and 66 have symmetrically well-balanced composition and lots of emotion. During the middle of this period, David developed his old theme of "house and trees" into a well organized yet very free, spiritual work of art (Figure 68). In this drawing, for the first time, he managed to express a three-dimensional aspect in the whole drawing. This success gave him a strong self-confidence in his art work. He began to think of himself as a good artist. It had been two years since David shyly drew his first tiny "David's tree." He became very active and independent in his art work, buying large painting boards, drawing in a very free style, and presenting his works to people.

He also willingly took a big brother's role in the class and worked hard to keep everyone in the class happy. All of the class members began to depend on him, obey him, and respect his leadership. Even those students who did not listen to the regular instructors and those severely 
retarded students for whom the instructors could not do much, willingly followed David's leadership. By sincerely working for the welfare of the class, David became the central figure, the group's most important person. His earlier bad temperment which frightened even the male teachers had completely disappeared. David's act of taking a big brother's role had significant effect on his maturation process. David gave himself to the class. In return he received trust and love from his classmates and it enforced his self-confidence. Helping the severely retarded women, Eve and Kay, was an especially important experience in David's maturation. Because of the severe retardation and deep emotional disturbance of these women, they were very difficult to help. Neither their regular teacher nor I could do anything at the beginning. It was David who took care of them and helped them greatly to improve. As a result of his participating in the rapid improvement of Eve and Kay, David himself grew and became a truly dependable leader for the group. This experience was significant because it laid a firm foundation for David's further development. To understand fully David's development in its fourth stage it would be helpful to know something of the development of these two women. For this reason I would like to interrupt the history of David at this point to present the case histories of Eve and Kay. Then I will present the narrative of David's fourth stage. 


\section{CHAPTER V}

\section{CASE HISTORY: EVE}

Eve came to the group home where I had my painting class in October 1972. She was twenty-two years old, suffered from epilepsy and was severely retarded. She was under heavy medication of several drugs including the anticonvulsants Dilantin and Mysoline and Phenobarbitol which made her very drowsy all the time. She sat in a chair all day long by herself and stared into space with glassy eyes. She could not walk across the room alone or even feed herself. She needed constant intensive care. I wanted to know more about Eve, but the group home did not have any official report about her at that time.

In my painting class, Eve just sat in a corner of the room by herself all day long and did nothing. She never spoke a word. I asked her many simple questions, such as what was her name, but I never received one answer from her. I felt that there was no way in which to communicate with her at this stage. I decided to leave her alone and wait. I had a hope that the creative and productive atmosphere of our painting class would stimulate Eve, and she would start to join in our activities. 
One day there was an incident which gave me a chance to approach much closer to Eve. During Iunch Eve was sitting by herself at a small table in a corner of the room. Lunch was placed in front of her on the table, but she didn't eat. As usual she just looked into space. I decided to feed her myself. I sat down beside her and tried to feed her some soup. She would not open her mouth. Instead, she gazed at me for a long time and finally stretched out her hand toward me. I held her hand with both of mine. She then threw herself against me and hugged me tightly without saying a word. She kept hugging me tightly and began sobbing with no tears flowing. Her whole body shook as she lay against me. I could feel her deep loneliness. I thought she should be with the group. I took her across the room and sat her down among the other students. She said nothing and just sat there, but I thought it was better than sitting alone in the corner. After the above episode, I always tried to keep Eve among the other people in the class. David soon started helping me every time I helped Eve. Eventually, he began helping her all by himself. He fed her breakfast and lunch, sometimes taking an hour to feed her a bowl of cereal and a glass of milk. She was very slow, but David was very patient with her.

Gradually Eve improved. Although she still didn't talk, she presented us with a smiling face once in a while. 
She began to walk by herself, holding onto the furniture and walls. One day while David and Eve were sitting side by side, I asked David, "Maybe Eve would like to draw? Will you give her paper and crayon?" David brought her the materials and told her to draw. But she wouldn't even hold the crayon for any length of time. I thought I should wait. David kept helping her and they became close friends. Finally, at the end of November, she began to feed herself if David stayed with her and encouraged her.

One day during this stage David brought Eve to the painting room, which was then in the basement. Although Eve could walk across the room by herself by holding on to the furniture and walls, she still needed help to walk up and down the stairs. David held both of her hands in his, and helped her down the stairs and to the painting table. He continually cautioned her, "Be careful. Be careful." David placed a large piece of paper in front of her on the table. Next he drew his favorite objects on the paper. $\mathrm{He}$ then gave the crayon to her and said, "You see, you draw like this!" Eve could not hold the crayon correctly, but David patiently helped and encouraged her. She finally started drawing. She didn't draw the objects which David had drawn as examples. Instead, she scribbled several curved diagonal lines, which later turned out to be her favorite brush strokes and her own painting theme. 
I soon introduced Eve to brush painting. At first she had great difficulty holding the brush and kept dropping it. She needed several days of practice before she could handle the paintbrush. During all of this time David was with Eve and gently took care of her. Eve finally learned to use the brush and began scribbling with brush and tempera paint. Her painting improved rapidly.

Eve became cheerful and friendly as she continued to paint. She started talking to us and showing an interest in the group activities. She was deeply dependent on David, but she also began to actively communicate with me. Eve stayed with us for about nineteen weeks and then moved to another group home.

I would now like to describe in detail Eve's painting improvement and behavior change during her painting activity. Eve's painting experience can be divided into four distinct stages. The first stage comprises the first three weeks, from late November to 18 December 1972. During this time she showed remarkably rapid improvement. The second stage consists of the next three weeks, including Christmas vacation. Eve did not paint at all during this period. The third stage includes the next three weeks in which she began painting again. She repeated the sequence in the first stage, reaching the same level that she had gained just before Christmas vacation. The fourth stage consists of the last three weeks when Eve progressed rapidly. 
improved her painting greatly, and finally achieved her own painting style.

I would like to describe Eve's development by following these four stages. Overall, Eve painted for about twelve weeks. Within this short time her painting developed rapidly. In each stage she showed an important, distinct developmental process.

\section{THE FIRST STAGE}

Late November to

18 December 1972

Figures 71 through 76 represent Eve's work in the first stage. Eve did her first drawing with David's help and companionship (Figure 71). David gave her a piece of paper and drew his "David's tree," "Christmas tree," and a rainbow on it. Then he handed the crayon to Eve and said, "You see, you draw like this!" Eve took the crayon and without any hesitation began to scribble diagonal lines on the paper. As she continued drawing she became more enthusiastic. She began drawing her lines rapidly with more force. David sat by Eve and calmly watched her drawing activity. Eve had ignored David's suggestion to copy his figures, but this did not bother him. He just kept company with her and let her draw as she pleased.

Eve tried her first brush painting the same day (Figure 72). With David's help she had begun to control 
the crayon better in her first drawing. I thought she could handle a paintbrush all right, so I gave her a brush and tempera paint. Why ask Eve to begin brush painting so soon? At this point, relying on my experience with them, I decided to encourage my students to begin brush painting as soon as they could handle the brush because brush painting allows more freedom of movement than crayon, pencil, chalk, or Cray-pas. At first Eve could not hold the brush. She dropped it on the paper often. I thought that the effort was too much for her to begin brush painting. I thought I should return the crayon to her, but she seemed to like brush painting very much and patiently tried again and again.

The yellow brush strokes in her first painting, Figure 72, are the results of Eve's struggle for thirty minutes. In spite of her difficulty at the beginning, she kept trying hard and improved.

Eve began to handle the brush with more skill. In her first two paintings, she drew diagonal lines from the upper right to lower left and upper left to lower right. In Figure 73 she also used diagonal lines the same way, but these lines became much longer and more deliberate. She confidently covered half of the paper with these lines. Moreover, she used contrasting colors, red and blue. She painted blue over red. These actions told me that she already had become very interested in painting and had 
begun to explore the use of different colors and the mixing of colors. She even tried to compose something with the use of colors and brush strokes. Eve was not afraid of painting. Instead, she was ready to express herself through painting. Eve soon revealed another step in her painting improvement in Figure 74 . In addition to diagonal lines, she used both vertical and horizontal lines. Her brush strokes ran freely over the entire paper. She tried to use up the whole surface. She used three colors, yellow, red, and green, very effectively. The left half of the paper is covered by a layer of yellow and red paint. The right half consists of several yellow and green diagonal lines, which seem to be one big diagonal line, and one red horizontal line. Here her attempt at composition and her emotional appeal through the use of colors and brush strokes are clearly shown. There is a great amount of dynamic movement and dramatic feeling in this painting. Eve continued to improve in her next painting (Figure 75). She became very involved with painting at this stage. Her brush strokes gained more speed and force. She pressed so hard on her brush that the metal part of the brush scratched the paper surface. She put a lot of blue paint on the brush and then hit the paper with the brush. Diluted blue paint spattered over the brown painted surface. She paused and gasped at the result. She seemed to 
be pleased with her work. She found painting a good emotional outlet and fully enjoyed this new experience.

Eve had expressed her feelings with her own unique scribbling method in the paintings in Figures 73 and 74 . She continued this emotional involvement in the painting in Figure 75. She also showed a strong interest in shapes and composition. This day, for the first time, Eve became aware of people around her while she painted. Until then she had scribbled all by herself and not paid any attention to the group. But on this day she reacted to our comments and painted more vigorously after each compliment. Eve's next painting reveals her awareness of shape (Figure 76). A combination of a large and a small shape are convincingly and deliberately painted. The dynamic directional change of the brush strokes in the small red shape creates a feeling of strong, rapid, ever-changing movement. The smooth diagonal brush strokes in the large, dark green mass create a slow upward-moving and expanding force. These two shapes are harmoniously balanced on the paper surface.

Eve painted red over green and blue in the small shape in the painting in Figure 76. She painted the large shape with green over red. She built up the whole painting with layers of paint, which creates an energetic, powerful image. Shape, placement, color, and brush strokes in the painting are all combined to express what she wants to say. 
Here she has effectively utilized all the learning she gained from the past three weeks of painting activity. There was an incident in class the day Eve did the painting in Figure 76. That morning David brought Eve to the painting class, sat her in a chair, and left the room immediately. David must have had something to do. At that time I was wiping up water from the classroom floor. Eve was left without anyone's attention for awhile. Suddenly she fell to the floor from her chair with a huge, terrible sound. I ran to her, picked her up, and asked if she was alright. Her forehead was cut and bleeding, but she calmly nodded yes to my question.

Eve's housemother at the group home later told me that Eve often fell down this way in order to draw attention to herself. I blamed myself. Even though I was busy, I should have taken time to give Eve paper, paint, and brush and let her begin painting. David also felt responsible for the incident and stayed close to Eve the rest of the day.

In spite of this sad incident, Eve painted eagerly and created such a good piece, Figure 76 , that it made me relieved and pleased. This was the last painting done by Eve during the first stage and before Christmas vacation.

During the first stage of her painting activity, Eve began painting and quickly moved forward. From the very beginning, she stuck with her own way and rapidly 
developed her own painting skill. At first when David suggested she copy his "David's tree," Eve ignored him. She began to scribble and stuck with it (Figure 71). Given a brush and paint, Eve had difficulty in handling a new medium (Figure 72). But her enthusiasm overcame her handicap, and soon she learned how to use the brush. She then went right on to explore various colors (Figures 71 through 75).

Eve tackled the composition problem along with experimenting with colors. She learned the harmonious placement of her scribbling on the whole paper surface and learned to create interesting shapes with her scribbling. More significantly, she used painting for her emotional outlet. Through the use of color, brush stroke, and shape, she freely expressed her emotions (Figure 75). She next became interested in planning more artistic work. She became involved with painting at a much deeper level and created a more complete piece in Figure 76. Various intellectual elements such as form and composition are clearly evident here.

Eve attempted to solve the important basic problems of painting all by herself during the first stage. Within a short time her development was swift and smooth. It was as if her long suppressed psychic energy began flowing out. There was such a natural, powerful movement in her learning process. 
THE SECOND STAGE

19 December 1972 to

8 January 1973

The second stage, a period of three weeks, was a time of painting inactivity for Eve. The first painting class held after Christmas vacation was on 2 January 1973. Eve seemed to be very happy to get together with the group again. She sat among her fellow students and looked around at everyone with a smiling face. When I asked her if she wanted to paint, she shook her head, no. So I decided not to force her. She did nothing, but looked very contented. The other students were coming and going at the painting table. When they left Eve's side, leaving her alone, she would become very depressed and put on a sad facial expression. Finally she looked as if she had shut the outside world out completely. Her face became like a mask; no emotional expression at all. I noticed her state, went to her, and started talking. Her facial expression relaxed, and she began to smile again.

When Eve first came to the group home, she showed no emotion whatsoever. This latest expression of sadness and happiness on 2 January was a great improvement over the past. To my surprise, she also clearly called out my name this same day. I had never heard Eve say anything before. 
THE THIRD STAGE

\section{$\frac{9 \text { January } 1973 \text { to }}{31 \text { January } 1973}$}

Eve began painting again at the 9 January painting class. I looked forward to her renewed activity as I recalled her rapid improvement up to Christmas vacation. I expected new development in her painting. But to my surprise, her painting took several steps backward. She returned to a state of development which was less than she had achieved at the end of the first stage. Her brush strokes were a replica of those in Figure 73, and she had no active spiritual movement in her painting. Seeking the reasons for such a backward movement in her painting development, I found two possibilities. Since she had not painted for three weeks she may have had to relearn the use of the brush once again. That was one possibility. Another reason seemed to be the lack of attention given to her by everyone during her inactive period. During the time in which Eve stopped painting for a while, three other girls in the class painted eagerly and showed remarkable progress. The other students and I paid so much attention to these three girls that it might have made Eve feel left out. I decided to give her more attention.

One day, during this stage, David was helping Eve walk to the lunchroom. As they passed by me, Eve stopped and held me. She puckered up her lips and began sucking 
air, as a baby sucks her mother's breast. This action surprised me because it seemed to be a backward step in her development, a clearly regressive act. As I held Eve in both arms, I said, "Eve, let's paint!" Eve replied, "That! I want to paint for you!" She then repeated, "I want to paint for you!" She spoke these words in a very determined manner. I was very surprised again. I understood that she needed more attention, but I didn't know that she was so much aware of me. Now I realize that although Eve moved her brush slowly as if she was half sleeping, she was very much aware of my presence. in the class. She painted to communicate with me. Until then I really did not know such a deep need of Eve's existed. I felt ashamed of my negligence and lack of feeling for her. After the above incident took place, I began spending more time with Eve. I still gave her complete freedom in her painting. But I always kept my eyes on her, gave her enough paints, frequently changed her painting water, and generally fussed over her. She began concentrating on painting and her attention span became much longer; that is, her painting time increased. She gradually developed her skills to the point she had reached at the end of the first stage.

Eve painted a total of fourteen pieces during the third stage. I can clearly see that she repeated the first stage sequence of paintings in Figures 73 through 76 . Had 
what she explored and gained in her painting in the first stage been deep-seated learning or was this process of learning her own unique and only way of learning?

Figures 77 through 81 are selected from the fourteen paintings done during Eve's third stage. Figure 77 resembles Figure 73, which was painted at an earlier stage when Eve was learning to hold the paint brush. The structure of the painting in Figure 78 resembles that of Figure 74 with its many brush strokes fanning out in different directions. In Figure 79 Eve painted two shapes just as she did in Figure 76. In Figure 80 she drew a shape that has similar characteristics of the large shape in Figure 76. Both shapes have expanding upward movement.

Although Eve mainly relearned her painting skills during the third stage she also made some drawings which suggested her future development. Figure 81 is an example. Here Eve started covering more paper surface with a constructive idea. Eve relearned her painting skills in the third stage by following her original learning path and at the same time prepared herself for the new development in her art.

THE FOURTH STAGE

$\frac{1 \text { February } 1973 \text { to }}{27 \text { February } 1973}$

Eve took three weeks during the third stage to reach the same level of development she had attained at the end 
of the first stage. She continued to develop her painting in the next three weeks of the fourth stage. Figures 82 through 87 represent her works during this period.

Eve painted red and yellow over a dark color in the painting in Figure 82. Her brush strokes took many directions. She placed the brush on the paper with such hard force that the paint seemed to be pushed on. This type of brush stroke action is very powerful and shows Eve's enthusiasm. She also covered most of the paper surface. Eve shows much freedom and spiritual strength in this piece which we can use to explore her new world.

The will or intention for Eve to cover the whole paper surface with paint is a truly good sign to me. With my knowledge from past experience I have found that most beginning students use only part of the paper, leaving most of it blank. As they do more painting, they begin to utilize more of the space. Finally they begin to intentionally cover all of the paper. I interpret this progress as follows: as the student paints, he usually gains confidence and stability in his work. Use of space seems to parallel the development of this psychological strength.

Eve used cool colors such as blue and gray, and warm colors such as red, pink, and yellow in her next painting (Figure 83). Her brush strokes became larger and freer, covering the entire paper surface. She started showing more interest in composition. Both the use of different 
colors and the shapes created by brush strokes are not accidental results. These expressions tell of Eve's full awareness of the entire surface and her intention to express something specific. Compared to the emotional quality of the painting in Figure 82, the one in Figure 83 has a much more intellectual element in its cool colors and many distinct shapes.

Eve began her new work with a combination of blue and purple color (Figure 84). She painted the entire paper with these colors and the painting turned out to be a beautiful and colorful one. I asked her if she had finished it. She shook her head, no. Using black, she painted over the colorful surface. She next painted a layer of red over the black and then black over the red. She finally handed the painting to me and said, "You can take it home."

Eve had already expressed her emotion through the use of various colors in the first stage. Now she did it with more intensity. She used many colors and painted over and over the surface until she became satisfied. This could be a very natural process in her painting activity. As Eve continued to paint, her perception had been sharpened. Her emotions had become deeper and her self-expressive motivation had been strengthened. Therefore she now tried to express a more complicated, deeper emotional stage. She persistently painted until she satisfied her need for expressing her emotion on paper. 
Eve also showed greater intellectual quality in the piece in Figure 84 than in the one in Figure 83. She intentionally painted specific shapes. She painted large, long brush strokes on the paper on an angle from top right to bottom center and top left to bottom center. At bottom center is a mass of red color. The whole painting has a symmetrical, well-balanced, and pleasing composition.

When Eve started painting the piece in Figure 84 she was very drowsy and drooling saliva from her mouth. But as she started painting she began to concentrate on the painting. Finally, she was really involved in painting and forgot everything else. She took nearly two hours to do this painting. When she finished, her face looked very alert with shining eyes. She looked happy and cheerful.

Eve next tried to create the same kind of combination that appeared in Figure 84. But this next piece became more colorful, and her brush strokes became freer (Figure 85). At this point Eve began effectively to utilize her unique technique of scribbling and her rich color perception to express her inner world.

Eve's composition became simpler in her next painting (Figure 86). She divided the entire surface into two sections, the right half with dark colors and the left half with bright colors. She began to express a threedimensional effect by the use of contrasting colors, especially in the way an extension of the bright portion 
crosses the dark field in a sinuous path. Above all, Eve painted this piece with great and evident confidence. The shapes and colors are not accidental results, but are clearly established features.

Where did Eve's confidence come from? I believe that it is because she knew what she wanted to express and how to express it. Ever since her very first painting, she stuck with her own favorite brush stroke which turned out to be her own unique technique or her own painting theme. She continuously explored and developed her own way of painting. This process of exploring her own technique must have given her great confidence in her painting activity. She now freely utilized her self-taught technique to express her inner world.

Eve's paintings in Figure 85 and 86 were done on 8 February. On this day a young girl who took care of Eve told me of the following incident. Eve got up early in the morning, finished breakfast all by herself, put on her best dress, and said, "Yaeko is coming today." She then waited for me. She became drowsy, began to slobber, and was barely able to sit in her chair later while painting. But she put intense effort into the paintings despite her condition. Eve gradually became so involved in her painting activity that she forgot about the people around her, including David and myself. She sat in her chair, bent over the table, gazed at one spot on the paper, and slowly 
moved her brush. Once in a while she paused in her work and gave a big sigh, but soon returned to the painting. She continued painting in this manner for hours. Eve seemed to focus her entire mind on her inner world and tried to express what was there with colors and scribbles. The result is such a sensual, compassionate, and beautiful piece of painting as Figure 86.

The people around Eve, including myself, were excited and happy over her accomplishment. I was especially impressed by her work. I gazed at her painting for a long time. I wanted to give Eve a good comment, but I could not express my feelings in words at that time. I silently looked at Eve with a deep feeling of awe and respect. Eve looked back at me in a very calm, quiet, and satisfied way. The painting in Figure 87 was turned out by Eve two weeks after Figures 85 and 86 were completed. On that day she was sitting across the table from David and was truly involved with her painting. This last work has great complexity. Both color and composition became more complicated than in the previous paintings. Her space perception has become much deeper. There is warmth, passion, and lots of desire in the painting. It is full of natural and powerful movement which makes me think of the great continuous movement of sun and stars in the sky. 
Her inner world is rapidly expanding and she seems to be wondering and searching in this ever expanding world inside of herself.

Eve left our painting class and moved to another group home soon after completing the painting in Figure 87. I kept her company during these last days in class. She continued to paint, sitting at the table and moving her brush slowly over the paper. She paused once during this period, gazed at me, and said, "I love you, Yaeko." She had told me several weeks before that she wanted to paint for me. One day after that she had looked at me closely and said, "I like you, Yaeko." Today she really gazed at me and said, "I Iove you, Yaeko." Through painting, Eve and I became close and finally she clearly expressed her affection for me. I felt sad about her moving away from our group at this stage of her development.

David voluntarily painted with Eve on her last day in class. When time came for Eve to leave the room, I said goodbye to her. Eve looked at one of David's paintings and asked me if she could have it. I asked her if she knew who painted it. She replied, "I know, David did." With a warm feeling springing from my heart, I said, "Here, take this one with you and keep it all the time." I took the painting from the table and handed it to her. Eve held David's painting in both hands and slowly walked out of the room. 
Eve could neither speak nor walk by herself when she came to our group home. When she left she was able to paint, speak, and walk all by herself. What a great improvement it was. I recalled David's friendship and loving care of Eve which had supported her throughout her painting experience in the class. I thanked David again and again from the bottom of my heart.

Eve created her own unique painting style during the fourth stage which revealed her rich perceptive inner world. In her third stage, she relearned her self-taught painting skills from the very beginning step. At the end of the third stage, she reached the developmental level equaling that which she had achieved at the end of the first stage. She regained her sensitivity to color, shapes, and composition. She also regained the psychic energy of freedom in self-expression. She was ready to move ahead again.

Eve energetically covered the paper surface with layers of colors throughout her fourth stage. She stuck with this method and tried very hard to reveal her own world. At this point she had enough painting experiences and had gained a firm self-confidence in her painting skill. Her awareness of herself deepened. She began to feel an ever unfolding, rich, and deep emotional inner world in herself. She persistently searched and tried to recreate this world in her painting. She used many 
different colors and painted the surface over and over until she became satisfied.

Eve also had a very natural urge to beautify and perfect her own art. This urge led her to search for a more pleasing, harmonious composition in her painting. She diligently explored the ways to achieve this goal in the fourth stage. She varied the length and direction of her brush strokes. She experimented with various space divisions. At the end of the period, she even began to express depth in her paintings. In the paintings in Figures 86 and 87 , there is an expression of spatial depth which creates a sophisticated, yet mysteriously beautiful and powerful movement.

Eve showed an amazing improvement in her behavior along with her achievements in painting. She became more cheerful and stronger. She was able to feed herself and to walk unaided. She became very friendly to people and she talked and laughed with everyone. She finally left our group at the end of this fourth period. She walked out all by herself, leaving many beautiful paintings with us.

\section{Summary and Conclusion}

Eve stayed with our group for almost nineteen weeks. She was totally helpless when she first came. She could not eat or walk by herself. She shut herself out completely from the outer world and communicated with no one. She 
gradually gained strength with David's help. She began to feed herself and to walk unassisted. She even smiled at people.

Eve became so strong by the eighth week that David introduced her to painting. She began painting and quickly developed her own method. During the beginning three weeks of painting, she learned painting from the very first step, how to hold a brush. Once she learned that, she courageously tackled more complicated problems such as color, shape, form, and composition. During the next three weeks, she took a rest break and did not paint at all. After the break she began painting again and relearned her own selftaught method. And then, during the next three weeks, she gathered up all her self-taught skills and created her own painting style.

Eve showed remarkable change in her daily life along with her painting activity. She began taking care of herself. She participated in the group activities and enjoyed a friendly association with people. When she left our group, she was a completely different person that when she arrived. Having observed her developmental process, I realized an important factor which brought her such remarkable improvement. That is her honest self-expressive approach to painting.

Throughout her painting activity, Eve stuck i.th her favorite brush stroke and painted as she pleased. She felt 
good about her own painting and found out that she could do much on her own. This self-satisfaction and selfconfidence accelerated her motivation to try more. She eagerly explored new ideas and created her own style. As her painting improved, she received more praise from people around her. This encouraged her greatly and she worked even harder.

Through her painting activity, Eve gained selfconfidence and a way to communicate with people. She was no longer inactive or alone. Her psychological energy was flowing in her daily life. She learned to take care of herself and truly enjoyed mingling with people.

Given freedom Eve fully utilized painting to help herself. She used painting as an emotional outlet, a medium to explore intellectual capacity and, above all, as a powerful medium to experience creativity. Although Eve deeply depended on David's companionship, it was Eve's own effort that helped her most. It was as if a long suppressed psychic energy in Eve finally burst out through brush and paint! This same energy kept being nourished by her honest self-expressive painting activity. The energy gradually took the form of inexhaustible, self-generating psychic power. Eve was moved by this inner force and kept moving forward. It was truly a precious experience for me to participate in this impressive human achievement. 
CHAPTER VI

CASE HISTORY: KAY

Kay was a thirty-four year old woman with Down's Syndrome who came to our painting class in November 1972. She lived with her parents or relatives until the age of thirty-three. She did not attend any school or special program during this time. Her parents were over protective and, consequently, she had no experience socializing with others. At age thirty-three Kay was moved to a care center where she lived for six months. She became very unhappy and upset there. She isolated herself from others by staying in a dark room and doing nothing. She lost much weight in a very short time.

Kay acted the same way when she first joined our painting class. She seemed to be afraid of being with or even looking at people. She just stood in a corner of the room looking down at the floor with tears constantly flowing down her cheeks. She neither moved nor spoke a word. She acted like a tiny animal who was frightened to death.

We finally brought Kay to the painting table, sat her down, gave her pencil, paper, and crayon. For several days she just sat motionless in the chair. She never once 
picked up a crayon, but only gazed at the blank paper. Once in a while she would anxiously glance up, then lower her head again and start to cry. Then one day she finally picked up a crayon and began moving it in the air above the paper. She never touched the paper and seemed to be exercising or warming up. Kay had been taught by her parents that cleanliness was very important. Perhaps this training kept her from making a mess on the paper.

I did not want to give Kay any pressure whatsoever. She was still very afraid of people. She silently began dropping tears everytime someone came close to her. So I left her alone. I decided that she could practice painting in the air above the paper for as long as she wanted. Perhaps she would begin to paint on the paper when she finally satisfied herself.

It was at this time that David began voluntarily to take care of Kay. With David's help and encouragement, Kay finally began drawing on the paper. At first she drew several short, vertical and horizontal lines. She never seemed to be afraid of David, drawing with him for hours. After Kay had drawn several line-filled pictures in several days, I gave her a brush and tempera paint. She had difficulty in using the brush at first, but soon she became so interested in painting that she would paint all day, every day. Each morning she would be waiting at the classroom ahead of everyone. She could hardly wait until 
we got set up for the class. She was not so afraid of people as she had been at first. Her interest in painting overcame her fear of people. She was no longer frightened when people came near her. When she needed more paints or paper, she would sit up straight and try to draw someone's attention. She soon became more brave, getting paper and changing the watercolor water all by herself.

Kay painted in our class for eleven weeks. Within this short period she developed her painting style quickly. At first she painted only straight vertical lines. Next she started to paint circles and then many other shapes. Her development was one continuous, smooth movement. As her painting changed there was a visible improvement in her behavior. She left our group after eleven weeks as a strong and happy person, no longer afraid of people.

I would now like to present a detailed account of Kay's development in time sequence. Because of her smooth progress in painting in a short period of time, I will not divide her case into different stages but will instead follow her development step by step according to my diary.

Late November 1972

Kay, encouraged by David, finally began to draw on paper one day. David gave her a piece of paper and drew several "David's trees" on the paper with a crayon. Then he put the crayon in Kay's hand and said, "You draw too 
like this. You see?" Kay tried to copy his "David's tree" (left side of Figure 88). Here Kay recognized the shape of the leaves of "David's tree," but she could not copy the whole tree. Instead of copying the tree, she drew layers of horizontal and vertical leaf-like shapes. The regular class teacher came by, drew a circle on the same paper (Figure 88), and told Kay to copy it. Kay drew some small circles. She also drew many vertical lines and filled the space between these lines with short horizontal lines. Kay had been practicing drawing in the air for several days. On this day, with David's help, she began drawing on paper. I thought it was a remarkable improvement.

30 November 1972

Kay continued to draw after her initial breakthrough. I introduced brush painting with tempera paint to her on this day. I hesitated, thinking that it might be too early. But, after seeing her eagerness, I decided to go ahead. She had difficulty in handling the brush at first. She attempted to paint straight lines, but could not. Her lines were many short jerks instead of one smooth motion. But she patiently exercised and showed quite an improvement within one day.

Kay also was helped by David in her first brush painting. He placed a rectangular container on the paper and traced it with a crayon. He then told Kay to copy that 
rectangular shape. She could not copy the whole shape, but instead painted several "L" shapes.

Kay painted the next brush painting all by herself (Figure 89). In this painting she repeated several "L," " $\Gamma$ " and " 7 " shapes. She also painted many short vertical lines. Although many lines in the painting are jerky with many starts and stops, I can see that Kay was really trying to paint neat straight lines. She used three colors: orange, yellow, and blue. She divided the paper surface harmoniously by the use of these three colors. It seems that she is already well aware of the entire paper surface. Kay painted only vertical lines in her third painting (Figure 90). She started on the right side of the paper and worked to the left side. As I follow these lines from right to left, I can clearly see that Kay tried very hard to paint straight lines. She also tried to keep the space between the lines equal. She has begun to handle the brush with more skill and confidence. Consequently, she managed to paint longer lines in the piece.

The simple and direct use of three different colors (blue, green, and orange) indicates that Kay was also handling colors with more confidence. The vertical lines in the third painting are more simple than the ones in the second painting, which includes both vertical and horizontal lines. Kay is saying less in the third painting; but the feeling of the whole painting is stronger. She painted 
each line with more effort, concentration, and confidence. The third painting is a great improvement over the second one in all respects. Kay advanced greatly within one day.

\section{December 1972}

Kay had been practicing brush painting for one week. She handled the brush very well on this day. Her ambition was to achieve the skill of covering the paper with long straight lines (Figure 91). When she began brush painting the week before, her brush strokes stopped every few inches. On this day she painted nice straight lines, stopping only occasionally in mid-stroke. These lines were placed side by side and filled the paper. As I explained in Eve's history, covering the entire paper is a good sign that Kay is gaining more confidence and stability in her work. Within a very short period of time she began covering the whole paper. Examining her straight-line paintings, I can really feel her mind waking up and becoming active and energetic.

Kay also began to use two very different and contrasting colors on the same paper. By doing so she seemed to discover more definite shapes. For example, as shown in Figure 91, one side of the paper has purple stripes and the other side has white stripes. The overall effect is that two objects, one purple and one white, appear as rectangular shapes on the paper. Kay must have been fascinated with 
discovering these different shapes, one a large rectangle and the other a smaller rectangle.

Kay also had begun to create many different objects such as triangle-like shapes or more irregular shapes. The painting in Figure 92 is one good example of such an attempt. Here she used a strong colonderombination of green and red. The shape is more complicated and stronger than the shapes in the painting in Figure 91

Kay's discovery of shapes can beteraced back to the very beginning of her painting activity. In Figure 88 she had already created rectangular shapes zontal and vertical lines. More comp appeared in an uncertain manner in Figkive 89. In Figure 90, vertical lines were used and the rectangular shapes became clearer. In Figure 91 Kay was very mưch aware of rectangular shapes and In Figure 92 she intentionally searched for more interesting shapes.

Kay finished about forty paintings (size 18" x 24") during this week. She worked very hasid in completing each one, giving them very careful attention. That is quite a feat, considering she did nothing productive during her life until coming to our class. This is a great improvement within a short period of time.

At this time Kay was sitting and painting for hours without saying a word. She never raised her eyes from the paper and never looked at or spoke to sanyone around her.

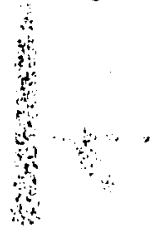


She was not as afraid of people as she was at first. Yet she did not show any urge to associate with people, usually ignoring them. She sat there in her own little world drawing lines by the hour. Outwardly she hadn't changed much. But by looking at her paintings, I could see that something good had begun to happen in her mind.

\section{December 1972}

Kay continued to paint in the same way, but even more eagerly. Her preference had become clear; she had been using many colors, preferring red, green, and yellow. Her painting was much better when she used these three colors. It seemed that she painted these colors with more confidence. She also had a good sense in matching colors. When I gave her different colored paper, she matched the paint to the paper very well. For example, she used yellow color on green paper and white and purple on gray paper. Every time I gave her different colored paper, she took a long time in deciding what color she would use.

Kay also responded in a sensitive way to the size of the paper. On this day I gave her a smaller size of paper. She painted in the same manner, but with smaller brush strokes. She made horizontal and diagonal lines in addition to her regular vertical lines. The whole painting was done neatly and showed that she had some kind of plan thought out in completing it. This development is interesting when compared to her painting on larger sheets of paper. 
Faced with a larger sheet of paper, Kay usually painted long vertical lines. The physical motion involved in painting long lines must have been an exhilarating experience for her. As she continued to paint these long lines she became carefree and enjoyed a feeling of power, not worrying about making a neat and finished painting.

This reaction to different sizes of paper is interesting because I have myself experienced almost the same kind of feeling. I get very excited when I am faced with a large blank canvas. Working with a large canvas I don't worry too much about the finished result and paint freely with large brush strokes. When I face a smaller canvas though, I tend to plan carefully how and what I want to paint. My brush strokes become smaller and softer. It was delightful to see Kay showing such sensitivity to the size difference of art paper.

Kay had also improved her technique of diluting watercolors. She had sometimes experimented with plenty of water and had enjoyed the freedom of smoother brush strokes. Her straight lines had also greatly improved. She had been continuously practicing painting long vertical lines without stops or zigzag motions. She now seemed to have achieved this skill very well. She had also begun to use a larger brush. With this large brush she painted long straight lines side by side from one edge of the paper to the other (Figure 93). 
In the painting in Figure 93, Kay first painted one dark purple stripe at the right edge of the paper, and then she painted a red stripe beside that one. After that she paired stripes. There are four pairs of such stripes. The first two stripes and the four paired stripes are neatly placed on the paper, keeping almost equal distance in between. There is reasoning in the painting. It seems as if she has mastered her main theme of drawing straight vertical lines and using these lines effectively to express her feelings.

When Kay began to paint, she was unskilled. All of her attention and energy were concentrated on holding the brush tightly and drawing straight lines. She worked very hard. But now she had begun to relax and enjoy her painting. She chose her colors and painted her lines with much confidence. She sat at the table and painted lines by the hour. She stopped for lunch, but she returned very quickly to her painting.

A famous Japanese painter once told me that painting is the whole sum of the painter. It is nothing but an expression of the painter himself. The painting is the mirror of the painter. If Jesus Christ returned to earth and painted a line, it must be something else. It would be the most beautiful line ever.

As I watched Kay painting her lines so eagerly, I could really feel the importance of these lines for her. 
During the past thirty-four years, she had done nothing. She often just sat alone and cried. Painting was the first activity she had ever experienced. By painting a line, she expressed herself for the very first time in her life. She assured herself in each line. Her long suppressed spirit sprang out of each line she drew. From each line I could hear Kay's shouting voice, "I am here!" This simple line was indeed the cry of life for Kay. To me this line is the simplest expression of the true beauty, life itself! I wanted to bow down in front of Kay.

\section{December 1972}

When I went into the painting room on this morning, Kay was already there, wearing a white apron and waiting to paint. She looked straight into my eyes as I walked in. I said, "Oh, you have been waiting for us." I tried to give her a good morning kiss. She was not afraid and gave me her cheek to be kissed. On this morning, for the first time, she raised her head and looked directly at me. She even let me kiss her cheek: She said nothing, but I felt her warm feeling toward me. I was happy to see her in such a good mood.

During painting class on this day, a boy across from Kay at the table cleaned his brush in Kay's water jar. Kay didn't like it. She began to mumble to herself and looked unhappy. I gave her clean water in another jar. She kept 
this jar close by her. Satisfied, she eagerly went back to her painting.

Painting was a very important activity for Kay. Her own paint and water jar were important tools for her painting. She had to make these items secure so that she could really get involved with her painting. The people who took care of Kay in the group home told me that during the past few days she had painted up to supper time. She often returned after supper to continue painting.

Here is an added note for this day. Although Kay was very friendly toward me on this day she kept her head down and never looked up while painting during the day.

\section{December 1972}

Kay continued enthusiastically to paint her line pictures. Someone brought a guitar to class on this day. In the morning we all sat around in a circle, a black girl played the guitar, and we sang. When I asked everyone to make a circle and sing, Kay got up, moved her chair to the circle by herself, and joined us. She did not sing, but sat there quietly with us, sometimes smiling contently. I was very surprised and happy. This was the first time that Kay had joined in the group activities.

Kay was not afraid of people anymore, instead, she willingly joined the singing group. Afterward she went back to painting. Before she began to paint, she looked at the boy's face across the tabie from her and then looked 
at each of the other students. She then began to paint in a very relaxed manner. She would frequently look up and around at the other students while painting. Up until this day she had never looked up from her painting. Even when I had looked at her work. She would look sideways at me out of the corner of her eye. This sudden change in her behavior delighted me.

\section{January 1973}

We had our first painting class on this day after two weeks of Christmas vacation. Kay had visited her aunt and uncle over the holidays, and she looked very happy when she returned to class on this morning. She was very neat looking in her new pants. She looked and smiled at everyone in class and seemed genuinely glad to see them.

On this day we worked on colored Japanese origami paper. This is thin art paper used for folding into various objects. We tore the colored paper into small, random shaped pieces and glued them onto a large sheet of paper in different designs. Kay followed my instructions on how to tear and glue the paper. She finished one picture and sat quietly thinking for quite some time. She carefully chose sheets of different colored paper and cut them into long strips. She took these long strips and began gluing them side by side on a new sheet of paper. Kay used new materials and a new method to accomplish her old theme of painting straight lines. She took her 
time, thought each move out, worked carefully, and apparently enjoyed this new activity. It took a lot of thought to take a new material, origami paper, and use it in reproducing her old theme of straight lines on paper (Figure 94). She discovered this whole new method by herself. It must have given her great satisfaction. She worked very hard, but continued to be relaxed and happy.

Up until this day Kay had generally painted with an intense urgency. It was as if she had finally found something to hang on to, her painting, and she did not want to lose it. There had been an atmosphere of a very sick person trying very hard to cure herself. But now, on this day, she was working in a completely relaxed manner and enjoying every minute of it. I felt that this was a very important change.

Kay went to lunch, quickly returned, and started to work by herself. Later, the other girls in the class and I began to dance to the radio music. Kay looked up at us. As she worked, she began to swing her body and smile. She looked so happy. Her round, smiling face and plump body were swinging sideways in the chair. It was an unforgettable, moving scene, a true joy to watch.

\section{January 1973}

There were two women in class who were improving very rapidly in painting. I wanted to give them and Kay special attention on this day. I divided the class into 
two groups. I kept Kay and the other two women in the painting room and sent the other students to another room. The classroom became very quiet, and Kay seemed to be uneasy. While I was mixing paint, she quietly started to cry. Her tears were running down her cheeks, and she put her tongue out on her lower lip. She looked so depressed and miserable. Since she had stopped crying for many weeks, I was very worried that I had made a mistake. I should not have separated her from the other students. While I was trying to decide what to do, a black student came into the room. I asked her to bring some Kleenex tissue for Kay. She said a cheerful "o.k." and brought the tissue for Kay. Kay said, "Thank you," and wiped her tears away. It caught my attention because I had never heard Kay speak to anyone previously.

David soon came back into the room. Kay really gazed at him and gave him a very warm smile. I could see in her face how much she trusted and depended on David. David had helped Kay a lot when she first began painting. I truly realized how much David meant to her. Kay needed the friendship with David and the warm, noisy atmosphere of the group in order to paint. I felt badly about my own insensitive act in dividing the group to give special help to certain individuals. But then I found out that Kay needed the group more than my special attention. It was a very good lesson for me. 
Although Kay didn't have a smooth start on this day, she made an attempt to do something else besides straight lines on paper. At first she did two paintings of straight lines. On the third paper she first painted a thick frame around the edge of the paper. Then she filled the paper with straight lines. Here was a new step. I was very interested in what she would do for the fourth painting. But she went back to the simple vertical straight line method again. She began the next painting with the same vertical straight lines, but as she reached the far left edge of the paper, she began to make circular lines on the paper (Figure 95). Here was a sudden change in her brush strokes. By gesture she asked me to give her a lot of fresh red paint. So I did. She took a new sheet of paper, and using the red paint, she painted that circular scribble. Next she changed to yellow paint and continued the circular scribbles (Figure 96). Her brush strokes and motions became free and strong as she continued this circular painting. I again felt that some new energy was bursting out from deep within her.

Kay had been painting straight lines for six weeks. I was beginning to think that she might go on painting these lines forever. If she had continued to do this, it would have been fine with me. Someday, I thought, she may produce the most beautiful straight lines in the world. 
But now, all of a sudden, a change had come from inside Kay. She had now started circular scribbling. Why did she start circular scribbling? Where did she get this new idea? I remembered that in her earlier painting activity she had copied some circles that her regular teacher had shown her (Figure 88). She might have remembered that experience or she might have adopted the idea from other students' paintings. Or moving toward circular scribbling from linear scribbling may be a natural learning process. Whatever the reason was for her change, Kay had broken away from her original painting theme of straight lines. She had accomplished this important task all by herself. She was discovering the joy of experiencing this new brush stroke.

I have noted in my past experience with students in my class that they tend to do the circular scribbling when they are excited. For instance, one girl drew many circles when she was with her boyfriend. Two other persons painted circles when they were extremely happy at times, just before going to a movie, for instance, or the zoo, or a picnic. So, for me, this circular scribbling is a symbol of happiness and an expression of the painter's joyous feeling. Kay also became happier as she continued to paint her circles. She showed her happy feeling by joining our singing group or swinging her body in the chair while she painted. As I watched her eagerly scribbling circles, my 
heart filled with joy. When the time came to go home, I did not want to leave the classroom. Neither did Kay. I finally told her that I had to leave and would she like to return to her own room? She said, "No!" As I left, she was alone in that big room, continuing her scribbling.

\section{January 1973}

Kay had been painting circular scribbles for the past five days. She had become very cheerful, and was now actively moving around. Her facial expression had also changed. She looked distinctly alert and alive. I felt that she now had the potential ability to do anything she wanted in the future. She had also become more friendly. Kay had shown much improvement in her behavior and painting on this day.

On the morning of this day, a black girl drew some shapes on Kay's paper. I worried about Kay's feelings. I thought she might get upset at being disturbed in this manner. She had always been so unyielding in doing her own work. But she just calmly filled in the shapes with color. I have seen many instances in my class where one of the members has finally joined the group through the medium of painting. Now, Kay too was becoming a member of the group through the sharing of painting ideas with her classmates.

Two physical education teachers visited our class before lunch time. As we all stood, made a circle, and got 
ready for the exercises, Kay walked into the circle by herself and joined the group. She just stood and watched during the quick movement exercises. But during the slower exercises, she slowly imitated the movements of the other students. It was such a pleasant scene. I could not take my eyes away from her. As her eyes met mine, she smiled a big smile and imitated the action of strumming a guitar. Everyone began dancing to the radio music after the physical education teachers had left. Kay began to swing her body and approached several of us, saying, "Come on, come on let's dance." We were all very surprised. She kept approaching people and dancing for a long time. Everyone spontaneously surrounded her and cheered her on.

In the afternoon Kay began to paint individual and complete circles, two or three to a page. These new circles were out of round, jerky, and imperfect. After painting the first circles, she colored them in as fast as she could. It was as if what she saw on the paper, the circles, frightened her, and she wanted to cover them up fast. On one paper Kay painted a circle and colored it. When she painted another circle, I took the paper away before she could fill in this last circle (Figure 97).

Kay took another sheet of paper and painted a new design or shape on the right side of the paper (Figure 98). Beside this new shape she painted an orange circle and colored it. On the next paper she started painting 
half-moon or crescent-shaped designs (Figure 99). She used a large brush and, as she continued, her brush strokes became swift and strong. She was very unsure about her circle painting, but she painted the crescent-shaped designs with much confidence. Her facial expression vividly showed her deep concentration. She truly enjoyed working on the new design.

I can see Kay's learning process by looking at Figures 97, 98, and 99. I can see how she learned the crescent-shaped design. At first she painted circles and colored them. These circles could have been an accidental result of her previous circular scribbling. She might have been frightened to see the new shapes and colored them. Or she might have intentionally painted circles but was dissatisfied with the result and colored them. Anyway she kept trying to paint perfect circles, but she could not do so. The unfinished square-like shape in Figure 98 could be just such an example. After this trial she decided that painting a perfect circle was beyond her capability. She began painting a crescent-shaped design repeatedly and quickly mastered this new task. Kay went through this selftaught learning process within a day. It was quite an achievement for her.

Several days before, the house parents at the group home had resigned, and now there was a new couple working as house parents. This new young couple was very active 
and took a general interest in the people at the home. They had stimulated the whole group. Kay too seemed to be more content and happier. With this kind of healthy, good environment, she was now enjoying painting more than ever. She had already shown much improvement, and I was truly looking forward to much more meaningful progress from her.

\section{January 1973}

Kay had intensely filled many papers with the crescent-shaped brush strokes during the previous week. She seemed to have mastered this new brush stroke. She had been handling her brush with confidence and even boldness. She had begun to use crescent-shaped brush strokes not just in one direction, but freely from left to right, right to left, up and down, down and up. She had even explored and discovered new shapes by using this new technique.

Figures 100 through 104 show Kay's learning process at this time. Because of my failing to trace the time order in which Kay painted the first four pieces (Figures 100 through 103), I can not present them in their correct sequence. They are placed in order of convenience based on my own interpretation.

Kay filled the entire paper with free-moving, crescent-shaped brush strokes in the painting in Figure 100. She created a design with her crescent-shaped brush strokes in the painting in Figure 101--she painted a filled-in 
circle and surrounded it with crescent-shaped brush strokes. In the painting in Figure 102, she created shapes by applying very rhytrmical crescent-shaped lines. In the painting in Figure 103 she filled the paper with irregular, crescent-shaped brush strokes, varying the length and thickness. The painting has a lot of freedom, yet it has a wellplanned composition.

Kay seemed to have intentionally created shapes and tried to express what was in her mind in the painting in Figure 104. These shapes are very interesting and the composition is excellent. Moreover, the whole painting is full of action which creates a strong, positive feeling. Kay is now intentionally trying to originate new designs and painting ideas. She is no longer afraid to try something new.

After studying Kay's works in Figures 100 through 104, I feel that she was developing spiritual freedom and gaining strong confidence in herself. She was indeed becoming more open and free, exploring new directions. On that day she took the guitar, played it, and sang a song. She was deeply involved in playing the guitar and singing. She looked very alert and was full of strength and life. She played and sang vigorously for a while and then quit by saying, "That's all." She put the guitar away, went back to the table, and began painting very enthusiastically. 
At physical education time she voluntarily joined the group and played the bean bag game with us.

\section{January 1973}

Kay repeated the simple crescent-shaped brush stroke using a big brush on this day. Her brush strokes were sometimes arranged neatly in the same direction and at other times they were placed randomly on the paper in all directions. After exercised with this crescent stroke on many sheets of paper, she painted two new shapes (Figures 105 and 106).

The painting in Figure 105 has some very different images. Kay moved from a linear shape to a compact shape. Using a combination of large and small circles plus vertical and horizontal lines, she created various designs. These shapes have unity as a whole and are very expressive. In the painting in Figure 106, Kay used long, curved, horizontal lines to create several beautiful and symmetrical shapes. The painting has strong composition along with a spontaneous and exploring freedom.

These two paintings show Kay's constructive ability as well as her deep emotional conviction. Ever since the beginning of her painting activity, Kay has been persistently exploring new possibilities, new worlds. Her creativity had greatly expanded. Kay put all of herself into these two paintings on this day. I could hear the 
loud chorus of Kay's inner life. She had indeed exercised powerful creativity in these paintings. After finishing these paintings, she looked very satisfied with her own work.

\section{January 1973}

Kay's painting creativity really blossomed on this day. From the very beginning of the day she was different. With brush in hand, she sat at the table, thinking and planning out her moves. She framed her first painting with a border. She then painted several shaped lines inside the border (Figure 107). She did this painting with confidence, as if it had been planned for a long time. She then painted another piece similar to this one. Kay next changed the color from vlue to pink and painted a very beautiful painting (Figure 108). The brush strokes in the painting are extremely free and rhythmical. The shape is very strong. It seemed as if Kay was utilizing all of the painting knowledge she had learned in the past several weeks.

Kay now had mastered several different types of brush strokes. Using these brush strokes, she put whatever idea came into her mind freely and boldly onto the paper. In her second painting (Figure 108) there was a large curved brush stroke of pink color which stretches from the bottom to the top of the paper and looks like water spouting from a water fountain. It seems to symbolize Kay's creativity 
exploding like a volcano. Compared to her first vertical line drawings, this new-found freedom is an amazing step. Kay changed colors again, this time to green. Her next painting was similar to her last one in Figure 108 with the same bold brush strokes (Figure 109). It does not have so much of the symmetrical construction of the previous painting, but it does have even stronger, energetic power. After doing the perfectly beautiful painting in Figure 108, Kay increased her self-confidence and pushed forward in expressing her feelings in the next painting (Figure 109).

Kay then became extremely free and began painting very different paintings, one after another, using a great variety of shapes and colors. She painted thirty-four paintings on this day, all different. She painted all day long with enthusiasm. She painted a different subject, one right after another, with great confidence. In this group were paintings of lines such as in Figures 110 and 111 . Others dealt in shapes such as in Figures 112 and 113. Each painting expresses something different and is done with great sureness.

In the late afternoon, just before time to go home, Kay did a painting which combined straight lines and a circle (Figure 114). Then on the next paper, she began to make almost perfect circles (Figure 115). It had been nine days since she drew the first jerky, oblong-like, imperfect 
circle which surprised her so. Now she kept repeating her round circles, often changing colors. She also changed the placement of the circles on the paper. Some sheets contained six circles; other contained twelve. In some of the sheets, the circles are clustered; in others they are scattered. She had attempted to show many different designs with her circles.

I watched Kay all day with a feeling of awe. Her suppressed creativity of many years had finally sprung out from deep within her. When she first came to our painting class, she was like a living corpse. But now she was full of life and dignity. She now boldly created and explored and looked as if she could live a hundred years.

Until this day I had been very impressed by Kay's attempting so hard to create her own world through painting. I did not want to disturb her, so I never showed any strong emotion. But after she had drawn that round, perfect circle, I just ran up to her, held her in my arms, and said, "Oh Kay, that's beautiful!" Kay stayed quiet in my arms, but I felt a very natural friendship begin to develop and grow between us. That day was a very important day for Kay because she finally achieved the power to express herself so freely. It was also a very special day for me because a close friendship had been born between Kay and me. 
1 February 1973

I had been sick and had not held a painting class for the past two weeks. Kay's regular teacher said that Kay had kept painting enthusiastically during this period. She had painted about 110 pieces. I expected to find something new in these paintings, but I couldn't see any new traits. The simple circles and straight lines remained the same in these latest paintings. There was no exploring of new shapes. I thought Kay had reached the peak of her creativity on 18 January when she painted thirty-four paintings in one day.

This day, while I was looking at her 110 new paintings, Kay was sitting by the table and holding her paintbrush. She looked at me thoughtfully for a long time before she finally began painting. She was planning something. She moved her brush and painted a new shape. The shape was a simple linear structure, but something she never had done before. When she finished this first one, she again gazed at me for awhile. Then she did another new shape. This process was repeated for some time. By looking at her, I realized that she was very much aware of me.

Although my basic philosophy and rule is not to interfere with anyone, this time I quite naturally suggested to Kay that she try two different colors in her next painting. She nodded her head in agreement to my suggestion. Using red and green she painted a very quick, spontaneous 
painting (Figure 116). Did Kay paint a red sun and a green tree side by side? No matter what the subjects are, this simple looking painting has an impressive, poetic image. The painting talks and sings to me. I hear Kay's warm, hopeful voice in the painting. Until today I didn't know that my presence stimulated Kay so much. I was glad to know that I was sharing in her creative activity.

I noted that Kay had become calmer and happier in the past two weeks. On this day she was sitting by the black girl who was playing the guitar. Kay was swinging her body right and left in time to the music. A short time later she began playing the guitar by herself. She played for a while, then brought the guitar to me and said, "You play!" As I played the guitar, Kay stood in front of me and danced to the music.

I kept strumming the guitar and Kay kept gently swinging her plump body. I recall how Kay had been just like a tiny, frightened animal when she first joined our painting class. How far she had come since then! How hard she had tried! My heart was full of deep affection and respect for her.

Kay left our group on 9 February 1973. There was a change in the group home personnel. Kay's relatives did not like the new situation, and she was taken to a new group home. She knew she was to leave several days before she actually left. She looked uneasy and sad. She sat by 
the table all day long and painted straight vertical lines, one after another. She had tears in her eyes as she painted. I felt so sad about the situation. There was not much that I could do. I just prayed that Kay would be happy in her new group home. The house people said that when Kay's relatives took her waay, they had to physically force her to leave. She did not want to go! The paintings in Figures 117 and 118 were completed shortly before she left our group.

Kay began her painting activity by painting straight vertical lines. She then went to circular scribbling and next to crescent scribbling. She finally explored various shapes with these brush strokes. Before leaving the group home, she became unhappy and went back to her original, straight, vertical lines. She persistently painted the Iines until she left. I again realized the significance of this straight line painting for Kay.

Small figures drawn in the four corners of the painting in Figure 117 are Kay's signature. I usually wrote her name on her paintings since she could not write her own name. If I forgot to do so, Kay sometimes signed her name this way. She usually put the figures in only one corner. In Figure 117 she put them in all four corners. She must have felt terribly insecure about her leaving the group. She had to paint her original vertical line painting and sign her name to reassure herself. 
The thick, red brush strokes in the piece in Figure 118 were painted with positive feeling. The painting is rich in emotion, yet it also carries a firm constructive atmosphere. To me these red lines look like people standing side by side. They could be David, Kay, and her classmates. I could be included too. As I looked at this painting, I again realized that she had become a very strong person. I believe she will no longer sit and cry in any new circumstance.

Kay painted with us for about eleven weeks. She always tried hard and made her own way. It was such a pleasure to see her advancing and exploring. Her classmates, teachers, and I had all respected her and cheered her on. Suddenly Kay left our group. We all felt a big loss and missed her so much. We soon heard good news concerning her which comforted us. Kay was doing all right at her new home. Someone saw her at a dance party with her new boyfriend.

\section{Summary and Conclusion}

Kay joined our group in late November 1972 and left 9 February 1973. During this short period of time she eagerly painted and showed great improvement in both her painting and daily behavior. At the beginning of her painting activity, she drew in the air and never touched the paper for several days. 
Kay next tried to copy David's "David's tree" and the circles which were drawn by her regular teacher as examples (Figure 88). But soon she quit copying and began painting straight vertical lines. Thereafter she strove to achieve the skill of painting perfect straight lines (Figures 89 through 95). At the same time, she experimented with many colors and learned the effective combination of various colors. By doing so, she also discovered different shapes (Figures 89 through 92 ).

When Kay had become satisfied with her straight-line painting, she moved to circular line painting. At first she scribbled with circular lines (Figures 95 and 96). Next she painted imperfect circles and colored them (Figures 97 and 98). Then she began painting with crescentshaped brush strokes (Figure 99). She soon mastered this new brush stroke and used it freely to create many different shapes and designs (Figures 100 through 104).

Kay became very free and energetically explored new shapes and designs (Figures 105 through 116). At this point she used all the brush strokes she had learned so far. For example, in the pictures in Figures 106 and 108, she used mostly long, curved, crescent-shaped lines. In the pictures in Figures 107, 110, and 111, she used straight lines; and in Figures 105 and 112 she combined both straight lines and curved lines. At last she even painted many 
circles with confidence and used them to create new painting ideas (Figures 114-116).

Kay became highly creative and strong. But before leaving the group, she became unhappy and went back to her original straight-line painting. She urgently painted these lines until she left. It seemed as if she had to secure her self-identity by painting these lines, which are her own original painting theme.

Kay's behavior change was also drastic. The first noticeable change was when she stopped the habit of always looking down at the paper. She began to raise her head and to look at people's faces. She wasn't afraid of people and willingly began to join the class activities.

Kay would move her chair into the singing circle and sit with the group, silently but contently. After awhile she began to sing with the group. She joined the physical education hour and tried to exercise and play games with the other students. She kept improving. After eight weeks she was even whistling while playing the guitar. She really surprised us one day by approaching us and saying, "Come on, dance with me."

In the beginning, Kay was rather cautious and moved slowly in her painting. But once she had mastered her original vertical, straight-line painting, she became very brave. She courageously explored new themes and new ideas and moved quickly forward. Kay took a strict, self- 
expressive attitude all the way in her painting activity, just as Eve had done. And she moved step by step on the base set up by her self-taught painting technique. Kay's self-confidence strengthened. She quickly recovered from the long inactive stage of her life and became an active, lively person. Given David's loving care and the group's support, Kay tried very hard to help herself. She left the group a completely different person compared to when she first arrived. Observing Kay's extremely rapid improvement was one of my best experiences in my painting class. 
DAVID: THE FOURTH STAGE

David's fourth stage took place from late June 1973 to 17 March 1974. The spring school term of 1973 evded in early June and the group had a long summer vacation. The special educational school's young adult class in which David was a member would not be able to continue next school year because of a budget cut. There were many students in David's class who had been studying together for years. Five students, including David, had been in the class for over ten years. They entered the program in their early childhood and had grown up together into young adults. I thought it was very sad that these long-time friends would lose their companionship.

I decided to continue our painting class at my apartment. I talked over my idea with the students and they accepted it. The oldest five students and I had our first painting class in my apartment on 21 June 1973. As we continued to meet through the summer, we gradually accepted other students. We had to take this slow step because some of my students needed special help due to their physical handicaps or emotional problems. They wouldn't be able to adjust to a new environment easily. Therefore $I$ only 
invited the capable students at first and, after they became familiar with the new situation, I gradually invited students needing special help. Our painting class in my apartment began in this way and eventually developed into a strong peer group activity.

The painting class had always been in the school setting until this new development. I had gone to the group's school and held the painting class in their classroom. I tried to give my students complete freedom in my painting class, but I sometimes had to compromise with the regular teacher's suggestions in educational goals. These goals were usually based on normal people's standards. They usually had a rigid program for the students to follow. Although I did not take the same attitude in teaching as these instructors, circumstances forced me to cooperate with them. In my new painting class at my apartment, I did not have to worry about other teachers. Therefore I could lead my painting class as I pleased. I gave maximum freedom to the students and our painting class began to have an entirely different atmosphere than it had before, at the school.

I have always regarded myself as a painting friend to the students since the beginning of our association and they have accepted me in the same way as their painting friend rather than as their painting instructor. In the free atmosphere of my new painting class our basic 
relationship of friendship became much stronger and everyone began to enjoy our gathering as a peer group activity. These long-time classmates met regularly at my apartment, painted together, exchanged daily news, and deepened their friendship.

I understood the importance of this class for these people. I tried to make our gathering enjoyable and meaningful. We painted together in the morning. At noon we made lunch and ate together. In the afternoon we would go for a walk or sit together around the table and chat.

We had extra group activities in addition to the painting class. We celebrated Halloween and Christmas by having a party in the evening. We would have dinner together, play games and exchange presents. The group's ages were nineteen to twenty-three years. Gathering in the evening for dinner and a party helped this group to be more aware of their adulthood. This awareness brought many good results to our group activity. As we got together more and more, every member began to realize that this group activity was a very important socializing experience for them. They began to contribute in making this gathering even more pleasant for themselves.

As the students continued to meet in the new setting they gradually began to express a part of their feelings which they had seldom shown in their meetings at school. 
They began to show their sexual feelings in a way that is natural for joung adults who have free expression.

They had never shown these feelings before because of the strong controls on the expression of sexuality which exists in our culture, especially for mentally retarded persons. This control came both from their parents and from the school staff, the two main social agents in their lives. It seemed as if they had their first chance to show these feelings when they entered the free atmosphere of their painting class in my home.

This expression of sexuality raised important problems which involved every part of their lives and all their relations with people. In fact, the effects were so farreaching that they would make a whole study in itself. I cannot say more about it in this thesis because of its complexity and because it was such a recent development that many questions about it still remain in my mind. I mention it at this point because it was an important new development in the group and because it showed as an important theme in the art work done in this new setting. In particular, the expression of sexuality became an important theme in this stage of David's development. Because of my limited understanding, this theme in David's painting will be developed in less detail than his earlier phases. David truly enjoyed this peer group experience. His long-time classmate and close friend, Lisa, joined our 
class. Iisa's participation in the group made him very happy. Several days before each painting class, David would call all of the group members to make sure they did not forget about the meeting. He also called me to make sure I was ready. He never missed a painting class and he continued to take care of everyone in the class.

David's contribution and complete devotion to Eve and Kay during his third stage helped them greatly. Through this unique experience David learned the meaning of loving and helping other people, which helped him to mature. The new experience he gained through the new painting class also accelerated his growing up process. He experienced more complicated adult emotions and expressed his emotions directly in his art work. He was aware of a need for an outlet for his strong emotional experience. He willingly used his art for this purpose.

David continued his art at a high emotional level until shortly after he entered into a workshop program toward the end of the fourth stage. During this period he preferred brush painting over drawing. Brush strokes gave him more freedom of movement. He painted very freely using several of his themes including "snow," an expression of his freedom and joy; "Christmas tree," which is his symbol of masculinity; and "tire" and "beehive plus," both of which are his striving for intellectual elements. David did not paint "David's tree," which is the image of his 
rather humble and shy self, and "house and tree," which is the symbol of his love for peaceful home life, during this period. He also introduced a new theme, straight linear brush strokes, in the middle of this period. The pieces in Figures 119 through 129 were painted at this time.

David began working at a workshop for the mentally retarded toward the end of the fourth stage. He worked there five days a week and received a wage. He had experienced a workshop environment before, but it was always under a school situation. This was David's first time working independently and earning his own money. This experience strengthened his self-recognition as an adult. As a result, his art work changed. The paintings and drawings in Figures 130 through 132 were done while David was in this new mood.

David did the painting in Figure 119 on 21 June 1973 at the beginning of the new group painting class. It was done on a large sheet of paper with strong contrasting colors of red, yellow, blue, and black. A boy and girl are singing and dancing side by side with their hands lifted up into the sky and their feet kicking. David said that the figures in this painting were his friend and his friend's girlfriend. This painting has a strong joyous feeling. David was extremely happy about his experiences in the new peer group setting. I think this painting was David's direct expression of his hopeful and happy feeling. 
The painting in Figure 120 was done on 29 June 1973 on a large sheet of paper. At this time I realized that David had begun enjoying brush painting. So I gave him larger paper and brushes and told him to use plenty of water with his paint. He enjoyed the brush strokes by boldly brushing horizontally and vertically. He became so free that he overlapped different colors such as blue, red, and yellow without hesitation. The whole painting became so muddy looking that he finally stopped. He could not paint anymore. I told him to use a different and a distinct color with a clean brush. He carefully cleaned his brush, chose a white color, and painted a large "tire" over the muddy looking surface. He then added a yellow diagonal scribble to finish the painting.

I seldom gave instructions to the students. This time I realized that brush painting was still very new to David and that he did not know how to use paint or how much water was needed. Therefore I decided to give him that much instruction. Although he was rather independent in his painting, he accepted my advice and learned the freedom that one can easily achieve in brush painting.

David painted a "Christmas tree" in Figure 121 on $E$ July 1973. In the drawing in Figure 50 he had developed his "Christmas tree" into a very definite symbolic form which represents his masculinity. In Figure 121, he painted a "Christmas tree" with blue paint in the same 
fashion as in Figure 50, and then he added a red linear structure around the tree. He created a very strong, positive feeling which reflects his self-image as an evergrowing young adult.

The painting in Figure 122 was painted on 24 August. It has strong and rhythmical movement as if a large wagon wheel was running down from the sky. The use of three different colors, green, red, and blue, and the circular scribble brush strokes effectively create this movement. David used his "snow" theme to express poetic beauty in this quick, spontaneous painting.

As the peer group painting class continued, David began to have special feelings for his long-time friend Lisa. He was going to be twenty-three years old soon, and for the first time in his life he was experiencing complicated emotions of love, joy, loneliness, and fear. When he met Iisa in the painting class, he was overwhelmed by his strong emotion.

David started to use straight linear brush strokes to express his new emotional experience. In the past he never did this kind of straight, linear scribble except when he occasionally copied Kay's straight-line painting (Figure 67). At that time he was merely curious about Kay's painting style and copied it. But in this new developing situation, he was truly involved in straight-line painting of his own. He expressed a very strong and moving 
emotion through this new theme. Figure 123, painted on 7 September, and Figure 124, painted on 30 September, are examples of his new painting theme.

In Figure 123 David curved the surface with short and swift brush strokes which run vertically, horizontally, or diagonally. He painted the center part of the painting with warm colors, red and yellow, and surrounded this portion with cool colors, green, blue, and purple. The painting is done spontaneously yet it is beautifully composed with free brush strokes. David directly expressed his fleeting emotion, a mixture of joy and fear, in this highly artistic painting.

David used several strong diagonal brush strokes, some long and some short, in the painting of Figure 124. Most of the brush strokes are done with dark brown and black paint, which are accentuated by a few warm-colored brush strokes of red and yellow. The painting is simple yet conveys a complicated and strong feeling. David was overpowered by his new emotional experience. He was suffering but he was fighting back to keep himself up. I would name this painting "A sailboat in the stormy sea."

We had our first Halloween party on 31 October. All the students gathered at my apartment in the afternoon. We made Halloween decorations and ate dinner together. We turned off the light and played a record of ghost stories. Some students dressed up as ghosts and witches 
and tried to scare and play jokes on others. We played several traditional Halloween games, bobbed for apples, and danced to favorite rock music.

This was the first time for these young people to have their own party at night. Their parties in the past were held during the day and under a teacher's supervision at the special educational program school. Therefore, having their own peer group party at night made them extremely happy. They showed a feeling of independent adulthood and mutually respected and celebrated the newly gained identity.

Everyone enjoyed the Halloween party so much that we decided to have a Christmas party together which also became a great success. One day shortly before Christmas we got together and decorated the room and then had dinner together. After dinner we listened to Christmas music and exchanged presents. After that we danced to record music.

David wanted to present a ring to Lisa for Christmas, but he did not know anything about buying a ring. He called me several times and asked what size of ring he should buy or where he would get a ring. He finally gave up trying to buy a ring by himself and asked me to do the shopping for him. He said, "I cannot drive. I don't know the size of a ring. Will you buy a ring for Lisa? I have one dollar for the ring." 
I looked around several different stores and found a nice looking ring. When Lisa received the ring at the party, she put it on her finger and looked at it for a while. She was so happy and started quietly to cry. The other students and I promptly cheered for David and Lisa. David became more closely attached to Iisa after these parties. He became too excited while he was with her and could not sit and paint quietly anymore. During this period he usually did only quick "snow" or "straightline" scribbles. He often just sat beside Iisa for hours. He helped her with her painting or looked around at his friends with a big smile on his face.

Figures 125, 126, and 127 show examples of David's work during this period. He painted all of these "snow" paintings within ten minutes on 6 January 1974. He used the warm colors red, orange, and yellow in the painting in Figure 125. He also used dark red to give structure to this random-looking scribble. His brush strokes were light and jumped around the paper.

The painting in Figure 126 has cool colors of blue and green. But warm colors of red, orange, and yellow are also combined in it. The dark red is again used to compose the free scribbles into a painting. Both brush strokes and color combinations become complicated, and the whole painting conveys more emotional weight. The painting in Figure 127 has only the cool colors of blue and green in it 
except for a touch of red here and there. The brush strokes are swift and powerful. The whole painting hus rhythmical movement and a unified; pleasing composition. David expressed a bright, happy feeling in Figure 125. In Figure 126 he expressed a more involved, confusing emotion. In Figure 127 he tried to integrate and beautify his emotion toward a creative direction. He first began to draw his "snow" theme, which is his expression of a free and happy feeling, on 1 June 1972. Ever since, he had continued to improve it and so created a beautiful "snow," as seen in Figures 62 through 64, and Figure 127. On his latest "snow" painting in Figures 125, 126, and 127, David broke away from these beautiful, joyous "snows" and took a very strong and direct emotional approach.

In early 1974 David got a job in a workshop for the mentally retarded. We had a painting class on 3 February 1974, the day before David's first working day at the new job. David brought a drawing which he had done at home, and presented it to me (Figure 128). The drawing was a very simple one of a "house and trees." I was puzzled about why David drew such a piece which resembled ones done in his first, early stages, and why he presented me with this simple drawing. I said, "Thank you, David," and put the drawing on the table. I then went back to instruct the other students' painting. David picked up the drawing, brought it to me and said, "Put it on the wall." For the 
past three years David had never asked me to put his work up on the wall. I was a bit surprised and looked at him. He silently and very seriously looked straight back at me. I immediately put the drawing on the wall. David seemed to be relieved. He sat down at the table and began driawing.

I thought David might have been anxious about going; to work at the workshop, and he wanted psychological support from me. Therefore he presented me with his "housc: and trees" drawing which he often did when he wanted to show his friendship toward me. He would have expected to rear a nice comment about his drawing. I asked David, "Do you worry about tomorrow?" He said, "Ya," and smiled with. a slight shyness.

The above incident made me think again about tho importance of David's "house and trees" theme. This thume is one of his old themes which he has been drawing and jainting repeatedly for the past three years. He had continualiy elaborated on it. About one year ago he dratwatically changed it into a more matured style paintirg and presented the work to me (Figure 68). At that time he was losing his leadership in the class because of the arrivil of the new house parents. He was suffering from a selfidentity crisis and needed my support. Recalling that incident, I truly understood why David presented me with the simple drawing in Figure 128 just before he startod to work on the new job. 
David began working at the workshop full timo. Ho: worked hard and soon became used to the job routinu. Hu: was very proud of himself working and earning his own money. He was expecially proud and happy wher he brought presents for Iisa with his own money. He became calm and acted like a perfect grown-up man. The works in Figures 129 through 132 were done during this happy time. David's painting in Figure 129 was done on 17 February 1974. On that day he at first did a very free scribble using both straight and circular lines, and then he rested. After it while he saw two other students begin painting huge humar faces. He came back to the table and very quickly painted the work in Figure 129.

In the past David had gradually shaped up his "Christmas tree" as a symbol of his manliness. On today's painting for the first time, he distinctly painted a man out of his "Christmas tree." He painted an outline of a human figure out of his "Christmas tree" and added eyes, mouth, and hands.

This human looking "Christmas tree" is dancing with both hands raised in the air and legs kicking out. It seems to be David's self-portrait. His strong, joyous feeling and firm self-confidence are vividly expressed in the figure.

Although David painted the figure in one quick, spontaneous movement, there are some technically good 
features in this painting. The curved lines surrourdinf; the figure and the dots covering almost the entire surface give the painting a unified structure with lots of rhythmical movement. The one large brush stroke line at the bottom of the figure is very effective. It provides a good base for the figure to stand and holds the whole painting into one complete composition. David painted exhuberantly, and the painting was a totally unplanned, spontaneous creation; yet it has natural and beautiful composition.

David's drawings in Figures 130 and 131 were done on 3 March. He called many times every day for several days before the scheduled class date. He told me that he had called everyone and that they were all coming to class. He was very anxious to see them again. He called me on the day before class and said, "I want to paint all day tomorrow." He sounded very enthusiastic. I wondered if. something special had happened to him. Next day he brought a new set of marking pens in a bright orange tool box. He also brought a small blank canvas board. He said he had purchased these materials with his first pay check. He sat and drew all day just as he said he would.

David used his own canvas board and marking pens for the drawing in Figure 130. He sat by himself in a corner. of the room and drew very carefully and slowly for holds. He first drew a horizontal line in the midale of the papes: 
which divided ground and sky. He then drew is housie and flowers on that line. He drew a path leading out l'rom lhw house. Then he drew two "Christmas trees" with roots holding dirt. He looked at the whole drawing and then carefully added another tiny "Christmas tree" behind one of the others. He finally placed dots all over the ground area and drew the sun and the moon in the sky.

A classmate looked at David's work and said, "David, it's funny to see the sun and moon together in the sky." David replied, "It is not funny. Stars can be here too at the same time." He then drew four black stars in the sky. David acted as if he wanted to show everyone that he drew as he wished and not with shyness or reserve.

There are two important features in this latest drawing. One is that David drew a house and three "Christmas trees" but he did not include any "David's tree." Just before he started working on his new job, he was anxious and drew a "house and trees" for me (Figure 118). Once he began working, he quickly adjusted himself to a new working environment. He even earned his own money. This situation changed his self-concept. He was no longer a helpless child who needed his home for a shelter. Instead he became a bread earner, an important family member. With this new self-respect and confidence, he changed his "house and trees" theme into a house with "Christmas trees." $\mathrm{He}$ expressed his strong confidence in his manliness. 
David also drew two of his "Christmas trees" in this drawing with roots holding soil. In the past he had arawn many "David's trees" with roots but never "Christmas trees" with roots. This was the first time his "Christmas trees" grew roots. It could have been very natural that at the same time David's masculine self-image had become firmly supported, his masculinity symbol, "Christmas tree," grew roots. These rooted "Christmas trees" seem to be ready to suck nourishment from the soil and grow into big trees. Another important feature is that unlike previous works in the fourth stage, this latest drawing was carefully planned to achieve designed beauty. From the beginning of the fourth stage up to getting the job, David had been extremely excited, mainly because of his new emotional experience with Iisa. During this period he kept painting in a highly emotional manner. He was often too excited to paint. But the new responsibility he felt as a bread earner overcame his emotion. He regarded himself as an important man in the family who protected its peaceful home life. He intentionally controlled himself and calmed down. He expressed this new perspective of himself through this carefully planned arawing in Figure 130.

The whole class praised David's drawing in Figure 130. He was encouraged and went to work on the second drawing (Figure 131). He selected a large sheet of paper and drew a large "David's tree" with a "beehive" beside it. This 
"David's tree" had new branches with many leaves, three berries, and roots holding red soil. The tree sucked nourishment from the red soil and grew leaves and berries to become a healthy, handsome-looking tree.

During the three years of his art activity, David had continued drawing and painting his "David's tree," varying the size and appearance. Some were drawn large (Figures 29 and 39) and others were drawn small, accompanied by a house (Figures 6 and 16). He sometimes decorated these trees with many branches and colorful leaves, flowers, or berries (Figures 3, 14, and 33). In the unique "David's tree" painting in Figure 66, David warmly cherished his important symbolic tree.

As David grew and gained more confidence in himself, his "David's tree" grew roots and took on human-like movement (Figures 68 and 69). Finally in the latest "David's tree" drawing in Figure 131, he created a handsome-looking, lively tree which holds red soil in it's roots and bears three big berries. This new "David's tree" has grown immensely when compared to the first tiny one in Figure 1.

David brought three drawings from home to the class on 17 March 1974. The subject of these drawings included houses, trees, and flowers in a pot. They were not his original work but copies of some conventional drawings. David had gained much confidence in himself and his art, and so he began challenging normal people's standards. 
. I thought it could be a phase he needed to go through.

The drawing in Figure 132, done on 17 March 1974 in class, combines David's themes with ideas he learned from copying conventional drawings. He first drew three flowers in a pot in the center of the paper with two red stars around the pot. He then drew curved red lines around the center objects. These curved red lines are a decorative "beehive plus." The outwardly expanding wavy lines and shapes convince me that David expressed his rapid psychological growth through this "beehive plus."

David initially constructed his "beehive plus" as a symbolic figure for his intellectual approach to spatial dimension (Figures 9 and 11). On the same line he even used "beehive plus" to express a three-dimensional quality in the rectangular mass of a house (Figure 30 ). He added emotional quality to his "beehive plus" in the drawing in Figure 56. He was very happy about the upcoming picnic and drew his pleasant "beehive plus" in order to express his joyous feeling. David's emotional projection in his "beehive plus" is clear in the painting in Figure 66. He surrounded "David's tree" with a "beehive plus" and effectively expressed his positive self-respect.

David was experiencing many things and growing quickly throughout the fourth stage. The drawing in Figure 132 is full of cheerful, positive feeling, reflecting: David's active mind. When I see his signature proudly 
written with a red pen, I can hear David's voicc suying that he is full of self-confidence and is living in a bright and peaceful world.

I previously witnessed two occasions where David expecially challenged normal people's standards. A young volunteer worker painted in our class one day. David was stimulated by this man's work and drew two drawings (Figures 54 and 55). The drawing in Figure 54 is a snake eating people, and the drawing in Figure 55 is a snake eating a bird. Both drawings were neatly done and the aggressive subject matter caught my attention at the time. When David felt a fear of losing his class leadership because of a new group home father, he did the drawing in Figure 68. At that time he tried so hard to meet normal people's standards. For instance, he adapted a conventional perspective drawing in order to express the threedimensional aspect of a house. He was quite competitive with normal people's standards during these two instances. But in the drawing in Figure 132, he completely mixed conventional subjects with his own theme and created a harmonious, peaceful world.

During the fourth stage David had several important experiences which promoted his socialization process. These new experiences were the peer group activities, his love toward Iisa, and his getting a new job and earning money. David felt refreshed when he left his old class where he 
had been for over fifteen years. In his new peer group, he voluntarily took an important role in decision making for the group's activities. He also became deeply involved in the planning for outside activities such as the night parties for Halloween and Christmas.

The new relationship with Iisa thrust David into a mighty strong emotional experience. He often suffered from his overpowering emotion. But after he began working and earning money at the new job, he grew out of this situation. He managed to control his emotion gracefully and have a gentle and friendly relationship with Iisa. By experiencing new human relations and situations, David grew into an independent and free young man during the fourth stage.

David boldly thrust himself into his art work and then used his art for emotional release during the fourth stage. In Figures 119 through 129 he expressed his strong, moving emotion as a young man. Figure 119 shows David's joyous, hopeful feeling about the peer group. He even created a new theme, straight-line painting, to express his strong, moving feeling (Figures 123 and 124). In Figures 125, 126, and 127, he used his old theme "snow" more freely than ever before and succeeded in expressing his complicated strong emotion.

David developed his "Christmas tree" into a strong form in Figure 121. He finally created a bis "Christmas 
tree man" in Figure 127 and secured his masculinity symbol. During this period he mainly used his theme which advocated his manliness or intellectual endeavor. He did not use such themes as "David's tree" or "house and trees" which indicate his helplessness.

David drew a simple "house and David's trees" for me just before he started working at his new job. He felt fear when faced with the new situation. But once he started working and earning his own money, a new confidence replaced the fear. He reorganized himself into an independent man and tried to take an adult role. This new mentality of his was immediately reflected in his art works. He sought a new order and peace in his art. In Figure 130 he gave an orderly beauty to his "house and trees" theme. He also developed his tiny "David's tree" into a growing young tree.

At the end of the fourth stage, David's adult selfimage was firmly established. He was full of confidence and tried to adopt normal people's conventional art forms. During this period he drew Figure 132 and beautifully expressed the hopeful, peaceful world he had newly reached. Both David's personal growth and achievement in art work during the fourth stage were outstnading. He becane a hard working young man with a high sense of responsibility as well as a good, honest artist whose attitude was purely open and direct. 
Summary

David studied in my painting class for three years, from age twenty to age twenty-three. Throughout his art activity he took an honest self-expressive attitude, and he learned all of his art through the self-teaching process. He created his own themes and then used them repeatedly as a basic vocabulary in his drawings and paintings. He combined some of these themes to get new ideas. He often used them as vehicles for psychological support for himself. He also consistently polished these themes into a higher form as he continued to learn.

David was concerned about normal people's conventional art forms from the very beginning. He wanted to meet normal people's standards in his art, and he worked hard to achieve this goal. Naturally, his six earlier themes of "David's tree," "house and trees," "Christmas tree," "beehive," "beehive plus," and "tire" took a conventional art form, whereas his later two themes of "snow" and "straight lines" took a spontaneous and direct selfexpressive art form.

David's attitude changed greatly during the three years. His personality growth progressed reciprocally with his art. At first he was very shy, and isolated himself from his classmates and teachers. Exercising selfexpression in art made David open and friendlier to people. In return, the experiencing of positive human relationships 
contributed to the improvement of his art work. Producing better art work brought him a more stable confidence, and this situation made him open to people even more. At the middle of his art activity, David regarded himself as a good artist, and he began helping his classmates in my painting class. He became the central figure in the class and thereafter led the group. This experience brought him strong self-confidence as a big brother in the group. In the following peer group painting class, David began boldly expressing himself and greatly improving his art. Toward the end, he got a job and secured his young adult's self-image. At the same time he combined conventional art forms with his own themes and created his own fine art style.

During the first stage while he was shy and insecure, David introduced five themes. These are: "David's tree" (Figure 1), "house and trees" (Figure 2), "Christmas tree" (Figure 4), "beehive" (Figure 7), and "beehive plus" (Figure 9).

"David's tree" is a symbolic figure of the helpless, childish David himself. "House and trees" stands for David's attachment and dependency on his family. "Christmas tree" started as a symbol of happy home life and grew into the symbolic figure for David's masculine self-image. "Beehive" is David's organic form of expressing spatial dimension, 
and "beehive plus" is his conceptual form of expressing spatial dimension.

The first three themes of "David's tree," "house and trees," and "Christmas tree" were drawn out of emotional need. The last two themes, "beehive" and "beehive plus," were created to meet David's technical need of indicating spatial dimension. Thus, at the beginning stage, David already sought both the emotional approach and the intellectual element in his art. In the drawing in Figure 10 he achieved both goals satisfactorily. Most importantly, David introduced these five themes at this early stage and laid the foundation for further development in his art.

During the second developmental stage David became very ambitious. He wanted to improve the quality of his art work and attempted to draw many objects in perfect form. In the early stages of this period, David drew a big valentine heart (Figure 15). In this work he achieved a well-balanced shape using a free, emotional approach. By working on this piece, David experienced the joy of selfexpression and also discovered his ability to draw a wellbalanced and symmetrical form. He gained much confidence in his art work.

David began strenuously to search for both emotional freedom and intellectually higher form in his art. He created his "tire" theme which symbolizes a well-balanced, symmetrical form. Meanwhile, he was attracted by moving 
objects such as rain (Figure 12), and moving cars (Figure 24). Finally he learned to see movement in still objects, developing this perception through his themes of "snow" and "tire." As he traveled along this learning path, he grasped the idea of a house--of a rectangular mass--as a successive motion. He used "beehive plus" to draw this nature of a house and succeeded in expressing its perspective (Figure 30).

Perceiving objects as a movement gave David a new insight. He no longer saw objects as their surface features, but began to penetrate into the genuine nature of objects. He created a new theme, "snow, "and expressed his aspiration for beauty and freedom in motion. By the time he refined his "tire" (Figure 35) and "snow" (Figure 36), he was ready to try various complicated subjects. He drew many different objects one by one and kept improving the quality of his work (Figures 44,46 , and 48 ).

David drew the excellent form of a complicated subject, a snake eating people (Figure 54), toward the end of the second stage. He proved how far he had reached in his self-taught art with this drawing. During the patient and strenuous self-teaching process, he often drew his old themes such as "David's tree" and "house and trees" to encourage himself. He was still shy at this stage but gradually opened himself up to the people around him. He expressed this new and growing state by drawing a big 
"Christmas tree" (Figure 50) and presenting it to a male visitor to our class.

David's personality blossomed in the third stage. He voluntarily took an assistant teacher's role in my painting class and helped his classmates. He devoted himself to the group's welfare. His teachers and classmates respected him as the most dependable leader for the group. During this period he took care of the two severely retarded women, Eve and Kay, and changed their lives. These experiences made David aware of his own potential ability. He was no longer shy and timid. David expressed his new self-image by combining "Christmas tree" with "tire" (Figure 6I) and "David's tree" with "beehive plus" (Figure 66). David's attitude in his art was the same as in the previous stages. He kept searching for freedom in expression (Figures 62 through 64) and well-balanced form (Figures 6.1, 65, and 66). When he was faced with the self-identity crisis of losing his class leadership to the group home foster father, he combined these two elements in improving his "house and trees" theme in Figure 68. This achievement made David believe that he was truly a good artist. He began presenting his art work to his teachers and actively communicating with them through his art.

David left his school and painted in the peer group painting class in the fourth stage. This situation freed him from concern about normal people's standards. For the 
first time he was comfortably just being himself. He enjoyed complete freedom in expressing himself in his ar.t work. He created a new theme, "straight line," in order to express his new emotional experience. As he boldly painted, his art form rapidly matured. His works in Figures 119 through 129, except for Figure 128, contain both rich emotion and dynamic poem.

When David was going through a stormy emotional experience because of his love toward Iisa, he intentionally used painting as an emotional outlet. Painting became an important, self-expressive, communicative medium for him. In an attempt to express his intricate emotion, he polished his art form to a higher level than ever before. He became highly creative and very strong. At this point he perfected his important masculinity symbol by drawing his "Christmas tree man" (Figure 129).

David got a job in a workshop for the mentally retarded toward the end of the fourth stage. He worked under normal people's supervision. This situation again made him concerned about normal people's standards. He went back to conventional art forms, but this time with the new self-image of a hard working young man. He expressed this new self-concept by neatly arranging "Christmas trees" with a house (Figure 130). He also developed his tiny "David's tree" into a young growing tree (Figure 131). With this new "David's tree," David declared that he 
finally had grown out of his infantile and helpless mental stage. He combined flowers, stars, and "beehive plus" in the drawing in Figure 132 to express beautifully his ever growing, positive self-image.

I would like to survey David's progress from some different angles. How did each of his themes develop? How did his self-expressive attitude contribute to his selftaught art? How did his attitude toward normal people change? Among David's eight themes, the first three are the most important because they are expressions of his.selfimage. By tracing several important works involved with these themes, changes in David's self-image become clear. The tiny, original "David's tree" in Figure 1 is an expression of David's helpless, infantile self-image. He drew the "David's tree" in Figure 66 to express his new and bright, enlightened self-image when he became my assistant teacher and began taking a big brother's role for his classmates. Toward the end of the fourth stage he drew a growing young "David's tree" (Figure 131) and showed his positive self-image as a young adult.

The Christmas tree in Figure 4 is the first "Christmas tree" in a drawing by itself. David began symbolizing the tree with emotional projection in Figure 10. He clarified its masculine symbolic nature in Figure 50. Toward the end of the fourth stage, he created the "Christmas tree man" (Figure 129) in his peer group painting class. David 
expressed perfectly his self-image of a happy, active young man with the tree.

The drawing in Figure 2 is David's first "house and trees." Two self-symbolic figures, a "David's tree" and a "Christmas tree" are standing beside a house. David greatly developed this theme in the drawing in Figure 68, during the third stage, when he faced his self-identity crisis. There are also "Christmas tree" and "David's trees" coexisting in this drawing. David also drew a "house and David's tree" when he was anxious just before starting work on his first job (Figure 128). In the drawing in Figure 130, he expressed a totally new self-image as a bread earner by drawing only "Christmas trees" with a house. "Beehive" was introduced to fill space around objects (Figure 7). David usually used this theme with other important themes such as "David's tree," "Christmas tree," and "house and trees." He extended the role of "beehive" from a mere space indication to an emotional element added to his self-symbolic figures. The "beehive" in Figures 10, 14, 47, and 131 show this nature clearly.

"Beehive plus" was introduced as David's conceptual expression of spatial dimension (Figures 9 and 10). David also used this theme as a tool to help tackle the problems of drawing the three-dimensional aspect of a house (Figure 30). He extended the use of this in expressing his psychological dimension. He perceived his deep emotional 
experience and mental growth as his psychological dimension expanded and deepened. He used "beehive" to express his enlarging psychological dimension. "Beehive plus" in Figures 56, 66, and 132 show this nature of the theme. The "tire" theme in Figure 20 was created out of the contour line of the valentine heart in Figure 15. At that time David was intensely searching for well-balanced shapes and composition. His "tire" was perfected along with the improvement in his art form (Figures 27 and 35). This theme was eventually developed into another symbolic figure which stands for David's well integrated personality (Figure 132). While David was striving for a well-balanced higher art form he began to perceive objects in terms of movement. He introduced the free circular line scribble, "snow," at this time (Figure 26). The "snow" theme played an important role because of its spontaneous, purely selfexpressive nature. When David expressed his joy and freedom through "snow" he was freed from normal people's standards and truly enjoyed the direct emotional approach in his art (Figures 62, 63, 64, 125, 126, and 127).

The straight-line theme was created to express David's new emotional experience of his love toward Lisa. This theme is also a purely self-expressive one, and it served very well for the purpose. David used it most efficiently in expressing a young adult's complicated and strong emotion of love (Figures 123 and 124). 
David kept the basic attitude of honest selfexpression throughout his art activity. This attitude greatly helped to promote his self-taught learning process. Figures 15 and 104 are important works in knowing the role that the self-expressive attitude played in his artistic development. David directly expressed his passion and love in the big valentine heart drawing in Figure 15. Before this drawing, he had mainly drawn "David's tree," "Christmas tree," and "house and trees" in a childish style. In the valentine heart drawing (Figure 15) he dropped this childish approach and strongly expressed a young man's love and energy. David gained so much confidence after achieving this new step. He created his "tire" theme, using the contour line of the heart, and searched for a refined and higher art form. He became involved with his art at a much deeper level and gained significant learning skills such as perceiving objects in terms of movement. David painted a boy and girl in Figure 119 at the beginning of the peer group painting class. In this painting he boldly expressed his love for his friends, and afterward he completely dropped his shyness and openly expressed his feeling in his painting. As a result his painting greatly advanced. Thereafter he produced many beautiful works such as in Figures 122, 123, and 132.

David was quite competitive with normal people from the very beginning of his art activity. He adopted 
conventional art forms and tried hard to meet normal people's standards. However, his attitude changed as he grew. He became less competitive. The change was important because he had suffered so long from an inferiority complex which hindered his potential personality growth. By tracing David's attitude change toward normal people, we can clearly see his maturing process.

David was stimulated by a visiting young male assistant teacher and drew a snake eating people (Figure 54). He managed to control his emotion and drew this aggressive subject into a well-composed poetic beauty. When he was fearful of losing his class leadership, he greatly improved his "house and trees" theme (Figure 68). In this drawing he adopted a conventional perspective house drawing and tried to perfect the quality of the drawing in every aspect. The success of this drawing brought back his selfconfidence. He began actively to communicate with his house parents and teachers by presenting his art work to them.

David became extremely happy about the new job and earning his own money toward the end of his art activity. He felt that he was accepted as a member of normal people's society. He expressed his satisfaction and gratitude in the drawing in Figure 132. In this drawing he harmoniously combined the conventional art form of stars and flowers with his own theme of "beehive plus." 
David kept patiently and courageously searching for his own way all through the three years of his art activity. Most significantly, along with his own study, David helped his classmates to learn their art. As his "David's tree" and "Christmas tree" had grown, so had David grown tremendously during the three years. He started with a helpless, infantile self-image and grew into an active young man. He had walked a long way, and at the end of his artistic journey, he was full of self-confidence. He became a mighty, strong young man and was ready to walk the miles stretching ahead in his life. 


\section{CHAPTER VIII}

\section{CONCLUSION}

David, Eve, and Kay went through a similar learning process when given freedom in their art activity. Their basic approach was one of self-expression and self-teaching. They painted whatever they wanted and in the way they wanted. They freely experienced creativity and improved the quality of their art. Technically, they used the same kind of basic method in their painting. They created their own themes and used them as primary tools for their development.

David drew a tiny "David's tree" at first and used it to develop his painting. During the three years of his art activity, he kept creating new themes to meet the needs in his progressing learning experience. Eve started her painting activity with her own theme of "diagonal straight line scribble." She stuck with this theme and developed her own unique painting style.

Kay tried to copy "David's tree" at the beginning of her art activity, but quickly moved to her own style. She introduced "vertical straight line scribble" as her first theme. Next she moved to "circular line scribble:" and then to "crescent-shaped line scribble." Finally, she 
combined all of these themes to create many differcut designs.

As their painting activity progressed, David, Eve, and Kay had a natural urge to refine their painting into a higher form of art. In order to do so, they had to tackle various problems such as color coordination, composition, and expressing the three-dimensional aspect on a twodimensional surface. Each one worked on these problems in his or her own way.

David laid out most of his themes in his early art work and kept polishing them. He had good sense for color and his color coordination developed naturally, as did his composition. But he had to study very hard in order to achieve well-balanced and symmetrical shapes. He freely used "beehive" to fill in space around objects. When he became concerned about normal people's art forms, he tried to express the spatial dimension conceptually. He used "beehive plus" for this purpose. In the peer group painting class, David effectively used all the techniques he had learned and painted in his own style.

Eve had very good color perception from the beginning. While she was learning to hold a paintbrush, she began exploring various color combinations. She painted layers of colors and discovered shapes through the contrasting color effect. Finally, she created her own unique painting style in which she composed a whole painting with 
various colors and shapes. Her approach to spatial depth was genuinely perceptive. In her last several paintings, she expressed very natural, superb depth perception.

Kay was attracted to colors at the outset of her painting activity. She tried different colors in her straight line painting and discovered simple shapes created by contrasting colors. In the following stage, Kay discovered more complicated shapes created by circular and crescent-shaped brush strokes. She finally created wellshaped designs by combining all of the three brush strokes. These three persons also greatly improved their attitudes along with their painting activity. David became less tempermental as his painting progressed. He began voluntarily taking care of the whole class and became the central figure in the class. In the peer group painting class, he boldly expressed himself in his painting. At the same time, he grew out of his childish mental stage and became an energetic young man.

Eve started painting in a totally helpless stage, incapable of even eating or walking by herself. She gradually gained strength as she painted and began reacting to people. At last, she became strong enough to take care of herself. By that time she enjoyed a friendly association with her classmates and teachers. When she left the class she walked out unaided. 
Kay followed very much the same pattern as David and Eve. At first she was so afraid of people that she completely isolated herself. As her painting activity developed she gradually changed. She began to look at people and then she voluntarily joined the group's activities. She finally became very cheerful and active. She played a guitar, sang and whistled, and danced with her classmates. After leaving the class her improvement continued. These three persons learned in each one's way and developed their own unique painting style. As they exercised creativity they all became contented and happy persons. This achievement was not limited to those three students. Almost everyone in the class followed the same learning pattern and achieved the same goal. Eventually the whole class became a happy, active group.

I noticed two important factors that contributed to the success of my painting class. One is the selfexpressive and communicative nature of painting. The other is the power of the group's dynamism. We paint because there is something we cannot otherwise express. Painting can express something beyond what verbal communication is capable of saying. When people understand what one is trying to express in a painting, then painting becomes an excellent communication medium. It can communicate at a deeper level than verbal communication. A great Japanese painted once said that we should 
look at a painting as we would look at a person because that painting is the expression of the painter himself. It expresses his whole world and personality.

From my own experience I believe this expressive and communicative power of a painting to be true. When I looked at each student's painting, I did not worry about small details, but tried to feel the painter's world that was revealed in his paintings. Someone expressed joy, someone sadness, some even agony in his paintings. But whatever his world was, I was always very much impressed by his uniqueness and beauty in a painting. Each person has his own beautiful world. When I could feel this uniqueness and beauty in a painting; then the painting became significant and I accepted it with all my heart.

When the students painted in a self-expressive manner they opened up themselves. And my response to them completed the communication. They had been so starved for communication with people that my feedback became the best reward for them. Everyone in my painting class always expected to have my comments on their work. Even the severely retarded persons who barely moved the paintbrush on the paper eagerly waited for my comment.

Their mutual acceptance of their paintings also opened up communication channels among themselves. They understood each other's wonderful hidden world through painting. They painted with increasing interest in 
communicating with each other. Some of them presented their paintings to their parents and teachers and expanded their communication channels.

Our personality growth is largely promoted by our socialization process. And our socialization process is possible only through contact with other people. Therefore, active communication with others is indispensable for our personality growth. In my painting class, free painting activity broke down the wall between the students and provided a healthy communication network. As a result, their long suppressed personality growth was triggered. Within the three year period of painting activity, most of them grew out of their incapable and childish self-image and became beautiful young adults.

These young people had been treated as mentally retarded ever since an early age. Most of them suffered from severe inferiority complexes. Consequently, they were constantly being separated from normal people and so did not have much chance to communicate with people. Even when they had a chance they dared not try. They were so crushed by feelings of inferiority and so bound to a narrow, conforming life created by their parents and teachers that they had no open communication among themselves.

In my painting class, self-expressive painting activity freed these people from their inferiority complex, and brought a new, positive self-image to each of them. 
Eventually the whole class discovered itself as a group of creative and capable persons. The group revived. Each person in the class was no longer isolated but was tied strongly into the group. They had a friendly, happy atmosphere where they could freely share their feelings, thoughts, and life's experiences in addition to doing enjoyable things together.

The students sincerely helped each other and did their best for the group's welfare. For the first time they had a cohesive group of their own with which they could identify themselves. Each person put all of his effort into his group, and, in return, the group nourished each person for his further growth. With the group's strong support behind him, each person courageously explored his own art and improved his life. Creating their own cohesive peer group was an important achievement because this class was almost the only place where they had any significant social contact.

Mentally retarded peoplé are generally very different than normal people. We normal people are success-oriented. We identify ourselves by competing against each other. Mentally retarded people are incompetent in competition to begin with. Their main interest in life is to enjoy each other. They want to share themselves instead of competing with others. Their value system for life is completely different than ours. 
In our culture we believe that the "normal" way is the right way to be an able human being. We have a standard for being fully and capably human which does not include the nature of "retarded" persons. Parents and teachers are the chief carriers of culture to children. It is an important part of their roles to acculturate young people. So normal parents of retarded children tend to expect them to learn the normal people's way of life, in spite of their children's exceptional natures. Teachers must be proven normal to hold their jobs, and these normal teachers usually emphasize the teaching of normal people's standards. The whole situation makes it almost impossible for mentally retarded people to create their own peer group with which they can identify themselves.

The above situation applied to the people in my painting class. They previously had never experienced their own peer group association. Their personality development was severely hindered for this reason. Therefore my student's gaining their own peer group association was an extremely important achievement.

My class fully shared a self-expressive and communicative painting activity and created the happiest group I have ever seen. Their growth was the same as the growth of tiny seeds given rich soil, water, and sunlight, and blossoming into huge flowers. I learned one important fact while participating in their growing process: mentally 
retarded people have their own inherent potential power to grow into mighty, strong human beings. Our task is to offer them rich soil, plenty of water and food, and then remove every object that shades the sunshine from them. Self-expressive free painting activity can be one of the very best gifts we can give to these people. The learning pattern they acquire through this activity is purely their own. The self-confidence they gain through this activity is firm because it is built on their own experience.

So far we have failed to provide this group of people with a comfortable place in our society. Their daily psychological environment is far more difficult than ours. Some of them even have to move from one inadequate institution to another throughout their life. I sincerely hope that the independent learning experience and confidence they achieve through painting can help them cope with their problems and that they can survive in any difficult circumstance. 
GROUP PAINTING AS A MEANS OF SELF-EXPRESSION AND COMMUNICATION FOR MENTALLY RETARDED PERSONS: THREE CASE HISTORIES VOIUME II

\author{
by \\ YAEKO STEIDEL
}

A thesis submitted in partial fulfillment of the requirements for the degree of

\author{
MASTER OF SCIENCE \\ in \\ PSYCHOLOGY
}

Portland State University

1979

(C) Yaexo Steidel 1979 


\section{PREFACE}

This volume contains illustrations, in color, of most of the paintings discussed in this thesis, together with a list of all the illustrations or "figures." Each figure has a caption which gives the figure number, the name of the artist, the medium in which the work is done, and the measured dimensions of the work to the nearest millimeter. The dimensions are given with the vertical measurement first and the horizontal measurement last.

The List of Figures provides all the information for each figure which appears in the caption and adds, following the name of the artist, the most exact date which can be given for the completion of the work. In most cases this date is precise, but it is sometimes impossible to state the exact day on which a work was done because of the inadequacy of the record. In such cases a range of dates is given which is the smallest known definitely to include the actual date of the work. For example, Figure 32 illustrates a work which was definitely done between the 17th of March and the 29th of March 1972. Altogether, there are 29 works out of the 132 shown in this thesis which cannot be dated precisely. These works were done by the artists in their own homes during 
vacations from school, or in school during periods when the researcher was absent. In some cases works done in this way could be dated precisely with the help of the artist or a teacher who was present, but in other cases no record was kept or the witnesses were uncertain. Every effort was made to give the most precise date possible for each work. 
IIST OF FIGURES

FIGURE

PAGE

1. David, 13 April to 20 April 1972, Oil

Crayon on Paper, (Detail) . . . . . . 1

2. David, 21 October 1971, Wax Crayon on

Paper, $21.6 \mathrm{~cm} \times 27.9 \mathrm{~cm}$. . . . .

3. David, 21 October 1971, Wax Crayon on

Paper, $27.9 \mathrm{~cm} \times 21.6 \mathrm{~cm}$. . . . . .

4. David, 21 October 1971, Wax Crayon on

Paper, $21.6 \mathrm{~cm} \times 27.9 \mathrm{~cm}$. . . . . .

5. David, 21 October 1971, Wax Crayon on

Paper, $21.6 \mathrm{~cm} \times 27.9 \mathrm{~cm}$. . . . .

6. David, 28 October 1971, Wax Crayon on

Paper, $21.6 \mathrm{~cm} \times 29.8 \mathrm{~cm}$. . . . .

7. David, 11 November 1971, Wax Crayon on

Paper, $27.9 \mathrm{~cm} \times 21.6 \mathrm{~cm}$. . . . . .

8. David, 18 November 1971, Wax Crayon on

Paper, $21.6 \mathrm{~cm} \times 27.9 \mathrm{~cm}$. . . . .

9. David, 18 November 1971, Wax Crayon on

Paper, $21.6 \mathrm{~cm} \times 27.9 \mathrm{~cm}$. . . . .

10. David, 9 December 1971, Wax Crayon on

Paper, $22.0 \mathrm{~cm} \times 27.9 \mathrm{~cm}$. . . . . 
11. David, 9 December 1971, Wax Crayon on Paper, $21.3 \mathrm{~cm} \times 27.9 \mathrm{~cm}$. . . . . .

12. David, 13 January 1972, Oil Crayon on

Paper, $21.5 \mathrm{~cm} \times 27.9 \mathrm{~cm}$. . . . . .

13. David, 13 January 1972, 0il Crayon on

Paper, $22.0 \mathrm{~cm} \times 29.4 \mathrm{~cm}$. . . . .

14. David, 3 February 1972, Oil Crayon on

Paper, $21.3 \mathrm{~cm} \times 27.8 \mathrm{~cm}$. . . . . .

15. David, 3 February 1972, Oil Crayon on

Paper, $21.4 \mathrm{~cm} \times 28.0 \mathrm{~cm}$. . . . .

16. David, 10 February 1972, Oil Crayon on

Paper, $21.6 \mathrm{~cm} \times 28.0 \mathrm{~cm}$. . . . . .

17. David, 10 February 1972, Oil Crayon on

Paper, $21.6 \mathrm{~cm} \times 28.0 \mathrm{~cm}$. . . . . .

18. David, 10 February 1972, Oil Crayon on

Paper, $21.9 \mathrm{~cm} \times 28.0 \mathrm{~cm}$. . . . .

19. David, 10 February 1972, Oil Crayon on

Paper, $21.9 \mathrm{~cm} \times 28.0 \mathrm{~cm}$. . . . . .

20. David, 10 February 1972, Oil Crayon on

Paper, $21.6 \mathrm{~cm} \times 28.0 \mathrm{~cm}$. . . . . .

21. David, 17 February 1972, Oil Crayon on

Paper, $21.6 \mathrm{~cm} \times 28.0 \mathrm{~cm}$. . . . . .

22. David, 17 February 1972, Oil Crayon on

Paper, $21.6 \mathrm{~cm} \times 28.0 \mathrm{~cm}$. . . . . . 
23. David, 17 February 1972, Oil Crayon on

Paper, $21.6 \mathrm{~cm} \times 28.0 \mathrm{~cm}$. . . . .

24. David, 17 February 1972, Oil Crayon on

Paper, $21.6 \mathrm{~cm} \times 28.0 \mathrm{~cm}$. . . . .

25. David, 17 February 1972, Oil Crayon on

Paper, $21.6 \mathrm{~cm} \times 28.0 \mathrm{~cm}$. . . . .

26. David, 17 February 1972, Oil Crayon on

Paper, $21.6 \mathrm{~cm} \times 28.0 \mathrm{~cm}$. . . . .

27. David, 17 February 1972, Oil Crayon on

Paper, $21.6 \mathrm{~cm} \times 28.0 \mathrm{~cm}$. . . . .

28. David, 9 March 1972, Oil Crayon on Paper,

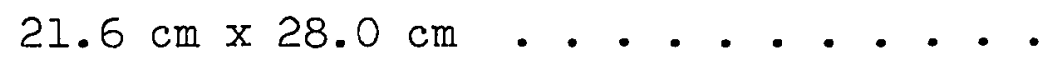

29. David, 9 March 1972, Oil Crayon on Paper,

$21.6 \mathrm{~cm} \mathrm{x} 28.0 \mathrm{~cm} \mathrm{........}$

30. David, 9 March 1972, Oil Crayon on Paper,

$21.6 \mathrm{~cm} \times 28.0 \mathrm{~cm}$. . . . . . . . . 16

31. David, 16 March 1972, Oil Crayon on Paper,

$22.8 \mathrm{~cm} \mathrm{x} 30.7 \mathrm{~cm} \mathrm{........}$

32. David, 17 March to 29 March 1972, Oil

Crayon on Paper, $22.3 \mathrm{~cm} \mathrm{x} 30.8 \mathrm{~cm}$. .

33. David, 14 April to 19 April 1972, Oil

Crayon on Paper, $21.0 \mathrm{~cm} \mathrm{x} 30.8 \mathrm{~cm}$..

34. David, 14 April to 19 April 1972, Oil

Crayon on Paper, $20.8 \mathrm{~cm} \times 30.7 \mathrm{~cm}$. . 
vii

FIGURE

PAGE

35. David, 27 April 1972, Oil Crayon on

Paper, $21.6 \mathrm{~cm} \times 27.9 \mathrm{~cm}$. . . . . .

36. David, 1 May 1972, Oil Crayon on Paper,

$21.6 \mathrm{~cm} \times 27.9 \mathrm{~cm}$. . . . . . . .

37. David, 1 May 1972, Oil Crayon on Paper,

$$
21.6 \mathrm{~cm} \times 27.9 \mathrm{~cm} \text {. . . . . . . . }
$$

38. David, 1 May 1972, Oil Crayon on Paper,

$$
21.6 \mathrm{~cm} \times 27.9 \mathrm{~cm} \text {. . . . . . . . }
$$

39. David, 1 May 1972, Oil Crayon on Paper,

$$
21.6 \mathrm{~cm} \times 27.9 \mathrm{~cm} \text {. . . . . . . . }
$$

40. David, 1 May 1972, Oil Crayon on Paper,

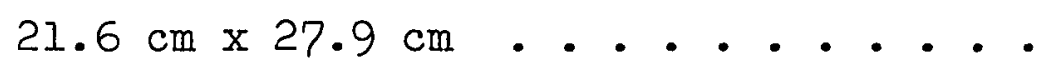

41. David, I May 1972, Oil Crayon on Paper,

$$
21.6 \mathrm{~cm} \times 27.9 \mathrm{~cm} \text {. . . . . . . }
$$

42. David, 1 May 1972, Oil Crayon on Paper,

$$
21.6 \mathrm{~cm} \times 27.9 \mathrm{~cm} \text {. . . . . . . . }
$$

43. David, 4 May 1972, Oil Crayon on Paper,

$$
21.6 \mathrm{~cm} \times 27.9 \mathrm{~cm} \text {. . . . . . . }
$$

44. David, 8 May 1972, Oil Crayon on Paper,

$$
21.6 \mathrm{~cm} \times 27.9 \mathrm{~cm} \text {. . . . . . . . }
$$

45. David, 11 May 1972, Oil Crayon on Paper,

$$
21.6 \mathrm{~cm} \times 27.9 \mathrm{~cm} \text {. . . . . . . . }
$$

46. David, 18 May 1972, Oil Crayon on Paper,

$$
21.6 \mathrm{~cm} \times 27.9 \mathrm{~cm} \cdot \text {. . . . . • . }
$$


viii

FIGURE

PAGE

47. David, 25 May 1972, Oil Crayon on Paper,

$$
21.6 \mathrm{~cm} \times 27.9 \mathrm{~cm} \text {. . . . . . . } 24
$$

48. David, I June 1972, Oil Crayon on Paper,

$$
21.6 \mathrm{~cm} \times 27.9 \mathrm{~cm} \text {. . . . . . . }
$$

49. David, I June 1972, Oil Crayon on Paper,

$$
21.6 \mathrm{~cm} \times 27.9 \mathrm{~cm} \text {. . . . . . . }
$$

50. David, I June 1972, Oil Crayon on Paper,

$$
21.6 \mathrm{~cm} \times 27.9 \mathrm{~cm} \text {. . . . . . . }
$$

51. David, 7 June 1972, Oil Crayon on Paper,

$$
21.6 \mathrm{~cm} \times 27.9 \mathrm{~cm} . . . . . . .
$$

52. David, 7 June 1972, Oil Crayon on Paper,

$$
27.9 \mathrm{~cm} \mathrm{x} 21.6 \mathrm{~cm} \text {. . . . . . • }
$$

53. David, 8 June 1972, Oil Crayon on Paper,

$$
21.6 \mathrm{~cm} \times 27.9 \mathrm{~cm} \text {. . . . . . . . } 28
$$

54. David, 8 June 1972, Oil Crayon on Paper,

$$
21.6 \mathrm{~cm} \times 27.9 \mathrm{~cm} \text {. . . . . . . . } 28
$$

55. David, 8 June 1972, Oil Crayon on Paper,

$$
21.6 \mathrm{~cm} \times 27.9 \mathrm{~cm} \text {. . . . . . . }
$$

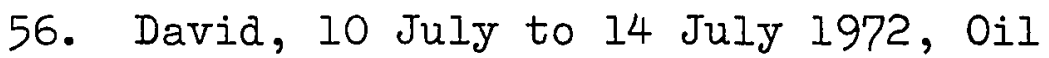

Crayon on Paper, $22.8 \mathrm{~cm} \times 30.7 \mathrm{~cm}$...

57. David, 10 July to 14 July 1972, Oil

$$
\text { Crayon on Paper, } 22.8 \mathrm{~cm} \mathrm{x} 30.7 \mathrm{~cm} \text {. . }
$$

58. David, 10 July to 14 July 1972, Oil

$$
\text { Crayon on Paper, } 22.8 \mathrm{~cm} \mathrm{x} 30.7 \mathrm{~cm} \text {... }
$$


FIGURE

59. David, 21 July 1972, Acrylic on Paper,

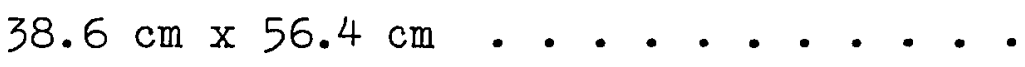

60. David, 11 September to 13 September 1972 ,

Oil Crayon on Paper, $22.8 \mathrm{~cm} \mathrm{x}$ $30.8 \mathrm{~cm}$. . . . . . . . . .

61. David, 11 September to 13 September 1972 ,

Oil Crayon on Paper, $27.5 \mathrm{~cm} \mathrm{x}$ $35.4 \mathrm{~cm}$. . . . . . . .

62. David, 11 September to 13 September 1972,

Oil Crayon on Paper, $27.5 \mathrm{~cm} \mathrm{x}$

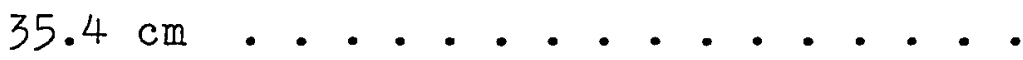

63. David, 11 September to 13 September 1972 ,

Oil Crayon on Paper, $27.5 \mathrm{~cm} \mathrm{x}$

$35.4 \mathrm{~cm}$. . . . . . . . .

64. David, 11 September to 13 September 1972,

Oil Crayon on Paper, $27.5 \mathrm{~cm} \mathrm{x}$

$35.4 \mathrm{~cm}$. . . . . . . . . .

65. David, 14 September 1972, Pencil and Oil

Crayon on Paper, $21.6 \mathrm{~cm} \times 28.0 \mathrm{~cm}$. .

66. David, 21 September 1972; Acrylic on

Paper, $46.0 \mathrm{~cm} \mathrm{x} 61.1 \mathrm{~cm}$......

67. David, 5 January to 8 January 1973,

Tempera on Paper, $12.9 \mathrm{~cm} \times 35.5 \mathrm{~cm}$.

68. David, 10 January to 15 January 1973,

Oil Crayon on Paper, $56.0 \mathrm{~cm} \mathrm{x}$

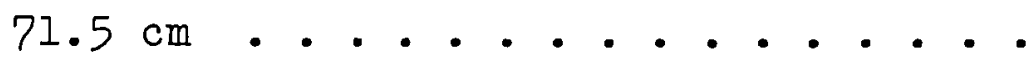


FIGURE

PAGE

69. David, 27 February 1973, Oil Crayon on

Canvas Board, $40.5 \mathrm{~cm} \times 50.7 \mathrm{~cm} \mathrm{...}$

70. David, 27 February to 28 February 1973,

Oil Crayon on Canvas Board, $30.6 \mathrm{~cm} \mathrm{x}$

$40.6 \mathrm{~cm} \mathrm{.} \mathrm{.} \mathrm{.} \mathrm{.} \mathrm{.} \mathrm{.} \mathrm{.} \mathrm{.} \mathrm{.} \mathrm{.}$

71. Eve, 30 November 1972, Wax Crayon on

Paper, (Detail) . . . . . . . . .

72. Eve, 30 November 1972, Wax Crayon and

Tempera on Paper, $45.0 \mathrm{~cm} \mathrm{x} 61.0 \mathrm{~cm}$.

73. Eve, I December to 13 December 1972 ,

Tempera on Paper, $44.4 \mathrm{~cm} \times 61.0 \mathrm{~cm}$.

74. Eve, 1 December to 13 December 1972 ,

Tempera on Paper, $44.4 \mathrm{~cm} \times 61.0 \mathrm{~cm}$.

75. Eve, 14 December 1972, Tempera on Paper,

$$
30.5 \mathrm{~cm} \times 45.8 \mathrm{~cm} \text {. . . . . . . }
$$

76. Eve, 18 December 1972, Tempera on Paper,

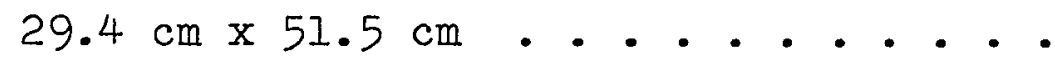

77. Eve, 9 January 1973, Tempera on Paper,

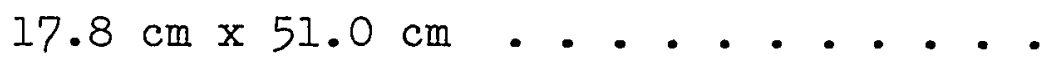

78. Eve, 9 January 1973, Tempera on Paper,

$$
17.8 \mathrm{~cm} \times 51.0 \mathrm{~cm} \text {. . . . . . . } 40
$$

79. Eve, 9 January 1973, Tempera on Paper,

$$
17.8 \mathrm{~cm} \times 51.0 \mathrm{~cm} \text {. . . . . . . . } 40
$$

80. Eve, 19 January to 31 January 1973, Tempera on Paper, $30.5 \mathrm{~cm} \times 45.5 \mathrm{~cm}$. . . . 
81. Eve, 19 January to 31 January 1973, Tempera on Paper, $29.3 \mathrm{~cm} \times 55.8 \mathrm{~cm}$. . . .

82. Eve, 2 February to 5 February 1973, Tempera on Paper, $29.2 \mathrm{~cm} \times 56.0 \mathrm{~cm}$. . . . 42

83. Eve, 2 February to 5 February 1973, Tempera on Paper, $29.2 \mathrm{~cm}$ x $51.0 \mathrm{~cm}$.....

84. Eve, 6 February 1973, Tempera on Paper, $29.2 \mathrm{~cm} \times 56.0 \mathrm{~cm}$. . . . . . .

85. Eve, 8 February 1973, Tempera on Paper, $29.2 \mathrm{~cm} \times 56.0 \mathrm{~cm}$. . . . . . . .

86. Eve, 8 February 1973, Tempera on Paper, $29.2 \mathrm{~cm} \times 56.0 \mathrm{~cm}$. . . . . . . . 44

87. Eve, 22 Febmuary 1973, Tempera on Paper, $29.2 \mathrm{~cm} \times 56.0 \mathrm{~cm}$. . . . . . . . 44

88. Kay, Late November 1972 , Wax Crayon on Paper, (Detail). • . . . . . . • 45

89. Kay, 30 November 1972, Tempera on Paper, $40.0 \mathrm{~cm} \mathrm{x} 60.5 \mathrm{~cm}$. . . . . . . 45

90. Kay, 30 November 1972, Tempera on Paper, $40.0 \mathrm{~cm} \times 60.5 \mathrm{~cm}$. . . . . . . . 46

91. Kay, 7 December 1972 , Tempera on Paper, $40.0 \mathrm{~cm} \times 60.5 \mathrm{~cm}$. . . . . . . . . 46

92. Kay, 1 December to 6 December 1972, Tempera on Paper, $40.0 \mathrm{~cm} \times 60.5 \mathrm{~cm}$..... 
93. Kay, 14 December to 19 December 1972 ,

Tempera on Paper, $29.2 \mathrm{~cm} \times 51.5 \mathrm{~cm}$.

94. Kay, 2 January 1973, Origami (Japanese

Folding Paper) on Paper, $50.6 \mathrm{~cm} \mathrm{x}$

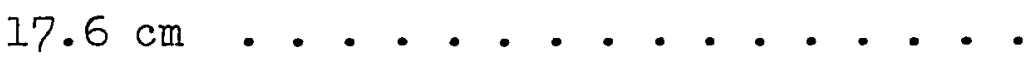

95. Kay, 4 January 1973, Tempera on Paper,

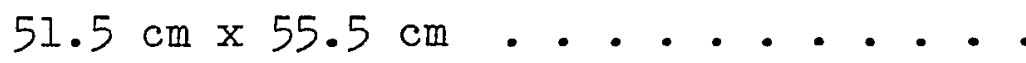

96. Kay, 4 January 1973, Tempera on Paper,

$17.8 \mathrm{~cm} \times 50.9 \mathrm{~cm}$. . . . . . .

97. Kay, 9 January 1973, Tempera on Paper,

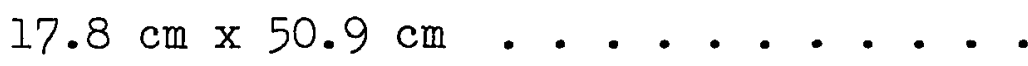

98. Kay, 9 January 1973, Tempera on Paper,

$17.8 \mathrm{~cm} \times 50.9 \mathrm{~cm}$. . . . . .

99. Kay, 9 January 1973, Tempera on Paper,

$17.8 \mathrm{~cm} \times 50.9 \mathrm{~cm}$. . . . . .

100. Kay, 10 January to 15 January 1973, Tempera

on Paper, $29.2 \mathrm{~cm} \times 56.0 \mathrm{~cm}$. . . . .

101. Kay, 10 January to 15 January 1973, Tempera

on Paper, $29.2 \mathrm{~cm} \times 56.0 \mathrm{~cm}$. . . . .

102. Kay, 10 January to 15 January 1973, Tempera

on Paper, $42.5 \mathrm{~cm} \times 60.9 \mathrm{~cm}$. . . .

51

103. Kay, 10 January to 15 January 1973, Tempera on Paper, $29.2 \mathrm{~cm} \times 56.0 \mathrm{~cm}$. . . .

104. Kay, 16 January 1973, Tempera on Paper,

$29.2 \mathrm{~cm} \times 56.0 \mathrm{~cm}$. . . . . . 
105. Kay, 17 January 1973, Tempera on Paper,

$$
29.2 \mathrm{~cm} \mathrm{x} 56.0 \mathrm{~cm} \text {. . . . . . . }
$$

106. Kay, 17 January 1973, Tempera on Paper,

$$
29.2 \mathrm{~cm} \times 56.0 \mathrm{~cm} \text {. . . . . . . }
$$

107. Kay, 18 January 1973, Tempera on Paper,

$$
29.2 \mathrm{~cm} \mathrm{x} 56.0 \mathrm{~cm} \cdot \text {. . . . . . }
$$

108. Kay, 18 January 1973, Tempera on Paper,

$$
29.2 \mathrm{~cm} \mathrm{x} 56.0 \mathrm{~cm} \cdot \text {. . . . • • }
$$

109. Kay, 18 January 1973, Tempera on Paper,

$$
29.2 \mathrm{~cm} \times 56.0 \mathrm{~cm} \text {. . . . . . • }
$$

110. Kay, 18 January 1973, Tempera on Paper,

$$
29.2 \mathrm{~cm} \times 56.0 \mathrm{~cm} \text {. . . . . . . }
$$

111. Kay, 18 January 1973, Tempera on Paper,

$$
43.0 \mathrm{~cm} \times 55.7 \mathrm{~cm} \text {. . . . . . }
$$

112. Kay, 18 January 1973, Tempera on Paper,

$$
29.2 \mathrm{~cm} \mathrm{x} 56.0 \mathrm{~cm} \text {........ }
$$

113. Kay, 18 January 1973, Tempera on Paper,

$$
29.2 \mathrm{~cm} \mathrm{x} 56.0 \mathrm{~cm} \text {. . . . . . . }
$$

114. Kay, 18 January 1973, Tempera on Paper,

$$
29.2 \mathrm{~cm} \mathrm{x} 56.0 \mathrm{~cm} \cdot \text {. . . . . . }
$$

115. Kay, 18 January 1973, Tempera on Paper,

$$
29.2 \mathrm{~cm} \mathrm{x} 56.0 \mathrm{~cm} \text {. • • • • • • }
$$

116. Kay, 1 February 1973, Tempera on Paper, 
117. Kay, 8 February to 9 February 1973, Tempera on Paper, $29.2 \mathrm{~cm} \times 56.0 \mathrm{~cm}$.....

118. Kay, 8 February to 9 February 1973, Tempera

$$
\text { on Paper, } 29.2 \mathrm{~cm} \times 56.0 \mathrm{~cm} \text {. . . . }
$$

119. David, 21 June 1973, Acrylic on Paper,

$$
56.0 \mathrm{~cm} \times 71.4 \mathrm{~cm} \text {. . . . . . }
$$

120. David, 29 June 1973, Acrylic on Paper,

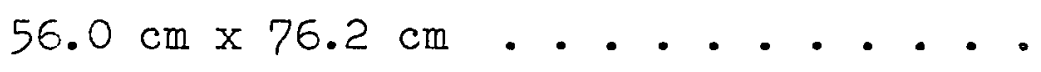

121. David, 6 July 1973, Acrylic on Paper,

$$
43.0 \mathrm{~cm} \times 56.0 \mathrm{~cm} \text {. . . . . . . . }
$$

122. David, 24 August 1973, Acrylic on Paper,

$$
45.7 \mathrm{~cm} \mathrm{x} 61.2 \mathrm{~cm} \mathrm{........}
$$

123. David, 7 September 1973, Acrylic on Paper,

$$
45.7 \mathrm{~cm} \mathrm{x} 61.0 \mathrm{~cm} \text {........ }
$$

124. David, 30 September 1973, Acrylic on Paper,

$$
61.0 \mathrm{~cm} \times 45.7 \mathrm{~cm} \mathrm{........}
$$

125. David, 6 January 1974, Acrylic on Paper,

$$
45.7 \mathrm{~cm} \mathrm{x} 61.0 \mathrm{~cm} \mathrm{........}
$$

126. David, 6 January 1974, Acrylic on Paper,

$$
45.7 \mathrm{~cm} \mathrm{x} 61.0 \mathrm{~cm} \cdot \text {. . . . . . }
$$

127. David, 6 January 1974, Acrylic on Paper,

$$
45.7 \mathrm{~cm} \mathrm{x} 61.0 \mathrm{~cm} \mathrm{........}
$$

64

128. David, 3 February 1974, Wax Crayon on

$$
\text { Paper, } 27.2 \mathrm{~cm} \times 31.5 \mathrm{~cm} \text {. . . . . }
$$


129. David, 17 February 1974, Acrylic on Paper,

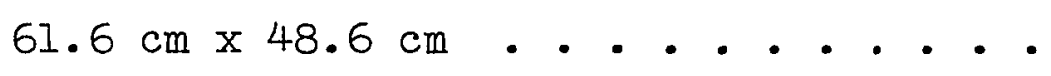

130. David, 3 March 1974, Marking Pen on Canvas

$$
\text { Board, } 20.2 \mathrm{~cm} \times 40.5 \mathrm{~cm} \text {. . . . . }
$$

131. David, 3 March 1974, Marking Pen on Paper,

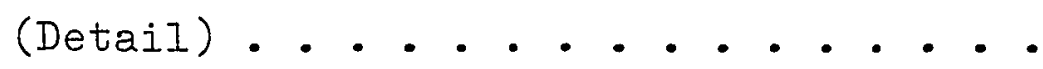

132. David, 17 March 1974, Marking Pen on Paper, $45.7 \mathrm{~cm} \mathrm{x} 61.0 \mathrm{~cm}$. . . . . . . 


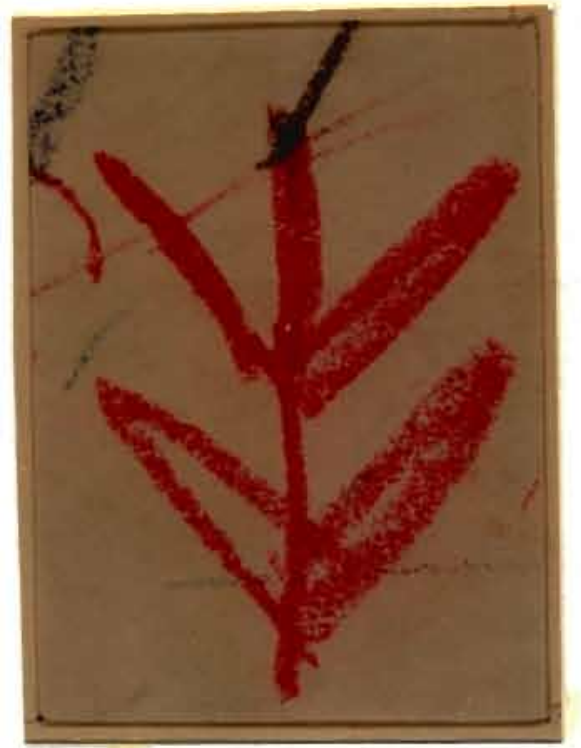

Figure 1. David, oil crayon on paper, (detail). 


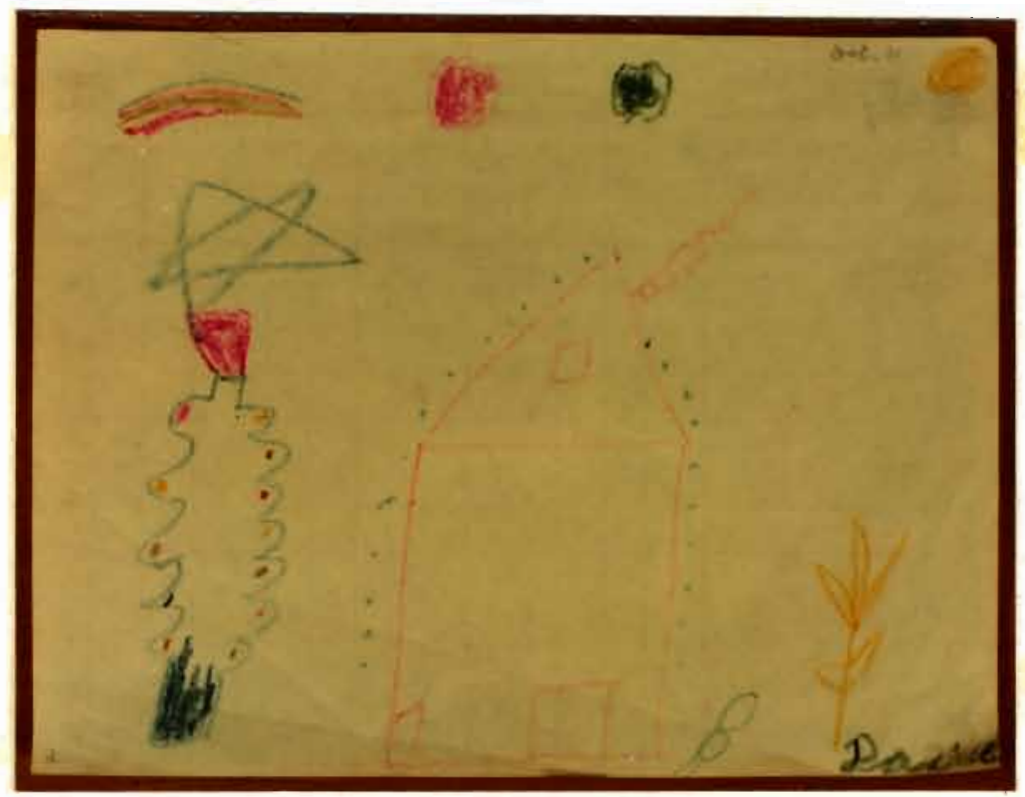
Figure 2. David, wax crayon on paper,
$21.6 \mathrm{~cm} \times 27.9 \mathrm{~cm}$.

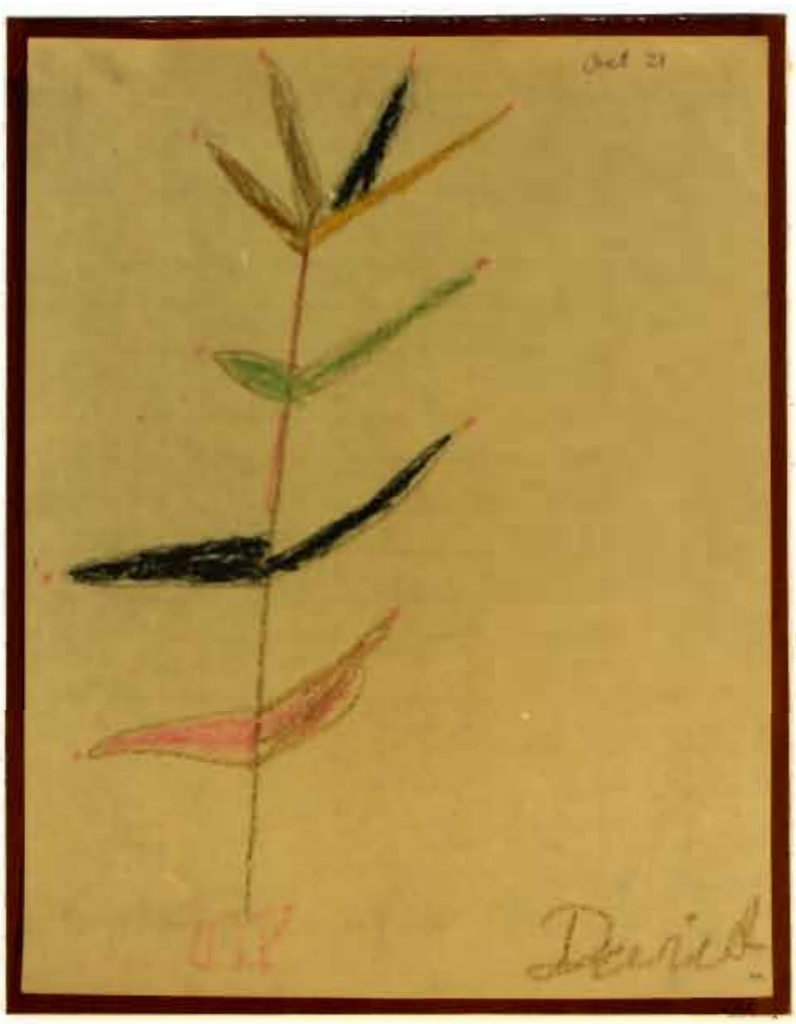

Figure 3. David, wax crayon on paper, $27.9 \mathrm{~cm} \times 21.6 \mathrm{~cm}$. 


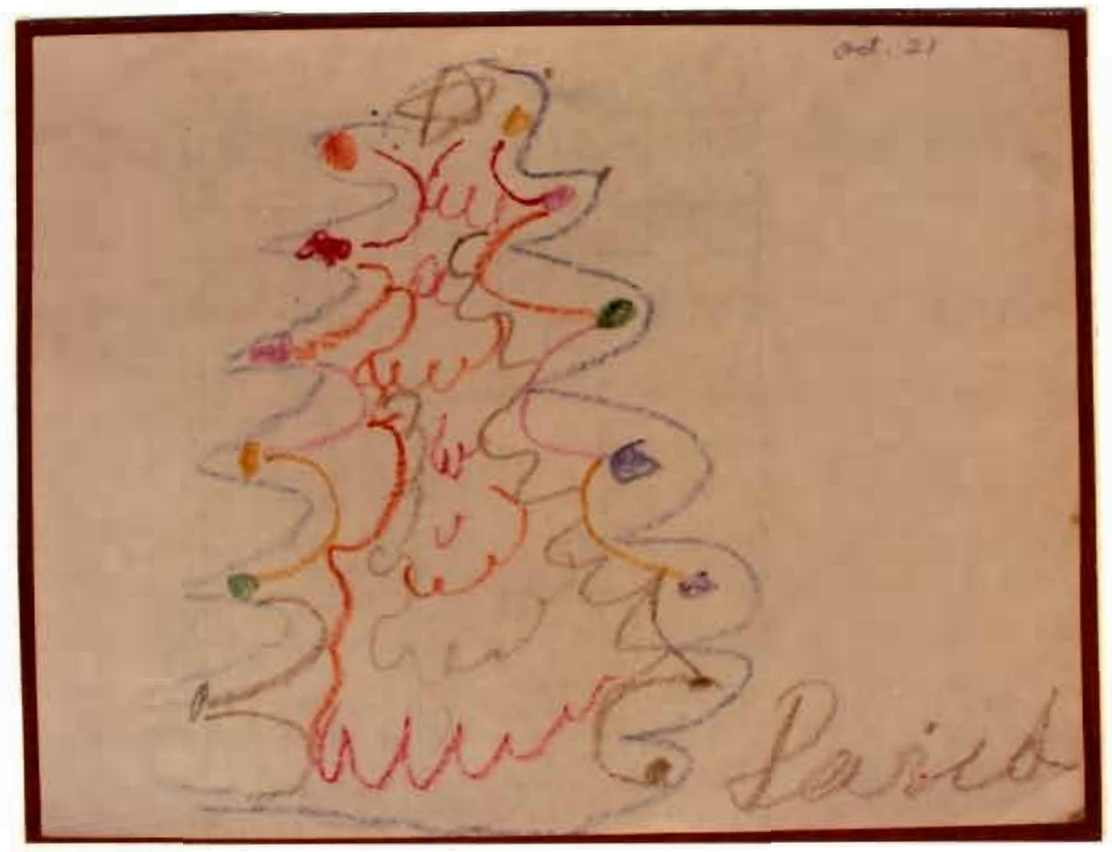

Figure 4. David, wax crayon on paper, $21.6 \mathrm{~cm} \times 27.9 \mathrm{~cm}$.

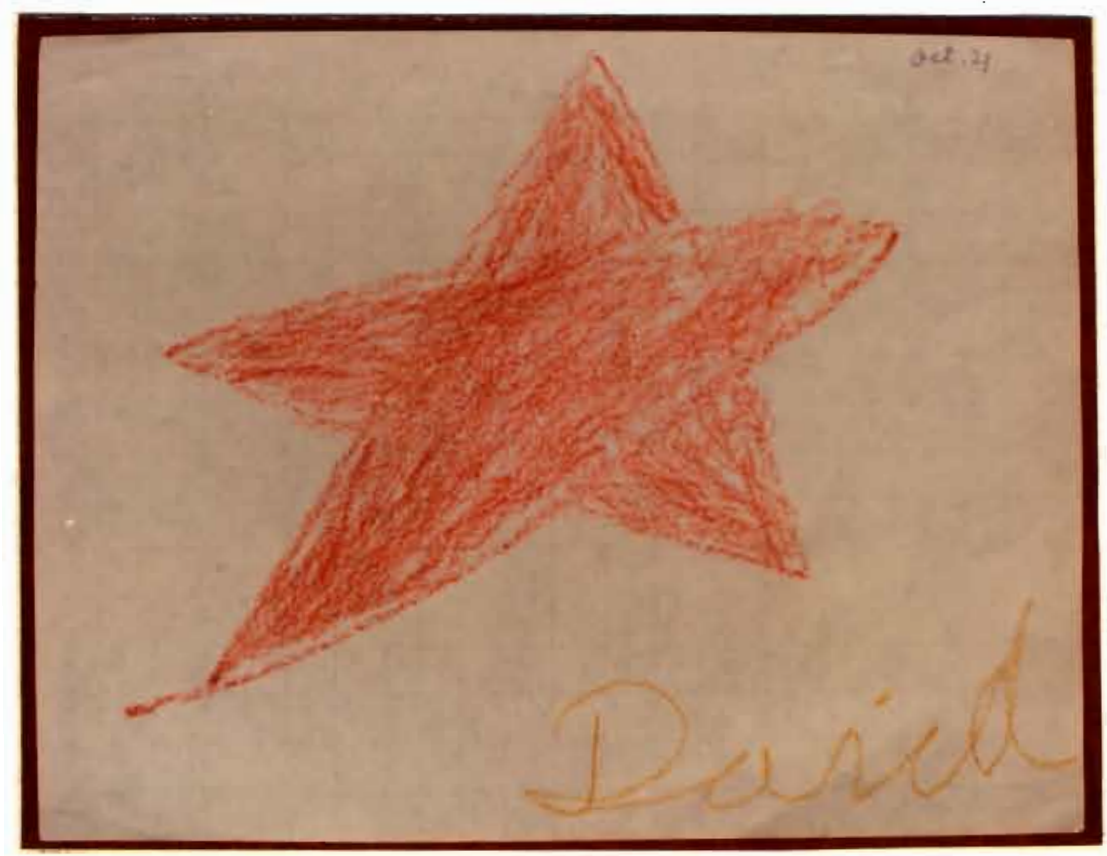

Figure 5. David, wax crayon on paper, $21.6 \mathrm{~cm} \times 27.9 \mathrm{~cm}$. 


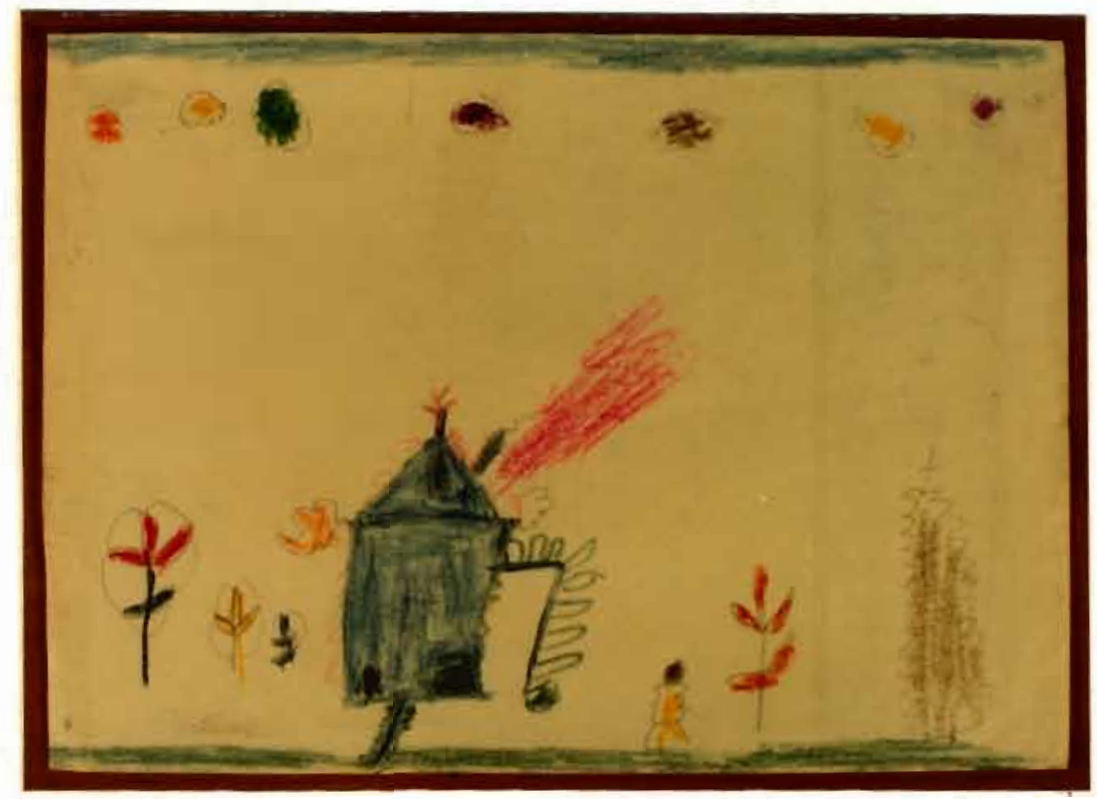

Figure 6. David, wax crayon on paper, $21.6 \mathrm{~cm} \times 29.8 \mathrm{~cm}$.

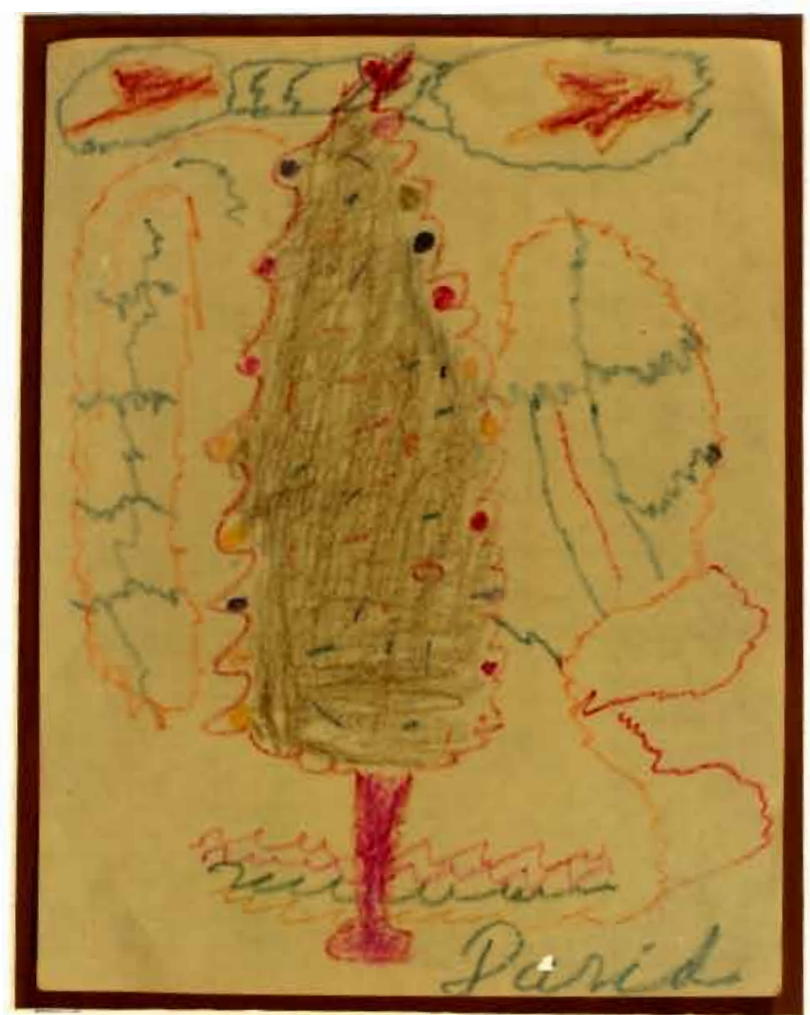

Figure 2. David, wax crayon on paper, $27.9 \mathrm{~cm} \times 21.6 \mathrm{~cm}$. 


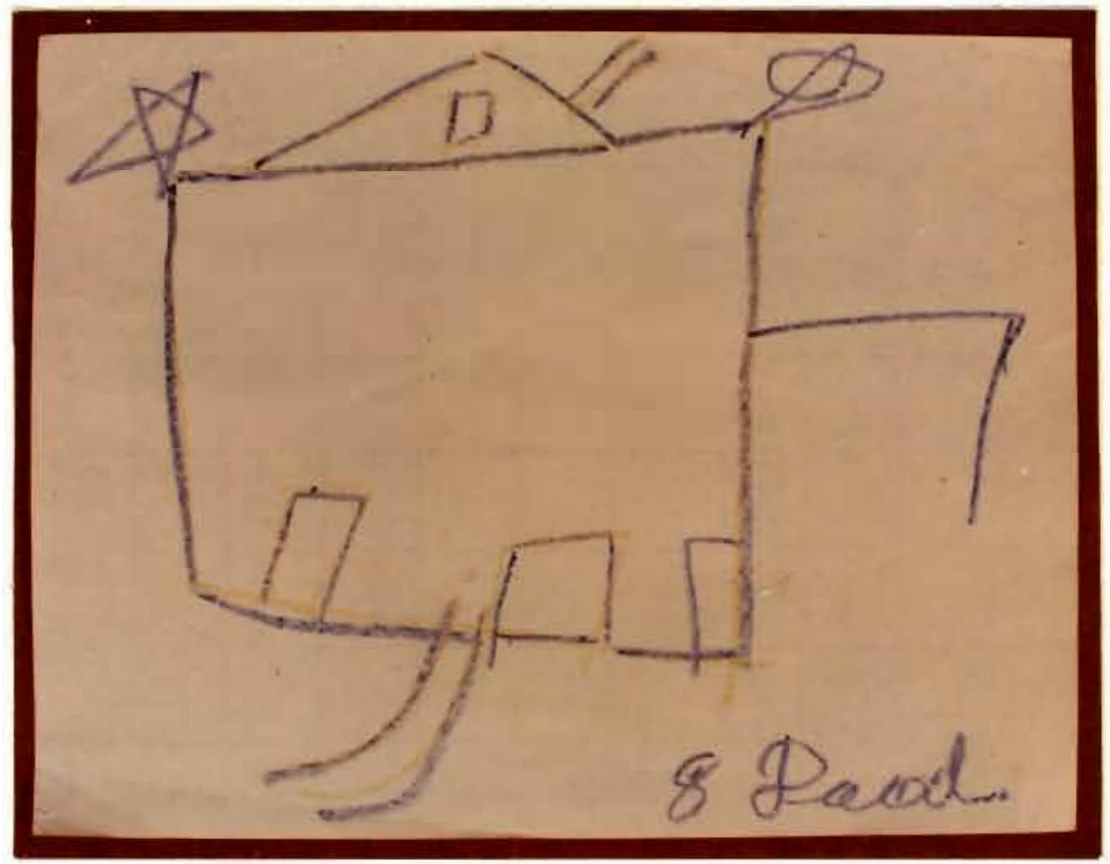

Figure 8. David, wax crayon on paper, $21.6 \mathrm{~cm} \times 27.9 \mathrm{~cm}$.

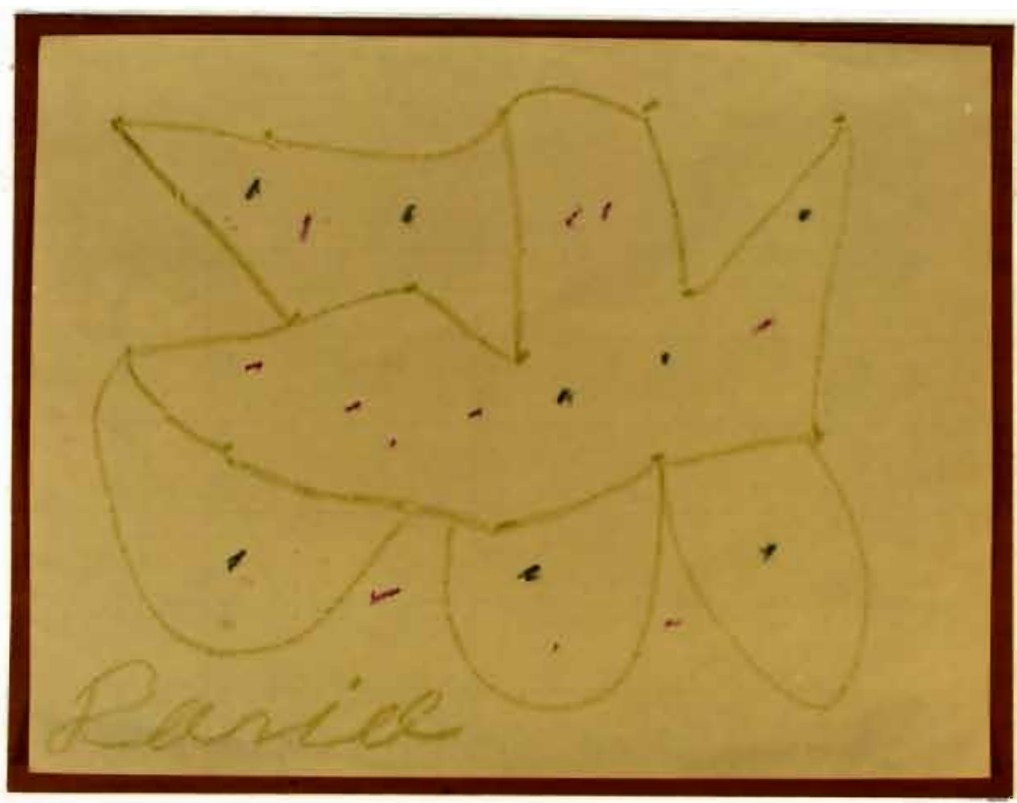

Figure 9. David, wax crayon on paper, 


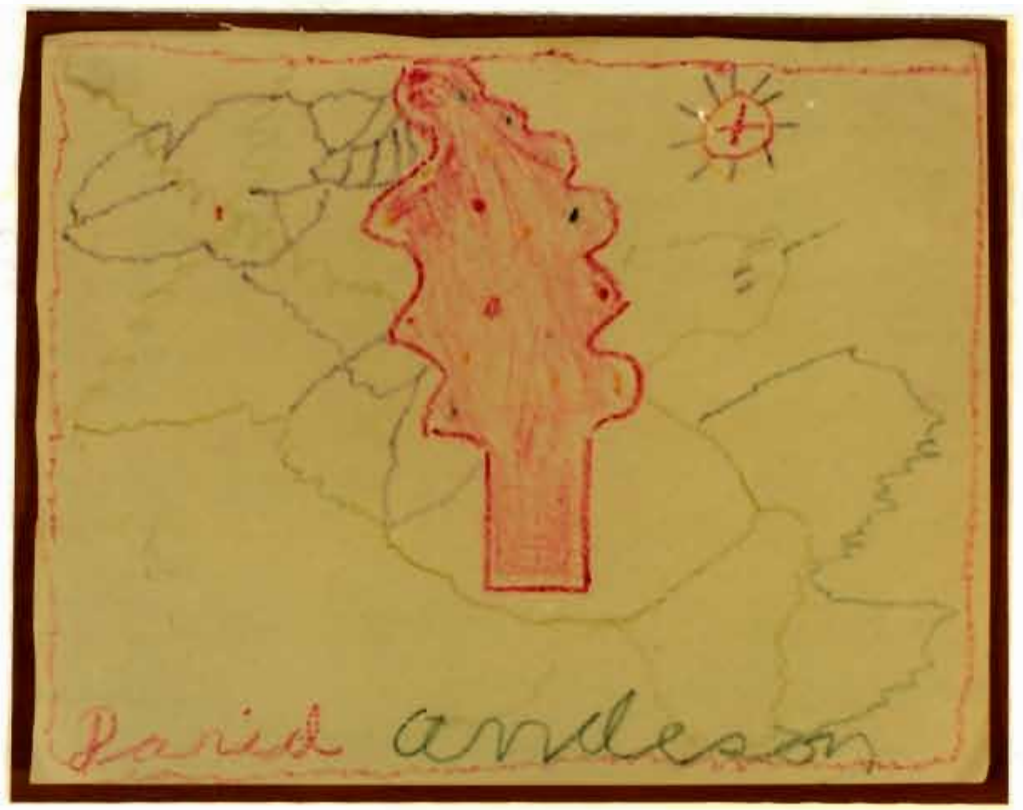

Figure 10. David, wax crayon on paper, 22.0 im x $27.9 \mathrm{~cm}$.

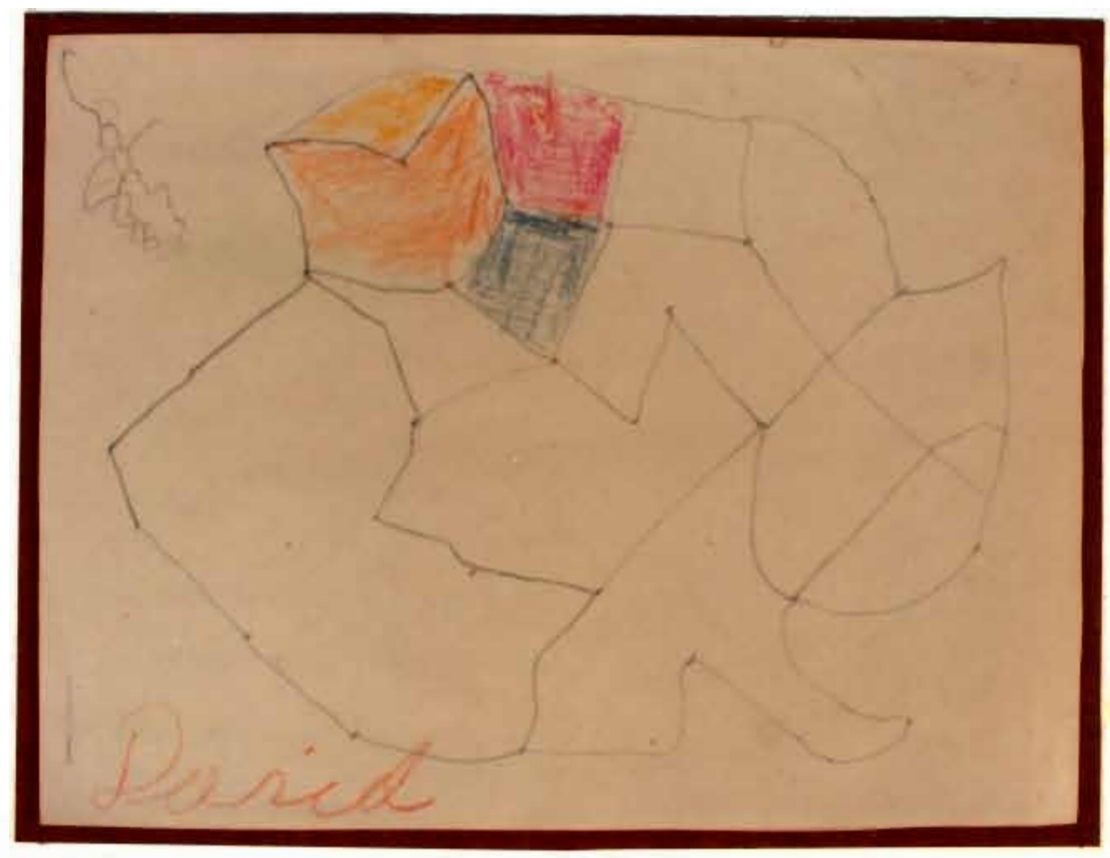

Figure 11. David, wax crayon on paper, $21.3 \mathrm{~cm} \mathrm{x} 27.9 \mathrm{~cm}$. 


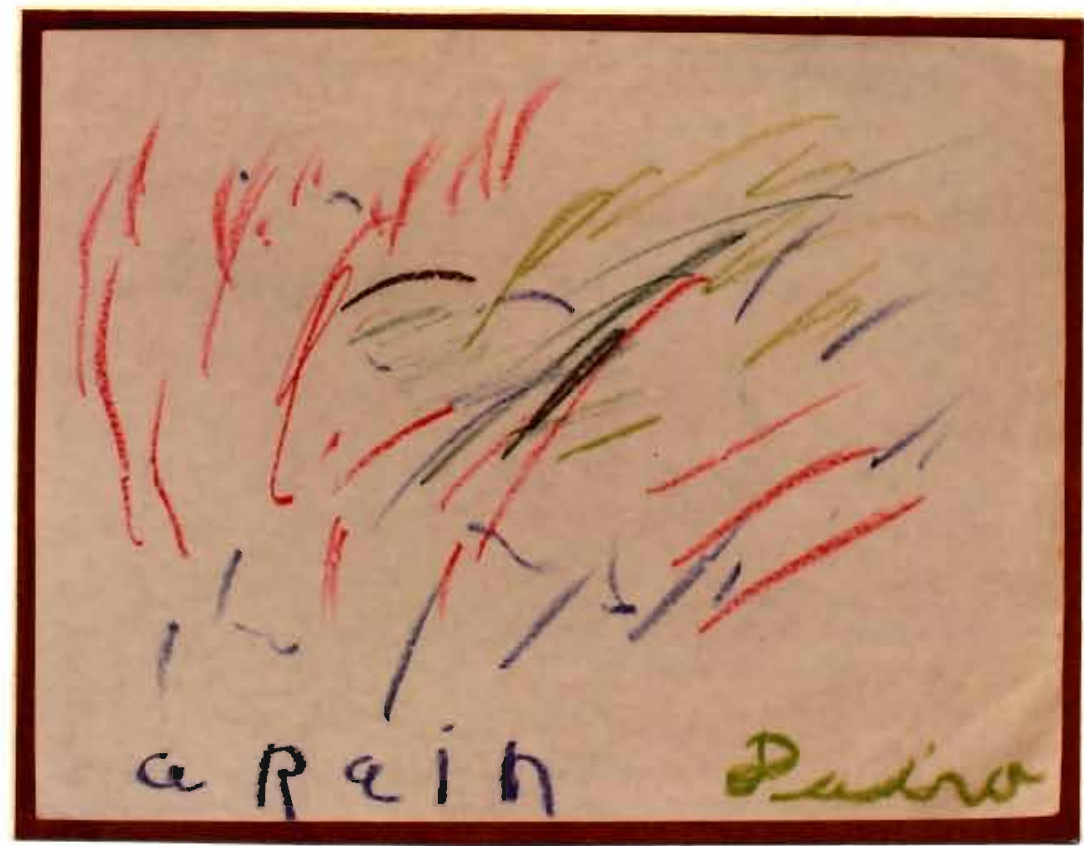

Figure 12. David, oil crayon on paper, $21.5 \mathrm{~cm} \mathrm{x} 27.9 \mathrm{~cm}$.

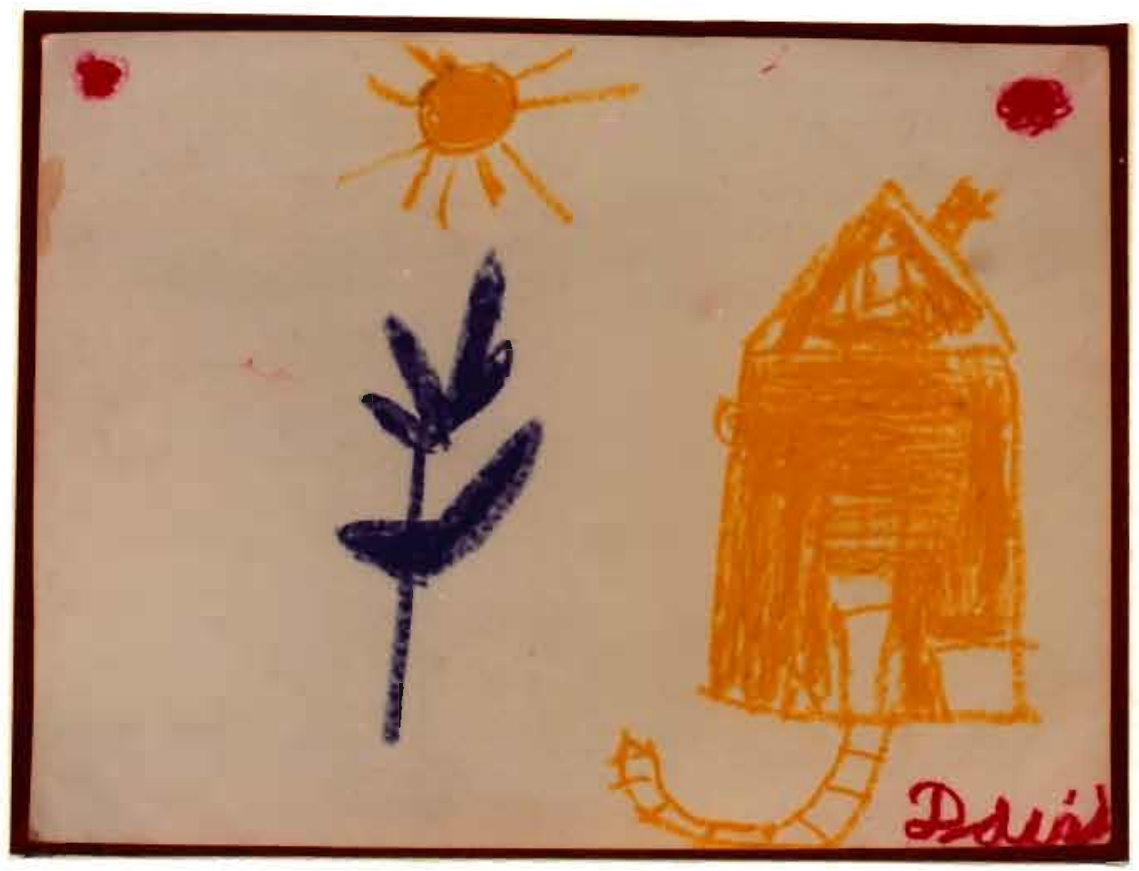

Figure 13. David, oil crayon on paper, $22.0 \mathrm{~cm} \mathrm{x} 29.4 \mathrm{~cm}$. 


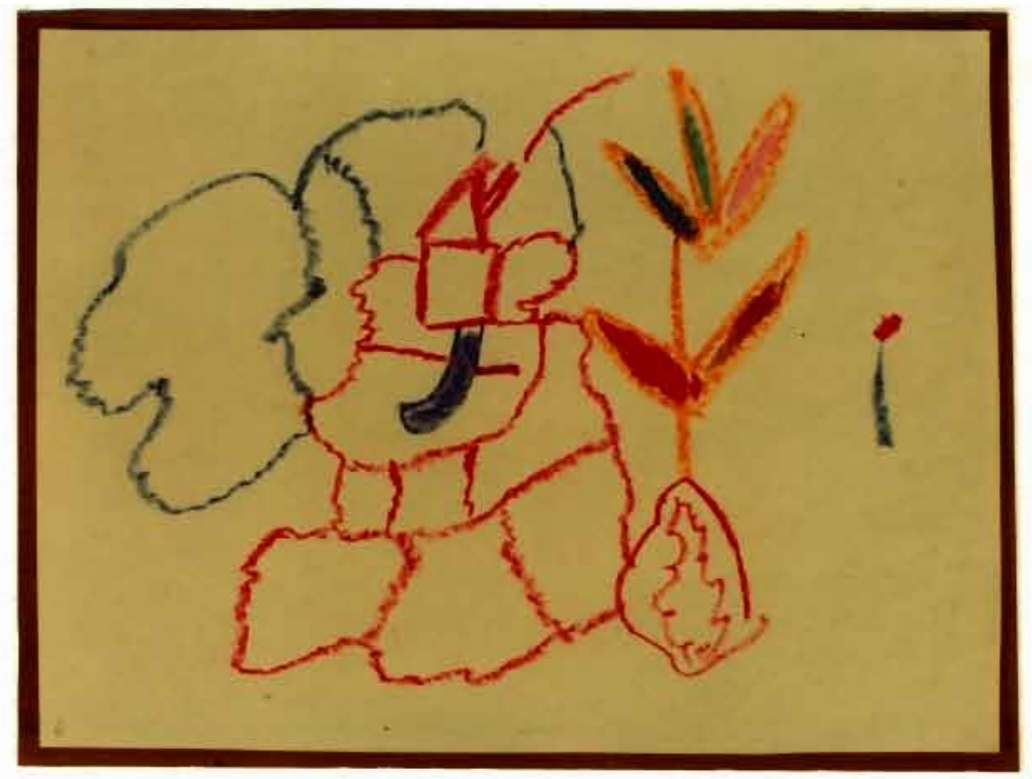

Figure 14. David, oil crayon on paper, $21.3 \mathrm{~cm} \times 27.8 \mathrm{~cm}$.

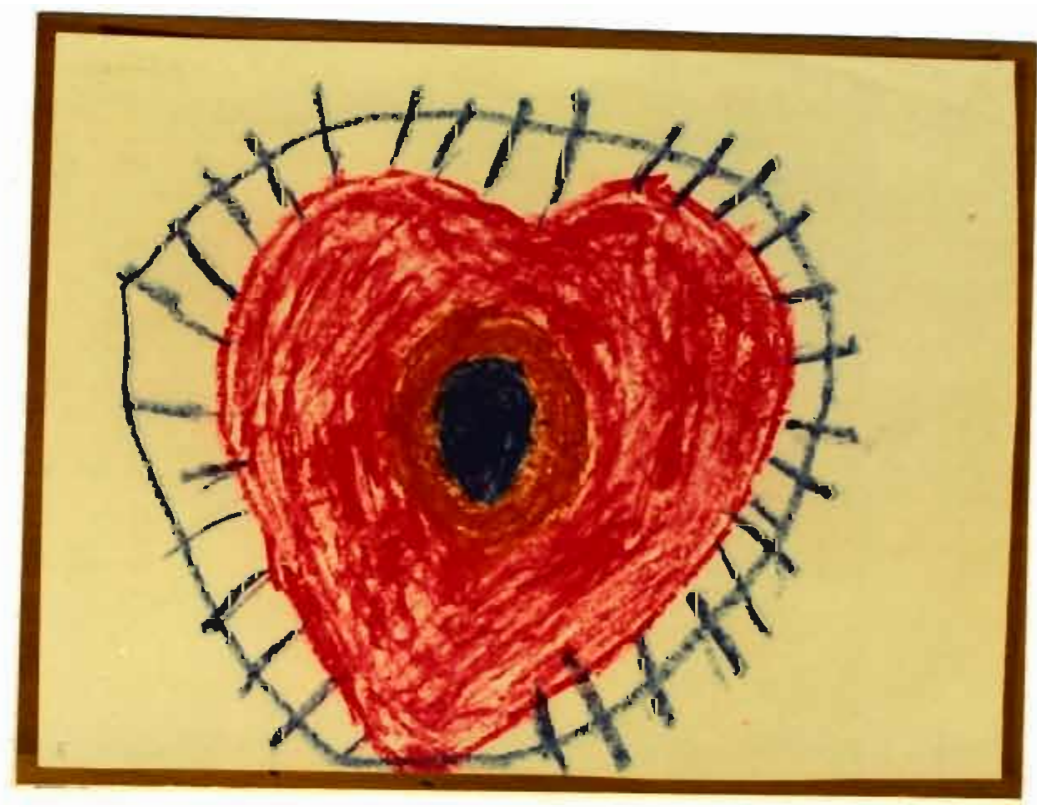

Figure 15. David, oil crayon on paper, $21.4 \mathrm{~cm} \times 28.0 \mathrm{~cm}$. 


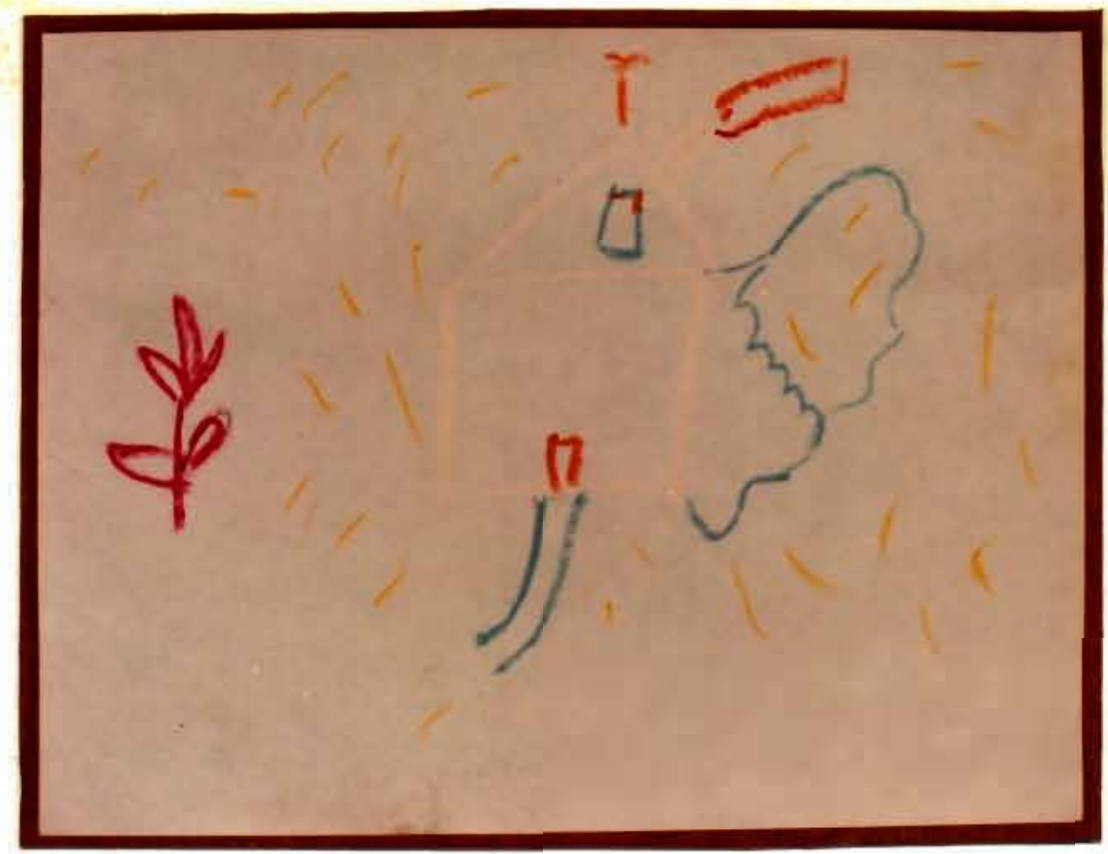

Figure 16. David, oil crayon on paper, $21.6 \mathrm{~cm} \mathrm{x} 28.0 \mathrm{~cm}$.

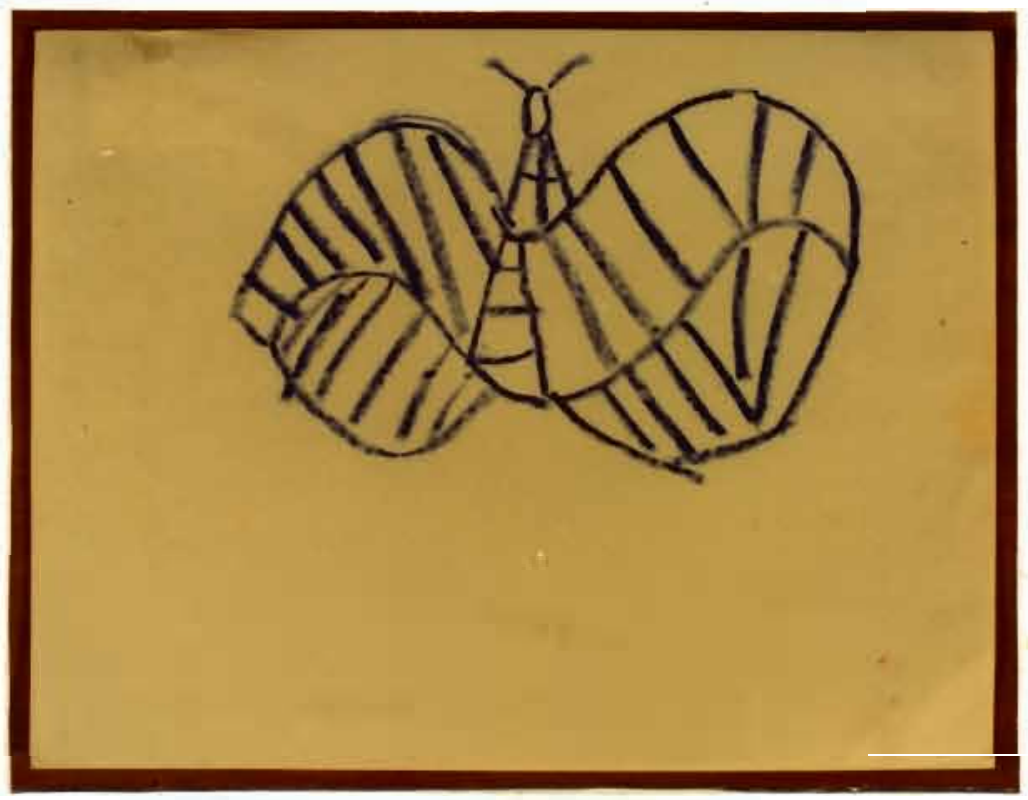

Figure 17. David, oil crayon on paper, $21.6 \mathrm{~cm} \times 28.0 \mathrm{~cm}$. 


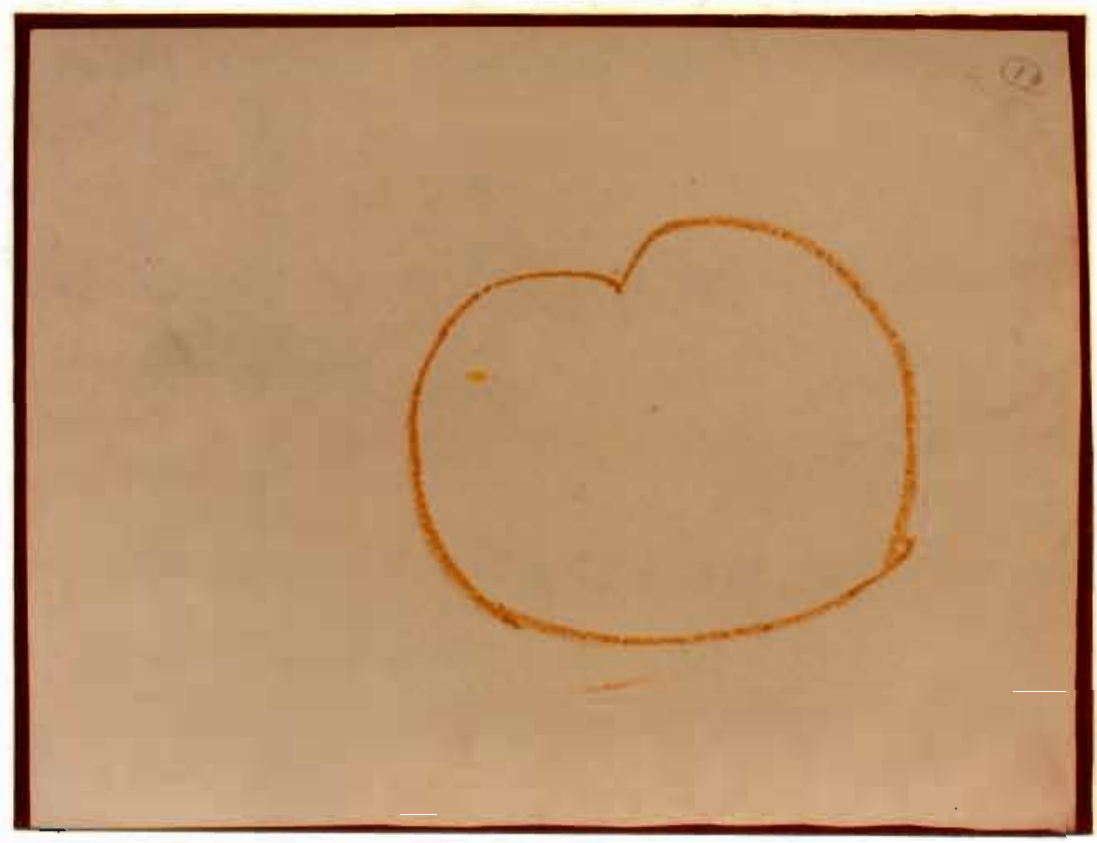

Figure 18. David, oil crayon on paper, $21.9 \mathrm{~cm} \mathrm{x} 28.0 \mathrm{~cm}$.

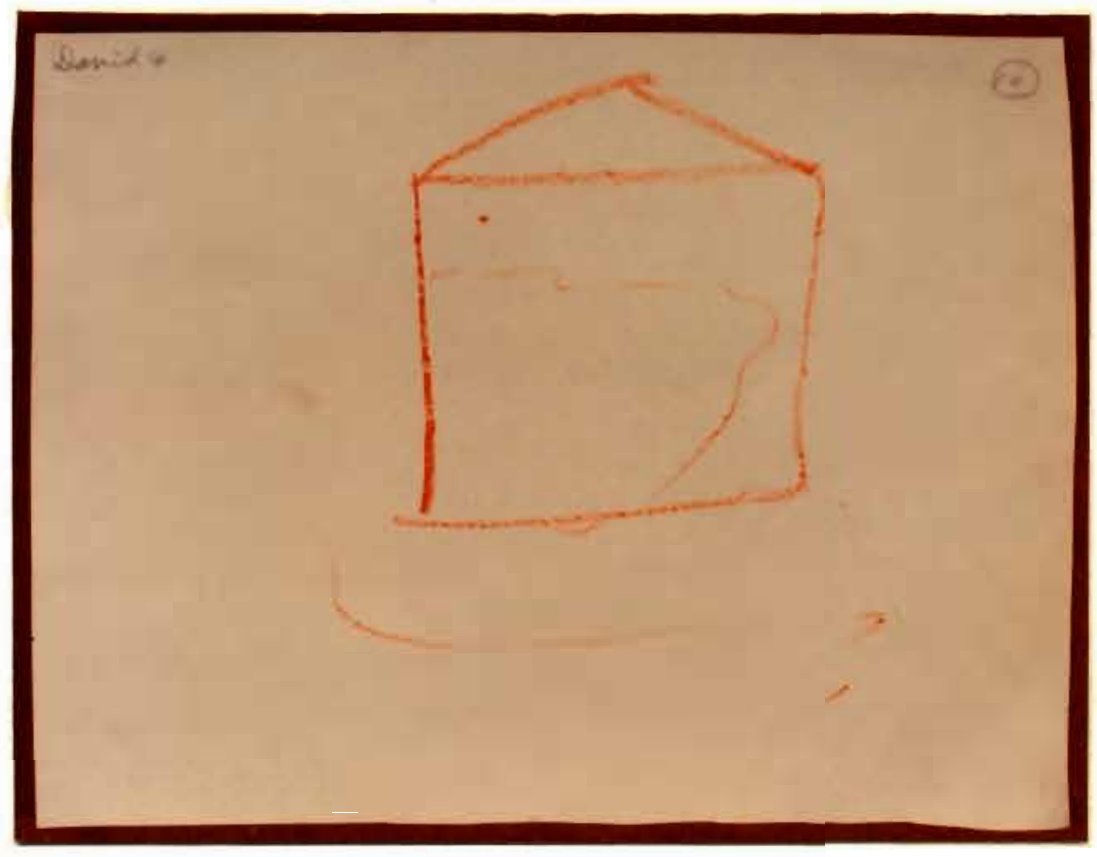

Figure 19. David, oil crayon on paper,

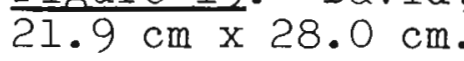




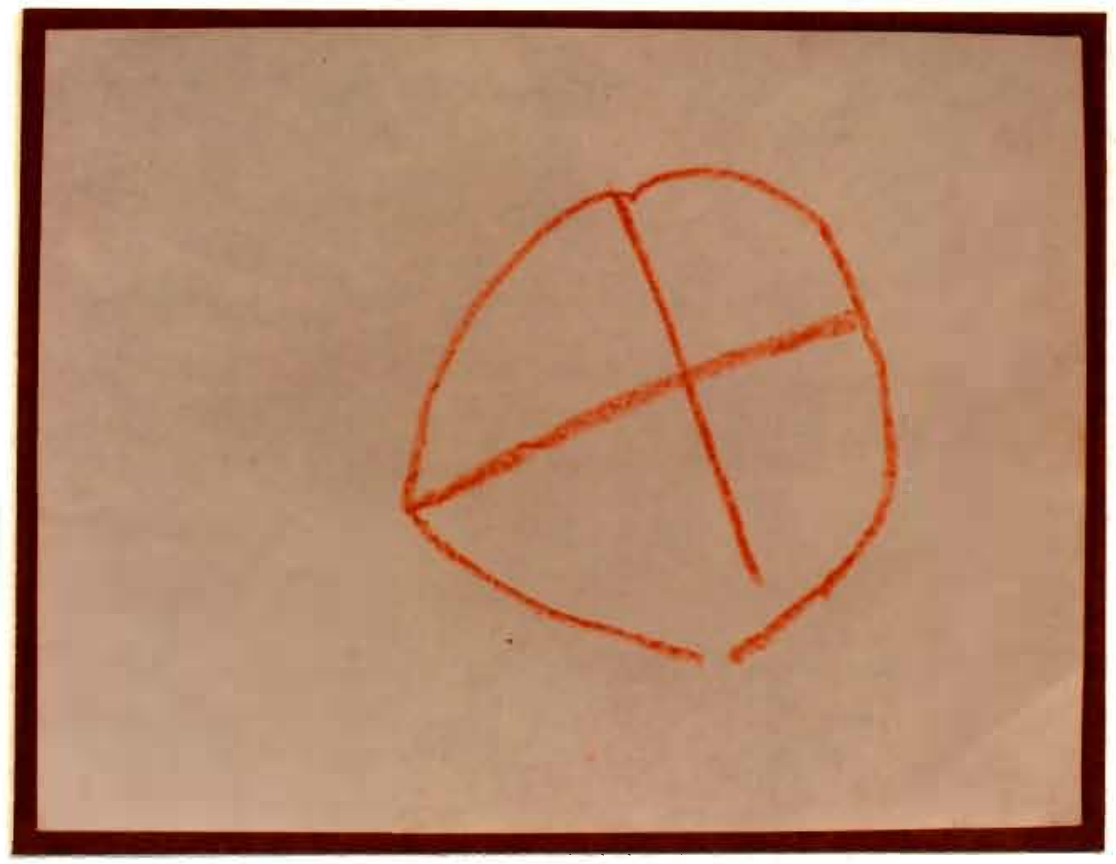

Figure 20. David, oil crayon on paper,

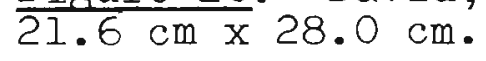

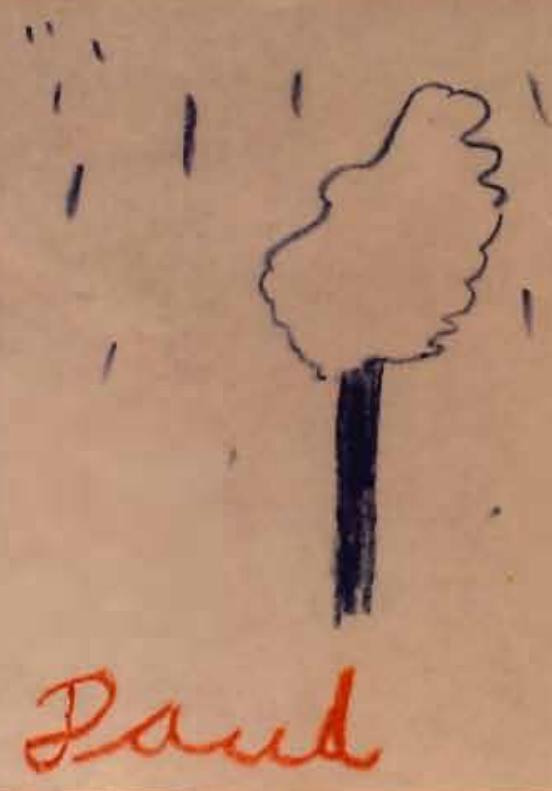

Figure 2l. David, oil crayon on paper,

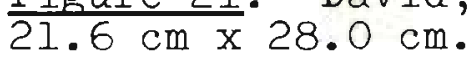




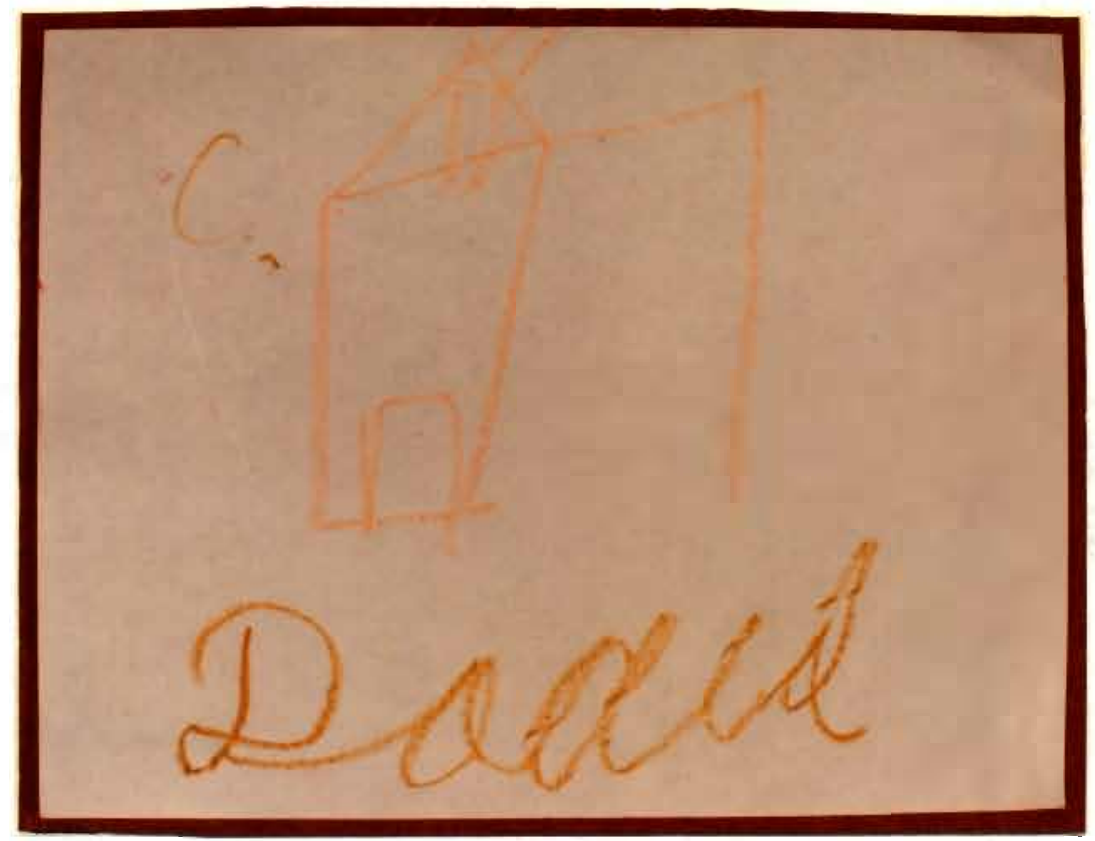

Figure 22. David, oil crayon on paper, $21.6 \mathrm{~cm} \mathrm{x} 28.0 \mathrm{~cm}$.

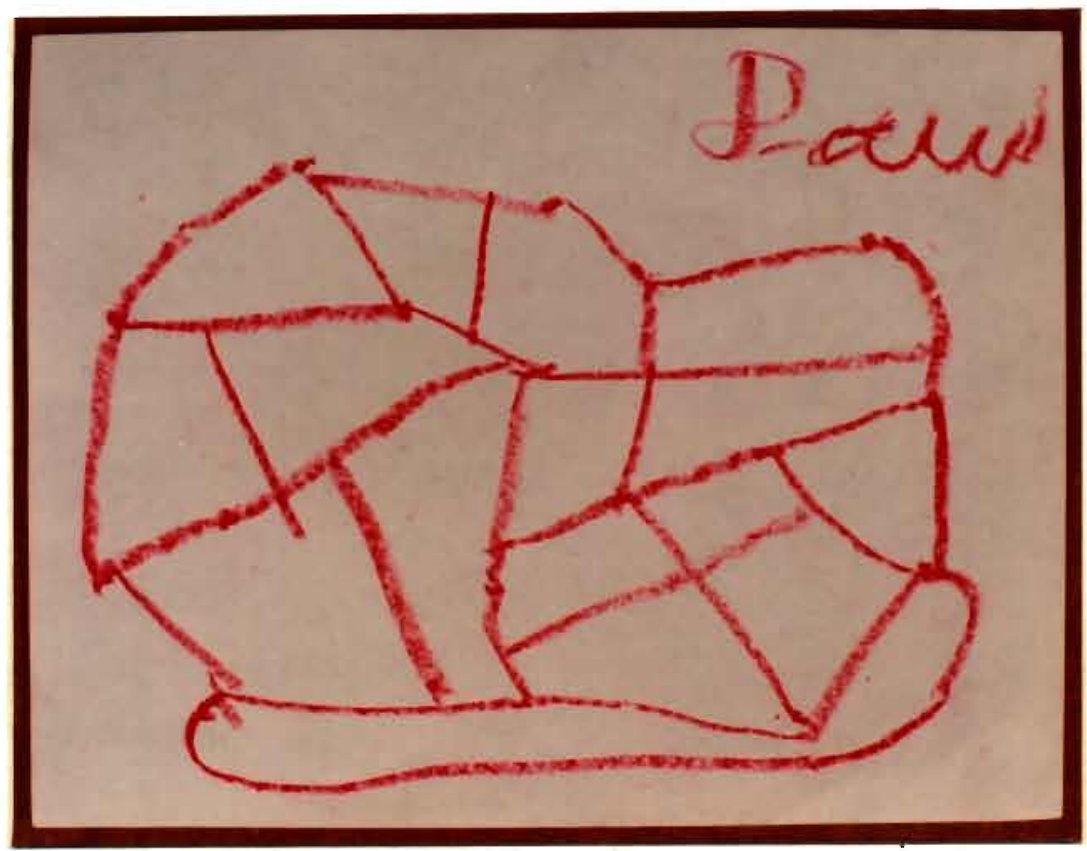

Figure 23. David, oil crayon on paper, $21.6 \mathrm{~cm} \mathrm{x} 28.0 \mathrm{~cm}$. 


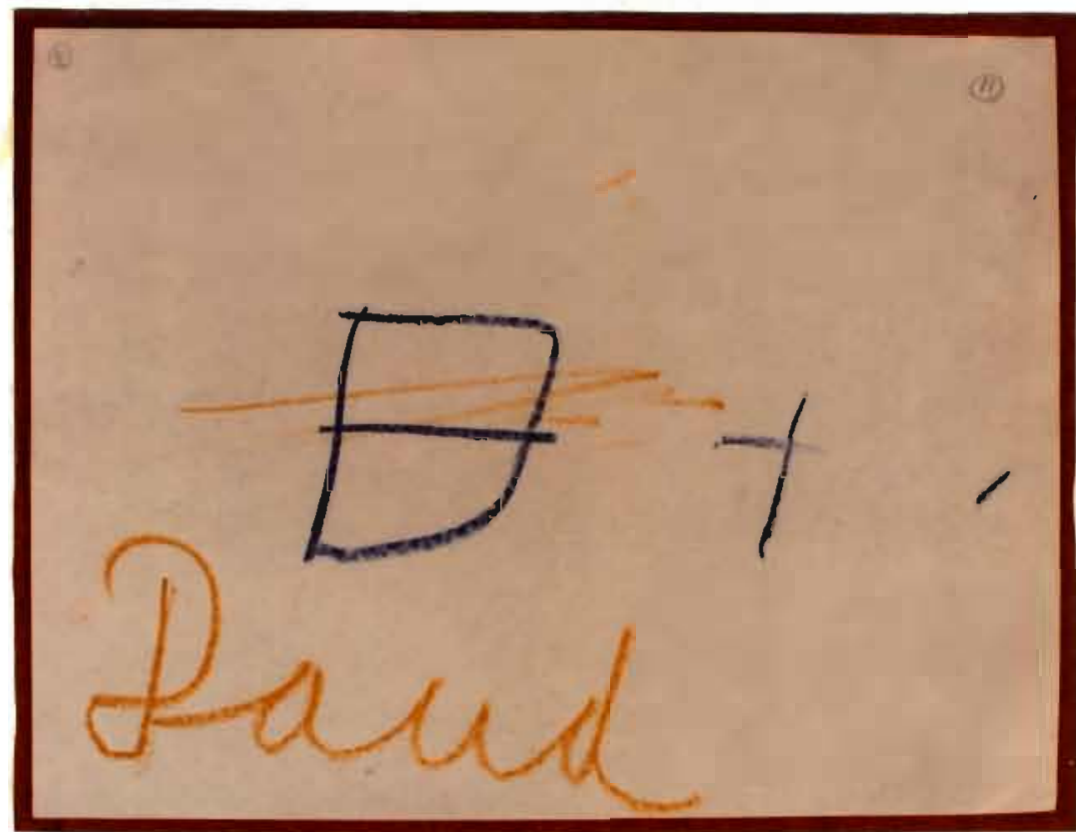

$\frac{\text { Figure 24 }}{21.6 \mathrm{~cm} \mathrm{x}} 28.0 \mathrm{~cm}$.

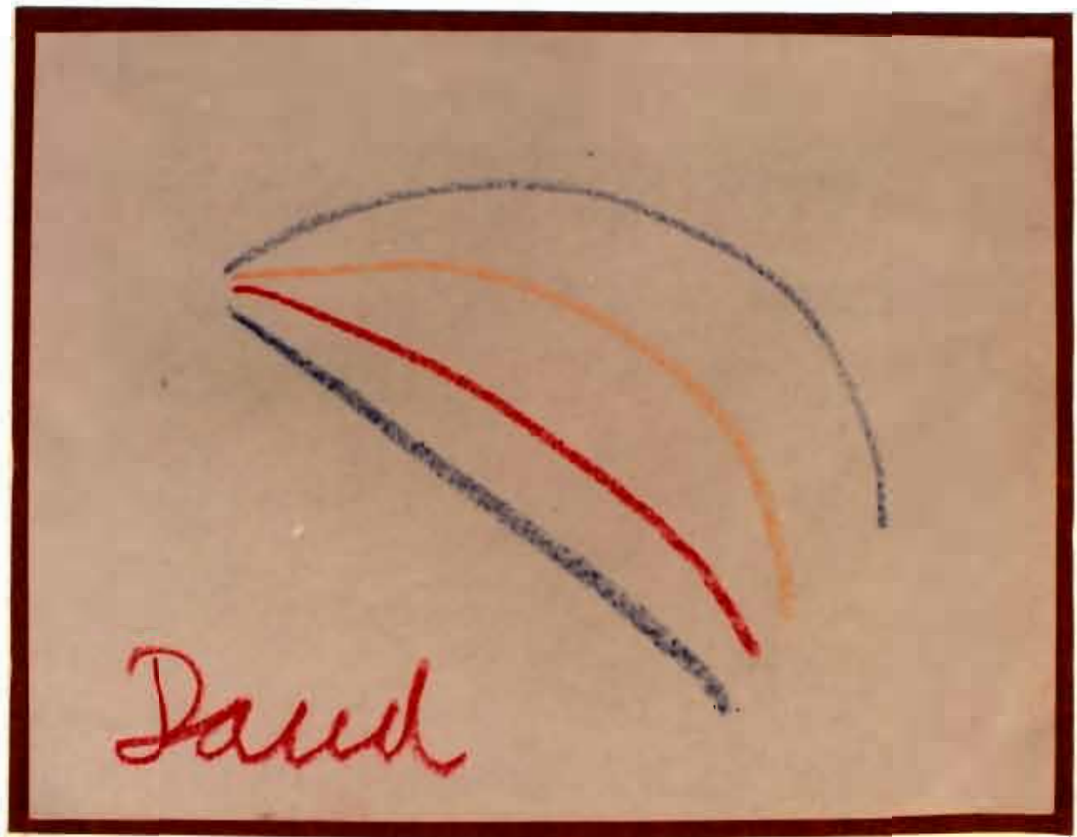

Figure 25. David, oil crayon on paper, $21.6 \mathrm{~cm} \mathrm{x} 28.0 \mathrm{~cm}$. 


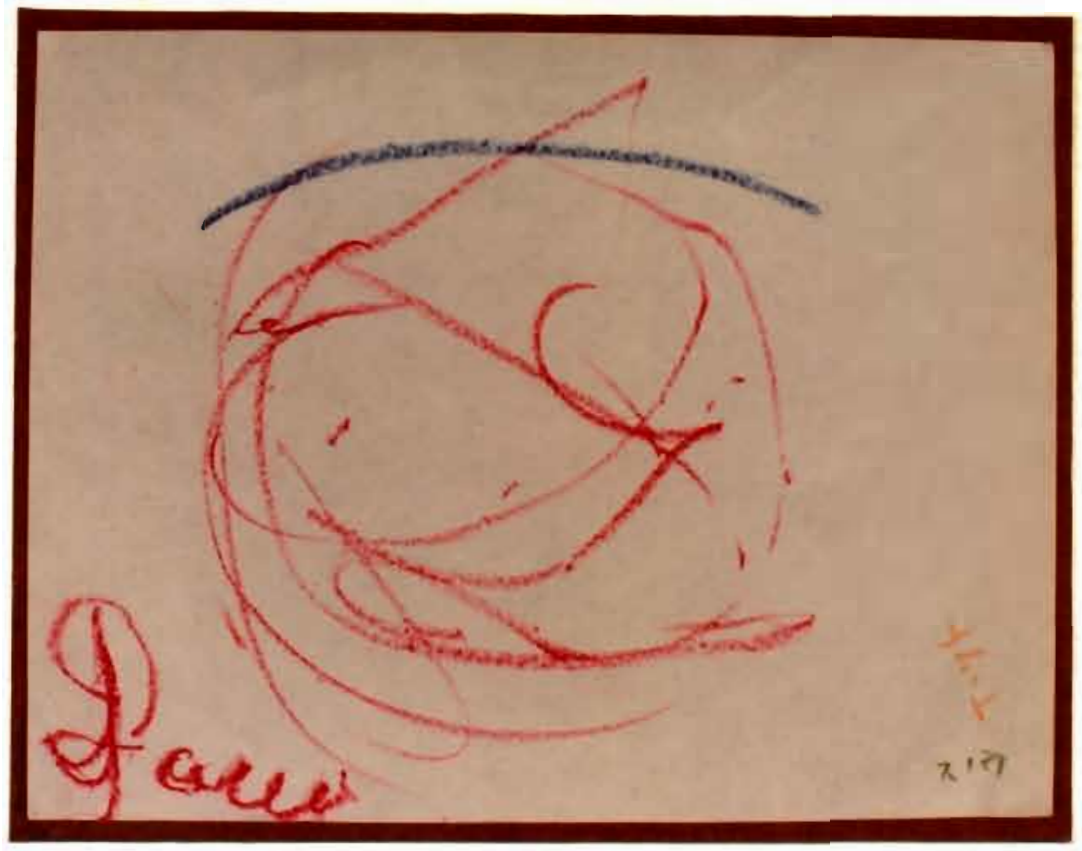

Figure 26. David, oil crayon on paper, $21.6 \mathrm{~cm} \mathrm{x} 28.0 \mathrm{~cm}$.

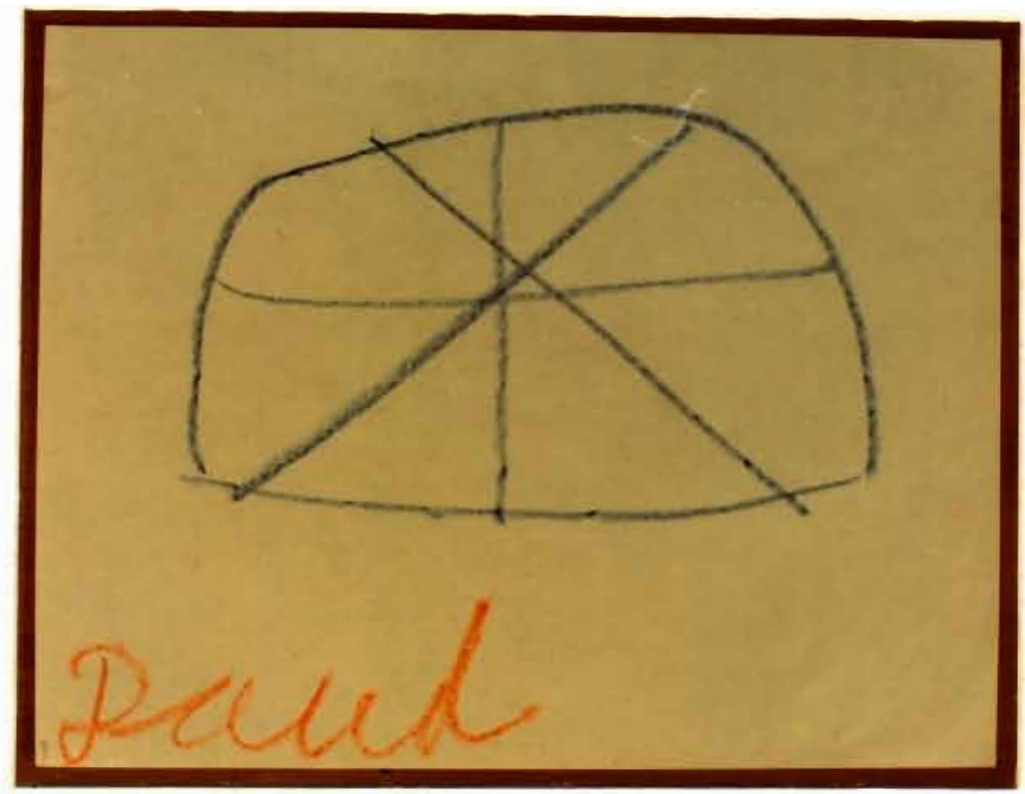

Figure 27. David, oil crayon on paper, $21.6 \mathrm{~cm}$ x $28.0 \mathrm{~cm}$. 


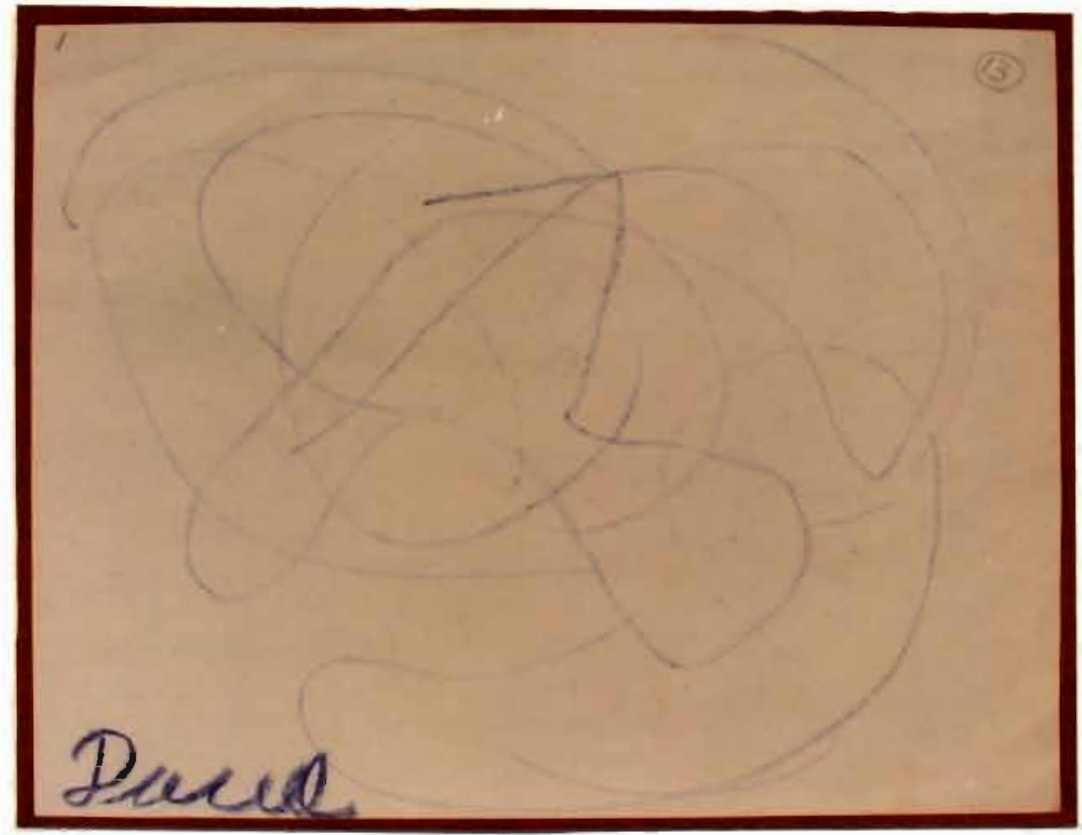

$\frac{\text { Figure 28 }}{21.6 \mathrm{~cm} \times} \cdot 28.0 \mathrm{~cm}$. Oil crayon on paper,

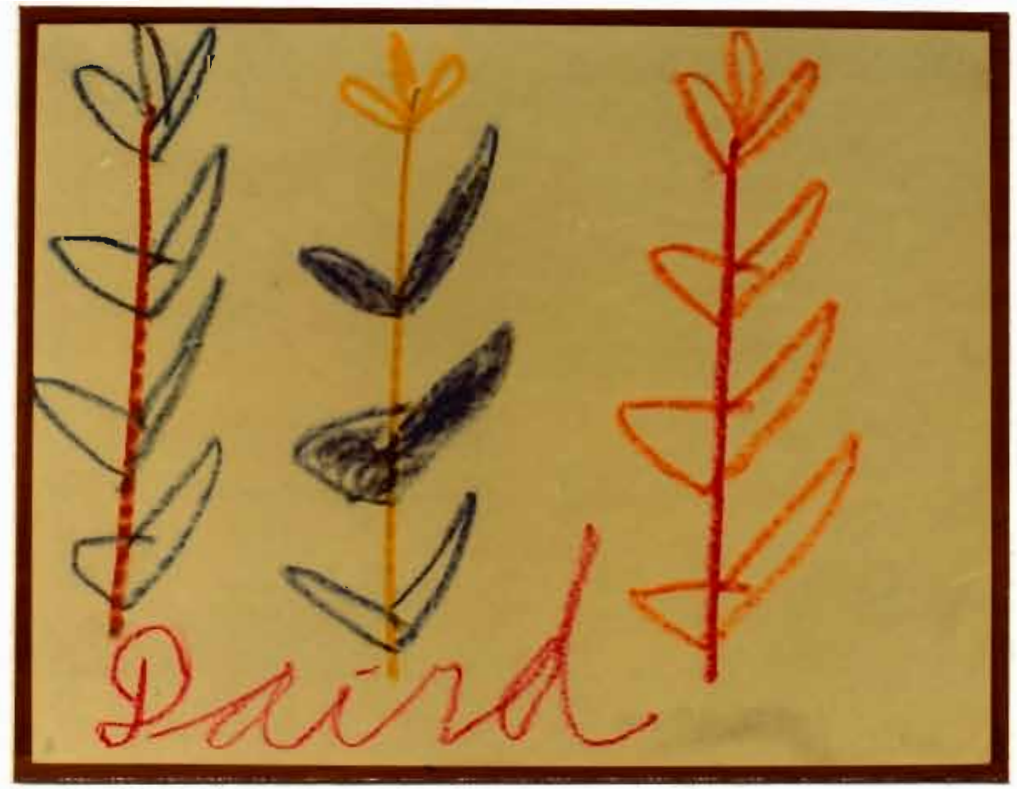

Figure 29. David, oil crayon on paper, $21.6 \mathrm{~cm} \times 28.0 \mathrm{~cm}$. 


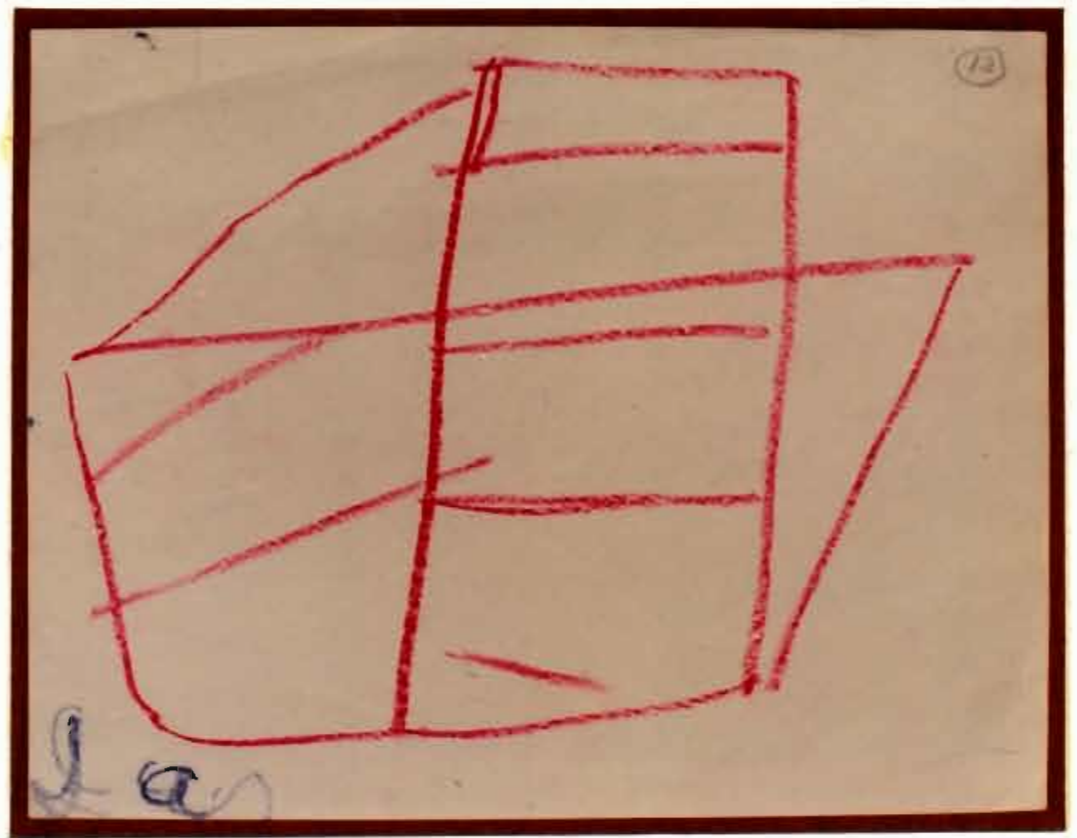

Figure 30. David, oil crayon on paper, $21.6 \mathrm{~cm} \mathrm{x} 28.0 \mathrm{~cm}$.

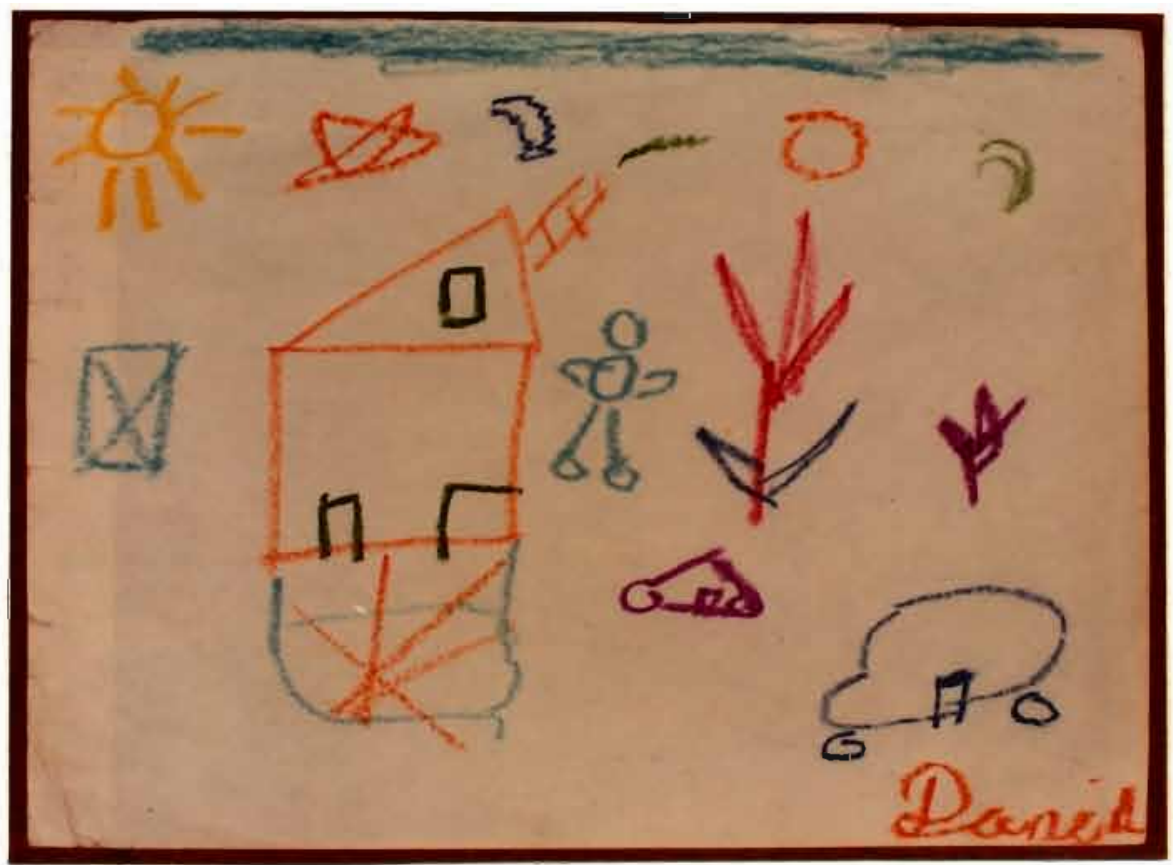

Figure 31. David, oil crayon on paper, $22.8 \mathrm{~cm} \mathrm{x} 30.7 \mathrm{~cm}$. 


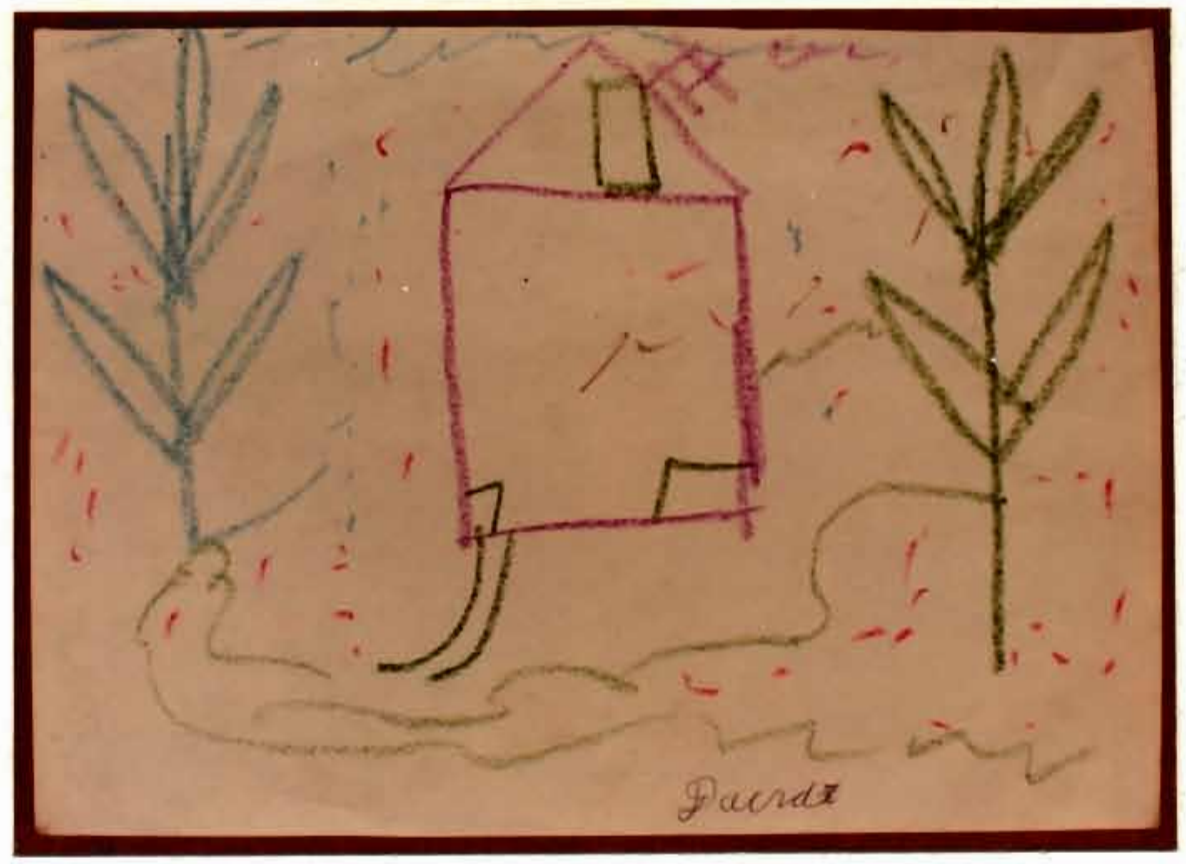

Figure 32. David, oil crayon on paper, $22.3 \mathrm{~cm} \times 30.8 \mathrm{~cm}$.

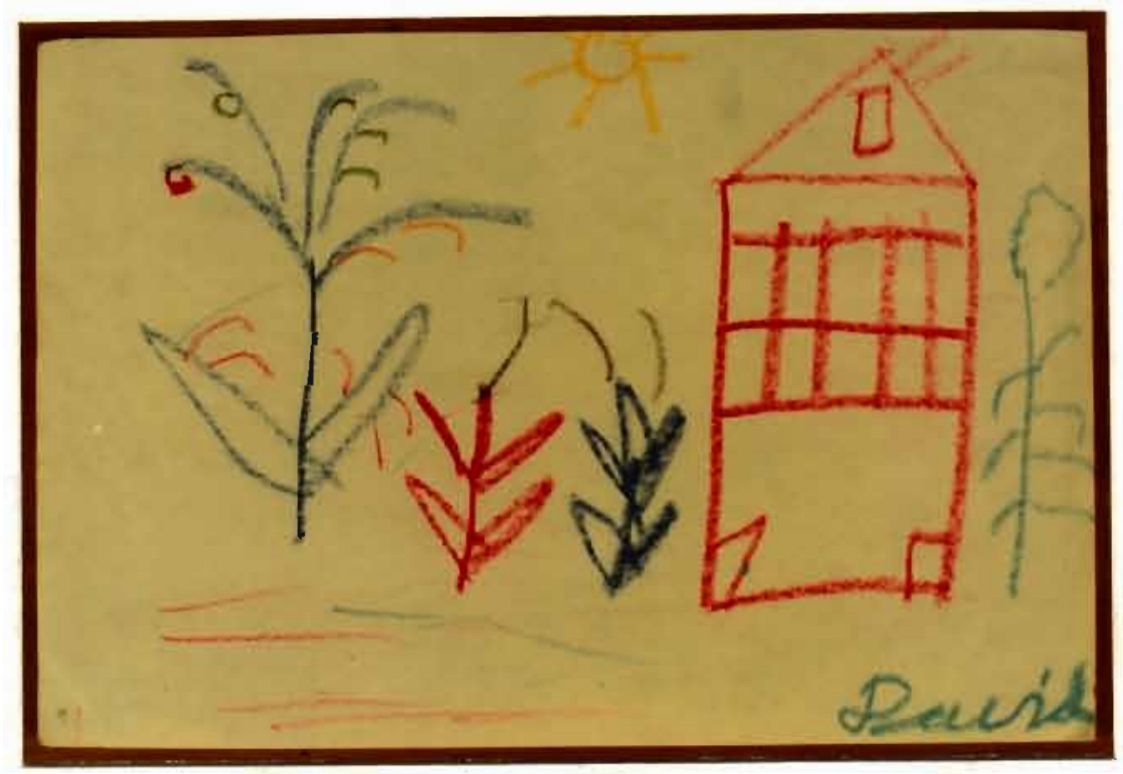

Figure 33. David, oil crayon on paper, $21.0 \mathrm{~cm} \mathrm{x} 30.8 \mathrm{~cm}$. 


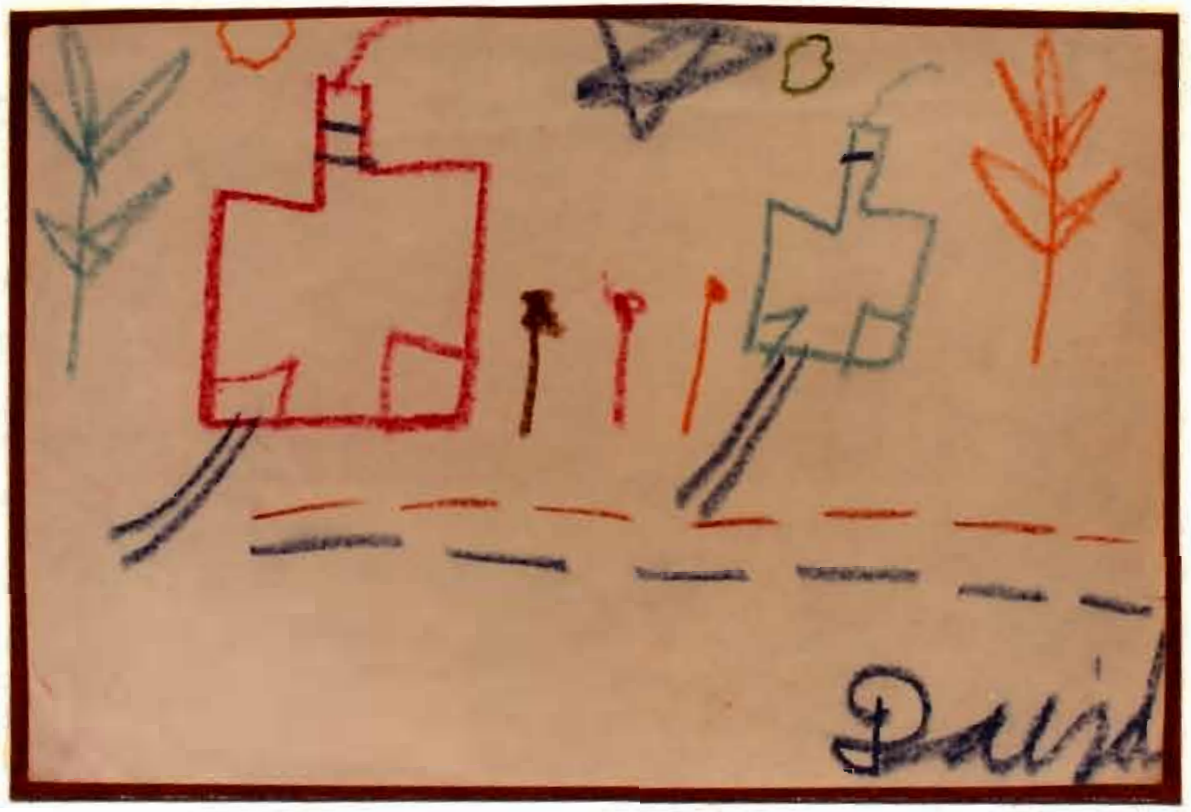

Figure 34. David, oil crayon on paper, $20.8 \mathrm{~cm} \mathrm{x} 30.7 \mathrm{~cm}$.

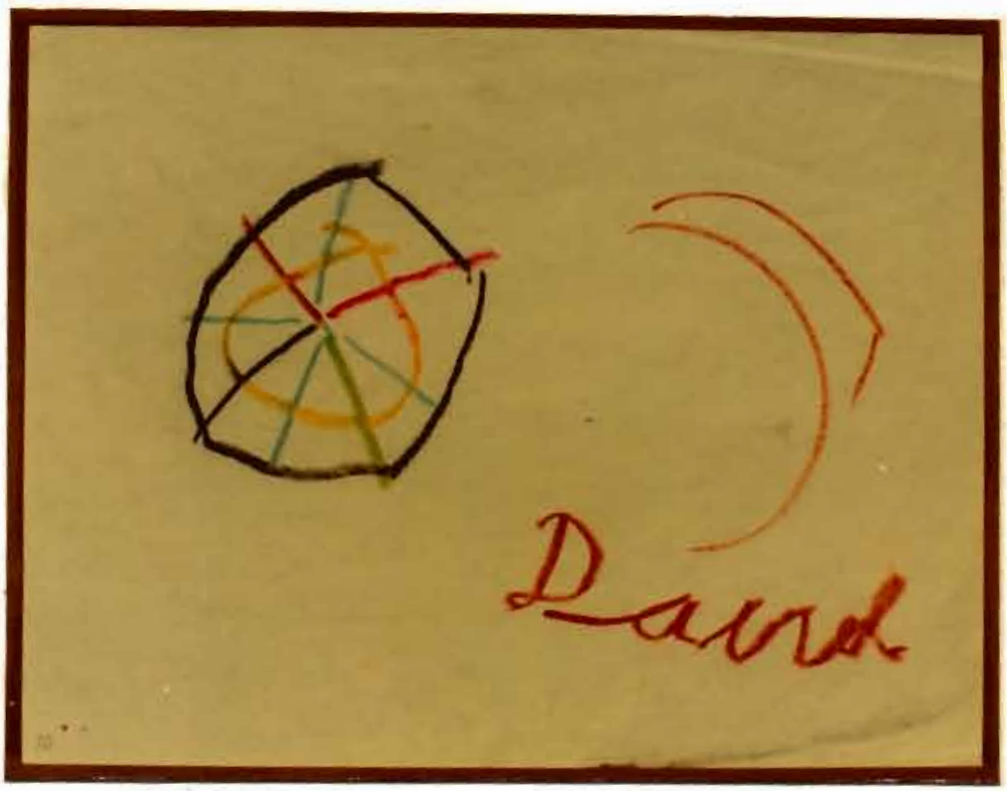

Figure 35. David, oil crayon on paper, $21.6 \mathrm{~cm} \times 27.9 \mathrm{~cm}$. 


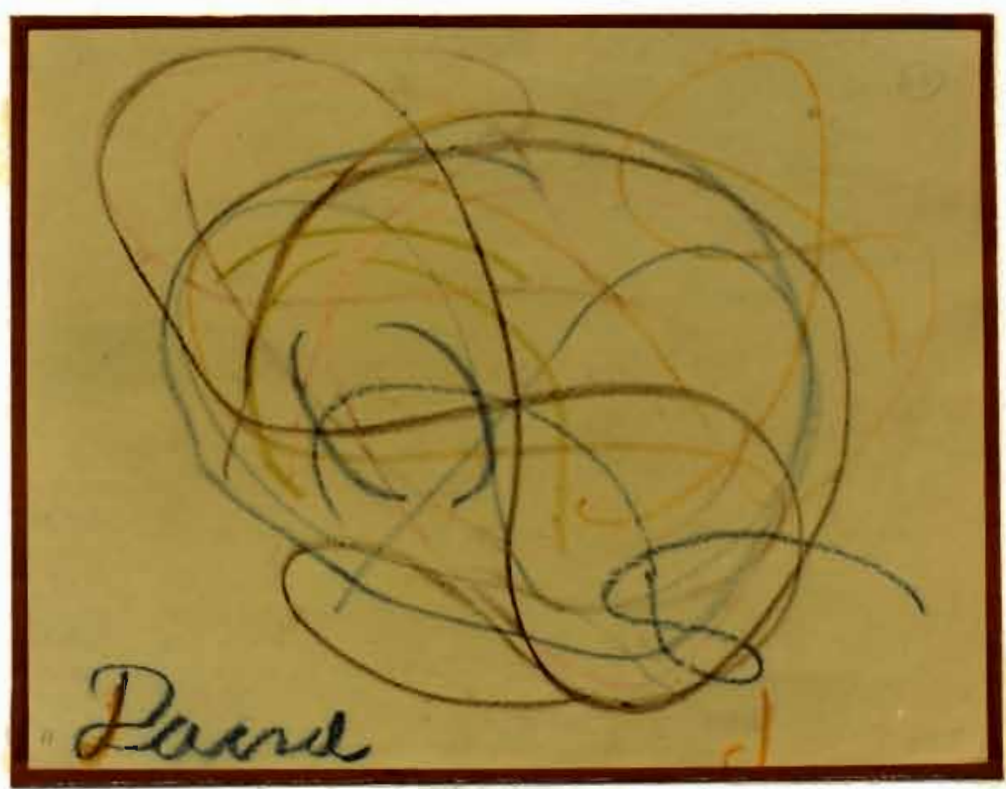

Figure 36. David, oil crayon on paper, $21.6 \mathrm{~cm} \times 27.9 \mathrm{~cm}$.

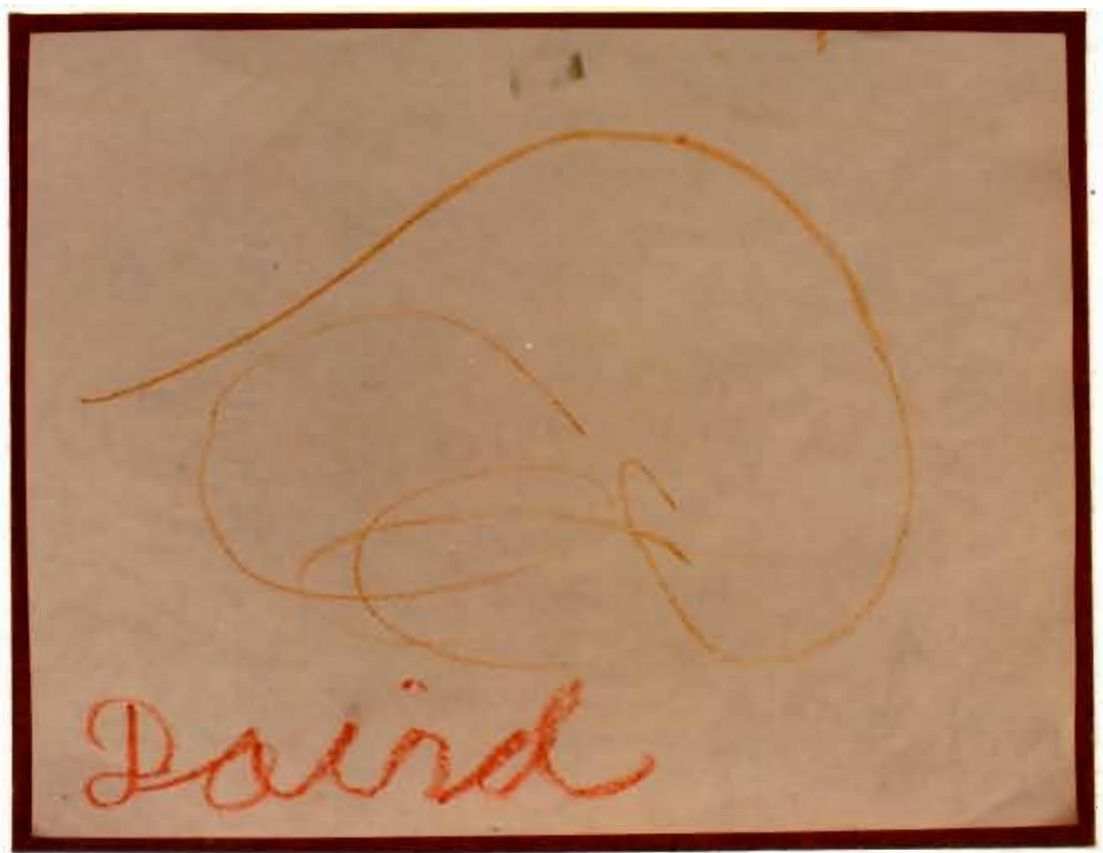

Figure 37. David, oil crayon on paper, $21.6 \mathrm{~cm} \times 27.9 \mathrm{~cm}$. 


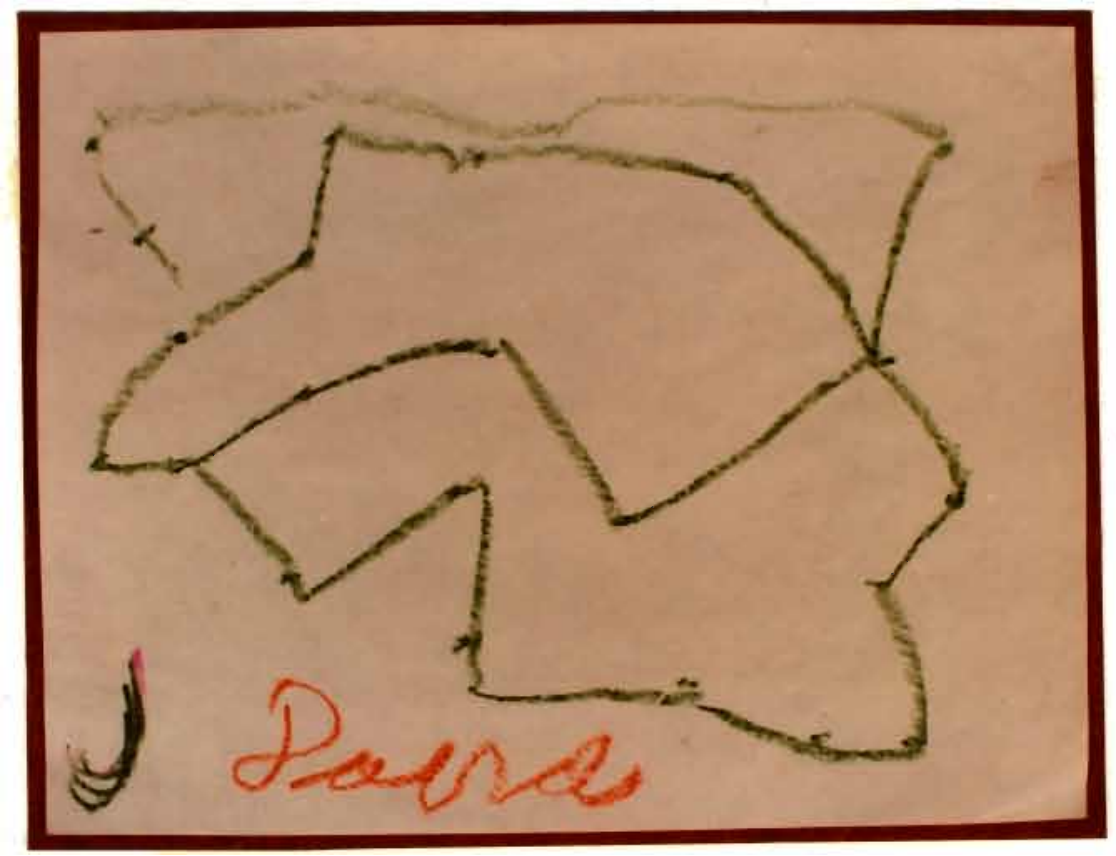

Figure 38. David, oil crayon on paper, $21.6 \mathrm{~cm} \times 27.9 \mathrm{~cm}$.

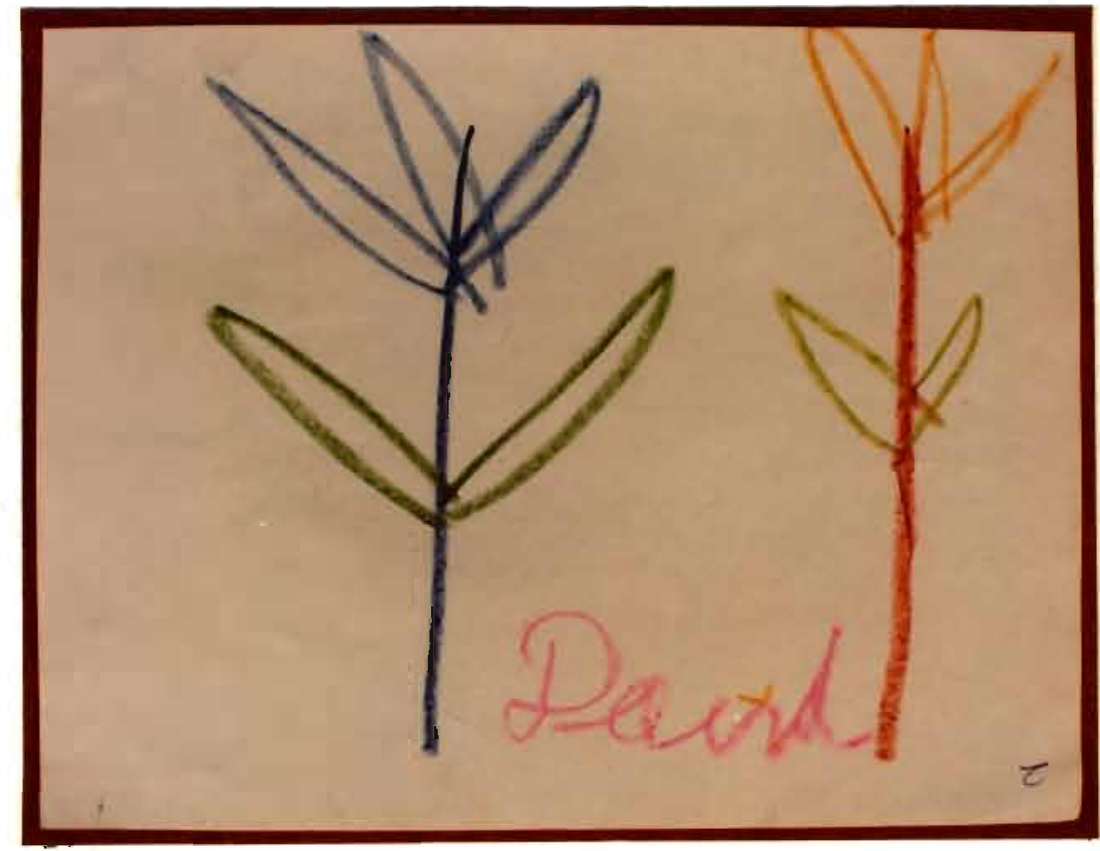
Figure 39
$21.6 \mathrm{~cm} x$
$27.9 \mathrm{~cm}$. 


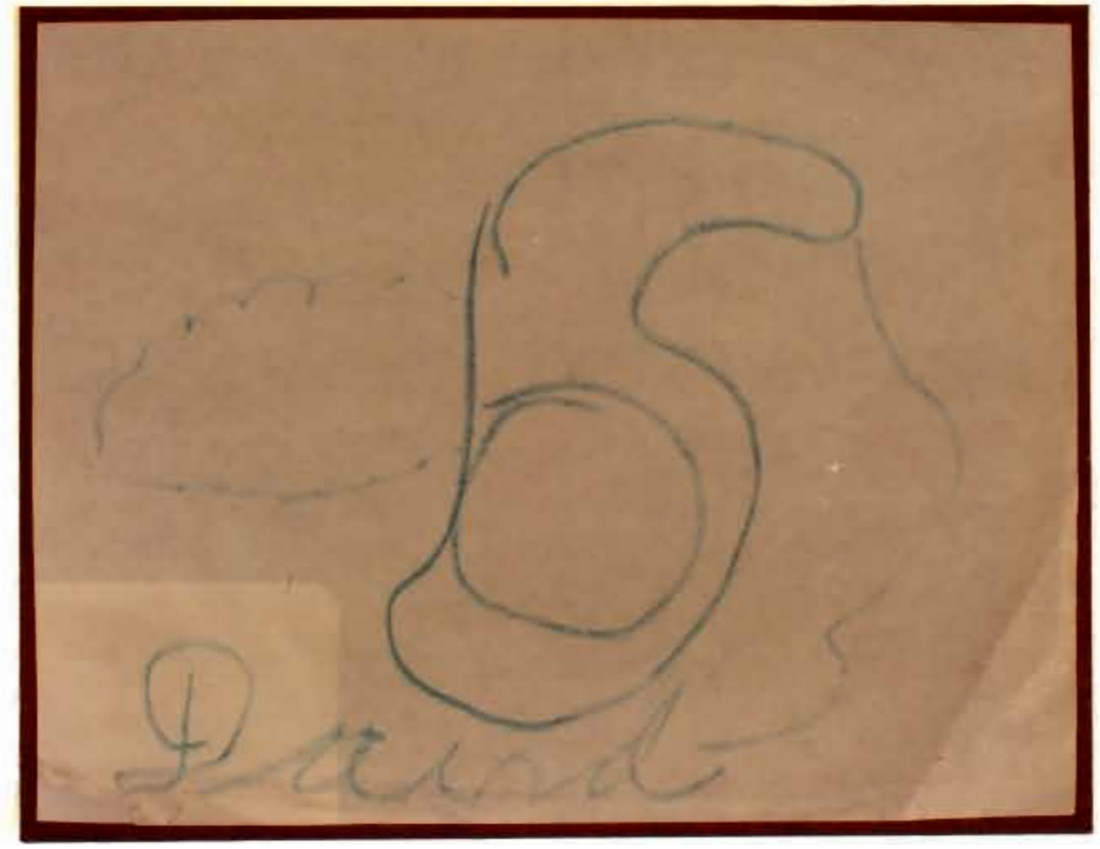

Figure 40. David, oil crayon on paper, $21.6 \mathrm{~cm} \mathrm{x} 27.9 \mathrm{~cm}$.

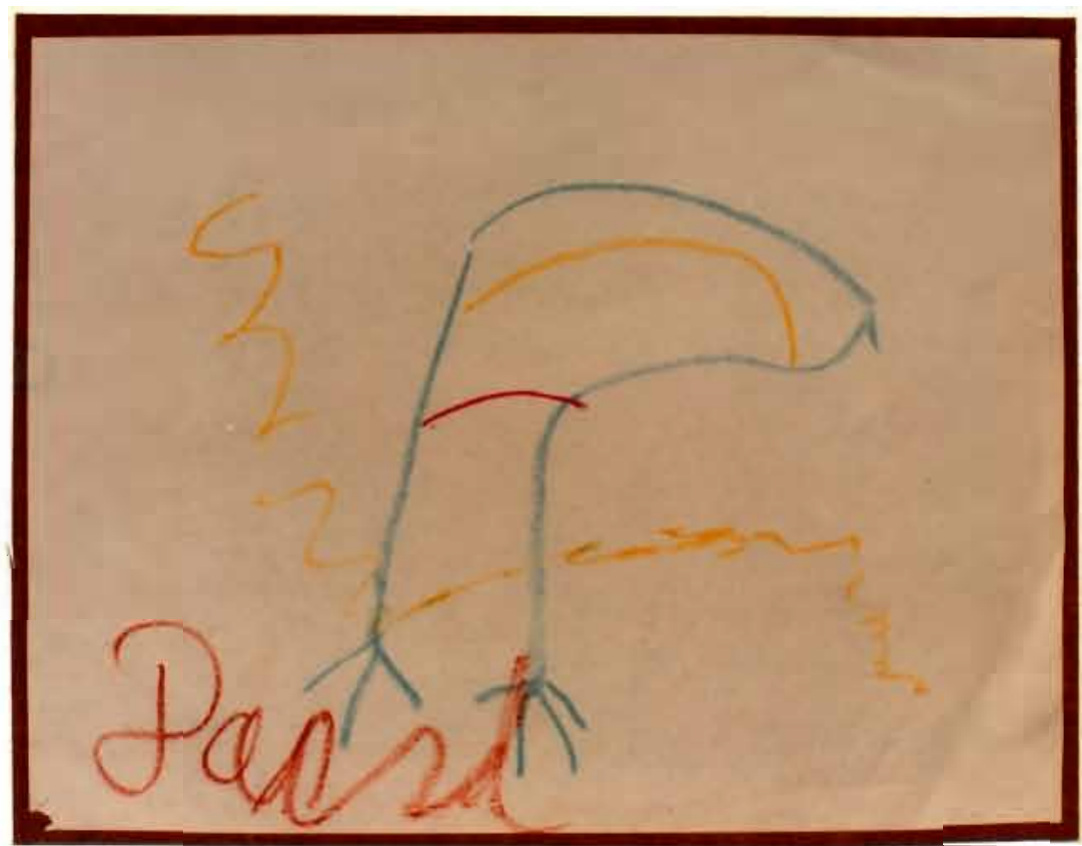

Figure 41. David, oil crayon on paper, $21.6 \mathrm{~cm} \mathrm{x} 27.9 \mathrm{~cm}$. 


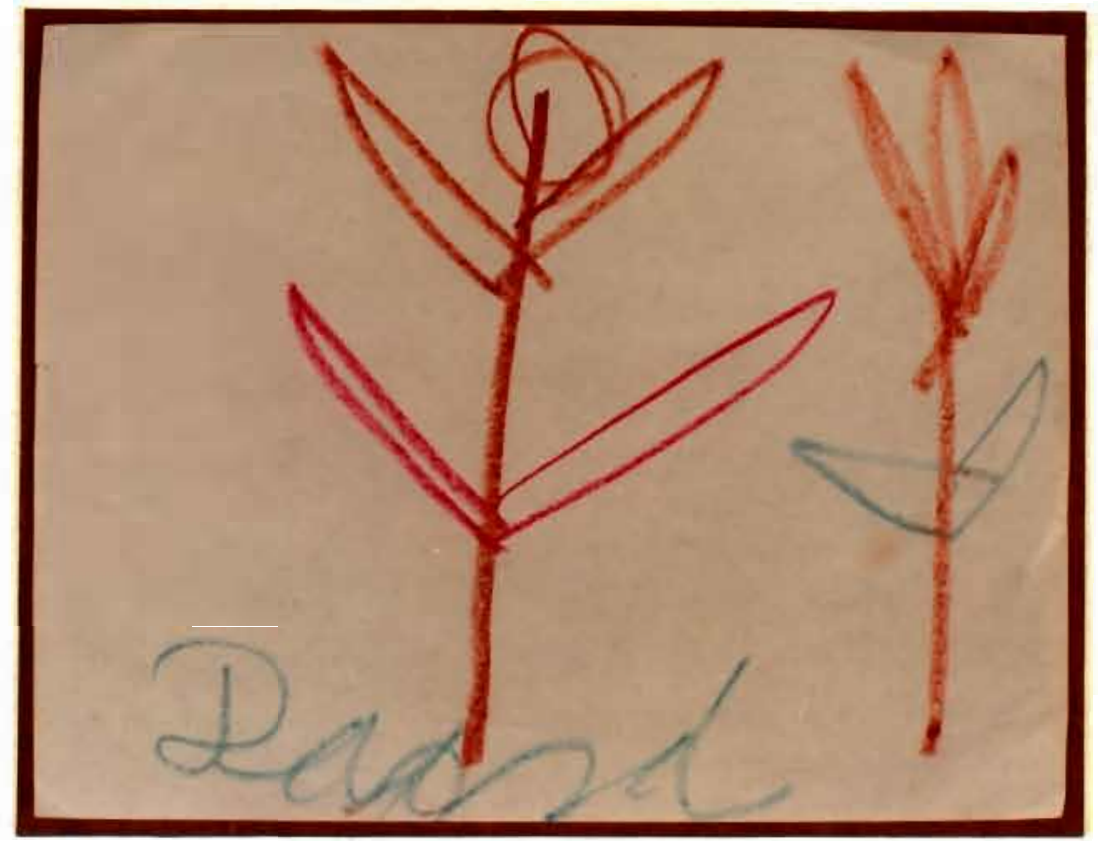

Figure 42. David, oil crayon on paper, $21.6 \mathrm{~cm} \times 27.9 \mathrm{~cm}$.

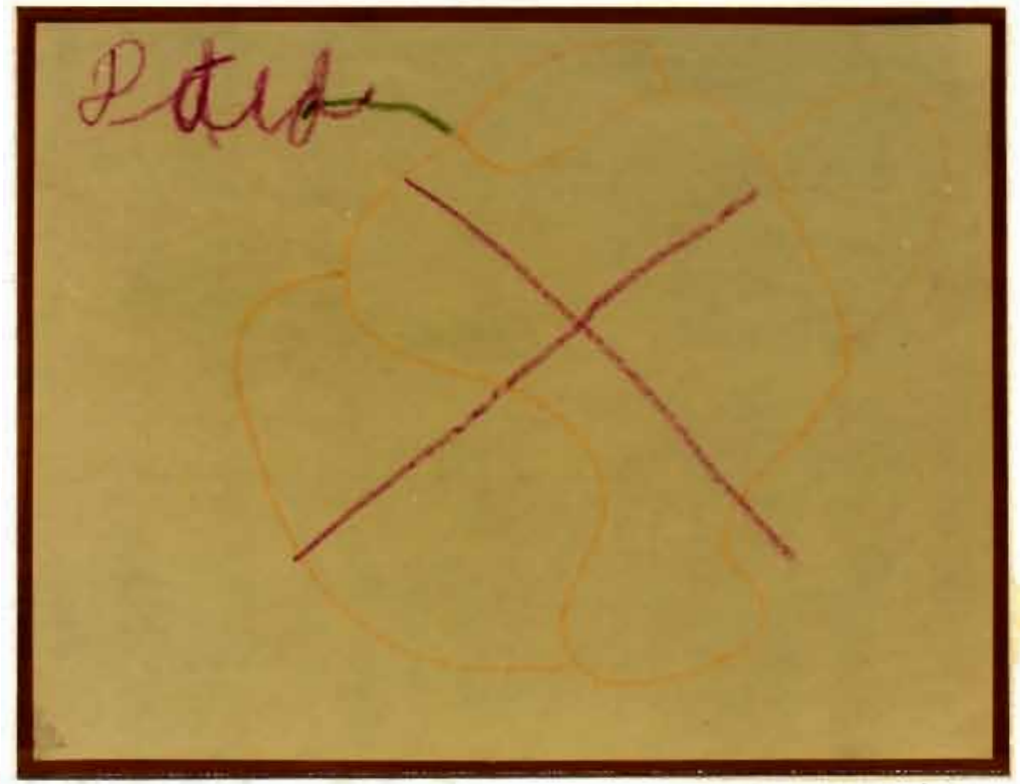

Figure 43. David, oil crayon on paper, $21.6 \mathrm{~cm} \times 27.9 \mathrm{~cm}$. 


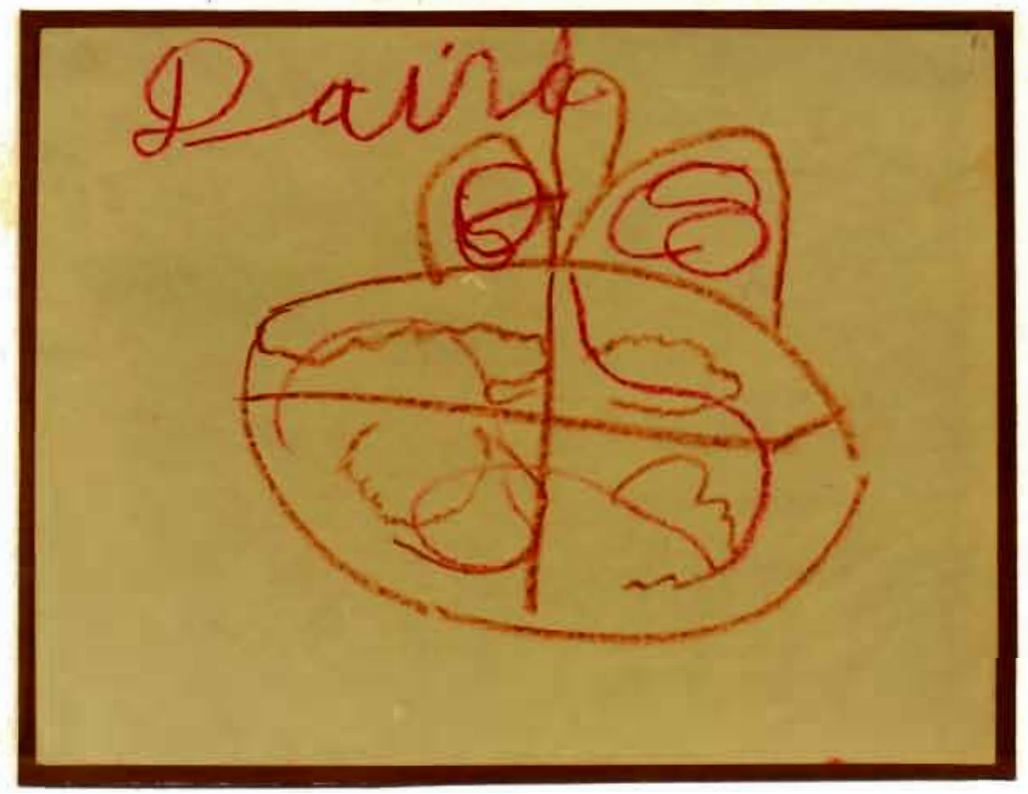

Figure 44
$21.6 \mathrm{~cm} \times$
$27.9 \mathrm{~cm}$.

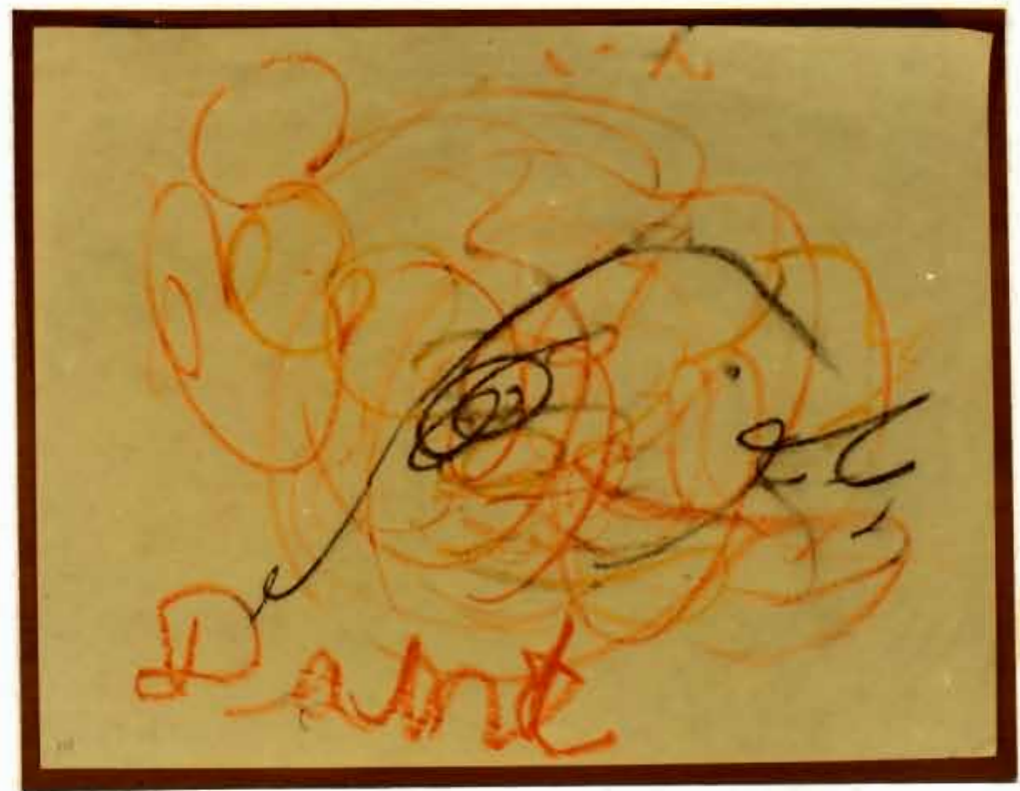

Figure 45. David, oil crayon on paper, $21.6 \mathrm{~cm} \times 27.9 \mathrm{~cm}$. 


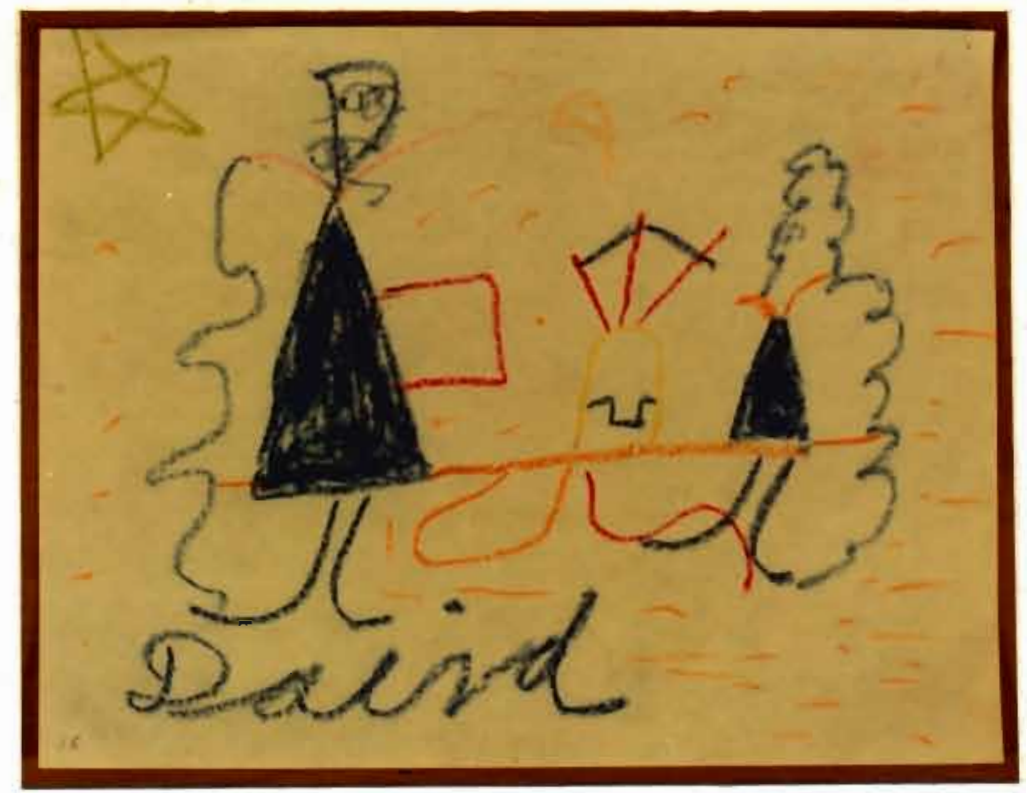

Figure 46. David, oil crayon on paper, $21.6 \mathrm{~cm} \mathrm{x} 27.9 \mathrm{~cm}$.

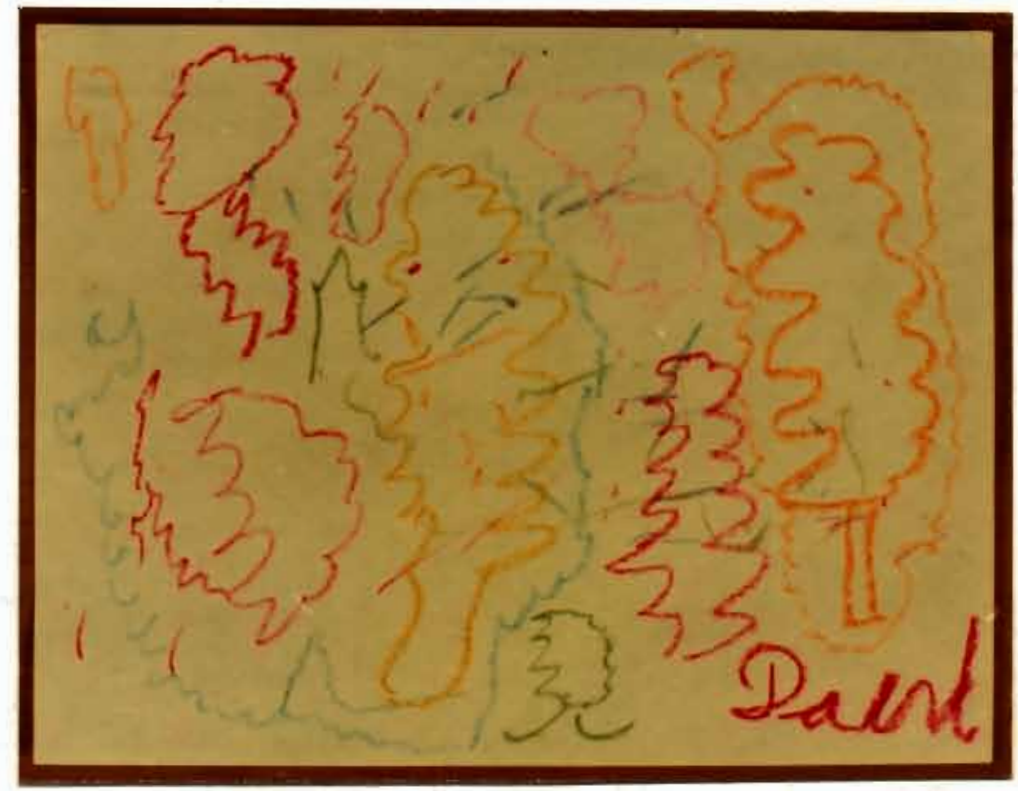

Figure 47. David, oil crayon on paper, 


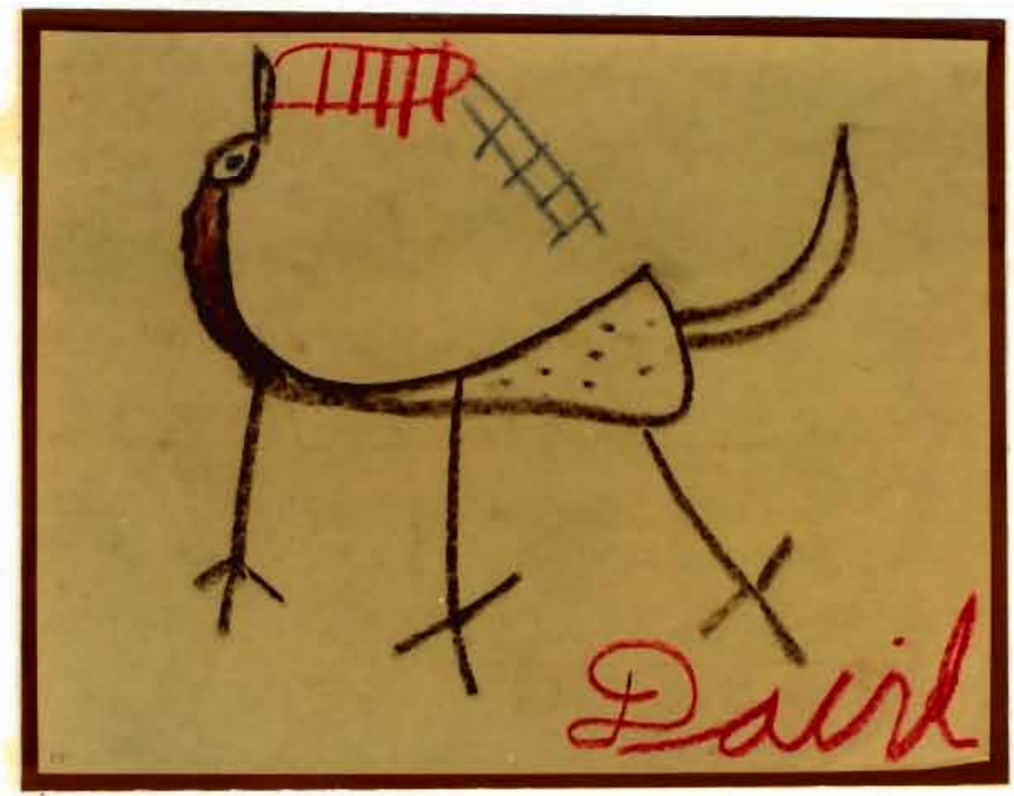

Figure 48. David, oil crayon on paper, $21.6 \mathrm{~cm} \times 27.9 \mathrm{~cm}$.

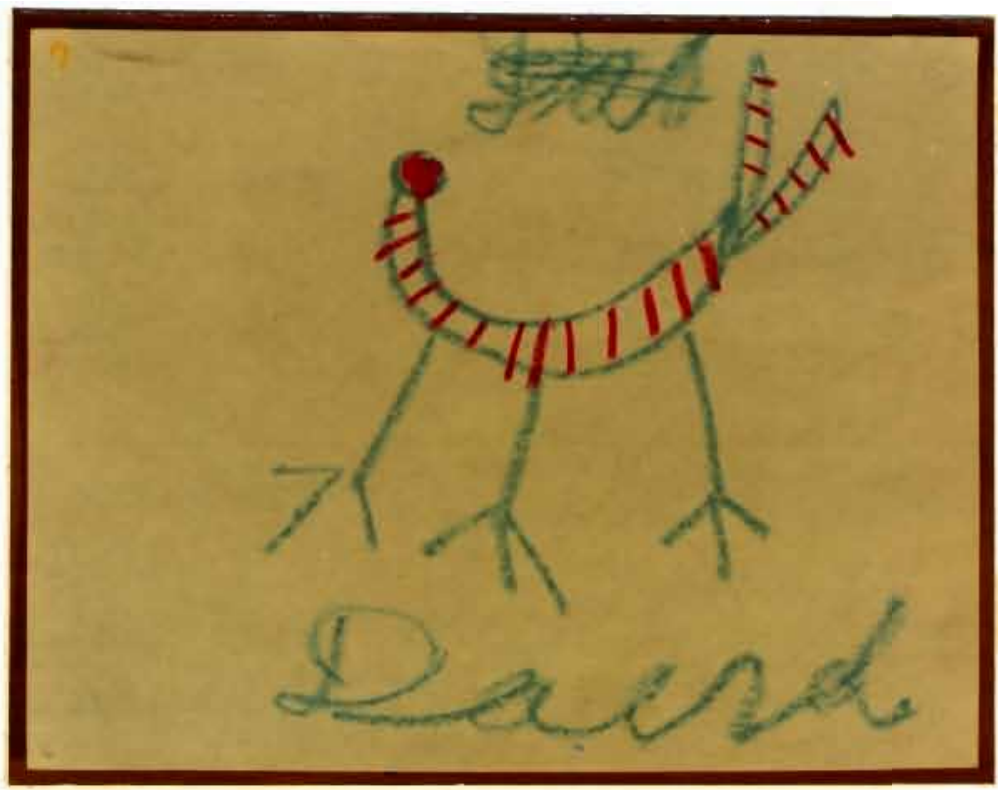

Figure 49. David, oil crayon on paper, $21.6 \mathrm{~cm} \times 27.9 \mathrm{~cm}$. 


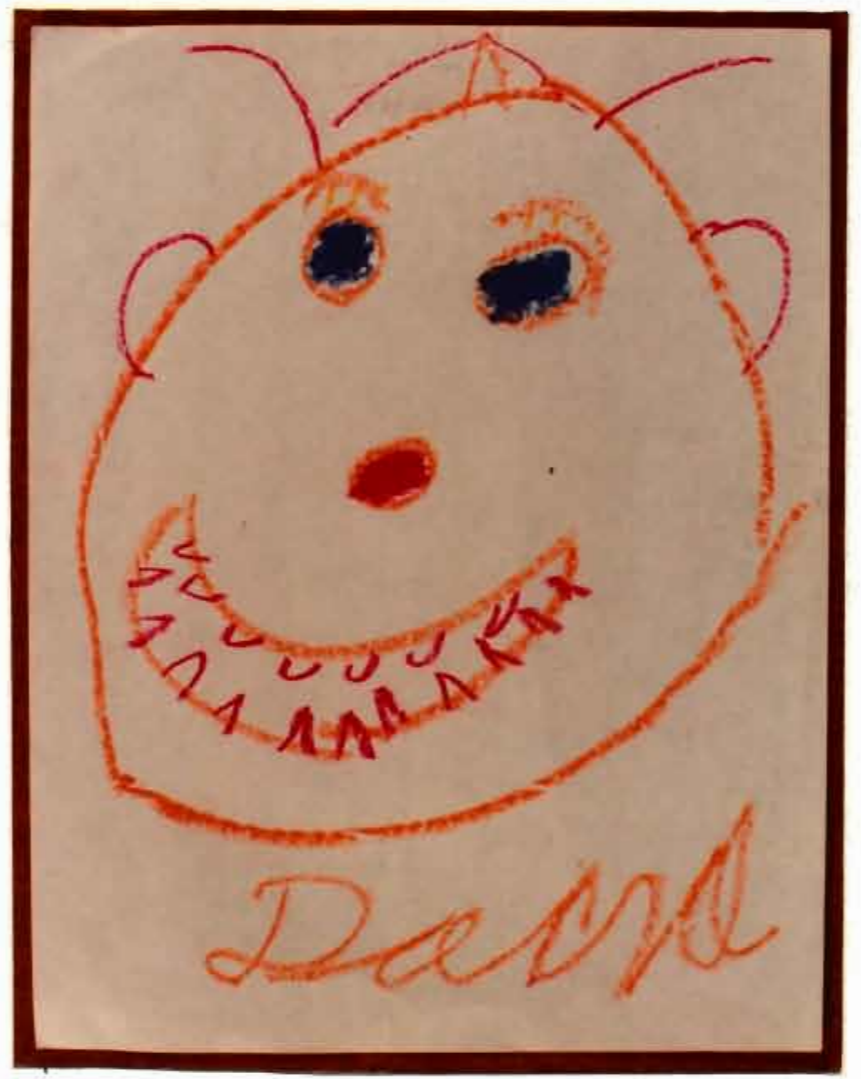

Figure 52. David, oil crayon on paper, $27.9 \mathrm{~cm} \times 21.6 \mathrm{~cm}$. 


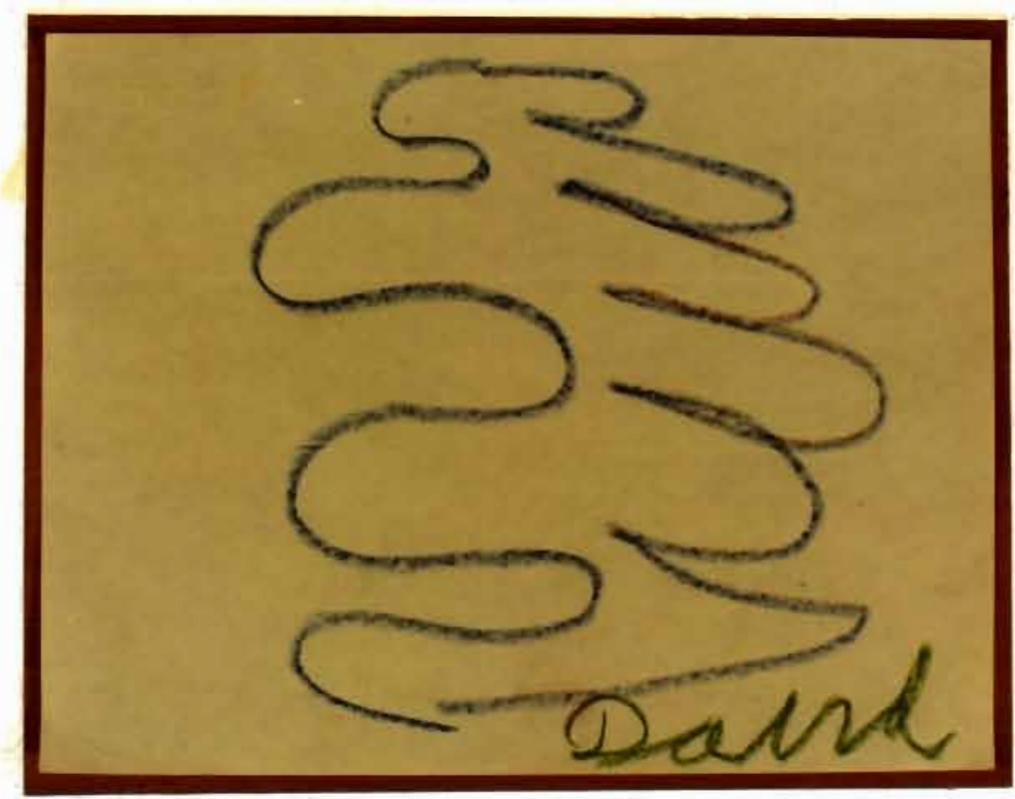

Figure 50. David, oil crayon on paper, $21.6 \mathrm{~cm} \times 27.9 \mathrm{~cm}$.

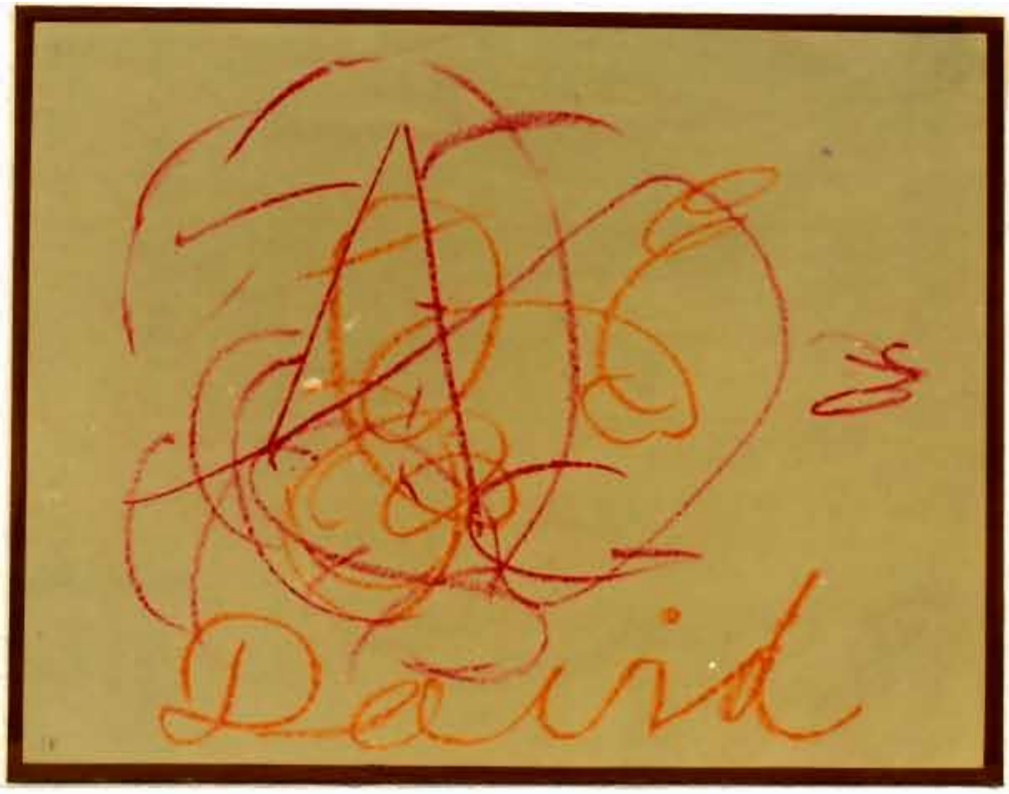

Figure 51. David, oil crayon on paper, $21.6 \mathrm{~cm} \times 27.9 \mathrm{~cm}$. 


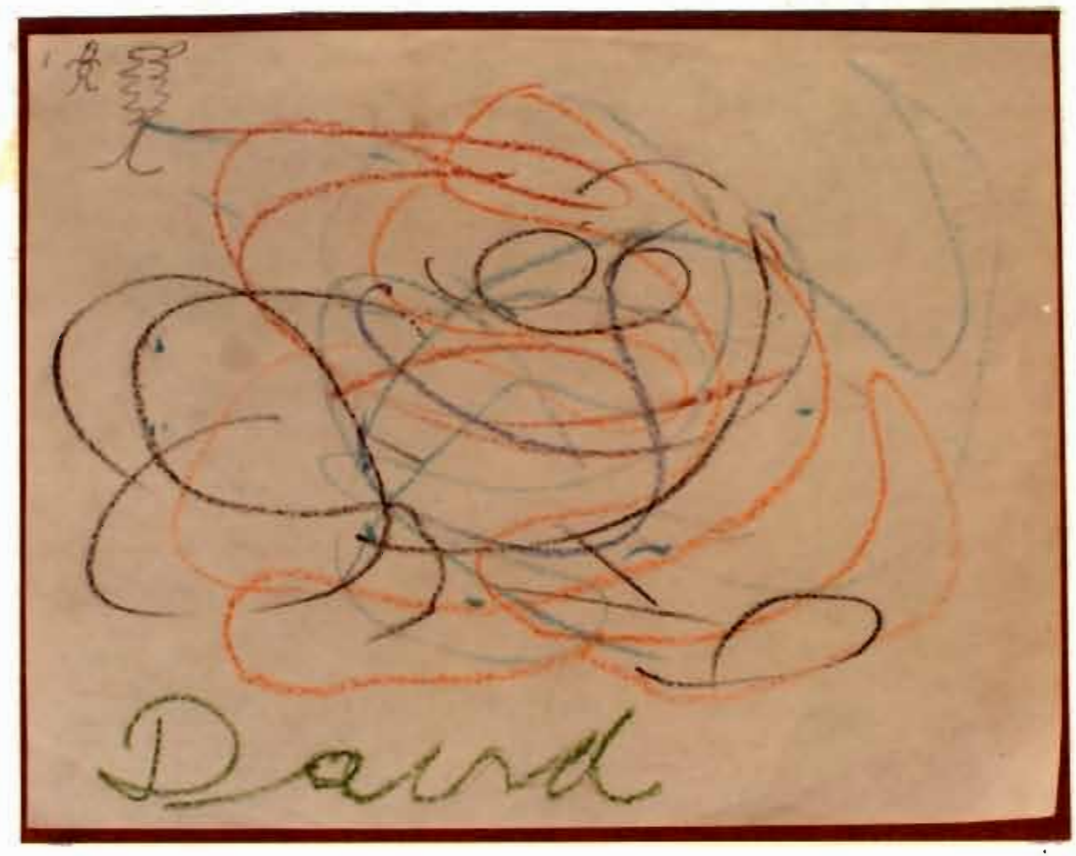

Figure 53. David, oil crayon on paper, $21.6 \mathrm{~cm} \times 27.9 \mathrm{~cm}$.

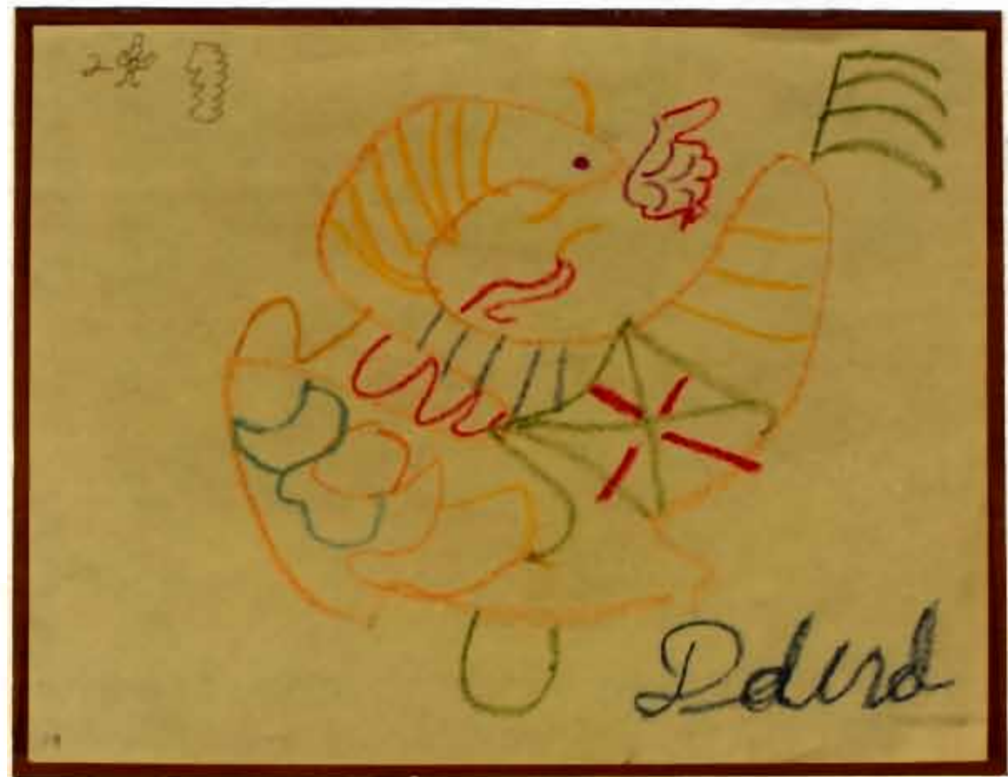

Figure 54. David, oil crayon on paper, $21.6 \mathrm{~cm} \times 27.9 \mathrm{~cm}$. 


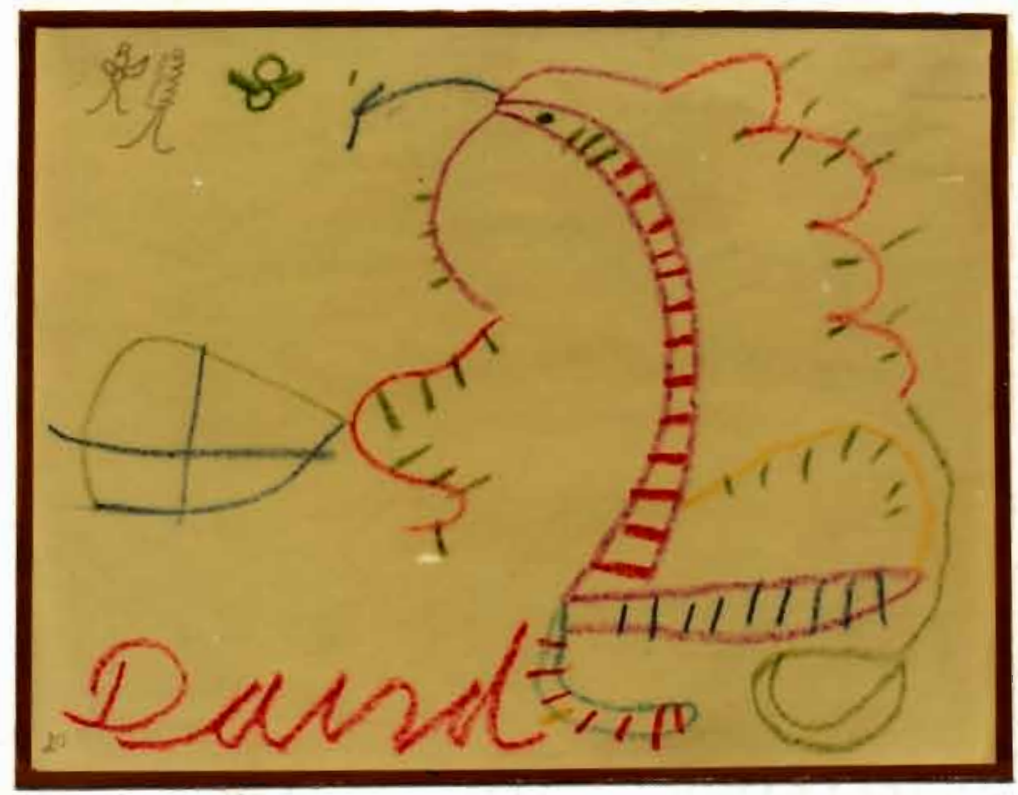

Figure 55. David, oil crayon on paper, $21.6 \mathrm{~cm} \times 27.9 \mathrm{~cm}$.

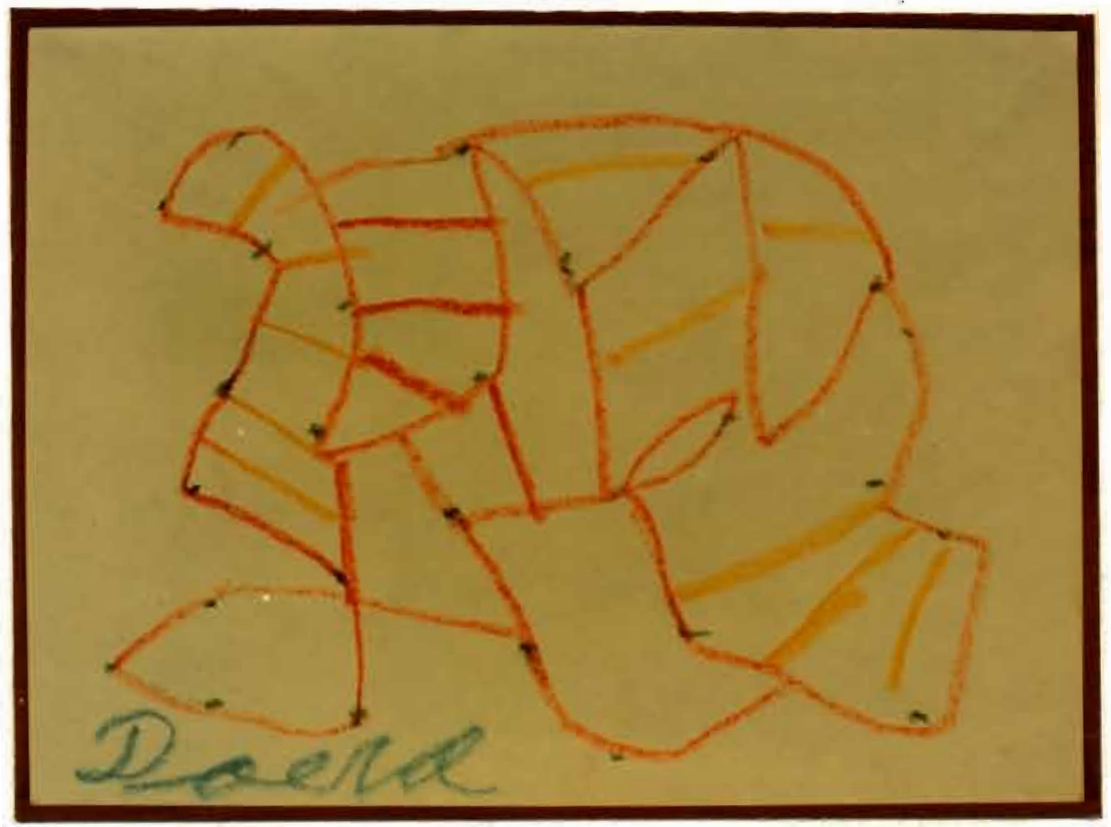

Figure 56. David, oil crayon on paper, $22.8 \mathrm{~cm} \mathrm{x} 30.7 \mathrm{~cm}$. 


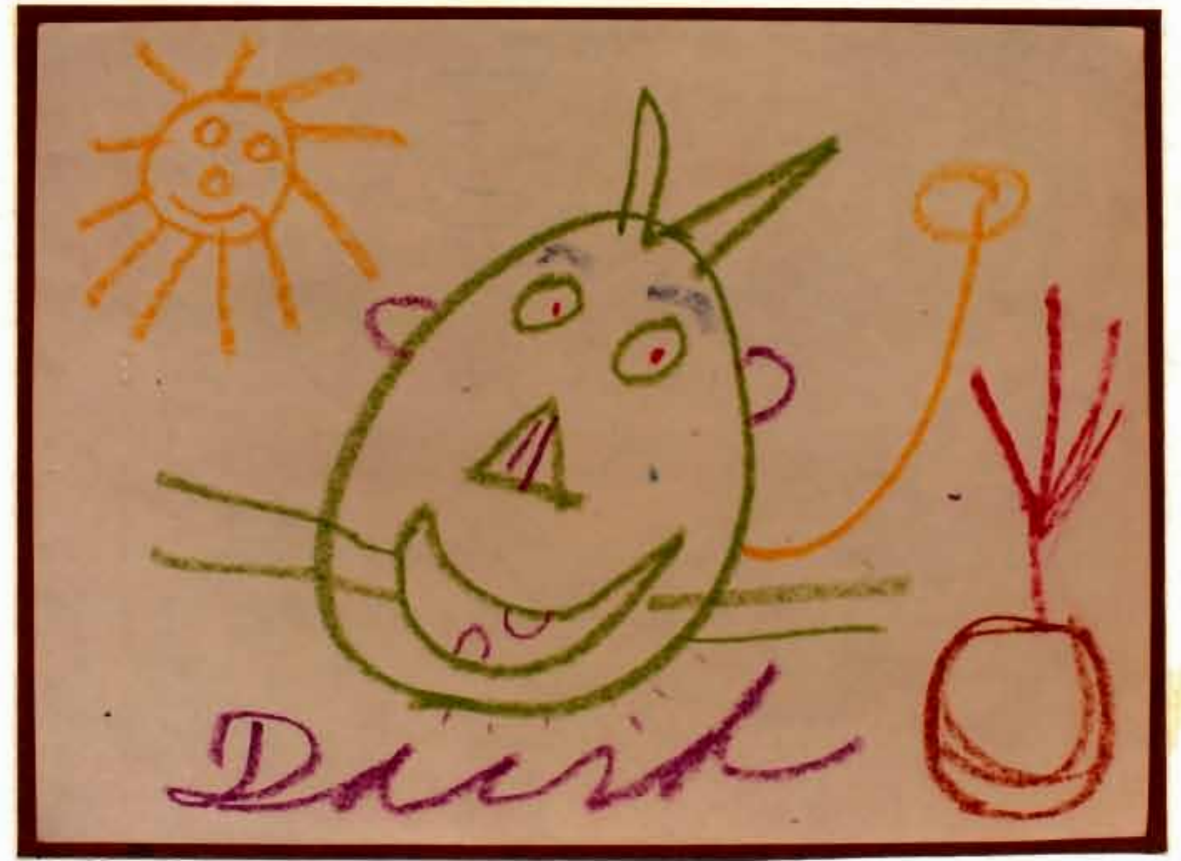

Figure 57. David, oil crayon on paper, $22.8 \mathrm{~cm} \mathrm{x} 30.7 \mathrm{~cm}$.

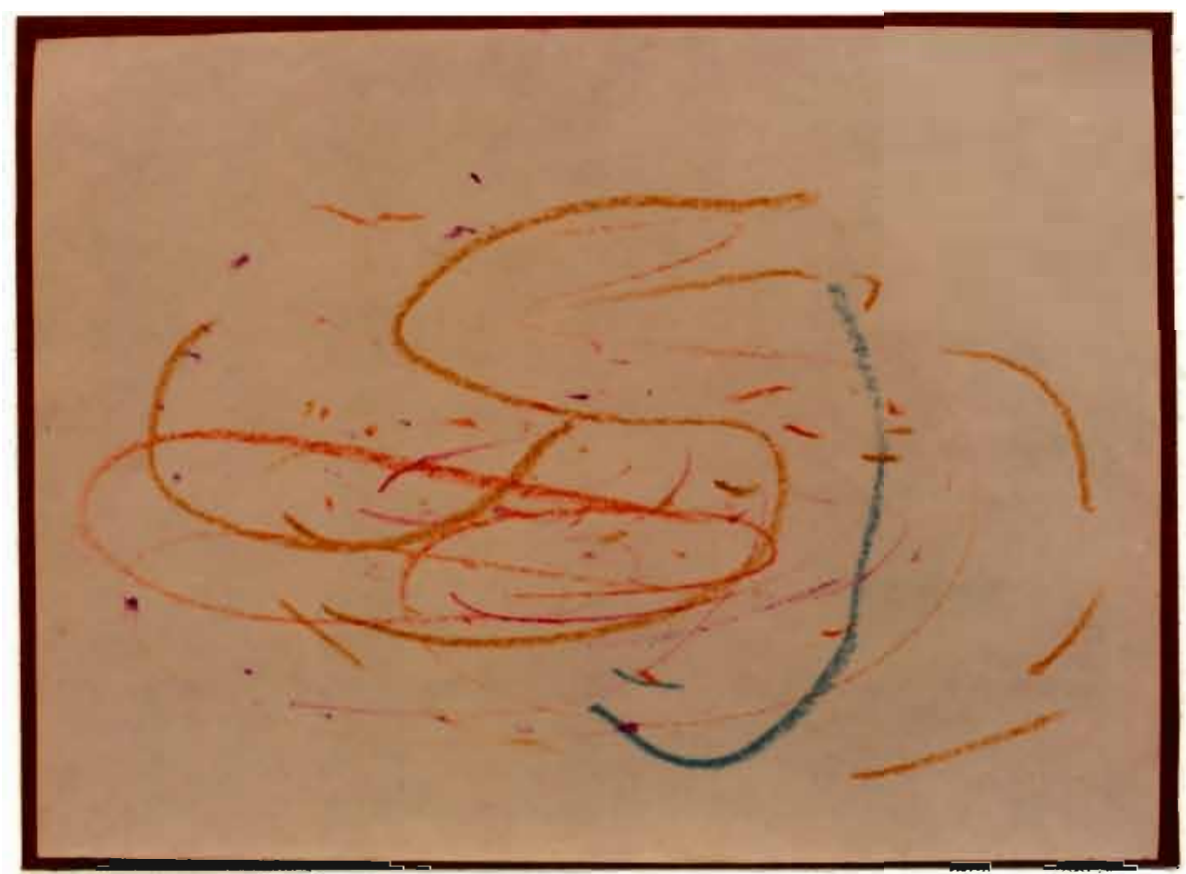

Figure 58. David, oil crayon on paper, $22.8 \mathrm{~cm} \mathrm{x} 30.7 \mathrm{~cm}$. 


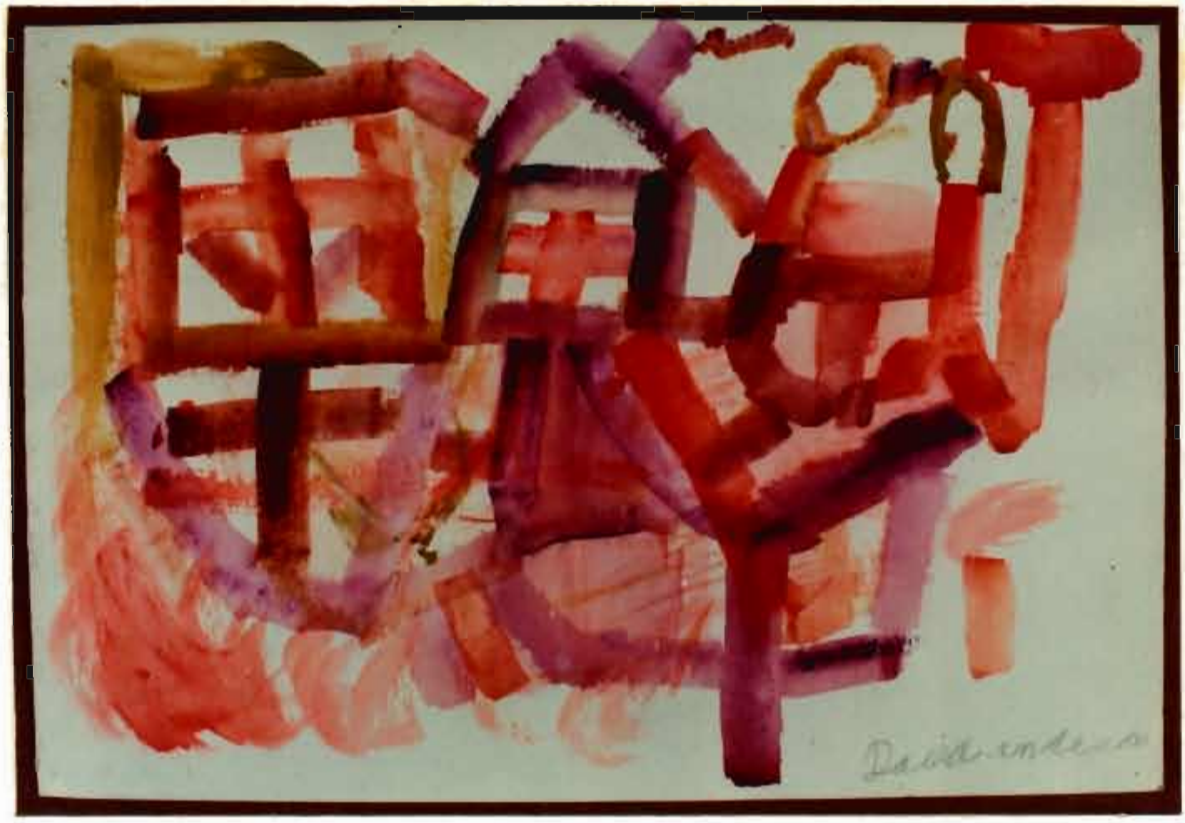

$\frac{\text { Figure 59. }}{\mathrm{x} 56.4 \mathrm{~cm}}$. David, acrylic on paper, $38.6 \mathrm{~cm}$

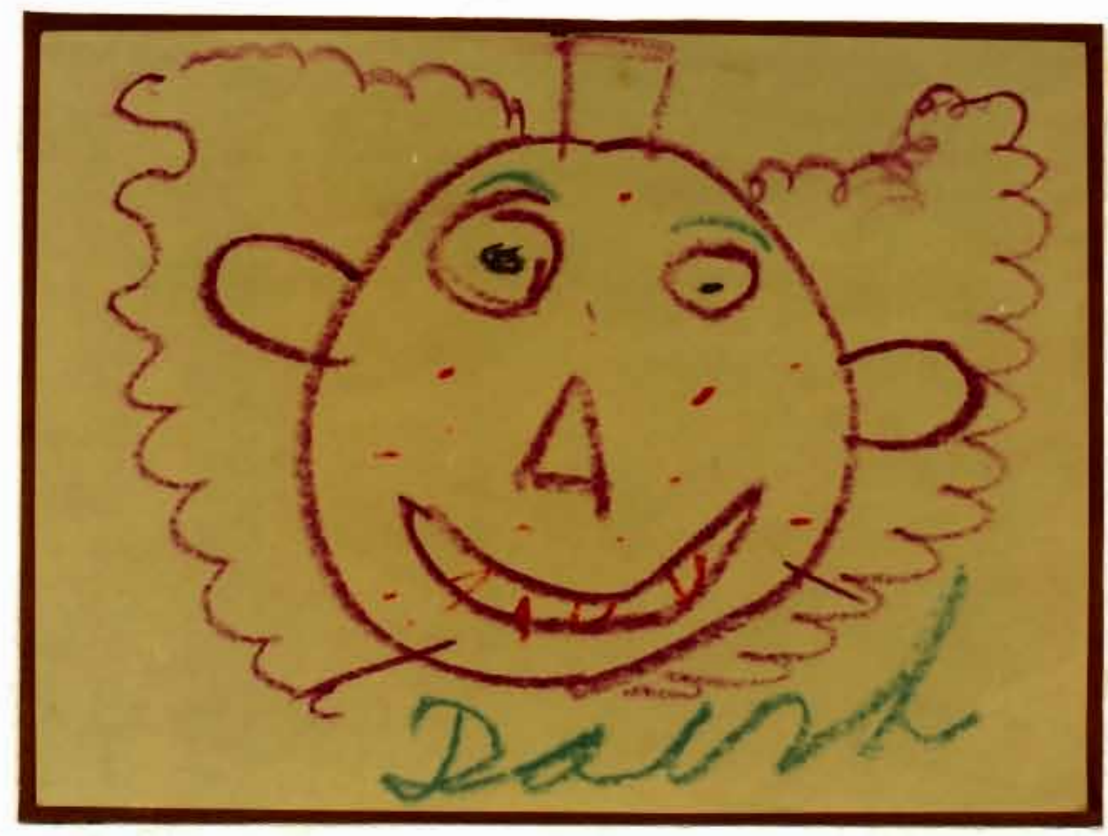

Figure 60. David, oil crayon on paper, $\frac{12.8 \mathrm{~cm} \times}{22.8} \mathrm{~cm}$. 


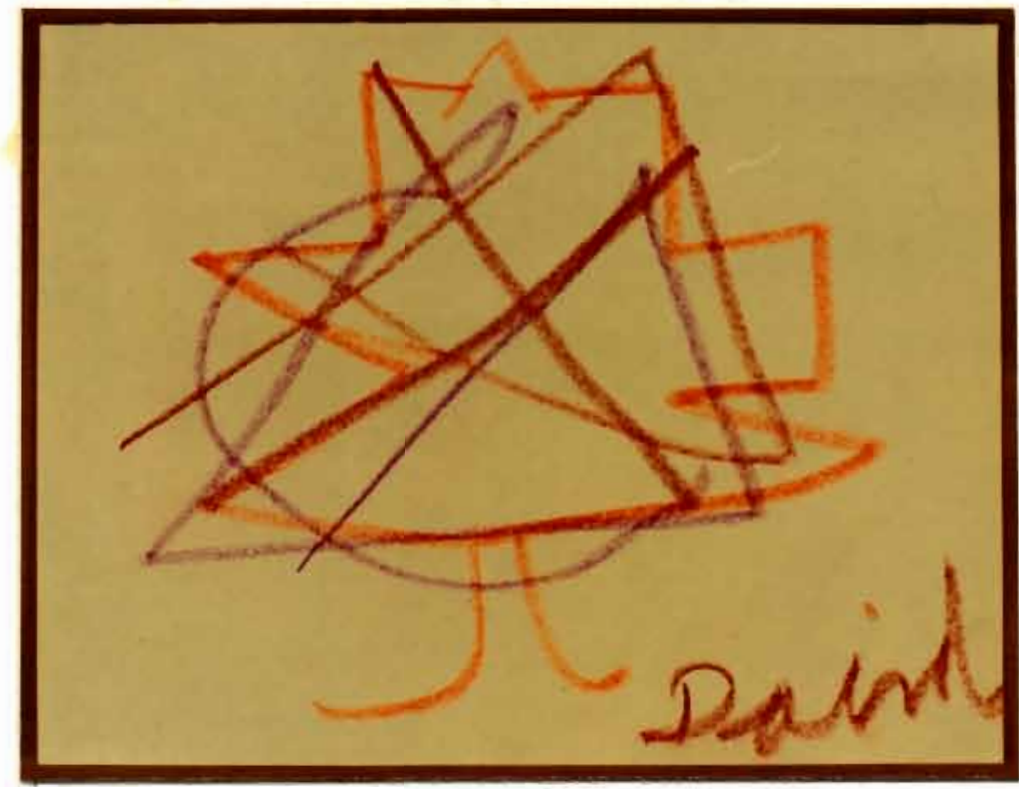

Figure 61. David, oil crayon on paper, $27.5 \mathrm{~cm} \mathrm{x} 35.4 \mathrm{~cm}$.

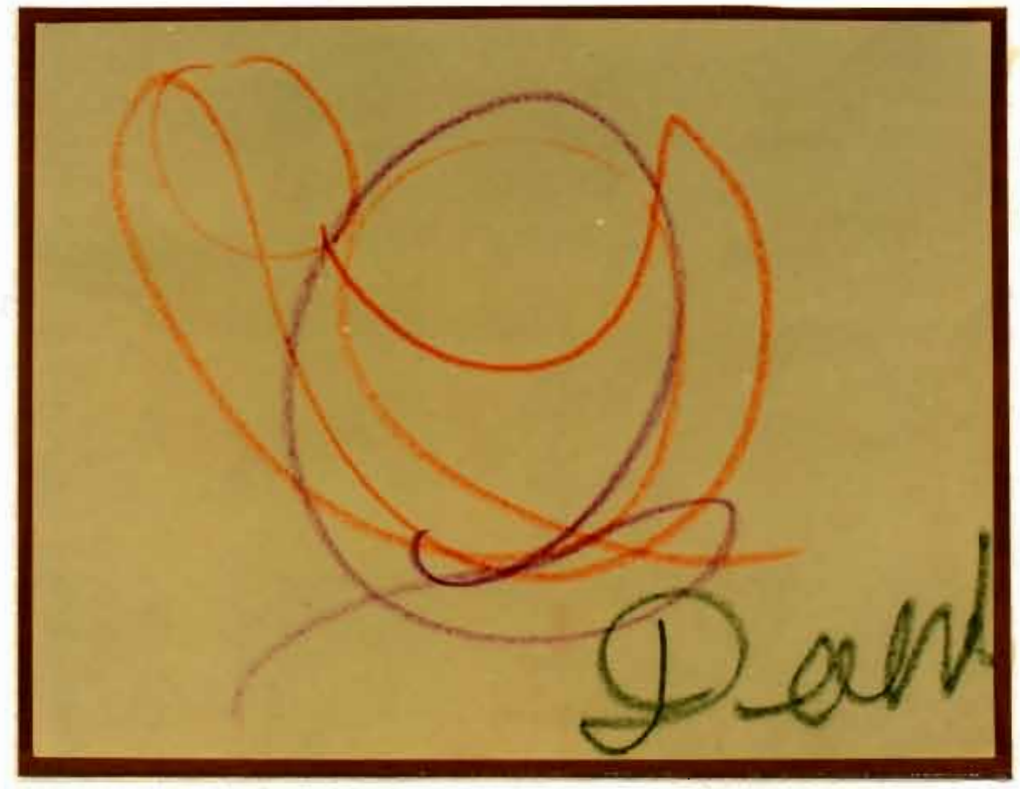

Figure 62. David, oil crayon on paper, $27.5 \mathrm{~cm} \mathrm{x} 35.4 \mathrm{~cm}$. 


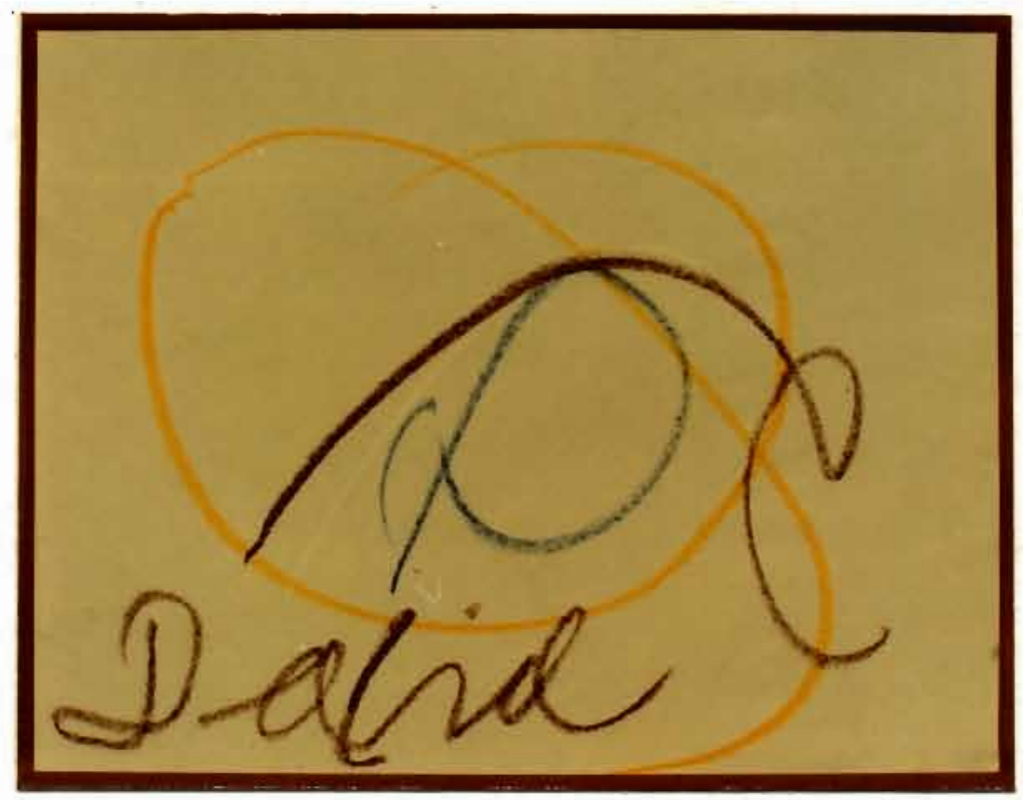

Figure 63. David, oil crayon on paper, $27.5 \mathrm{~cm} \mathrm{x} 35.4 \mathrm{~cm}$.

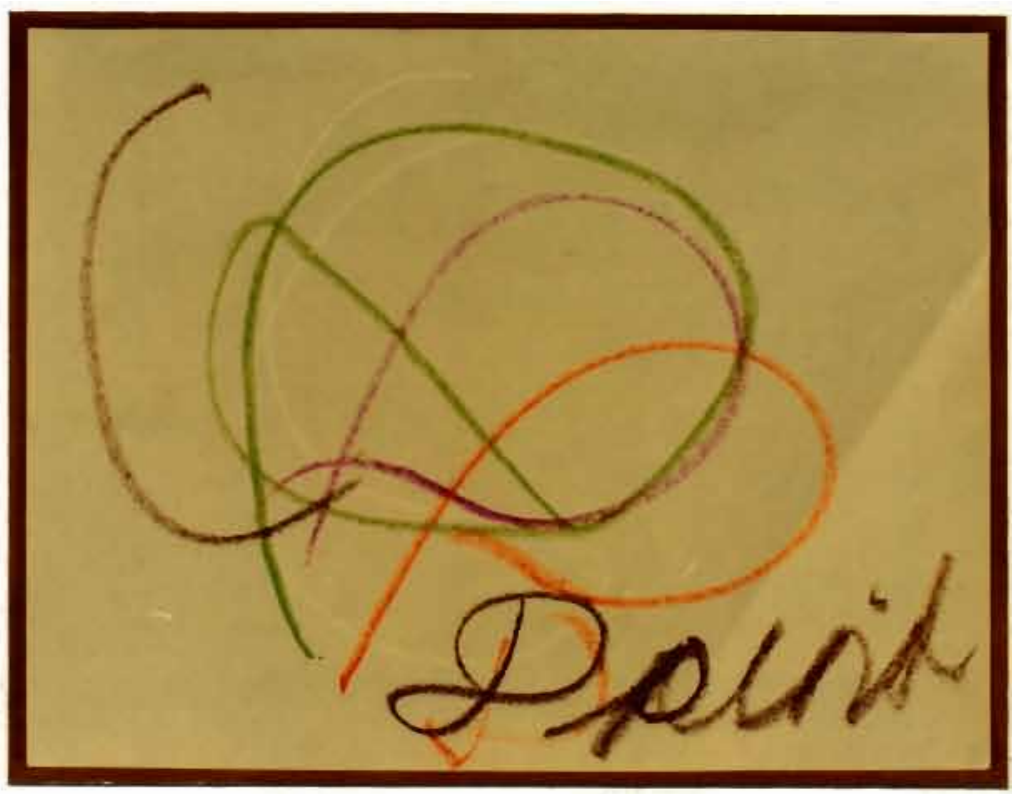

Figure 64. David, oil crayon on paper, $27.5 \mathrm{~cm} \mathrm{x} 35.4 \mathrm{~cm}$. 


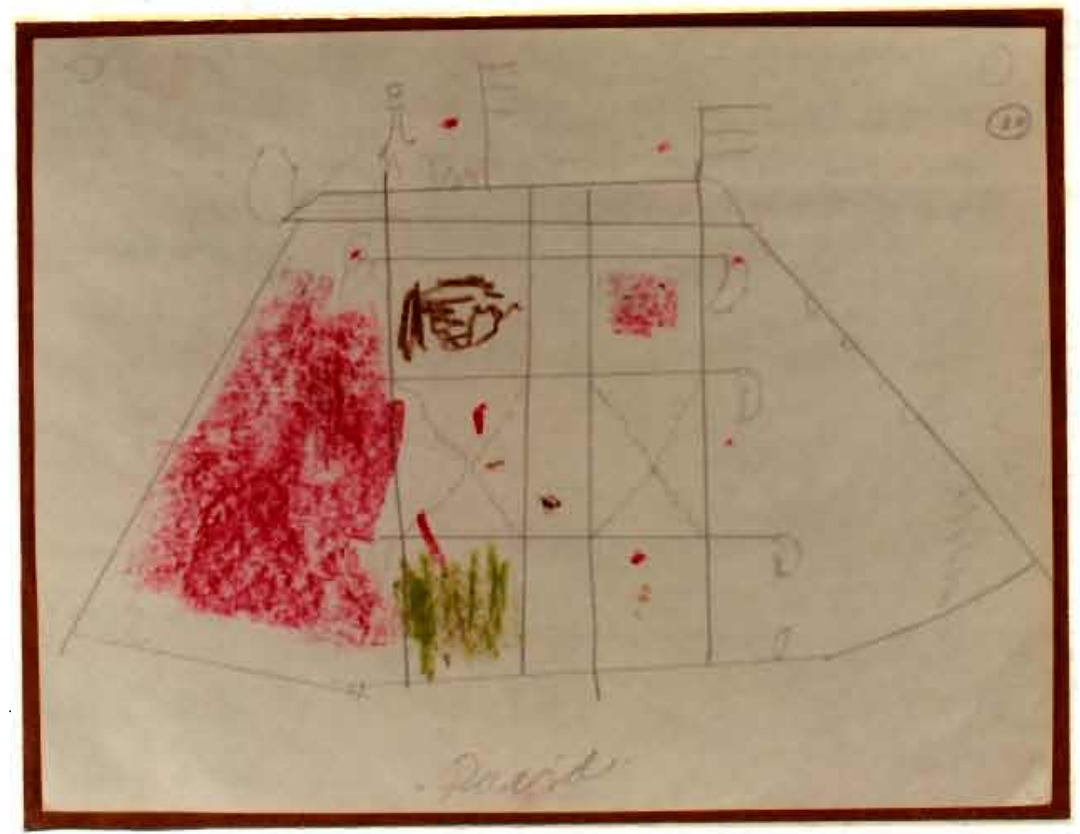

Figure 65. David, pencil and oil

crayon on paper, $21.6 \mathrm{~cm} \times 28.0 \mathrm{~cm}$.

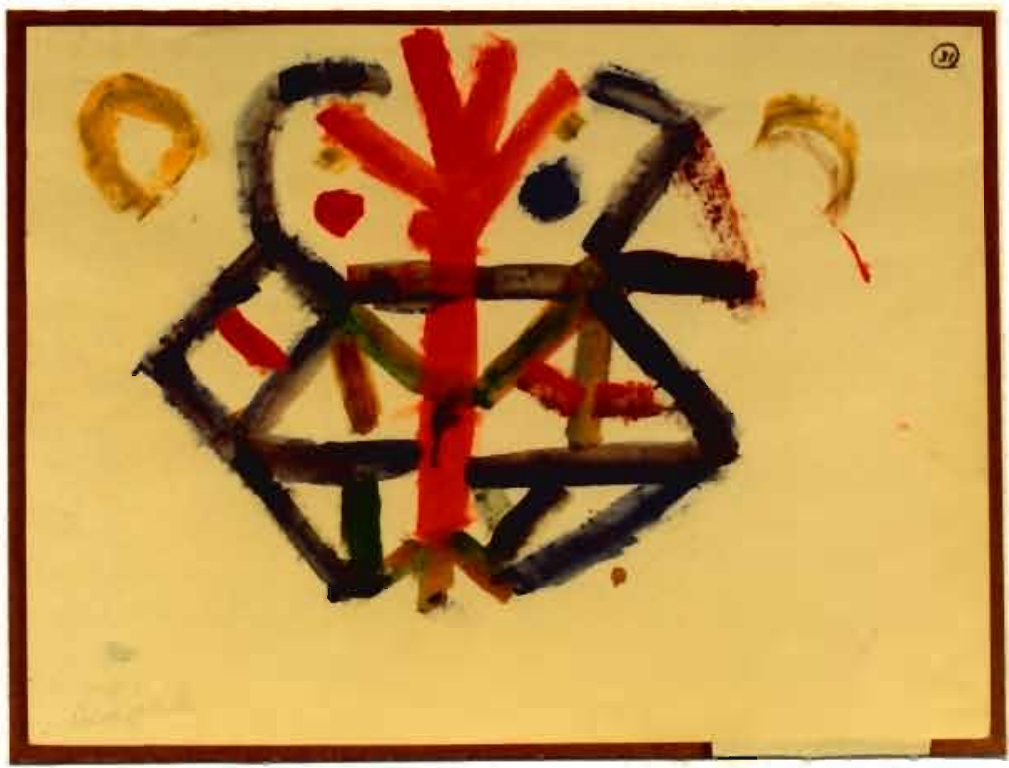

Figure 66. David, acrylic on paper, $46.0 \mathrm{~cm} \mathrm{x} 61.1 \mathrm{~cm}$. 


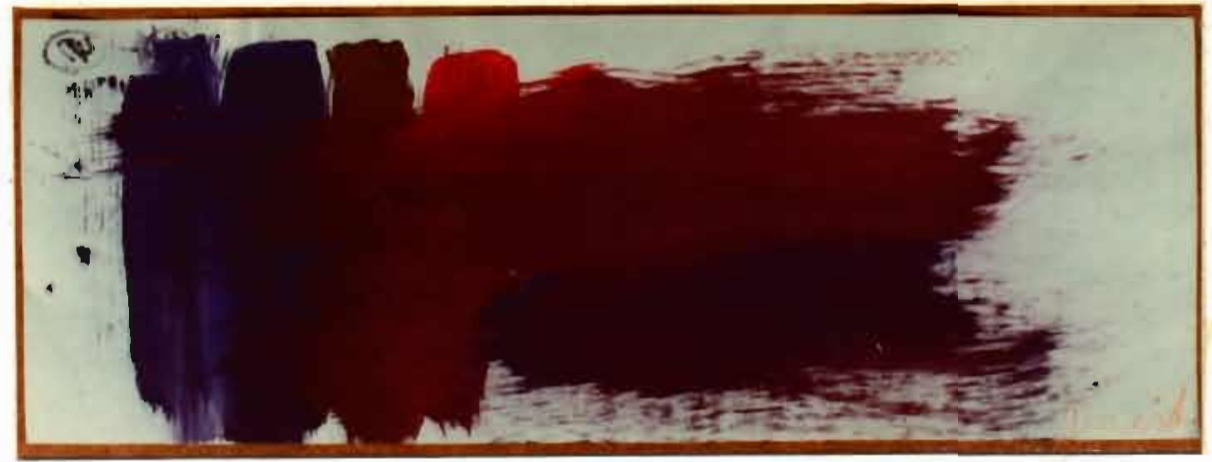

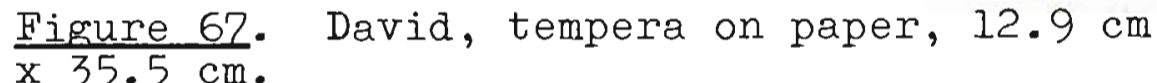

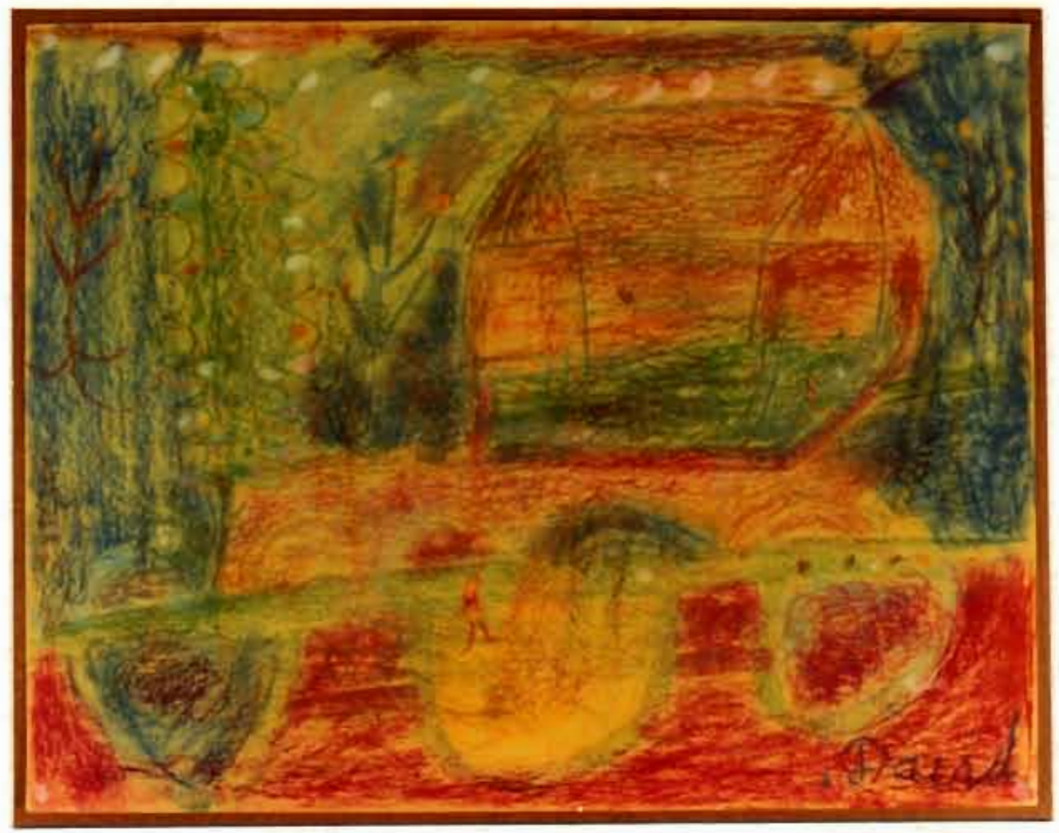

Figure 68. David, oil crayon on paper, $56.0 \mathrm{~cm} \mathrm{x} 71.5 \mathrm{~cm}$. 


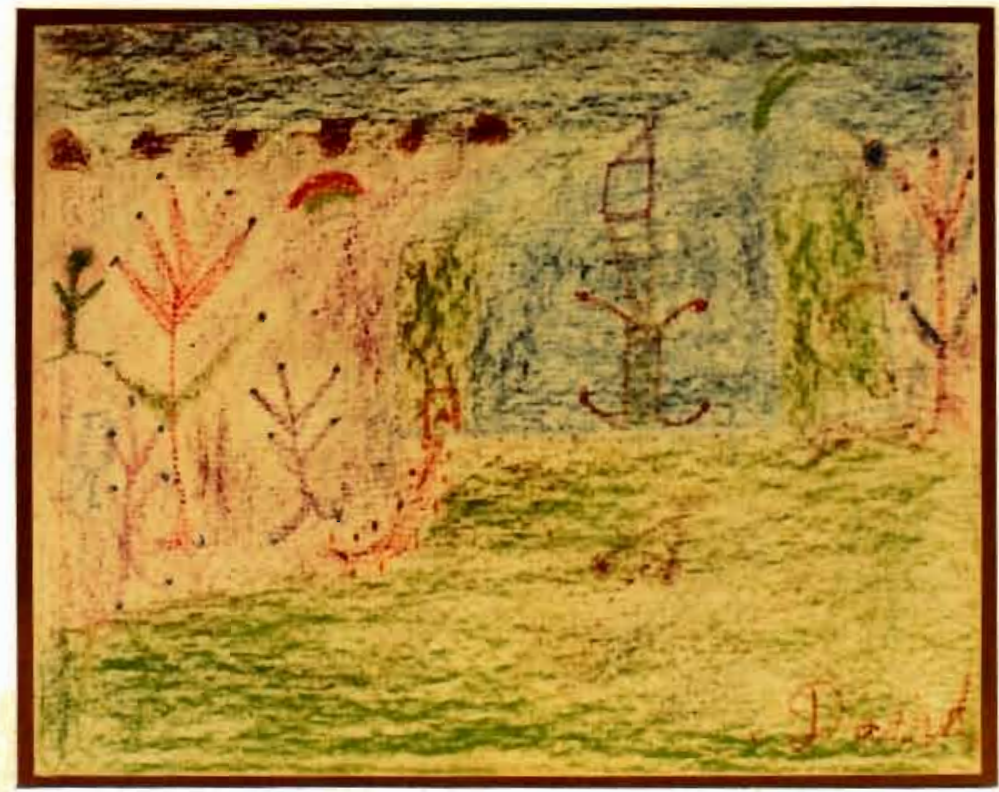

Figure 69. David, oil crayon on canvas board, $40.5 \mathrm{~cm} \times 50.7 \mathrm{~cm}$.

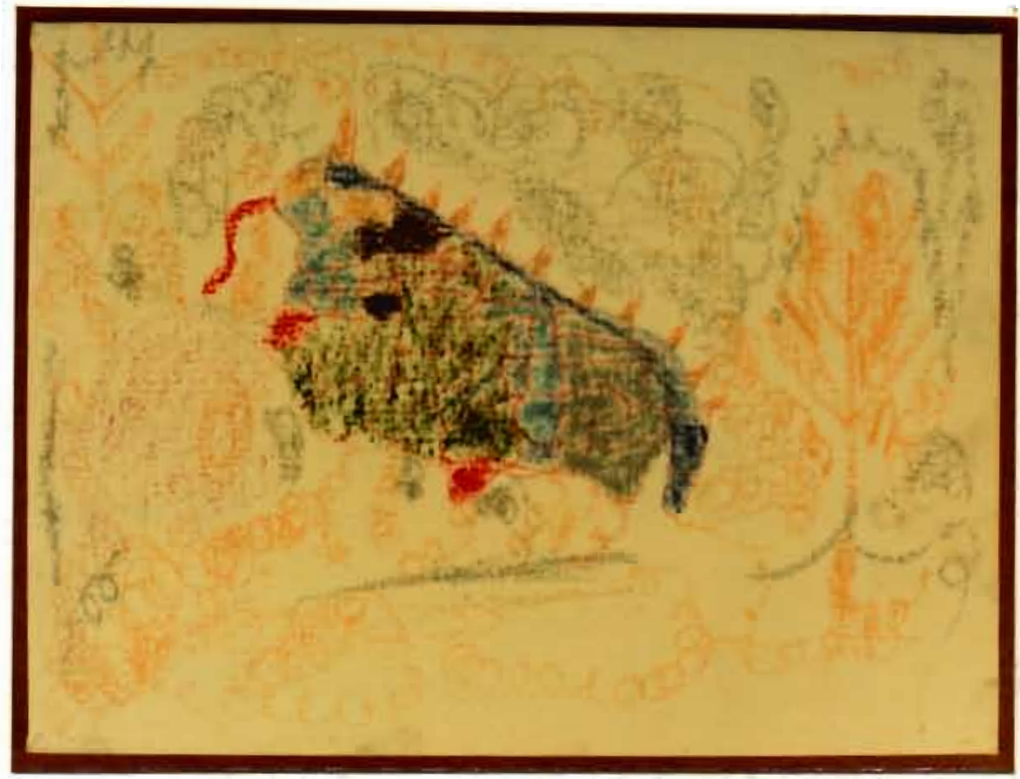

Figure 20. David, oil crayon on canvas board, $30.6 \mathrm{~cm} \times 40.6 \mathrm{~cm}$. 


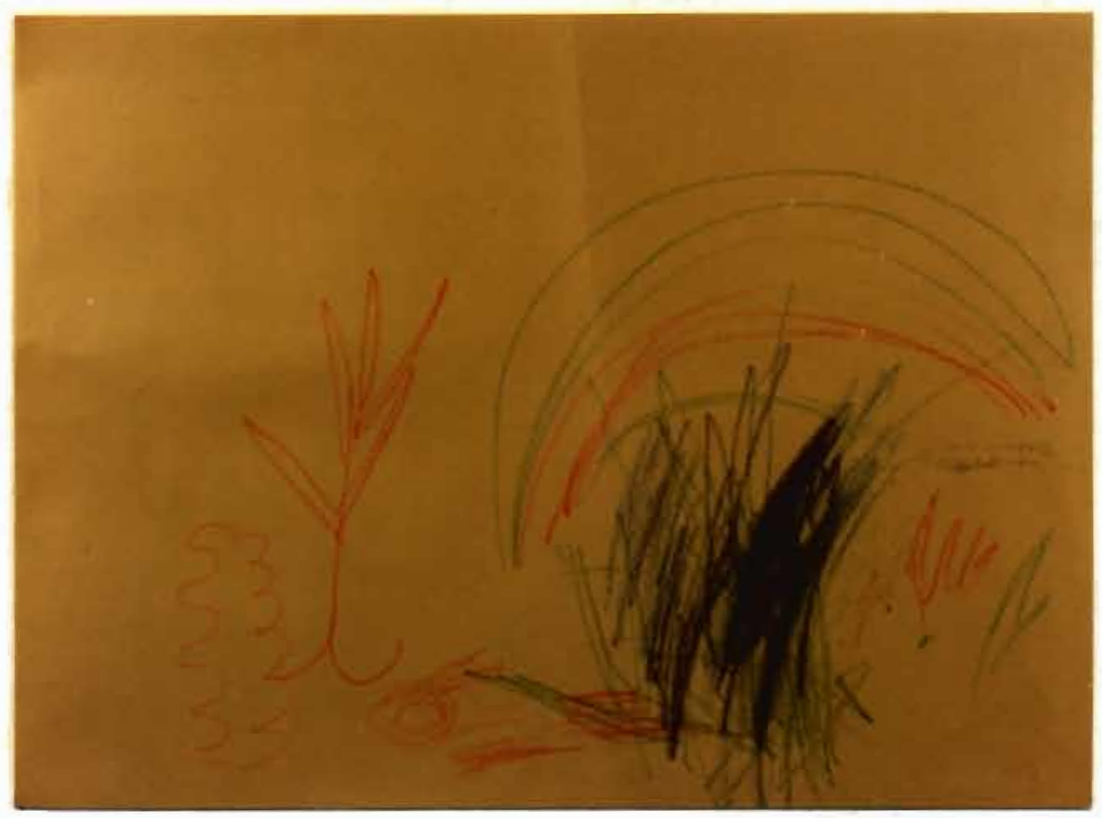

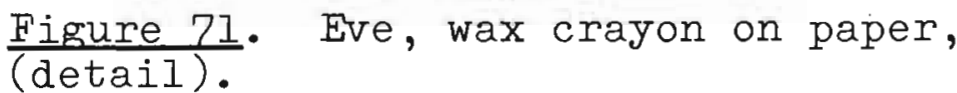

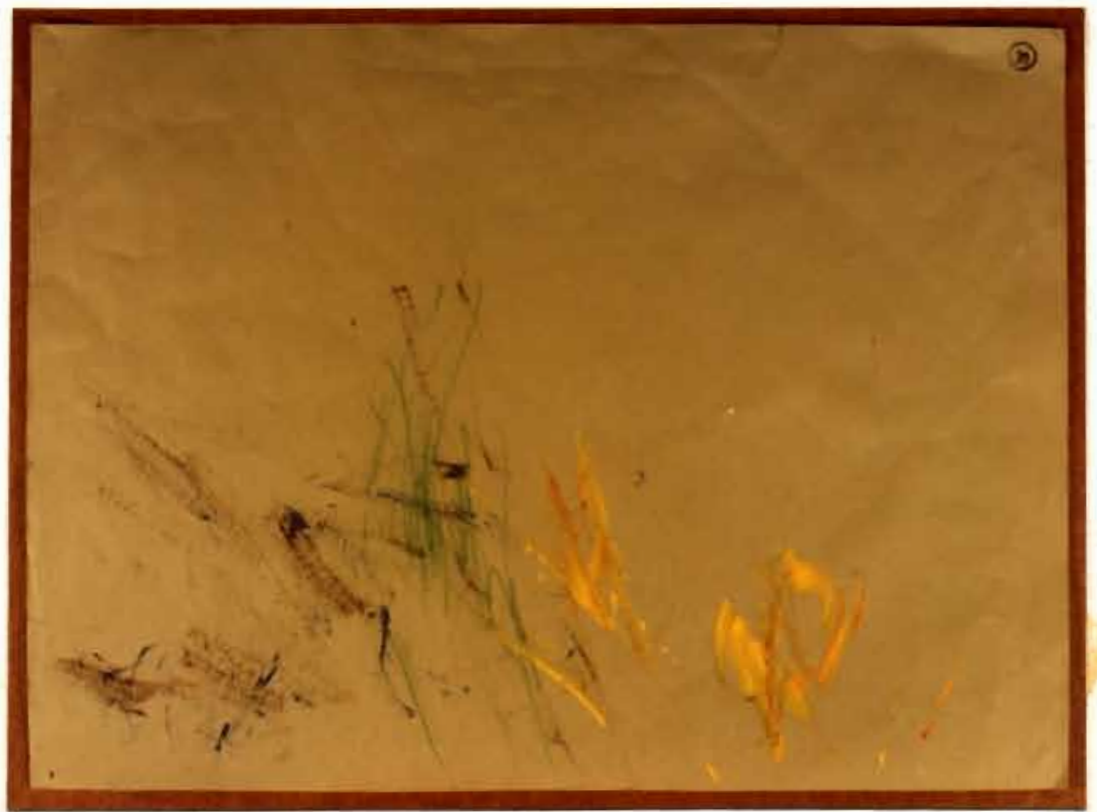

Figure 72. Eve, wax crayon and tempera on paper, $45.0 \mathrm{~cm} \times 61.0 \mathrm{~cm}$. 


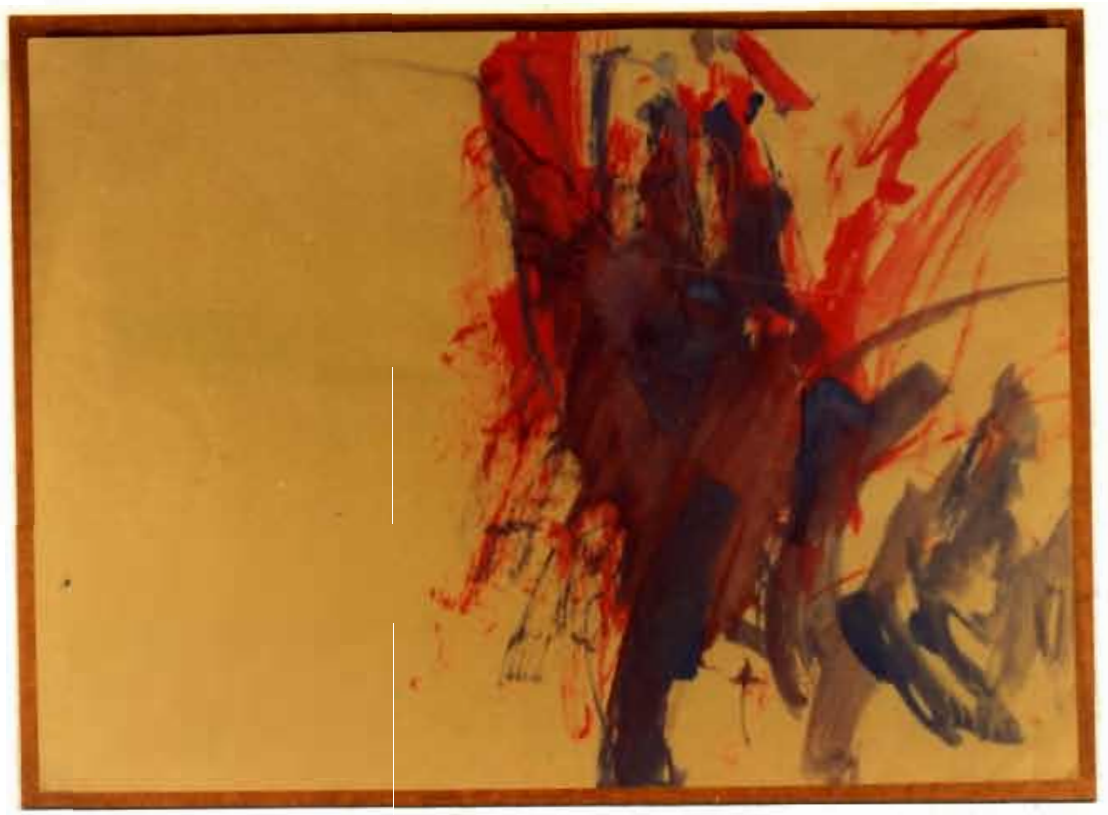

Figure 73. Eve, tempera on paper, $44.4 \mathrm{~cm} \mathrm{x} 61.0 \mathrm{~cm}$.

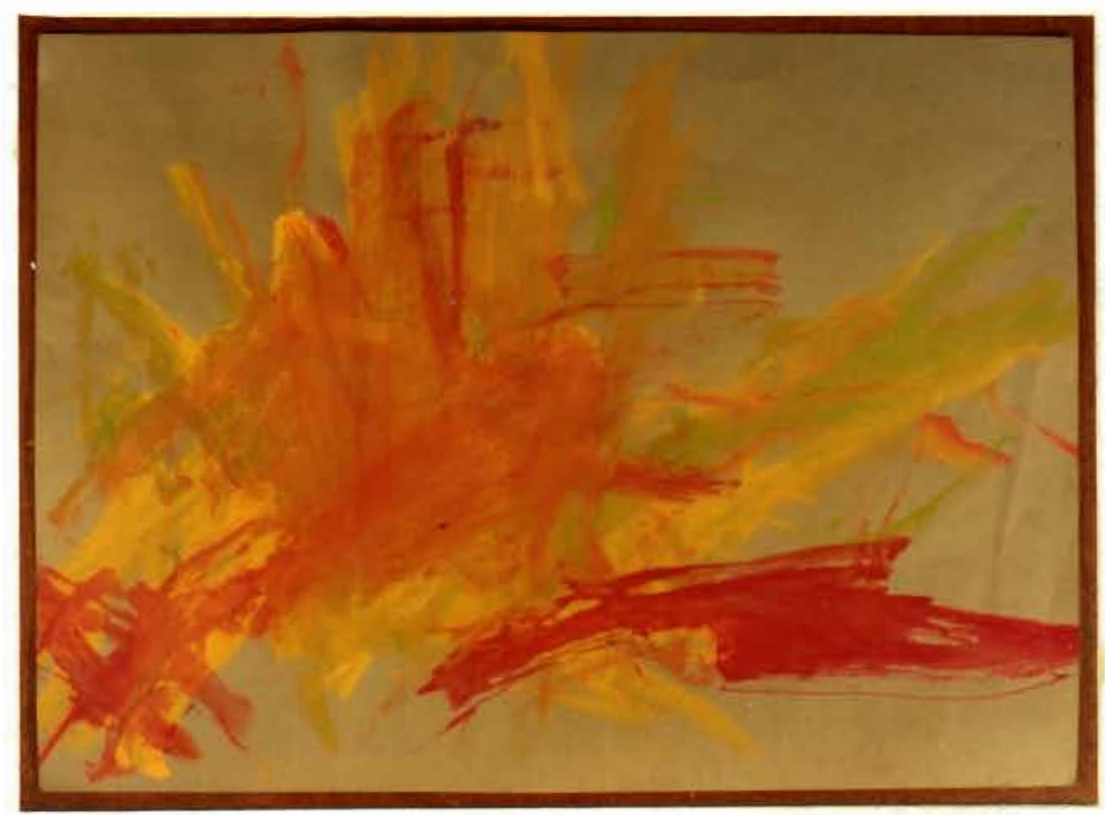

Figure 74. Eve, tempera on paper,

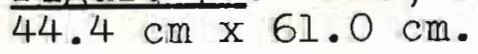




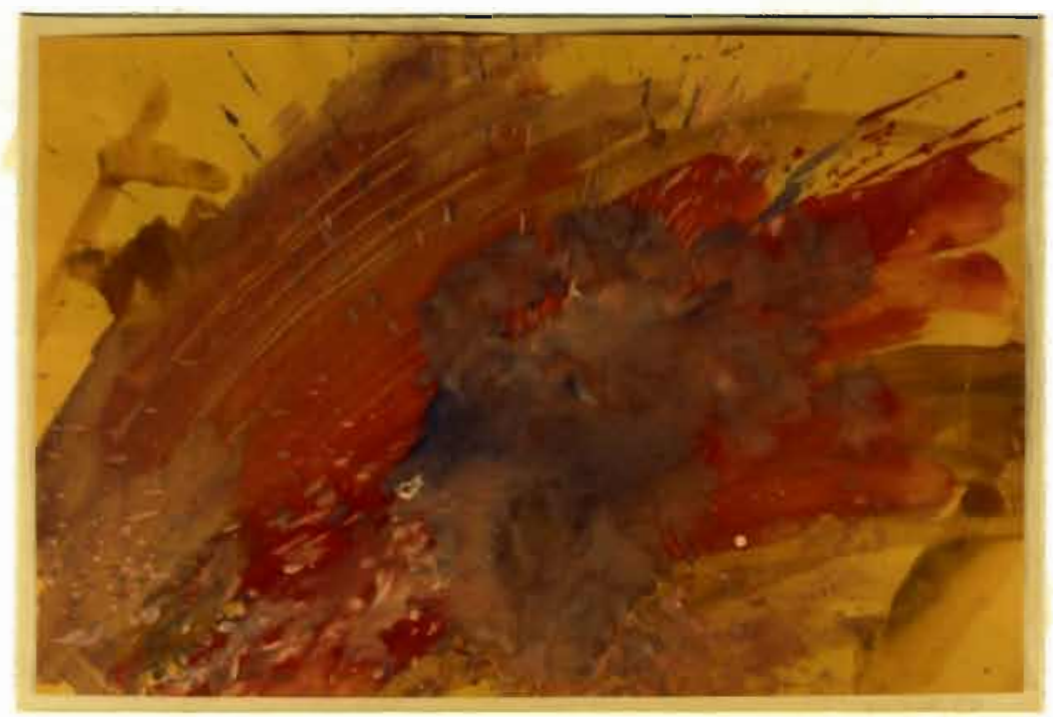

Figure 75. Eve, tempera on paper, $30.5 \mathrm{~cm} \mathrm{x} 45.8 \mathrm{~cm}$.

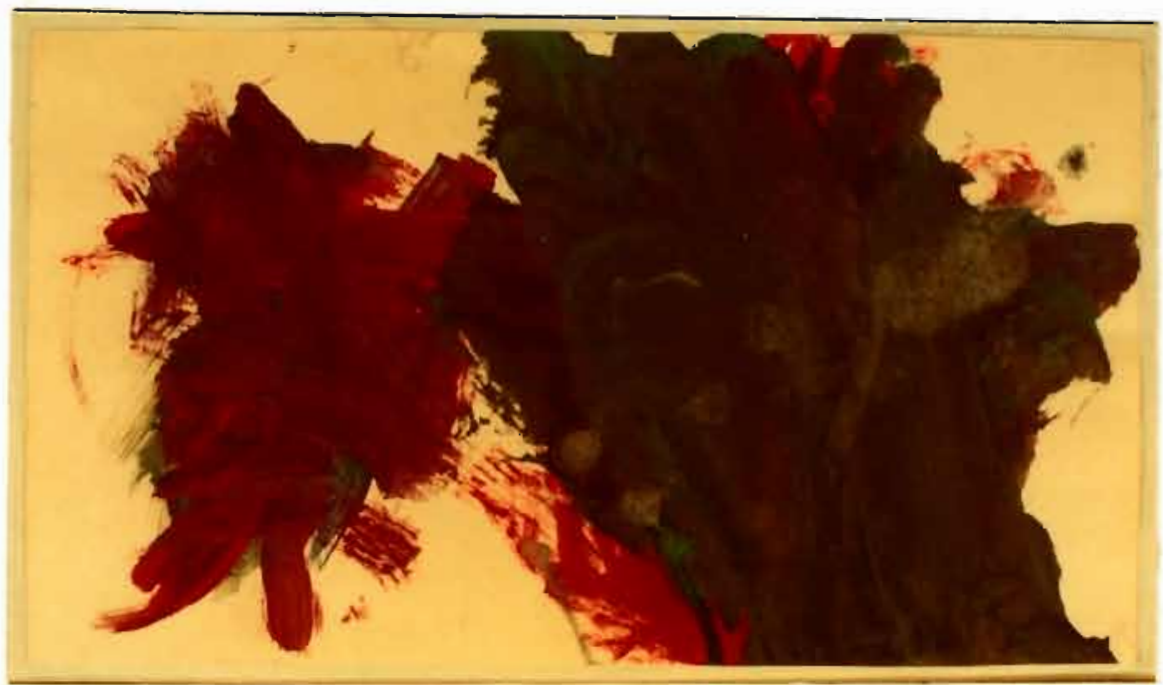

Figure 76. Eve, tempera on paper, $29.4 \mathrm{~cm}$ $\mathrm{x} 51.5 \mathrm{~cm}$. 


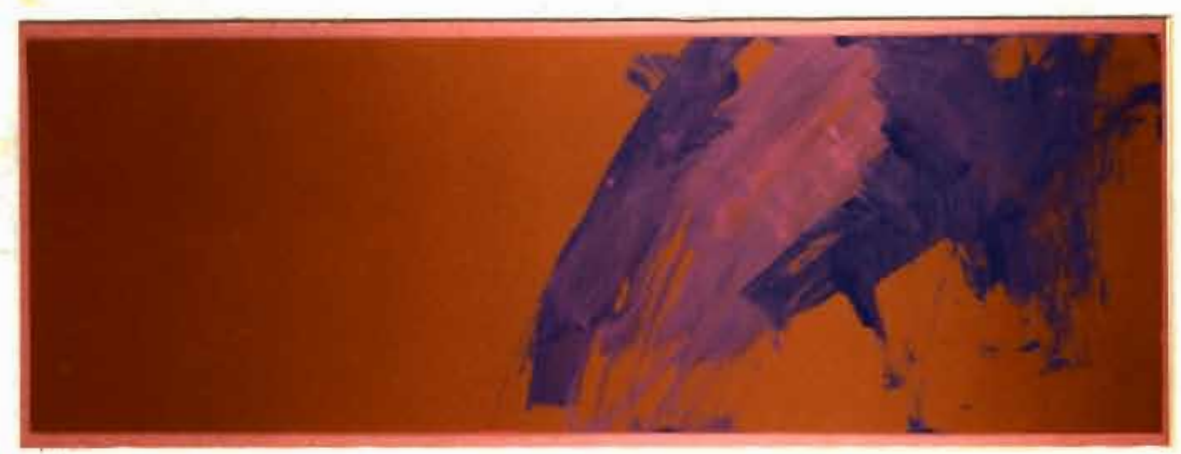

$\frac{\text { Figure 27. }}{\mathrm{x} 51.0 \mathrm{~cm} .}$ Eve, tempera on paper, $17.8 \mathrm{~cm}$

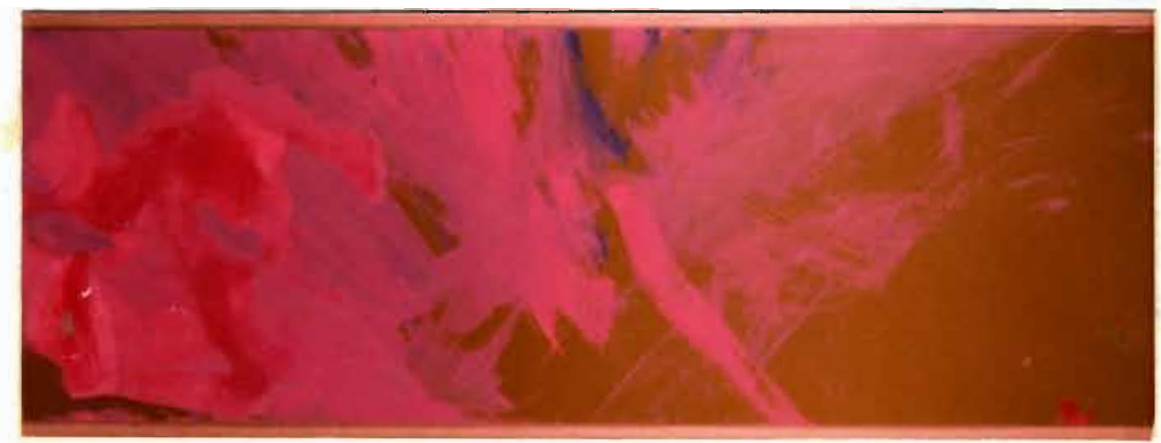

$\frac{\text { Figure 78. }}{\mathrm{x} 5 \mathrm{l} . \mathrm{O} \mathrm{cm} .}$ Eve, tempera on paper, $17.8 \mathrm{~cm}$

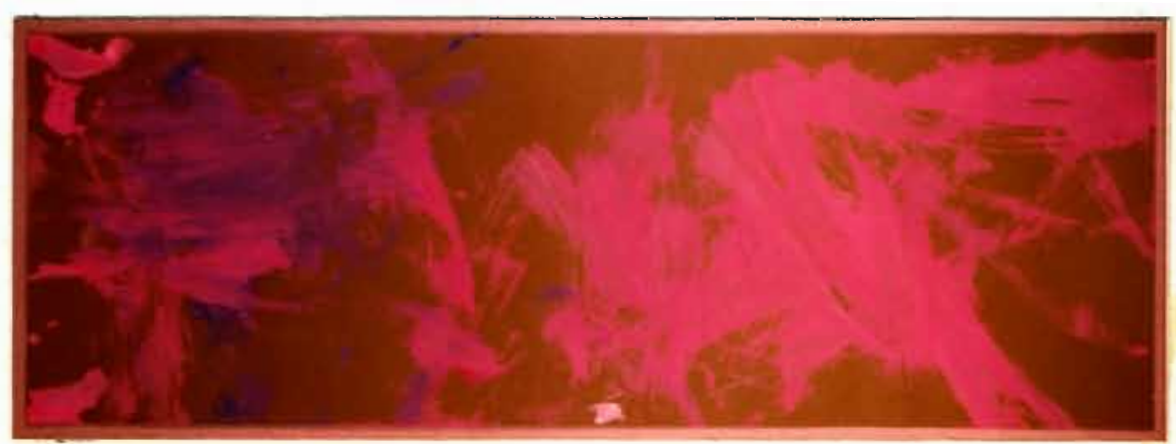

Figure 79. Eve, tempera on paper, $17.8 \mathrm{~cm}$ $\mathrm{x} 51.0 \mathrm{~cm}$. 


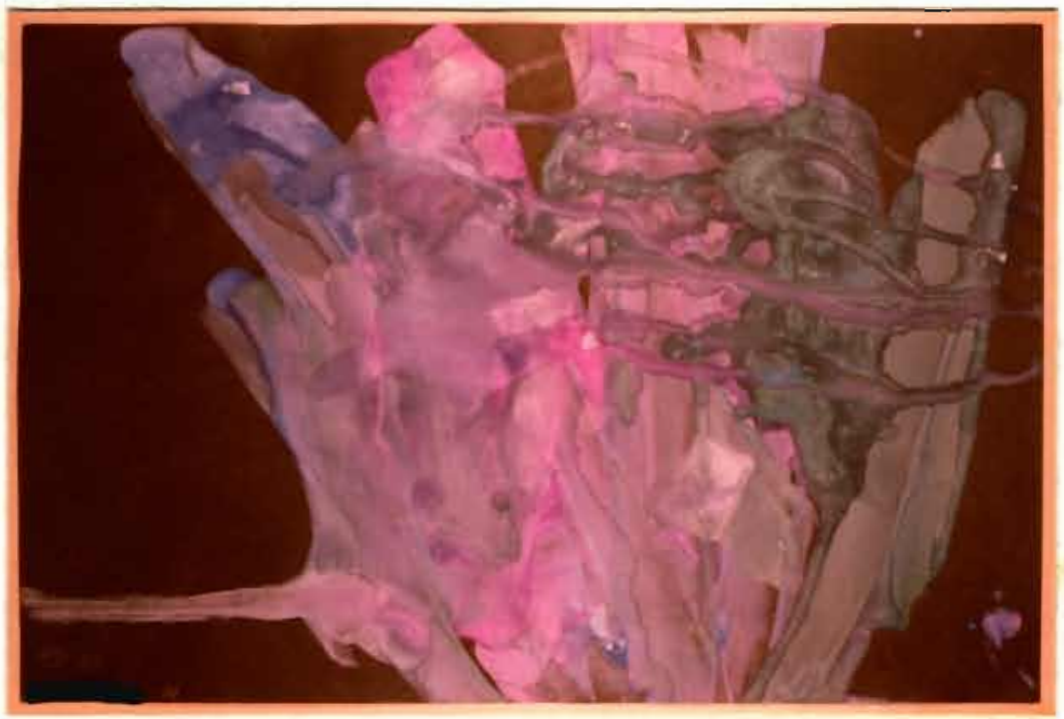

Figure 80. Eve, tempera on paper, $30.5 \mathrm{~cm} \mathrm{x} 45.5 \mathrm{~cm}$.

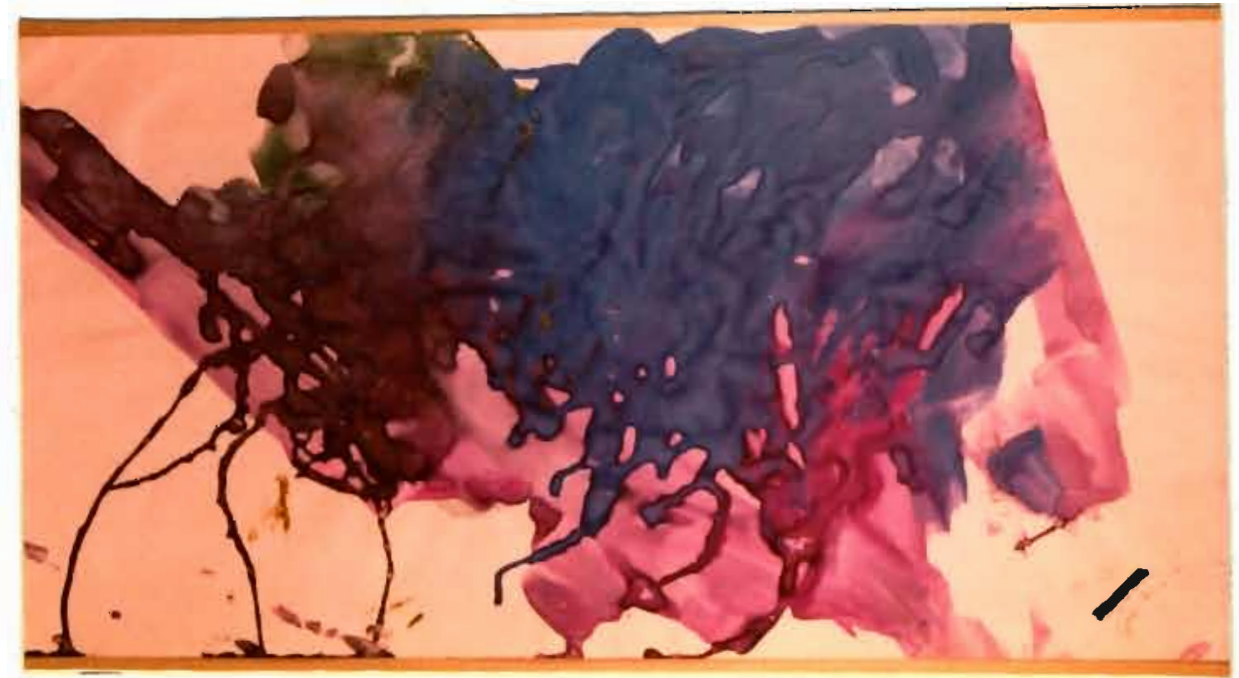

Figure 81. Eve, tempera on paper, $29.3 \mathrm{~cm}$ $\mathrm{x} 55.8 \mathrm{~cm}$. 


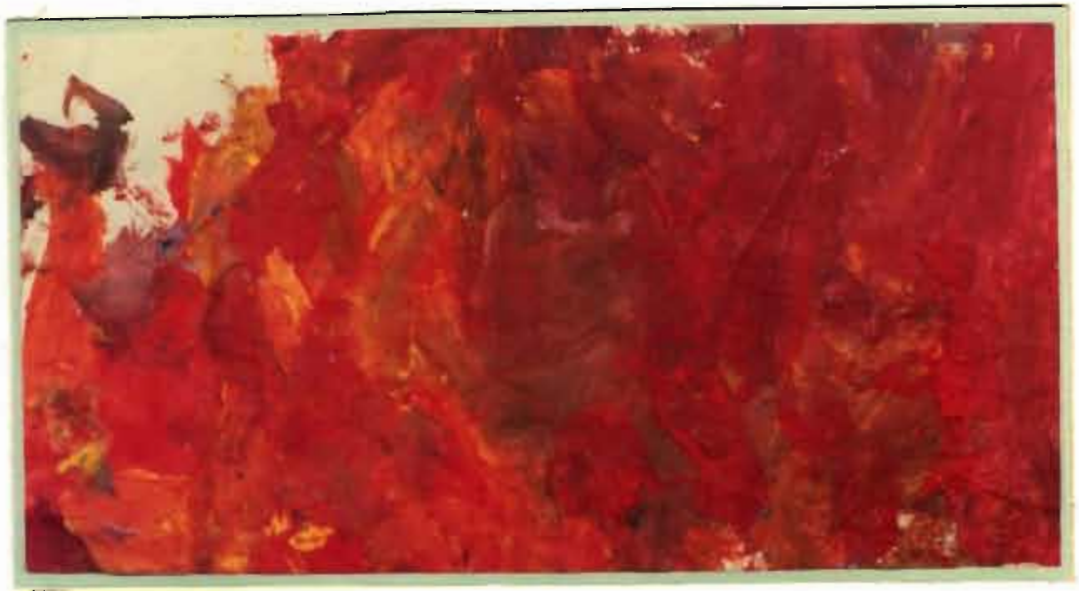

$\frac{\text { Figure 82 }}{29.2 \mathrm{~cm} \times} 56.0 \mathrm{~cm}$. Eve, tempera on paper,

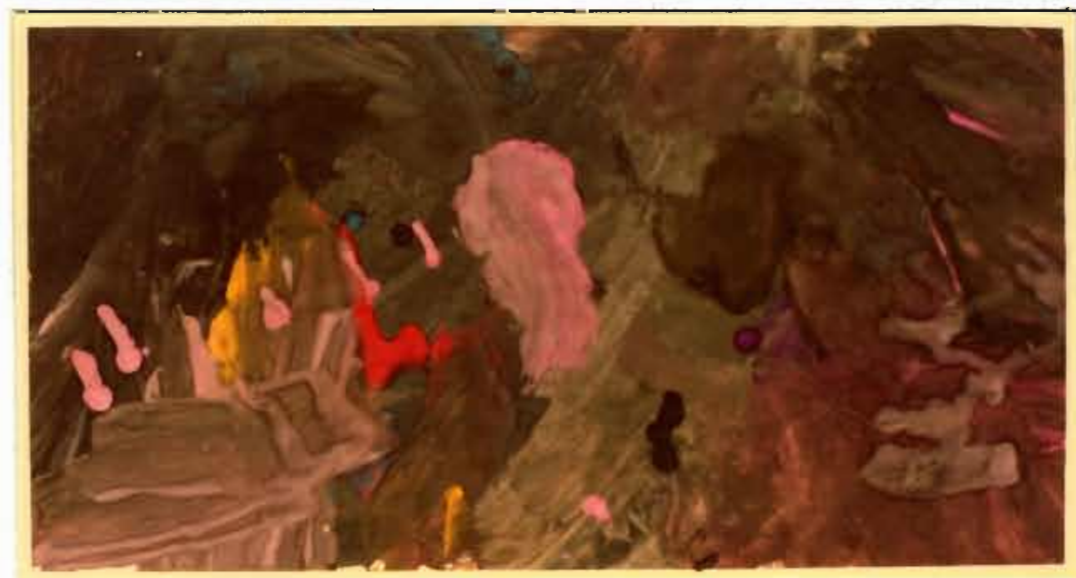

Figure 83. Eve, tempera on paper, $29.2 \mathrm{~cm} \mathrm{x} 51.0 \mathrm{~cm}$. 


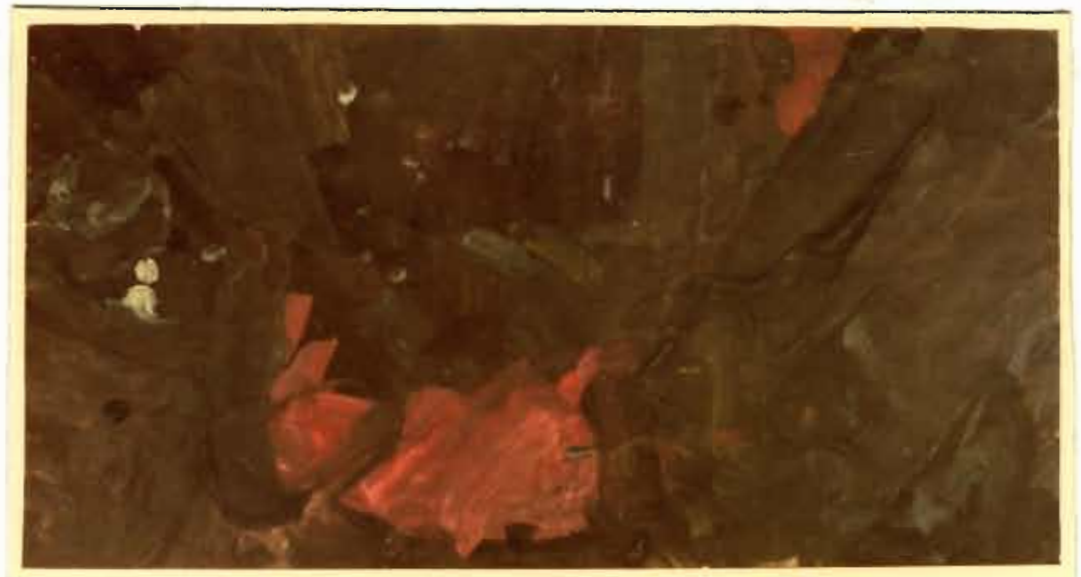

Figure 84. Eve, tempera on paper, $29.2 \mathrm{~cm} \mathrm{x} 56.0 \mathrm{~cm}$.

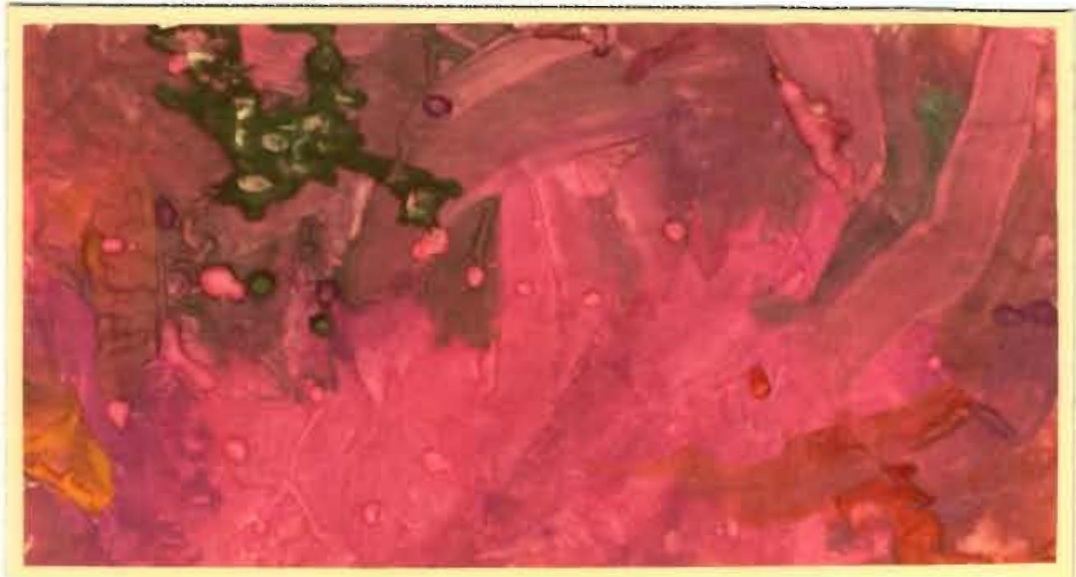

Figure 85. Eve, tempera on paper, $29.2 \mathrm{~cm} \mathrm{x} 56.0 \mathrm{~cm}$. 


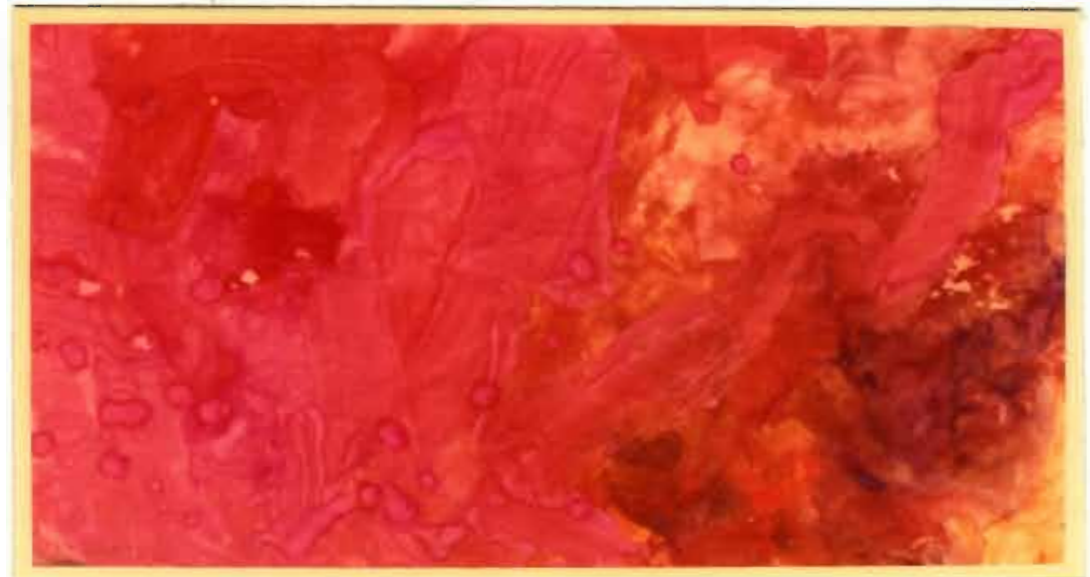

Figure 86. Eve, tempera on paper,

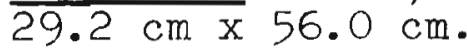

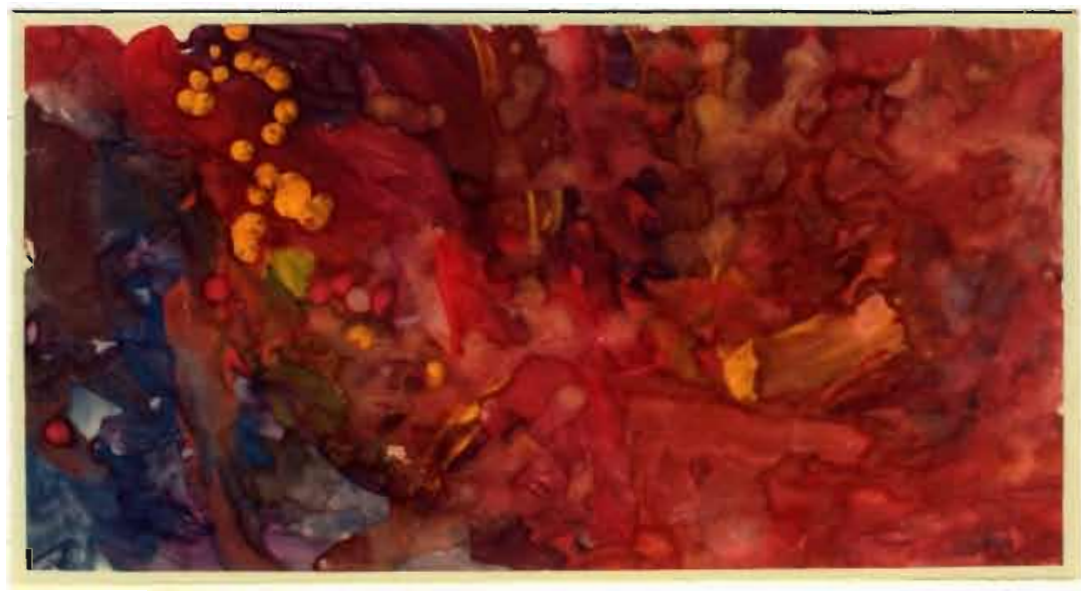

Figure 87. Eve, tempera on paper, $29.2 \mathrm{~cm} \mathrm{x} 56.0 \mathrm{~cm}$. 


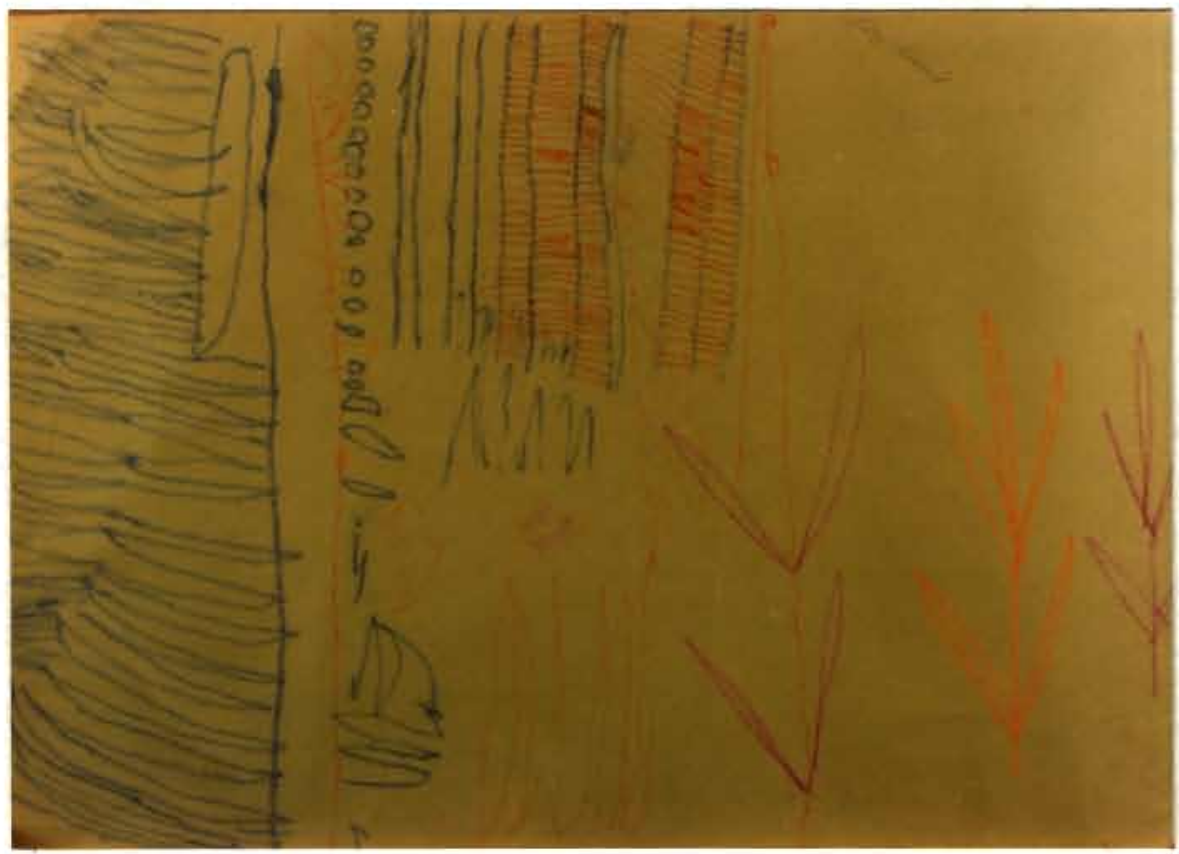

Figure 88. Kay, wax crayon on paper,

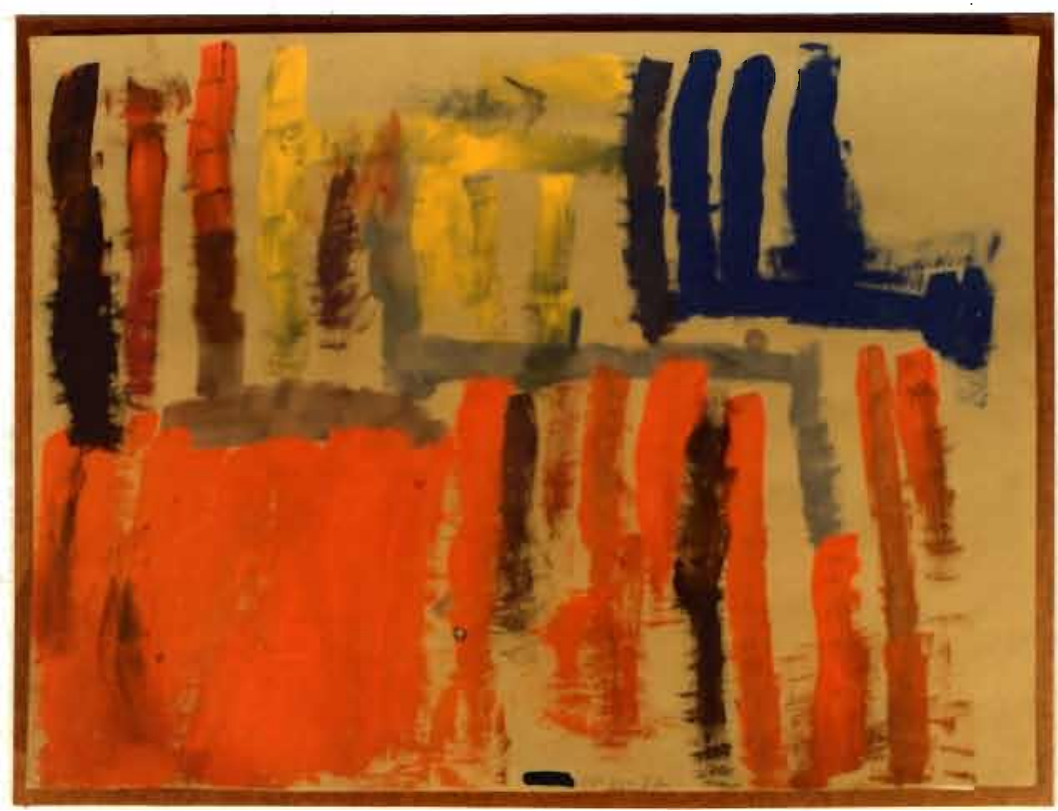

Figure 89. Kay, tempera on paper, $40.0 \mathrm{~cm} \mathrm{X} 60.5 \mathrm{~cm}$. 


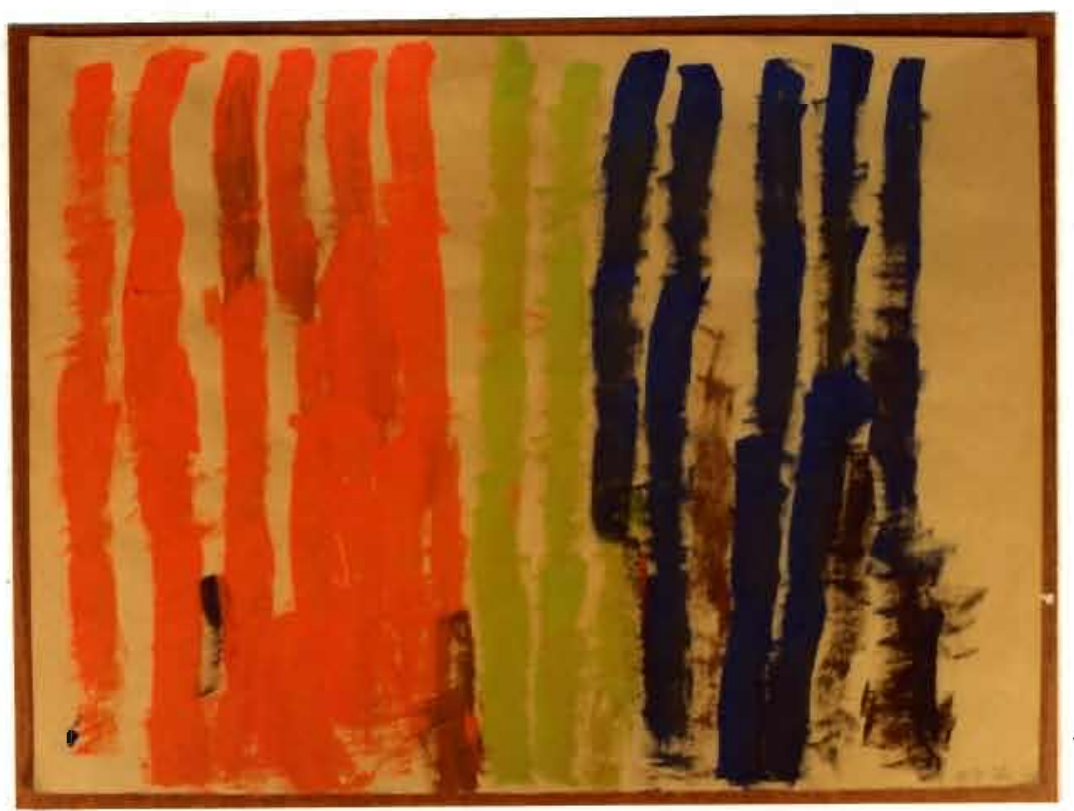

Figure 90. Kay, tempera on paper, $40.0 \mathrm{~cm} \mathrm{x} 60.5 \mathrm{~cm}$.

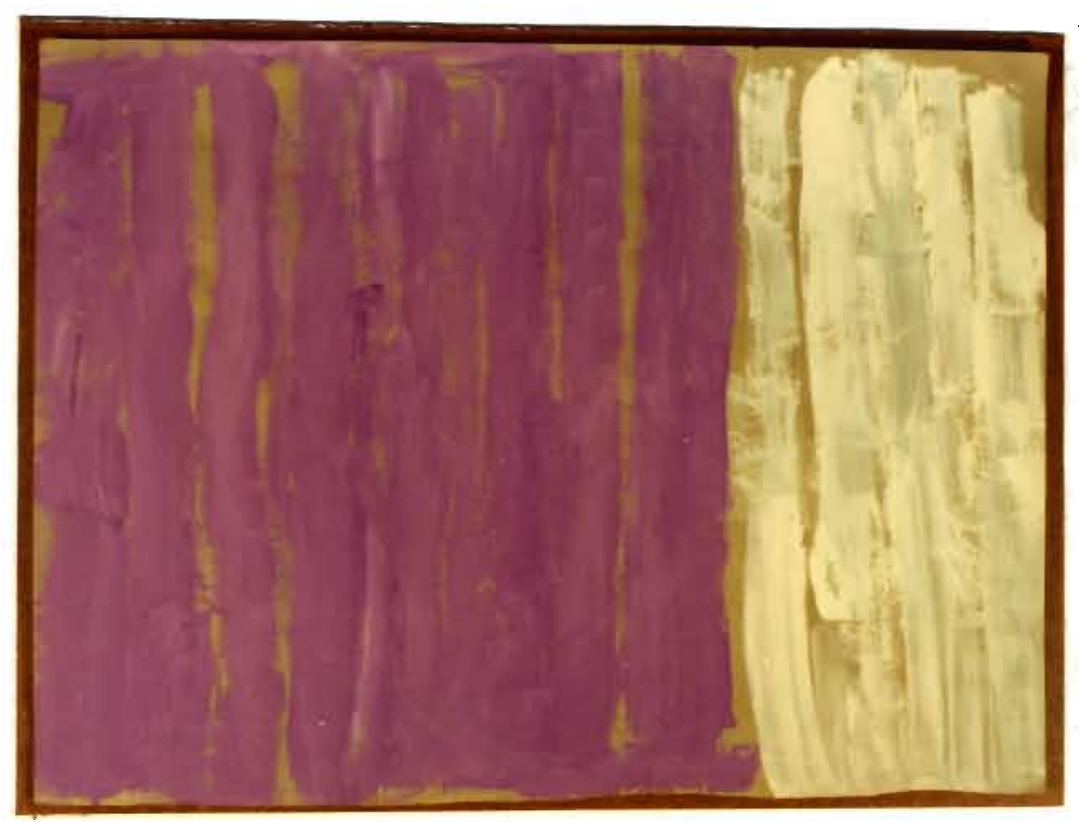

Figure 91. Kay, tempera on paper, $40.0 \mathrm{~cm} \mathrm{x} 60.5 \mathrm{~cm}$. 


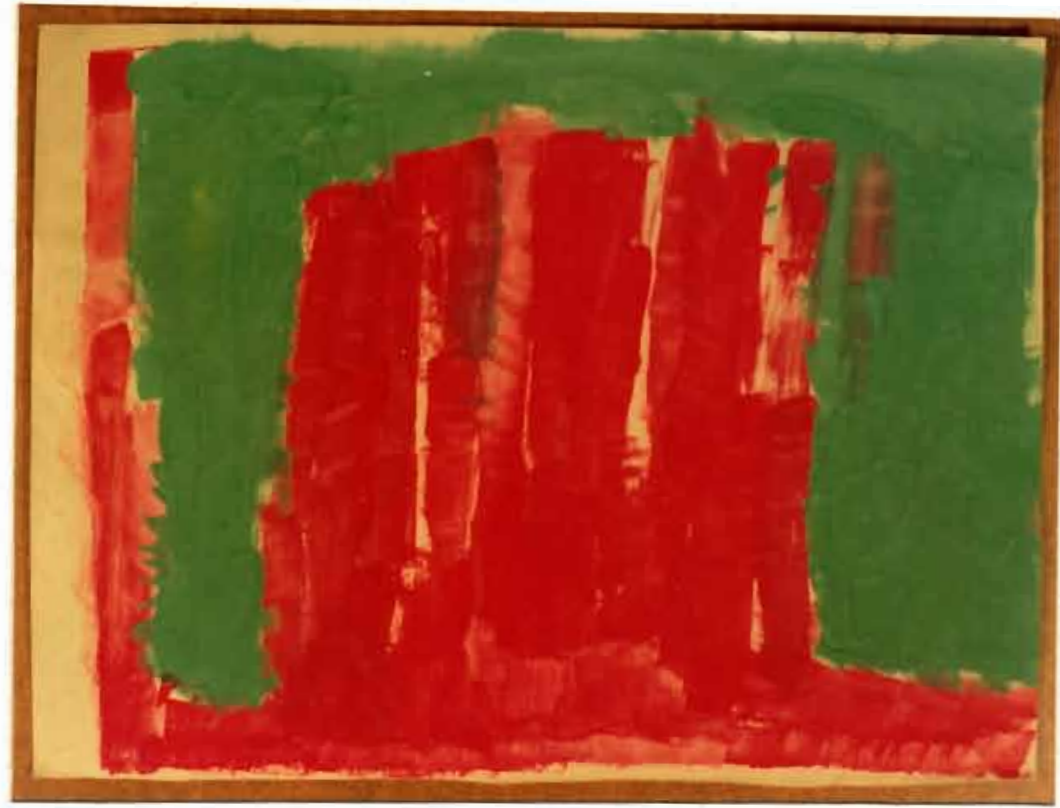

Figure 92. Kay, tempera on paper, $40.0 \mathrm{~cm} \mathrm{X} 60.5 \mathrm{~cm}$.

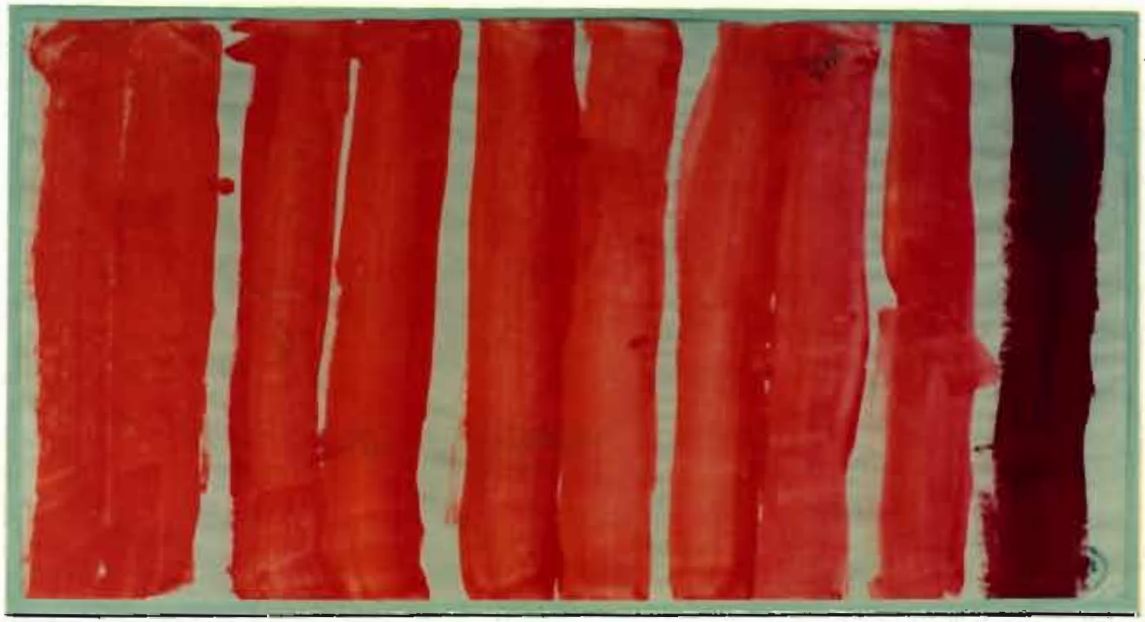

$\frac{\text { Figure 93. }}{\mathrm{x} 51.5 \mathrm{~cm}}$ Kay, tempera on paper, $29.2 \mathrm{~cm}$ 


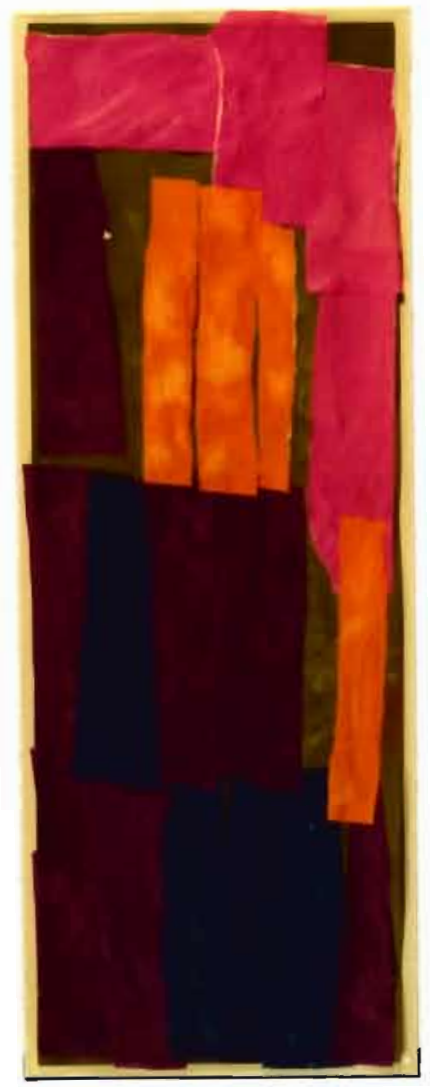

Figure 94. Kay, nese folding paper) on paper, $50.6 \mathrm{~cm} \mathrm{x}$ $17.6 \mathrm{~cm}$.

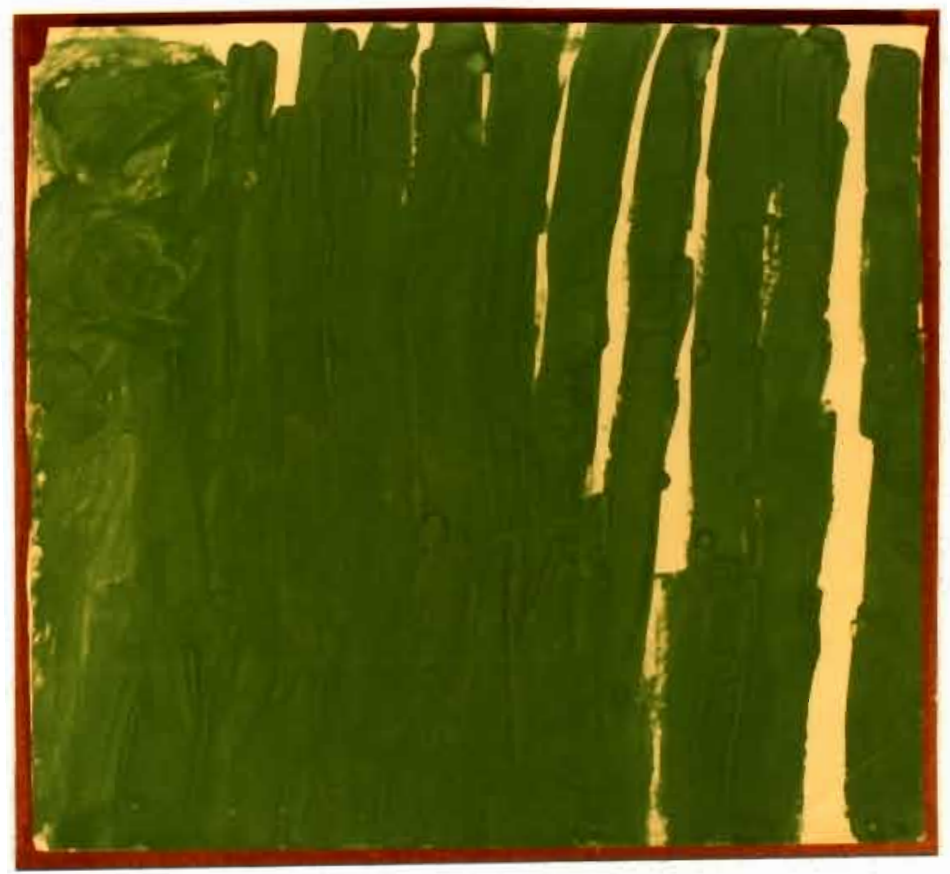

Figure 95. Kay, tempera on paper, $51.5 \mathrm{~cm} \times 55.5 \mathrm{~cm}$. 


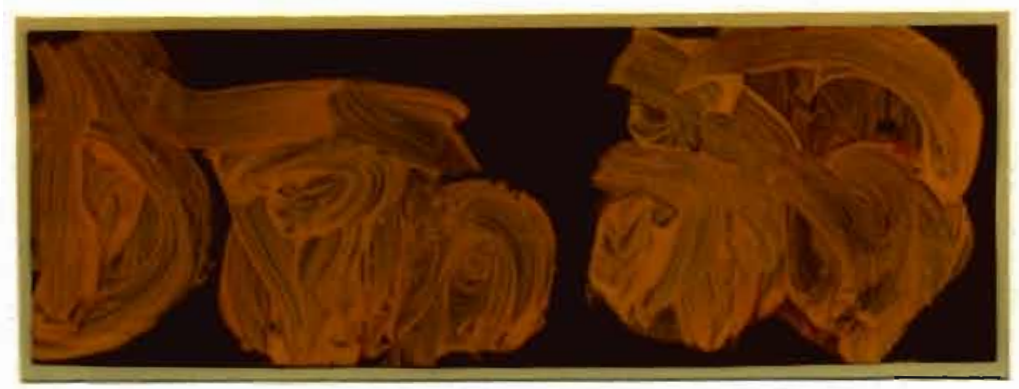

Figure 96. Kay, tempera on paper, $17.8 \mathrm{~cm} \times 50.9 \mathrm{~cm}$.

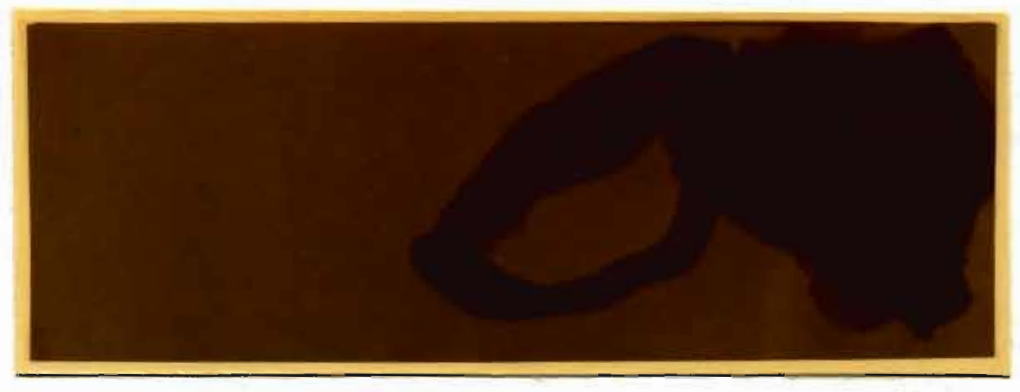

Figure 97. Kay, tempera on paper, $17.8 \mathrm{~cm} \times 50.9 \mathrm{~cm}$.

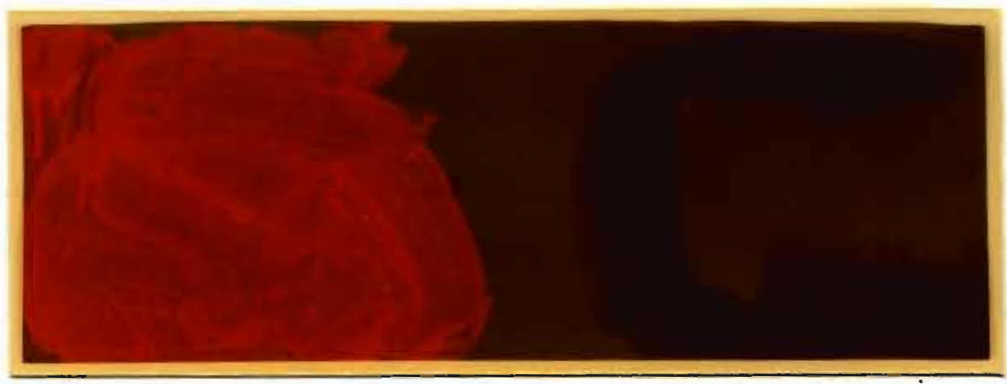

Figure 98. Kay, tempera on paper, $17.8 \mathrm{~cm} \mathrm{x} 50.9 \mathrm{~cm}$. 


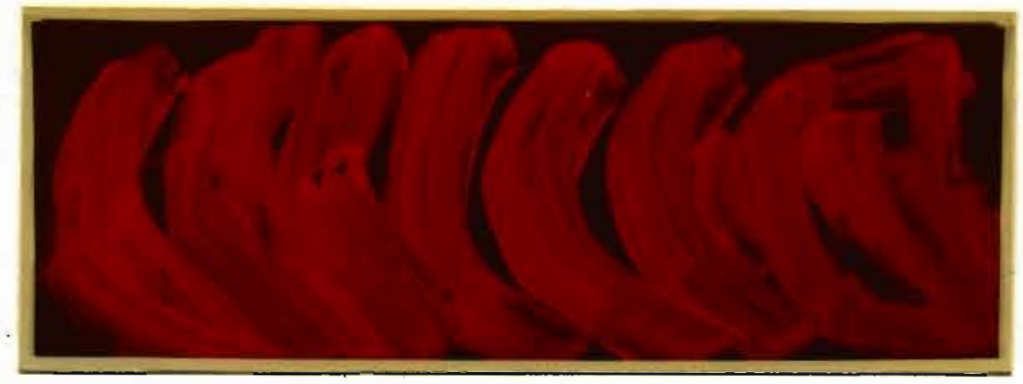

Figure 99. Kay, tempera on paper, $17.8 \mathrm{~cm} \mathrm{x} 50.9 \mathrm{~cm}$.

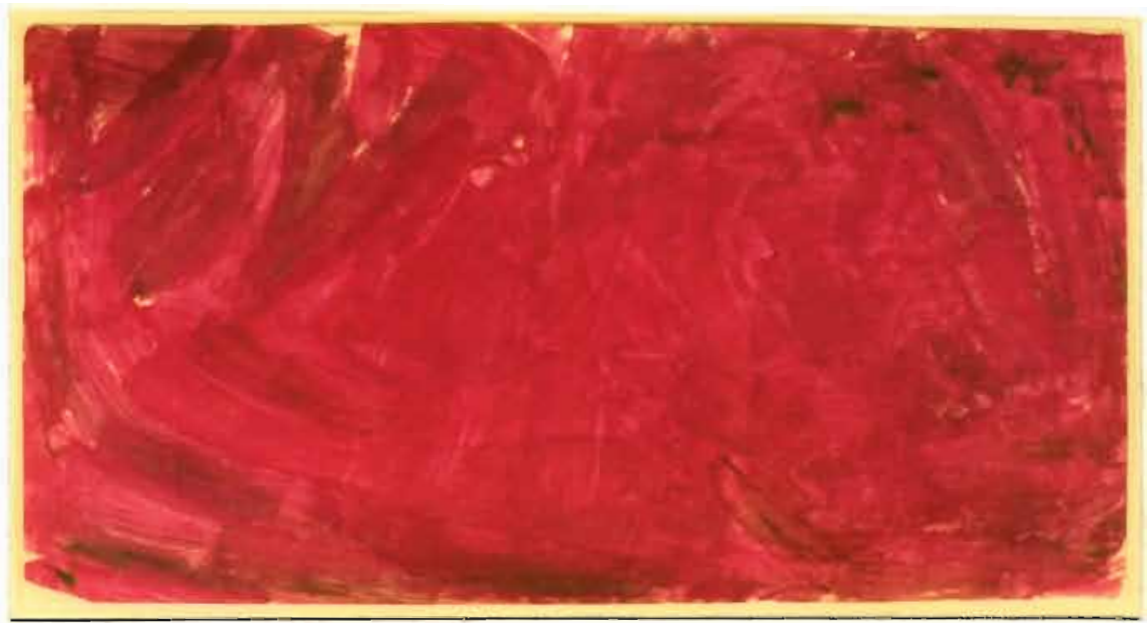

$\frac{\text { Figure } 100}{29.2 \mathrm{~cm} \times 56.0 \mathrm{~cm} \text {. }}$ 


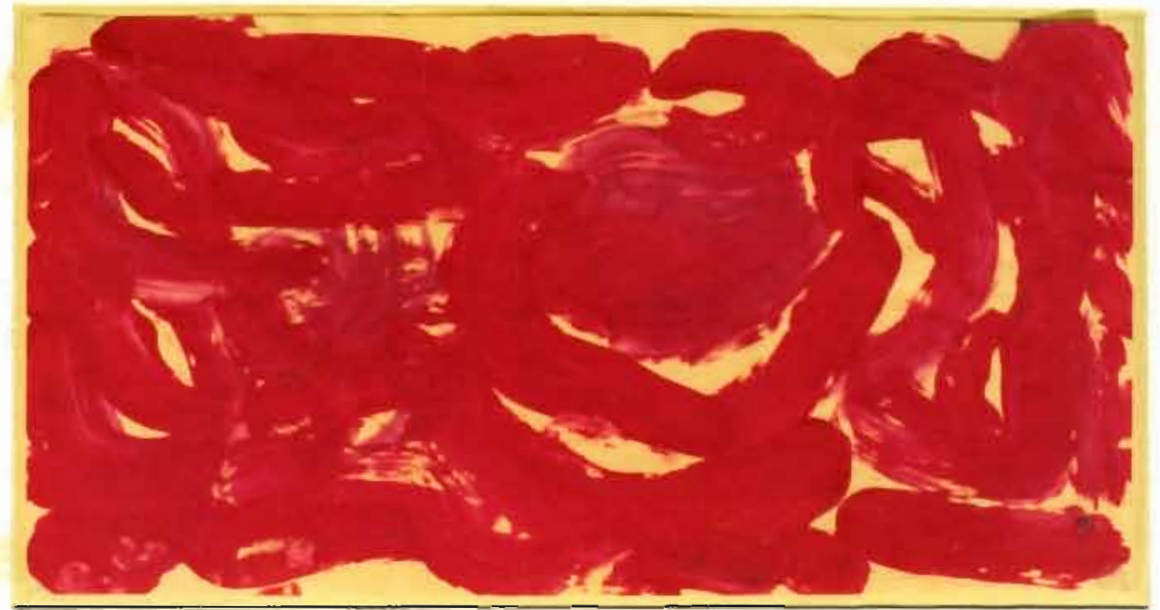

Figure 101. Kay, tempera on paper, $29.2 \mathrm{~cm} \mathrm{x} 56.0 \mathrm{~cm}$.

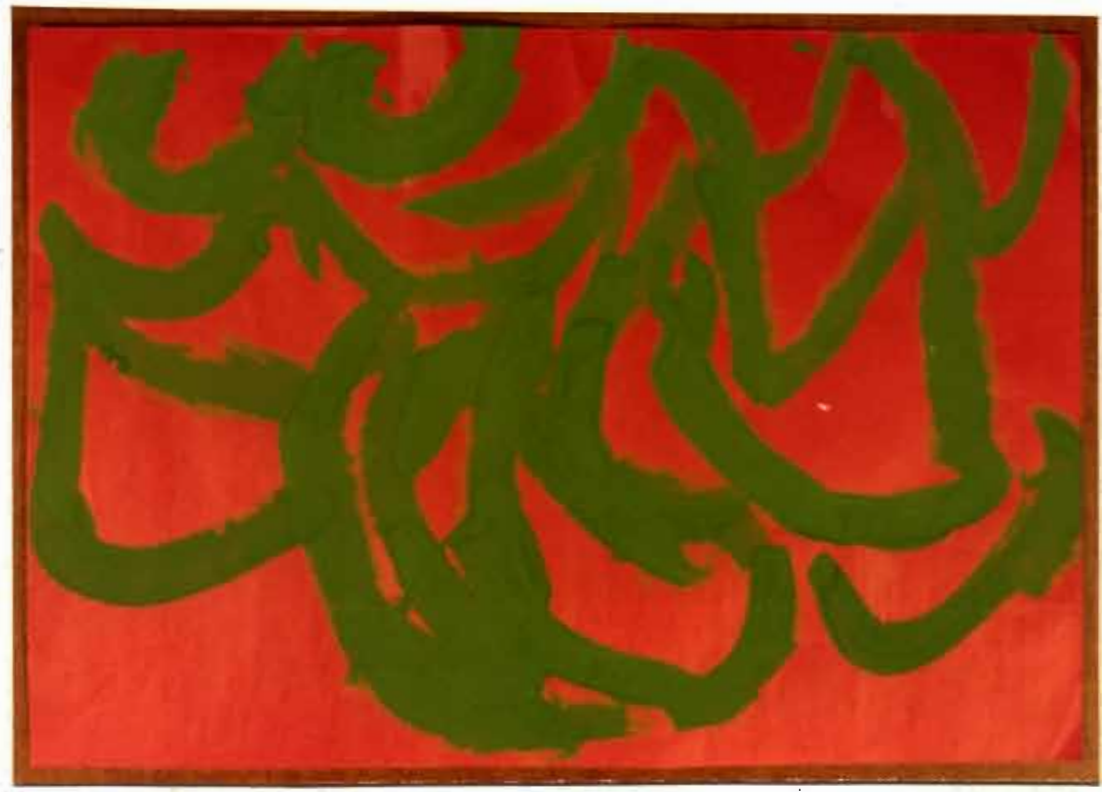

Figure 102. Kay, tempera on paper, $42.5 \mathrm{~cm} \mathrm{x} 60.9 \mathrm{~cm}$. 


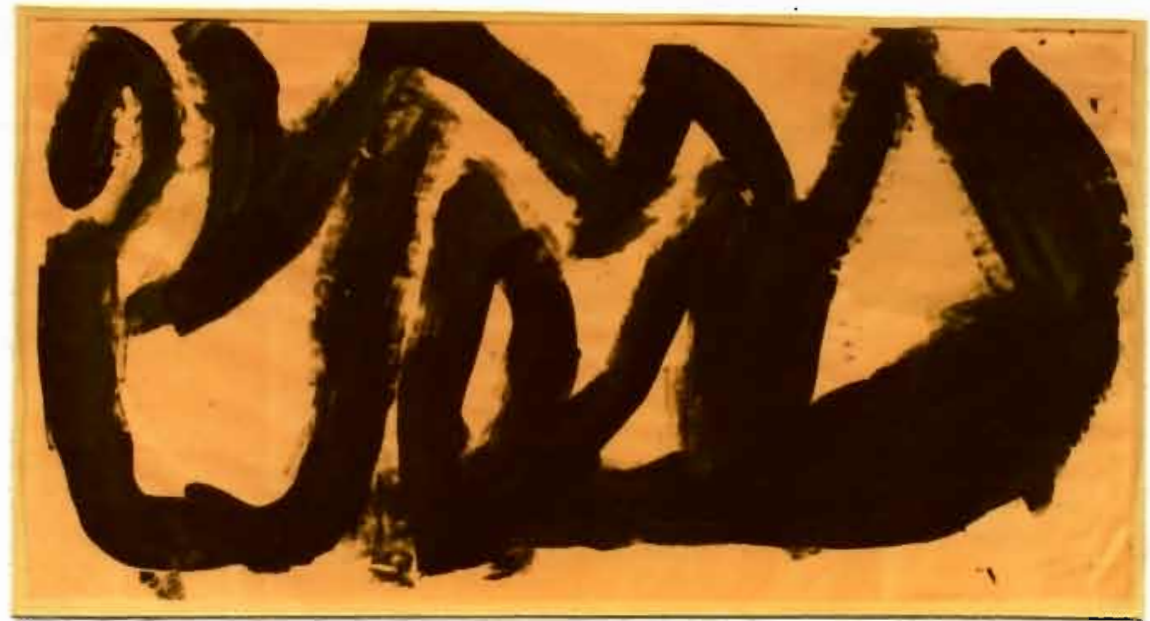

Figure 103. Kay, tempera on paper, $29.2 \mathrm{~cm} \mathrm{x} 56.0 \mathrm{~cm}$.

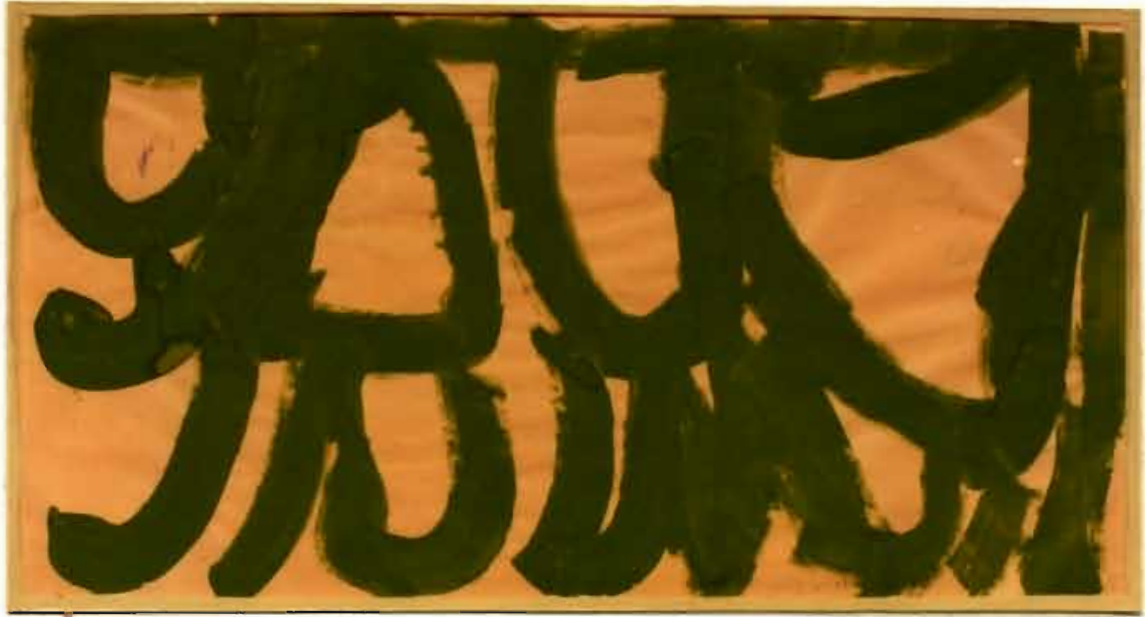

$\frac{\text { Figure } 104}{29.2 \mathrm{~cm} \times}$ K6. Kay, tempera on paper, 


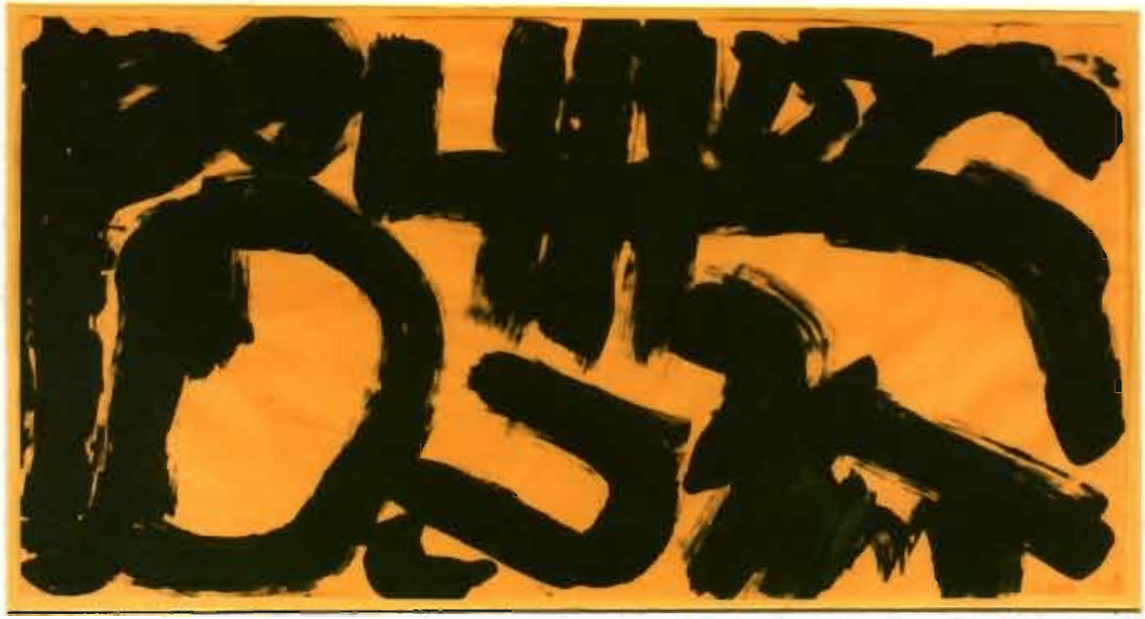

Figure 105. Kay, tempera on paper, $29.2 \mathrm{~cm}$ $\mathrm{x} 56.0 \mathrm{~cm}$.

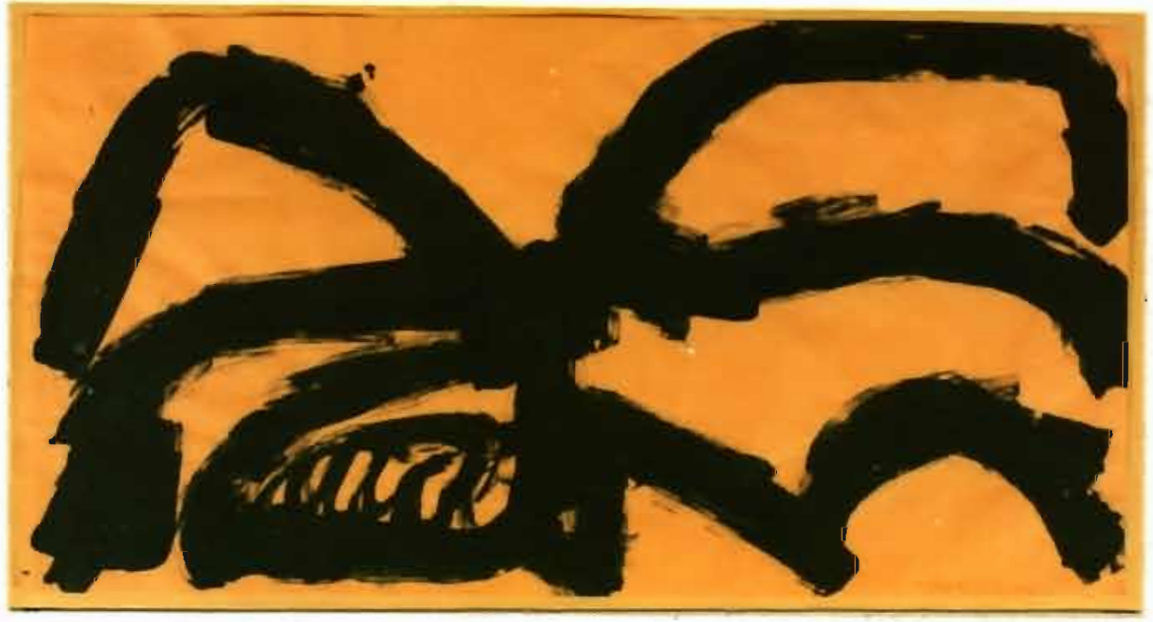

Figure 106. Kay, tempera on paper, $29.2 \mathrm{~cm}$ $\mathrm{x} 56.0 \mathrm{~cm}$. 


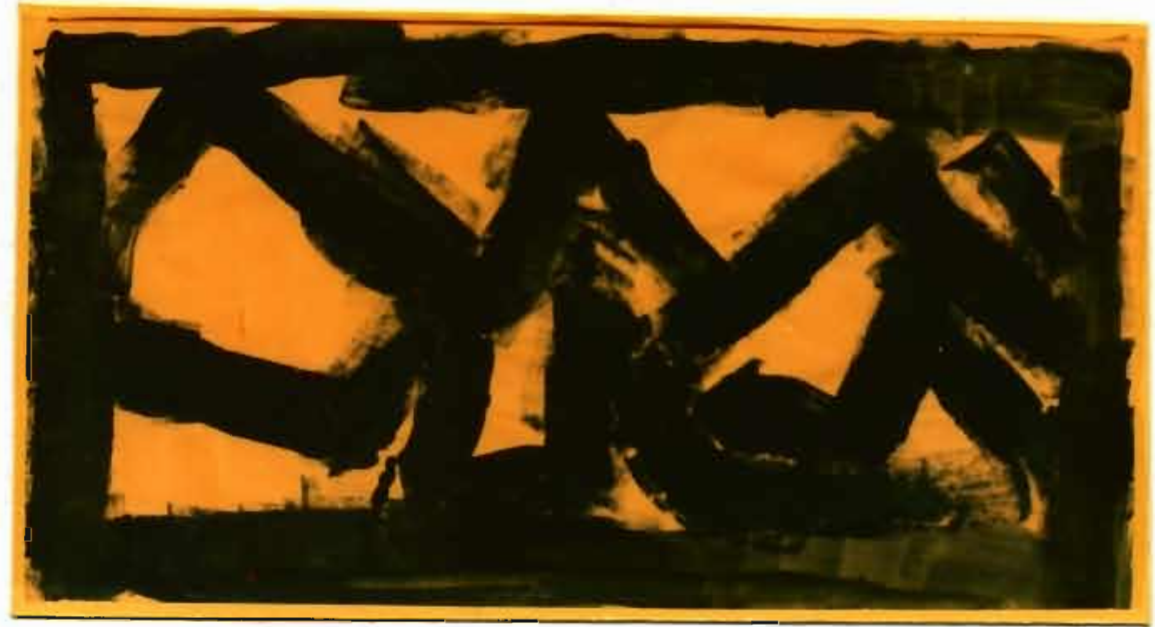

Figure 107. Kay, tempera on paper, $29.2 \mathrm{~cm} \mathrm{x} 56.0 \mathrm{~cm}$.

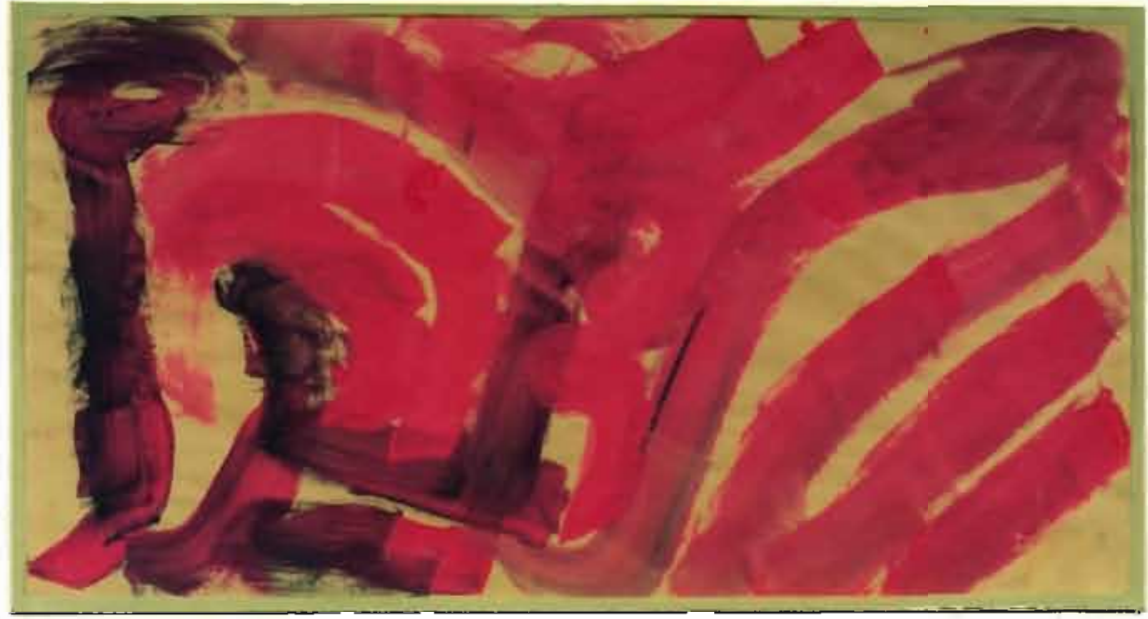

Figure 108. Kay, tempera on paper, $29.2 \mathrm{~cm}$ $\mathrm{x} 56.0 \mathrm{~cm}$. 


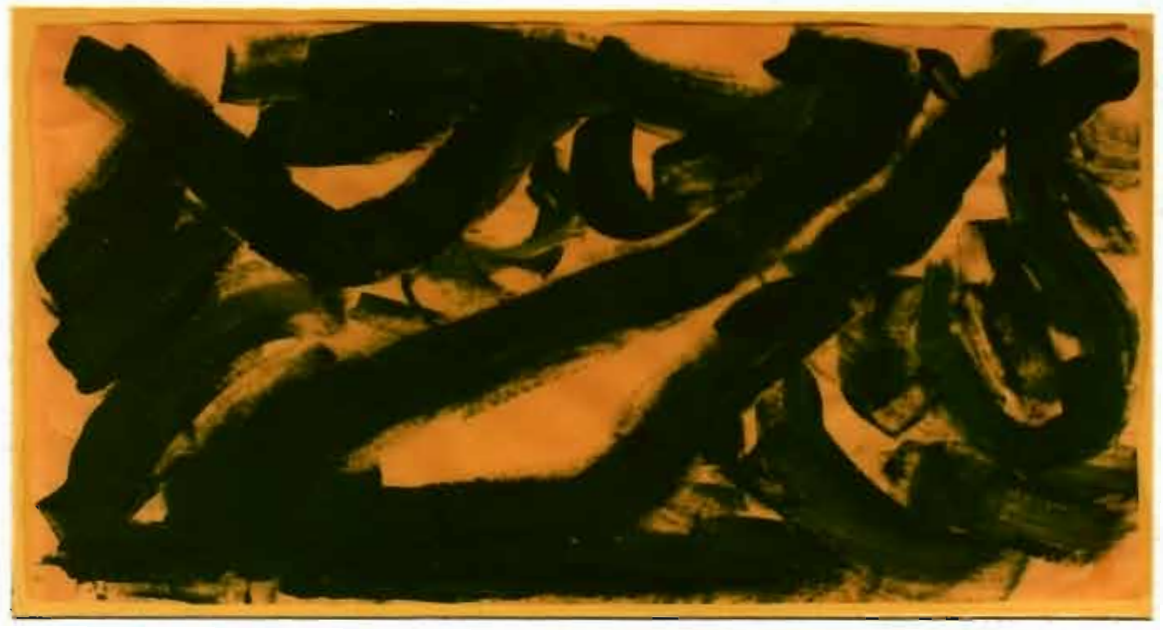

Figure 109. Kay, tempera on paper, $29.2 \mathrm{~cm}$ $\mathrm{x} 56.0 \mathrm{~cm}$.

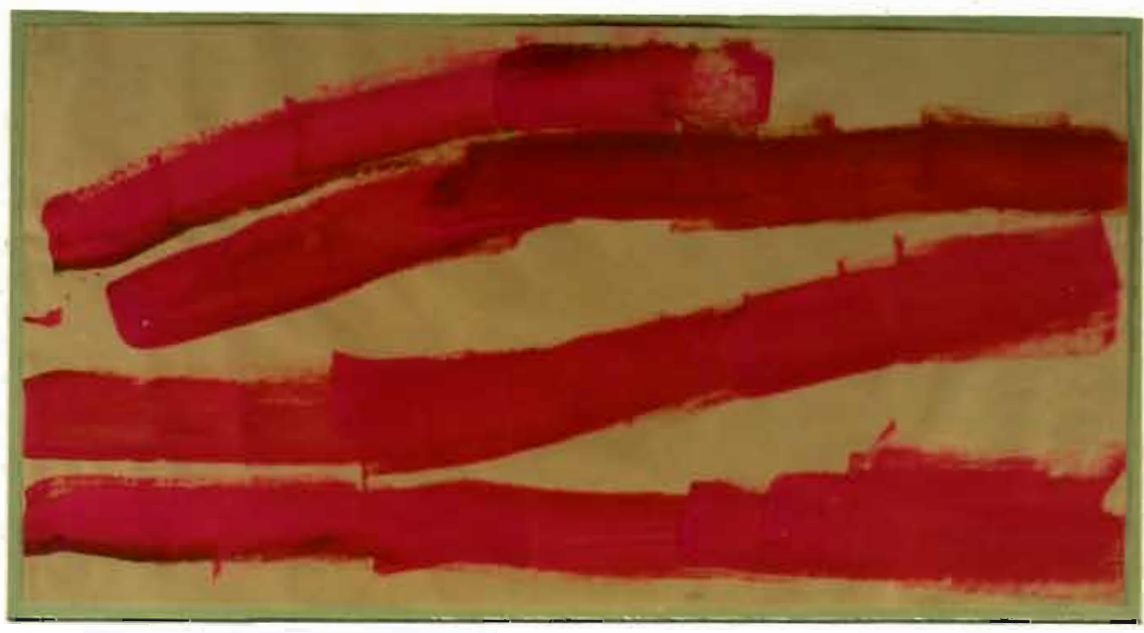

Figure 110. Kay, tempera on paper, $29.2 \mathrm{~cm}$ $\mathrm{x} 56.0 \mathrm{~cm}$. 


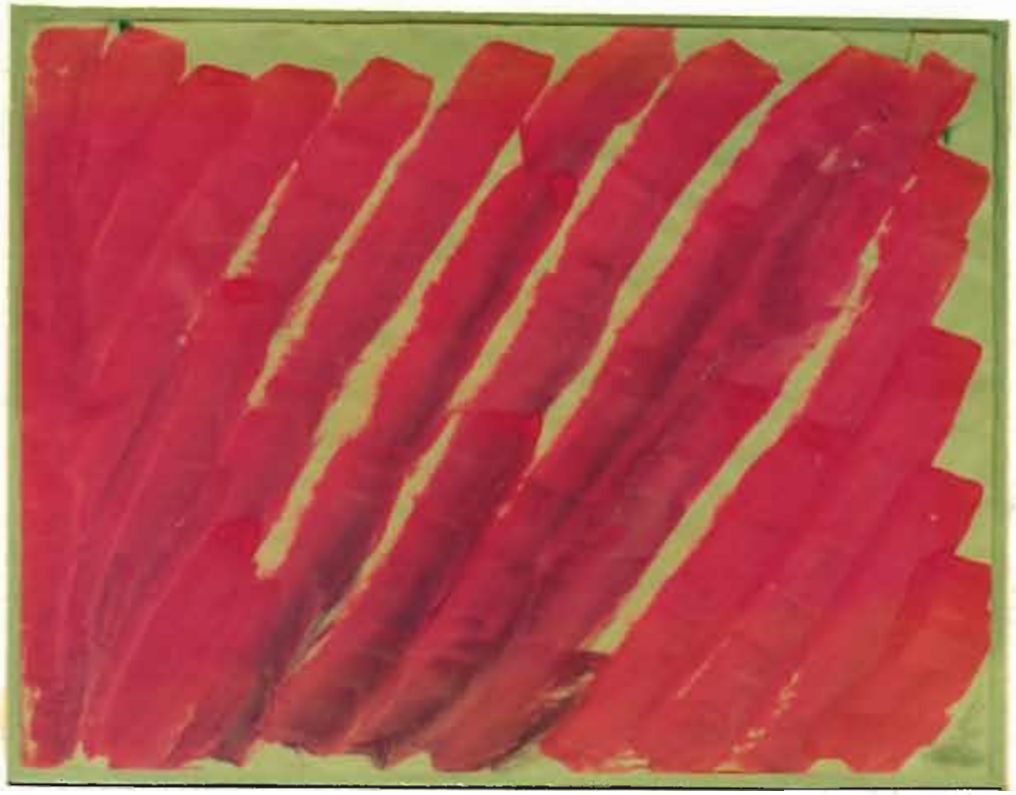

Figure 11l. Kay, tempera on paper, $43.0 \mathrm{~cm} \times 55.7 \mathrm{~cm}$.

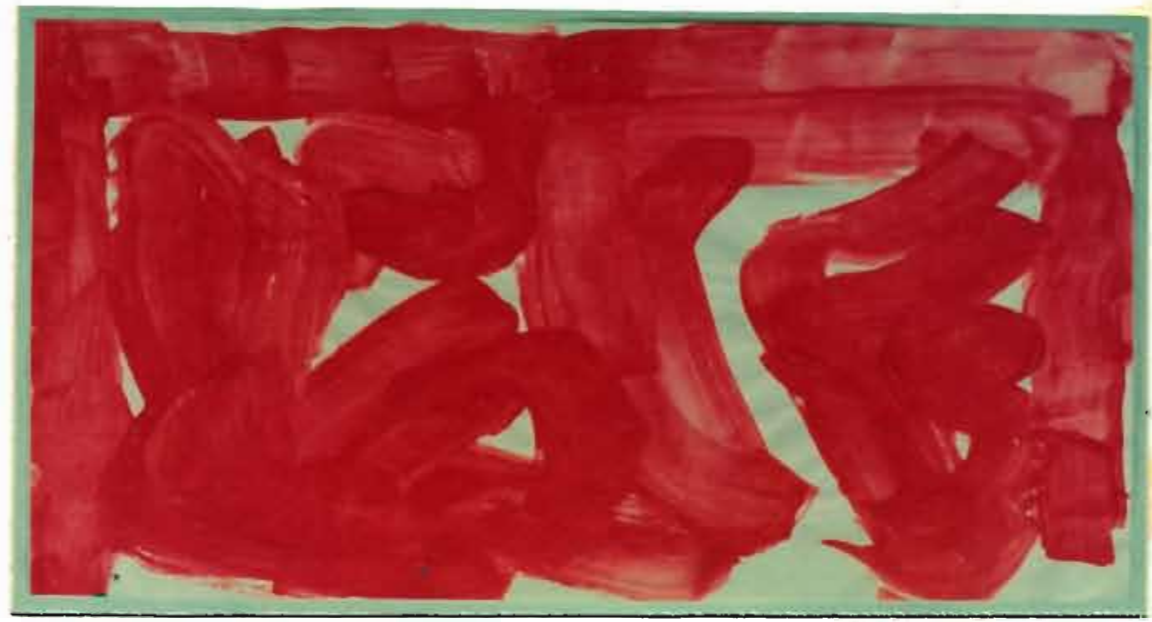

Figure 112. Kay, tempera on paper, $29.2 \mathrm{~cm} \times 56.0 \mathrm{~cm}$. 


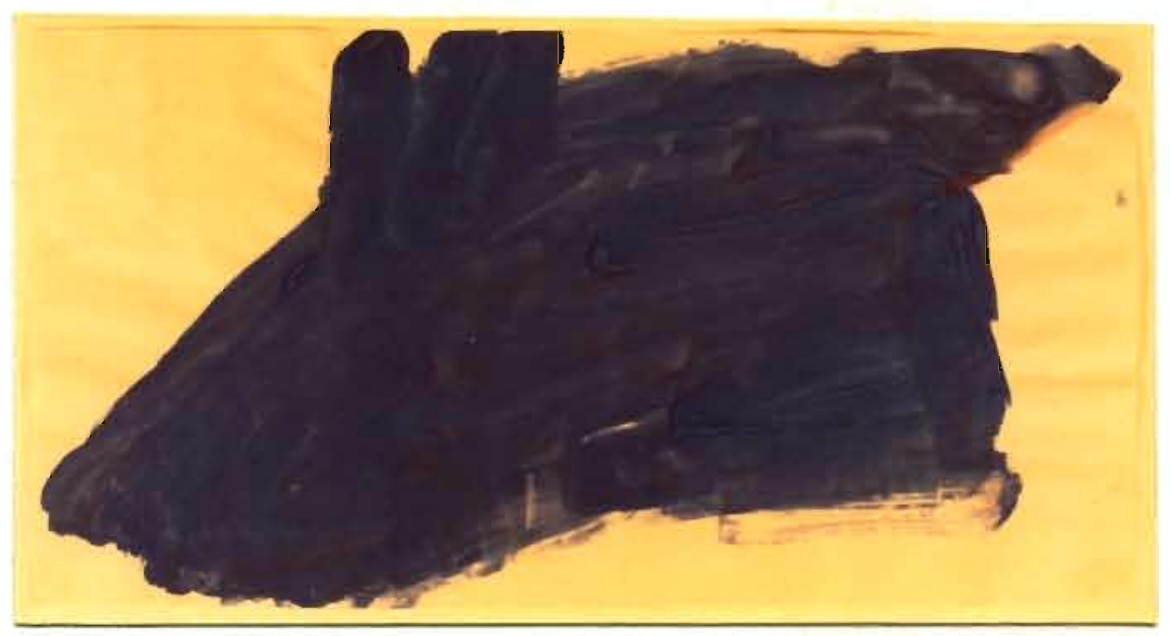
$\frac{\text { Figure 113. Kay, tempera on paper, }}{29.2 \mathrm{~cm} \times 56.0 \mathrm{~cm} \text {. }}$

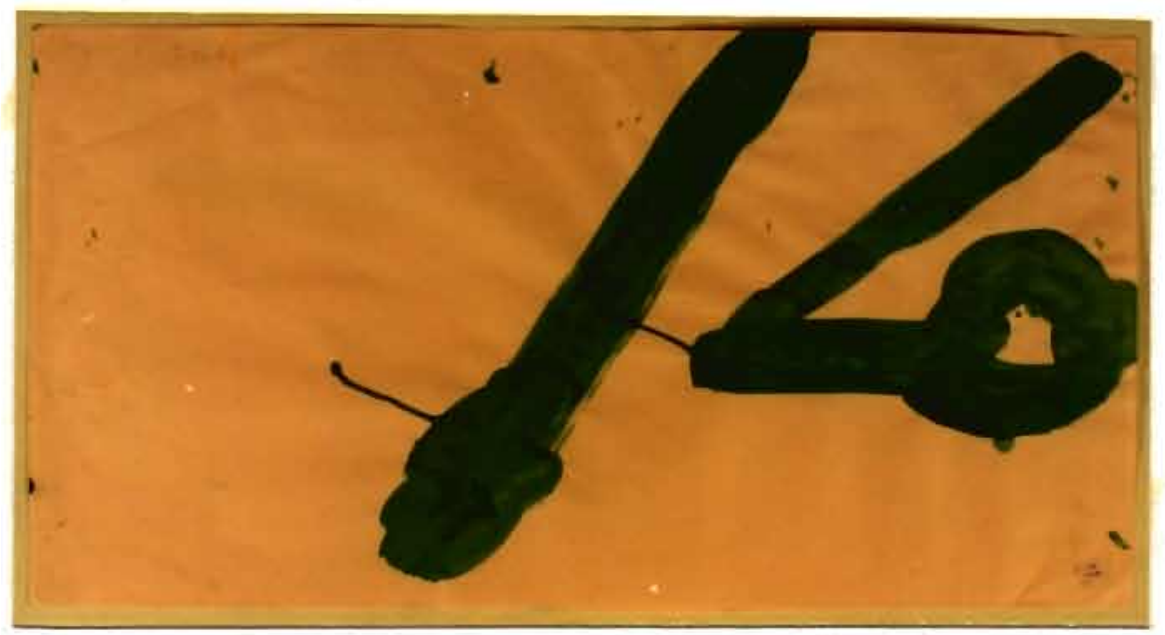

Figure 114. Kay, tempera on paper, $29.2 \mathrm{~cm} \times 56.0 \mathrm{~cm}$. 


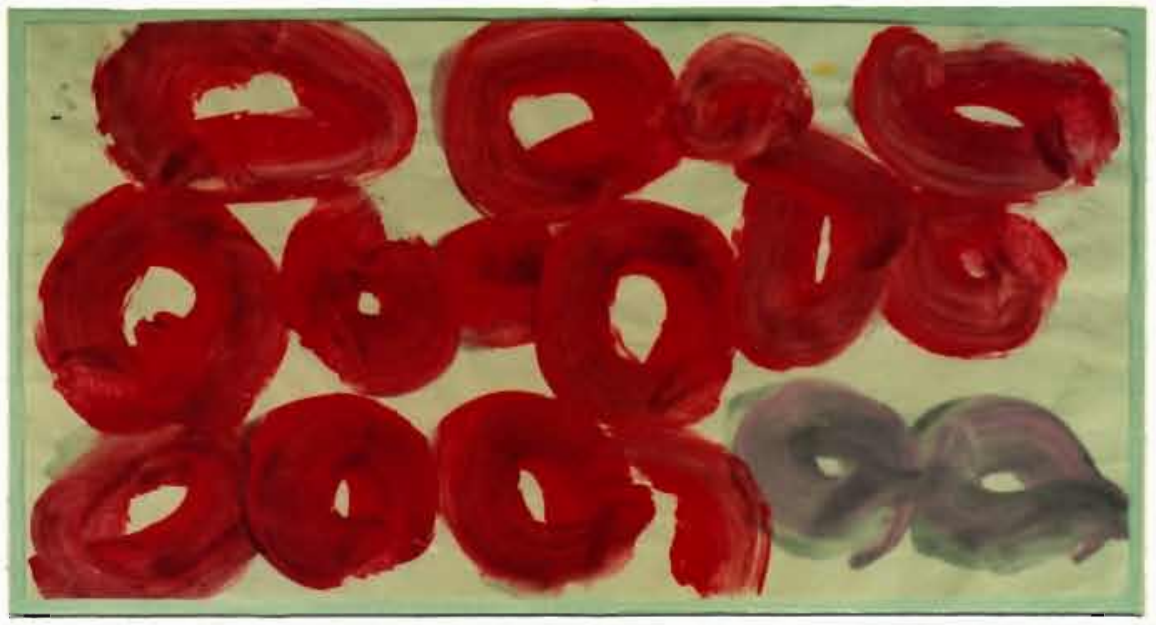

Figure 115. Kay, tempera on paper, $29.2 \mathrm{~cm} \mathrm{x} 56.0 \mathrm{~cm}$.

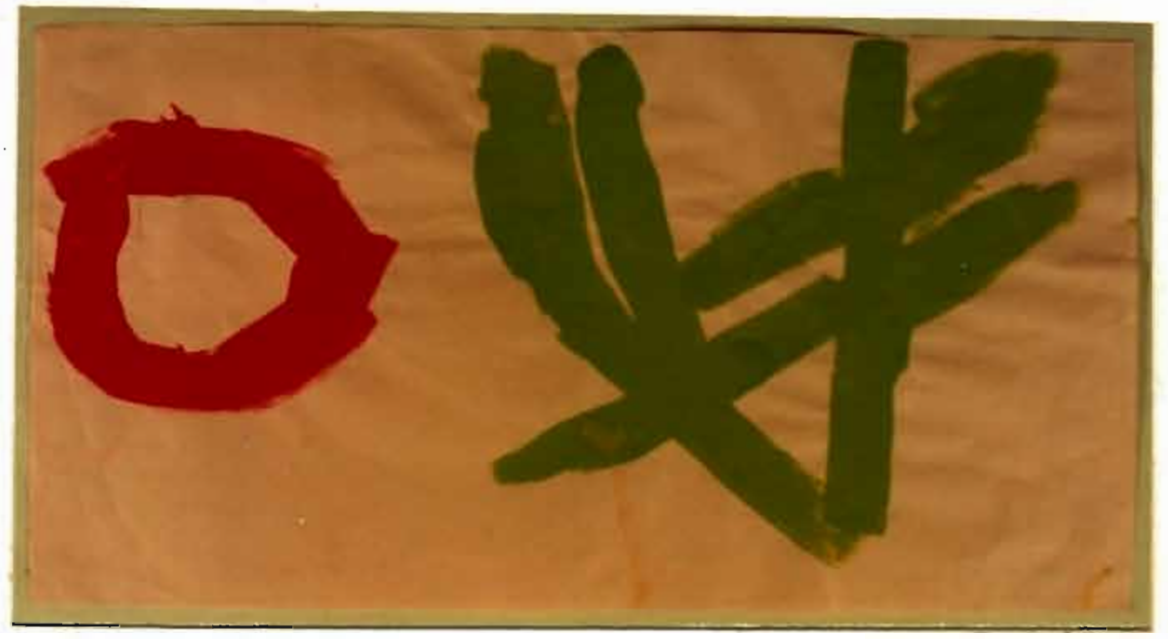

Figure 116. Kay, tempera on paper,

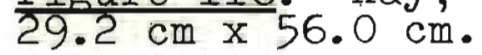




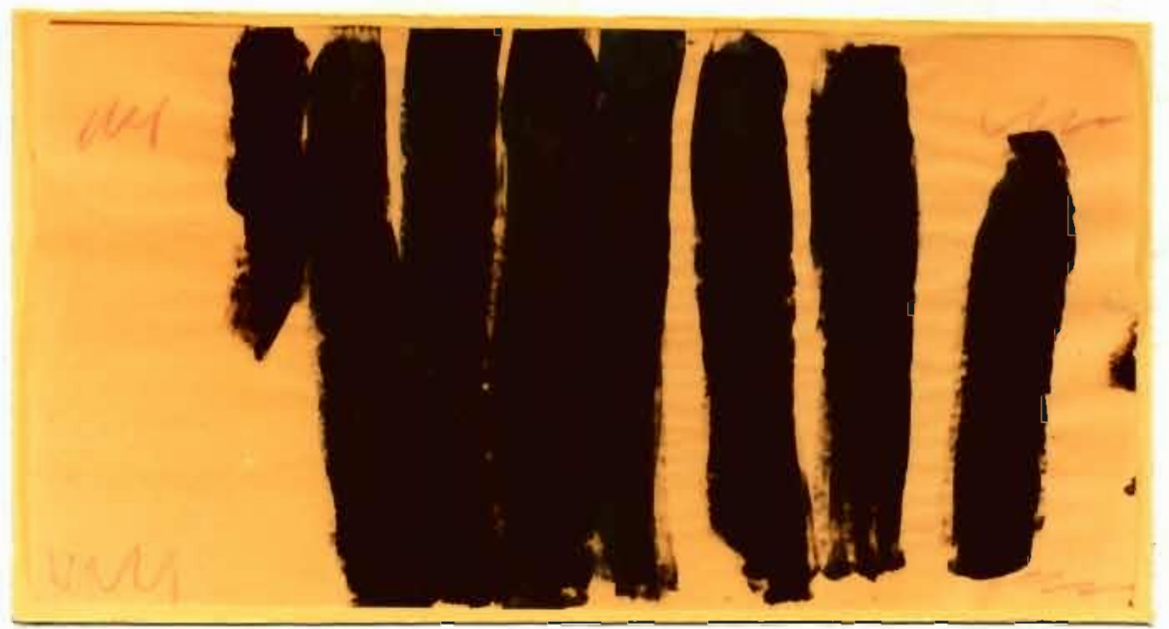
Figure 117. Kay, tempera on paper,
$29.2 \mathrm{~cm} \times 56.0 \mathrm{~cm}$.

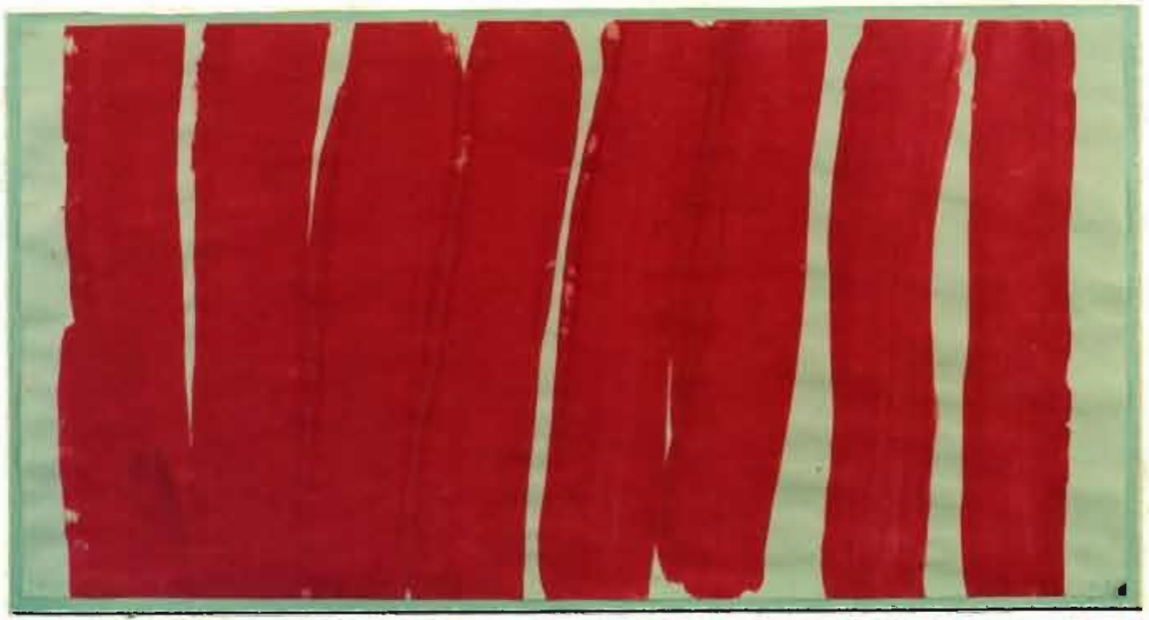

Figure 118. Kay, tempera on paper, $29.2 \mathrm{~cm} \times 56.0 \mathrm{~cm}$. 


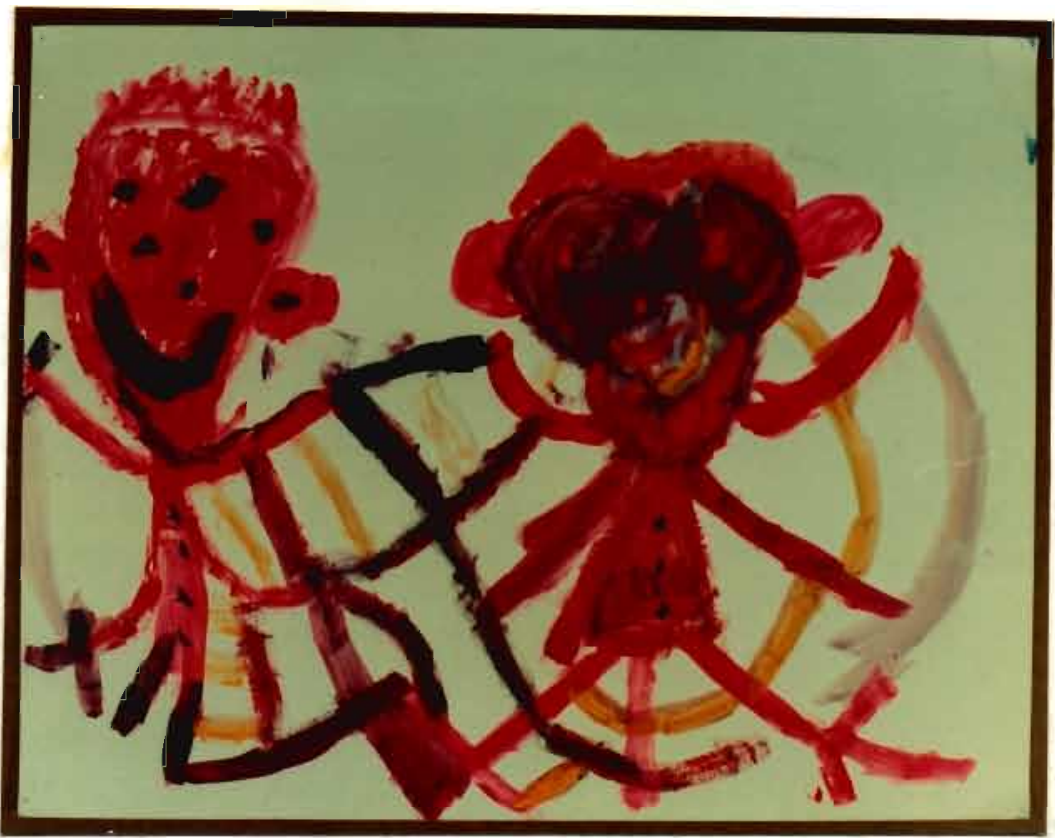

Figure 119. David, acrylic on paper, $56.0 \mathrm{~cm} \mathrm{x} 71.4 \mathrm{~cm}$.

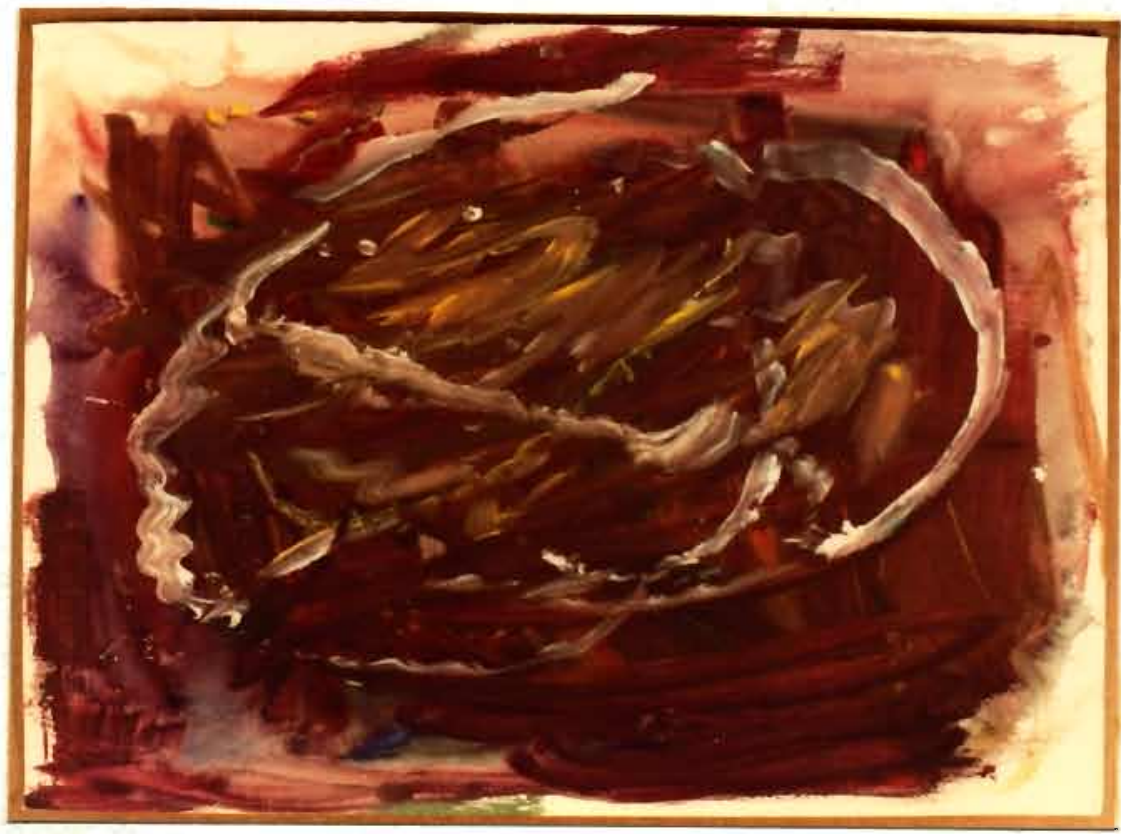

Figure 120. David, acrylic on paper, $56.0 \mathrm{~cm} \times 76.2 \mathrm{~cm}$. 


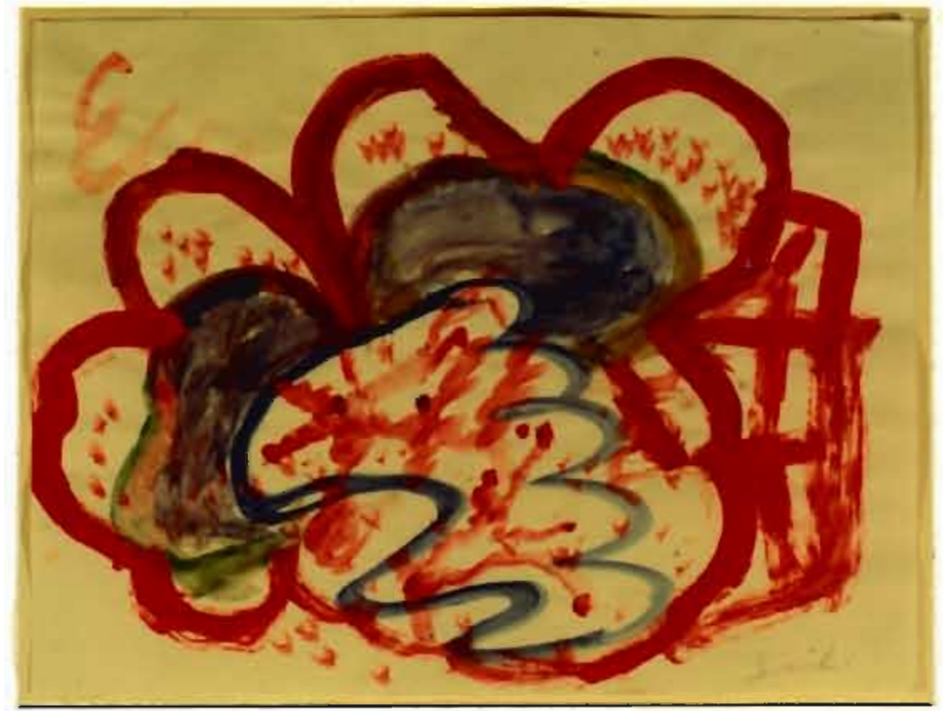

Figure 121. David, acrylic on paper, $43.0 \mathrm{~cm} \times 56.0 \mathrm{~cm}$.

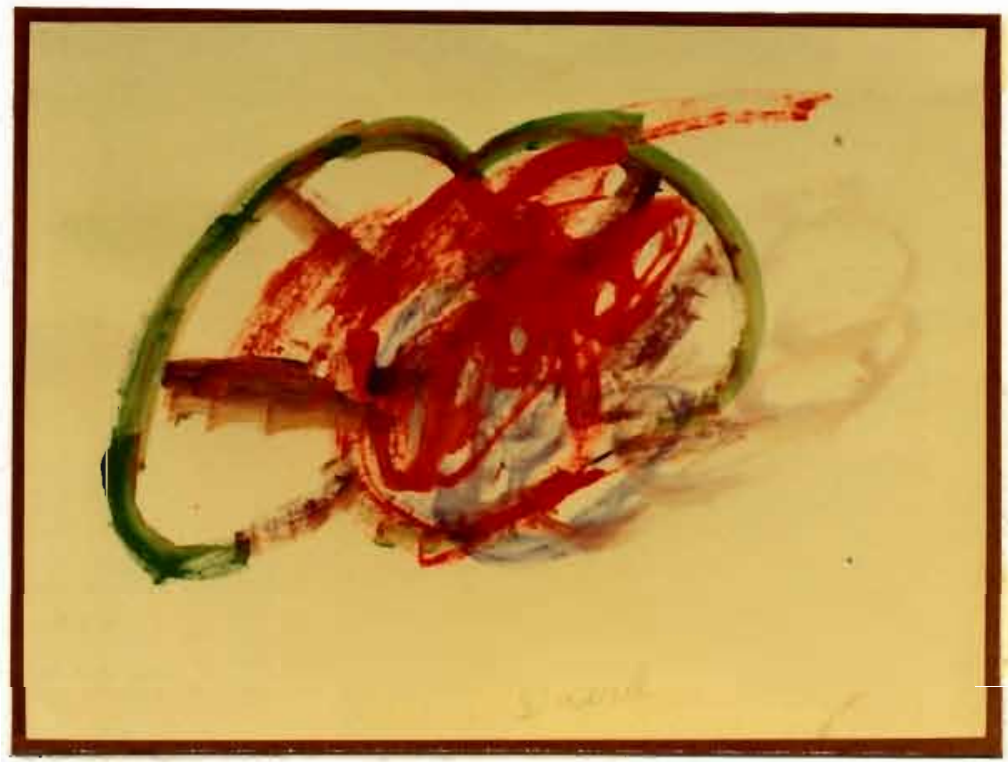

Figure 122. David, acrylic on paper, $45.7 \mathrm{~cm} \times 61.2 \mathrm{~cm}$. 


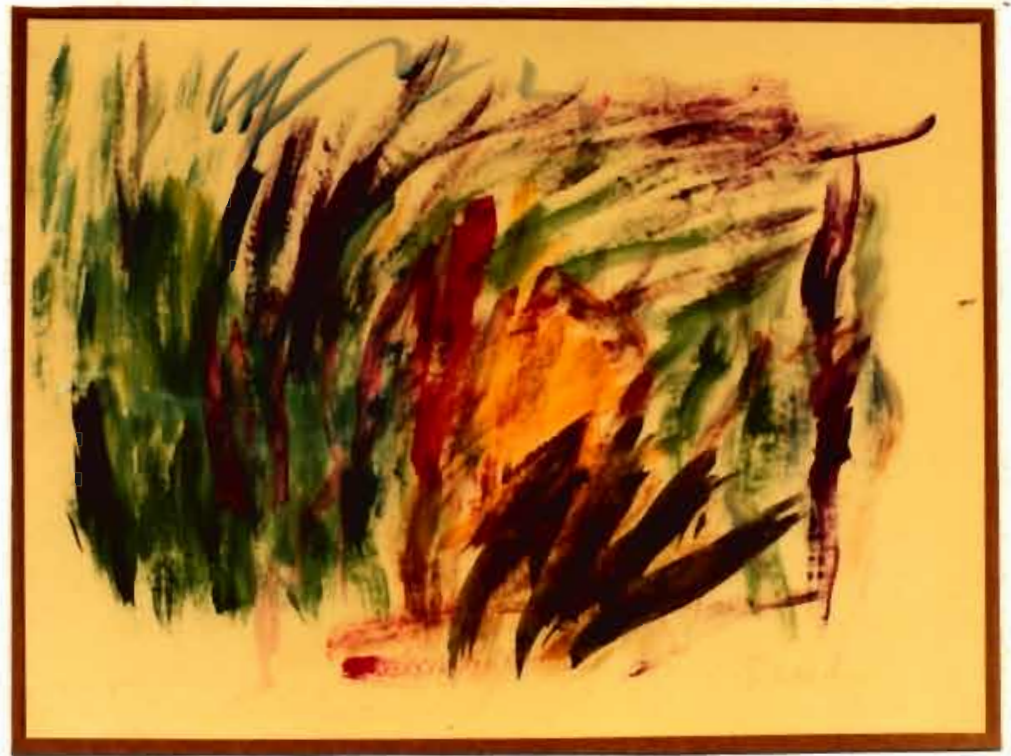

Figure 123. David, acrylic on paper, $45.7 \mathrm{~cm} \mathrm{x} 61.0 \mathrm{~cm}$.

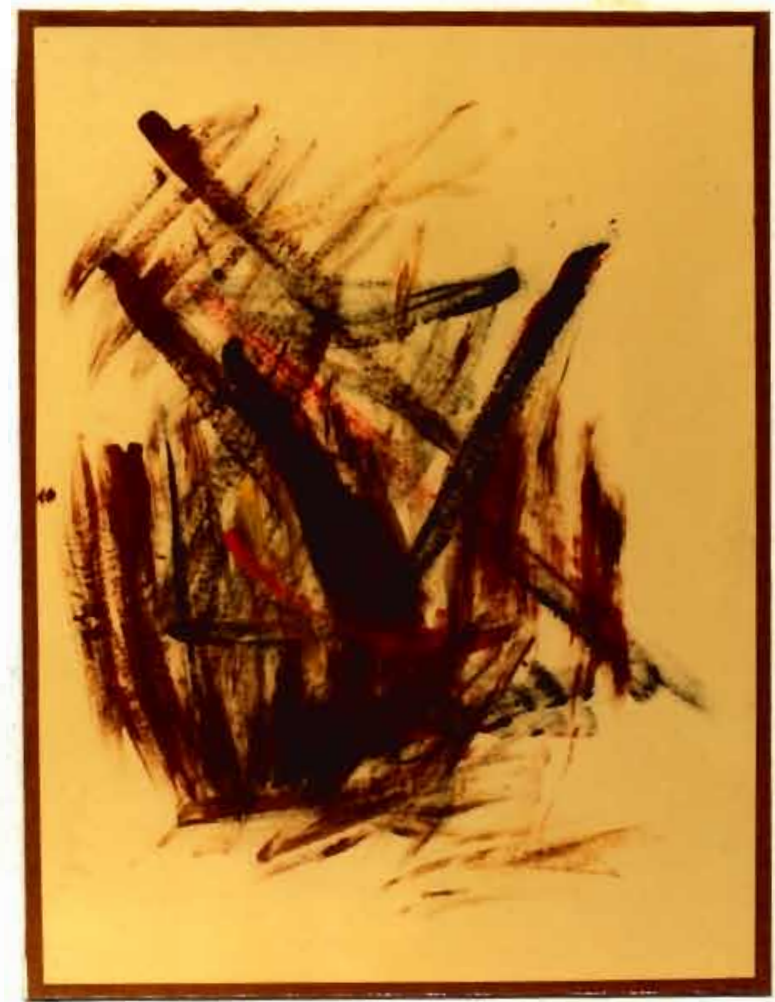

Figure 124. David, acrylic on paper, $61.0 \mathrm{~cm} \mathrm{x} 45.7 \mathrm{~cm}$. 


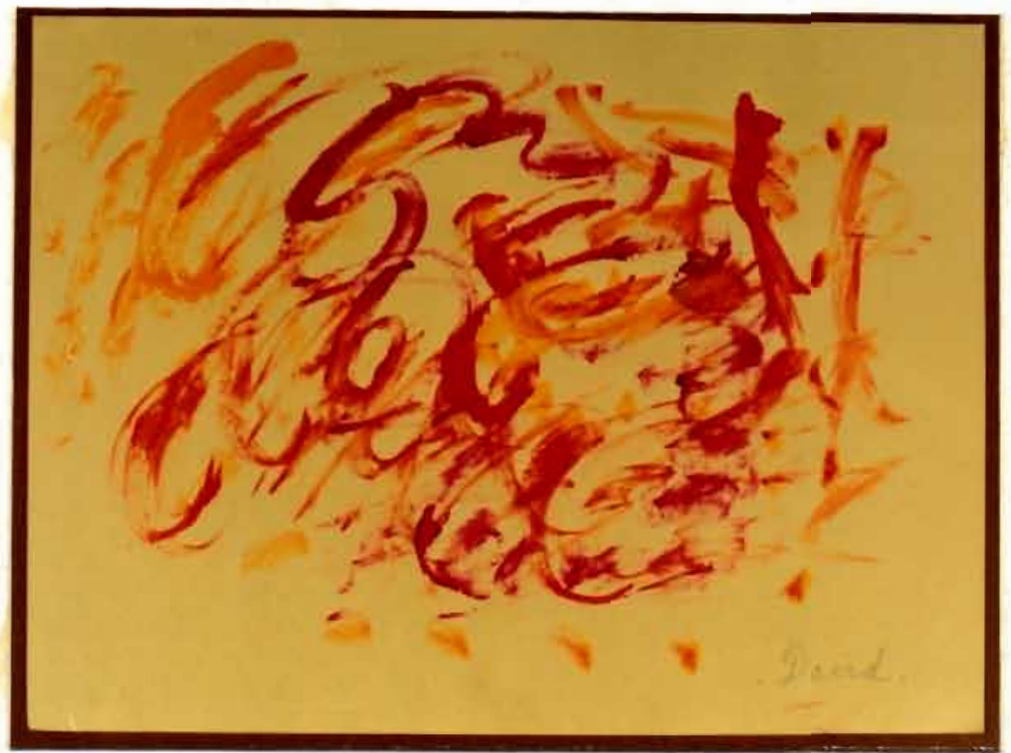

Figure 125. David, acrylic on paper, $45.7 \mathrm{~cm} \mathrm{x} 61.0 \mathrm{~cm}$.

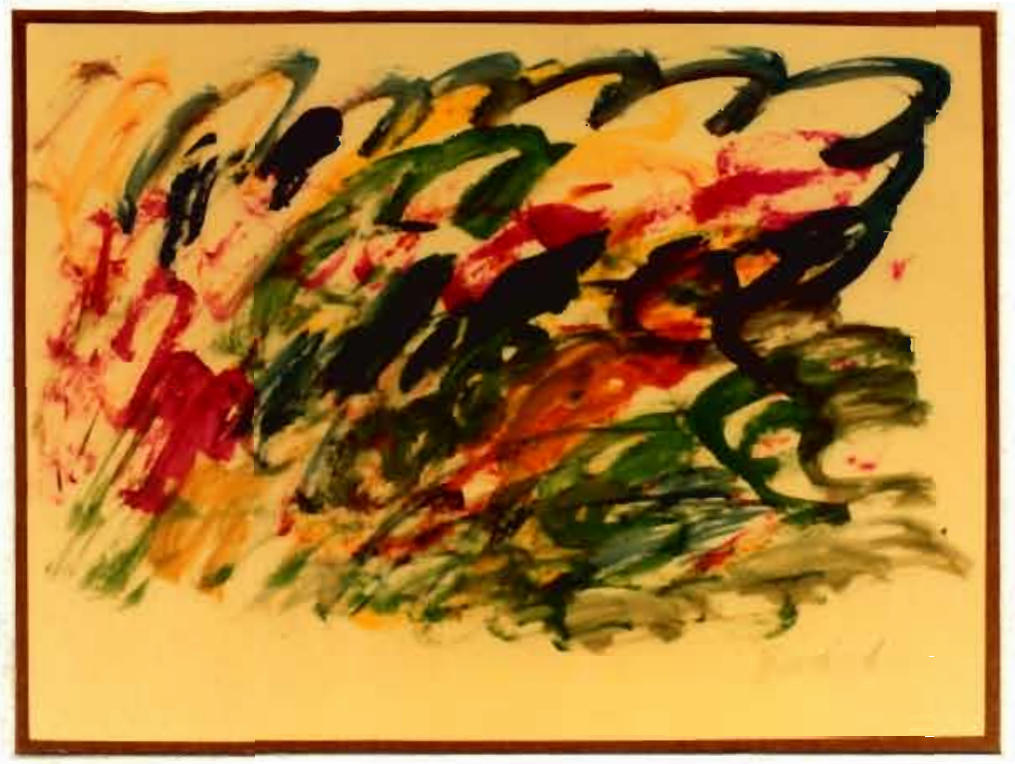

Figure 126. David, acrylic on paper, $45.7 \mathrm{~cm} \mathrm{x} 61.0 \mathrm{~cm}$. 


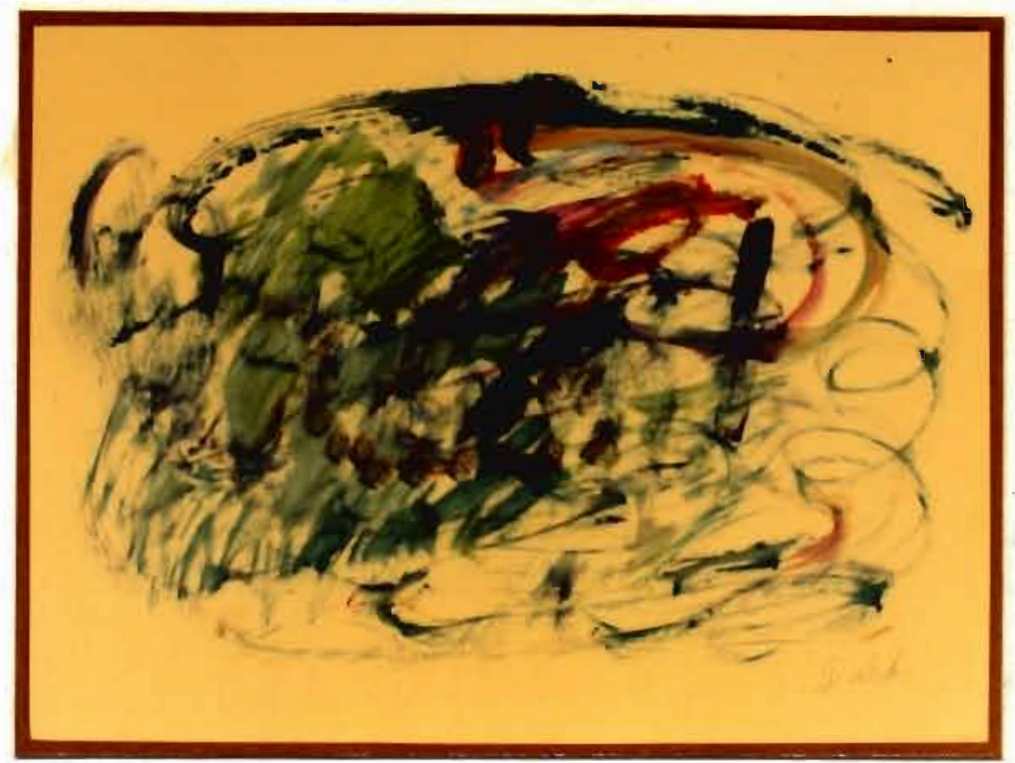

Figure 127. David, acrylic on paper, $45.7 \mathrm{~cm} \mathrm{x} 61.0 \mathrm{~cm}$.

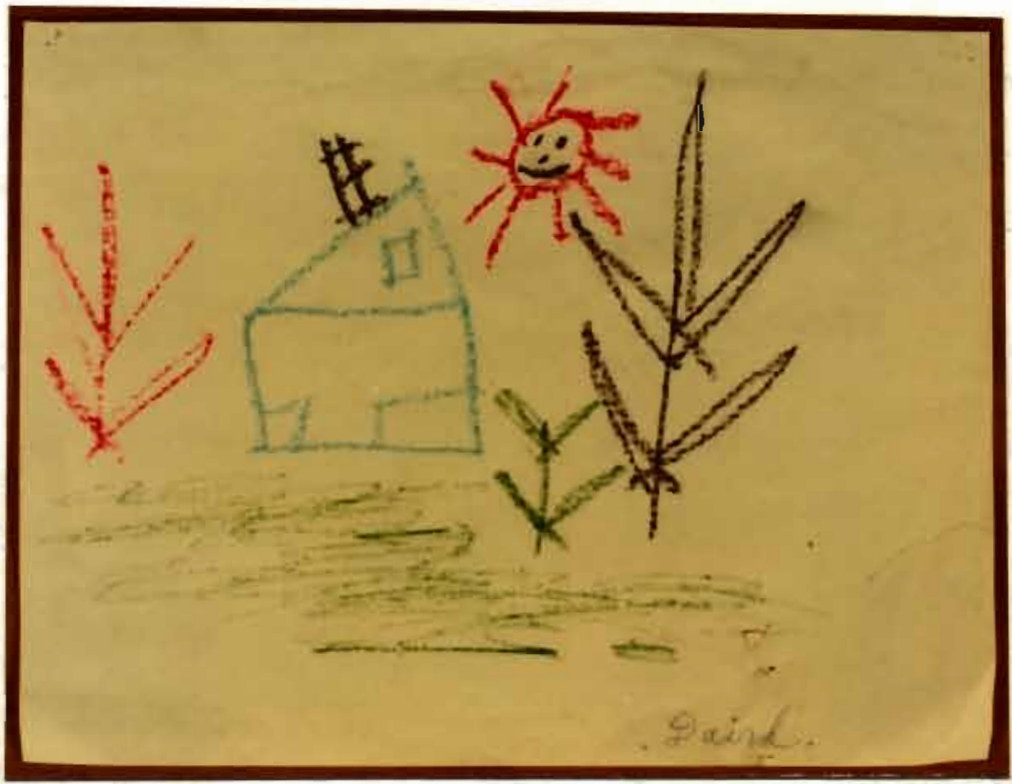

Figure 128. David, wax crayon on paper, $27.2 \mathrm{~cm} \times 31.5 \mathrm{~cm}$. 


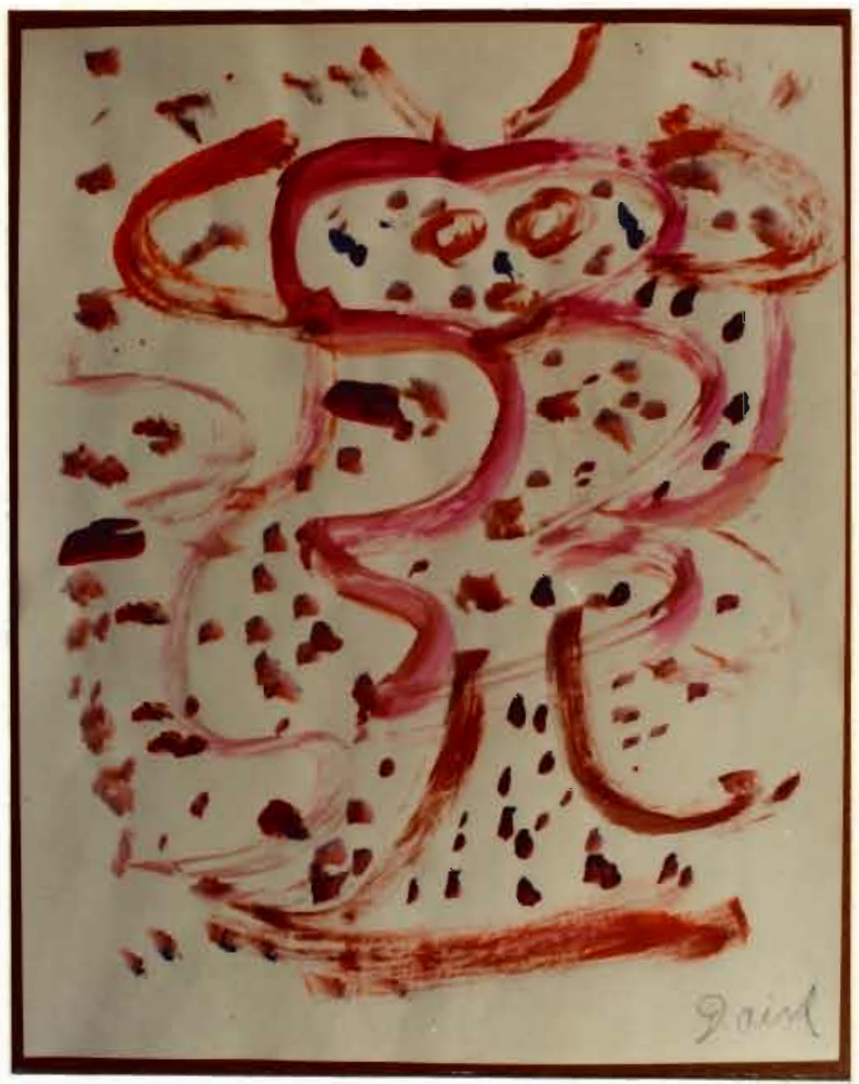

Figure 129. David, acrylic on paper, $61.1 \mathrm{~cm} \times 48.6 \mathrm{~cm}$.

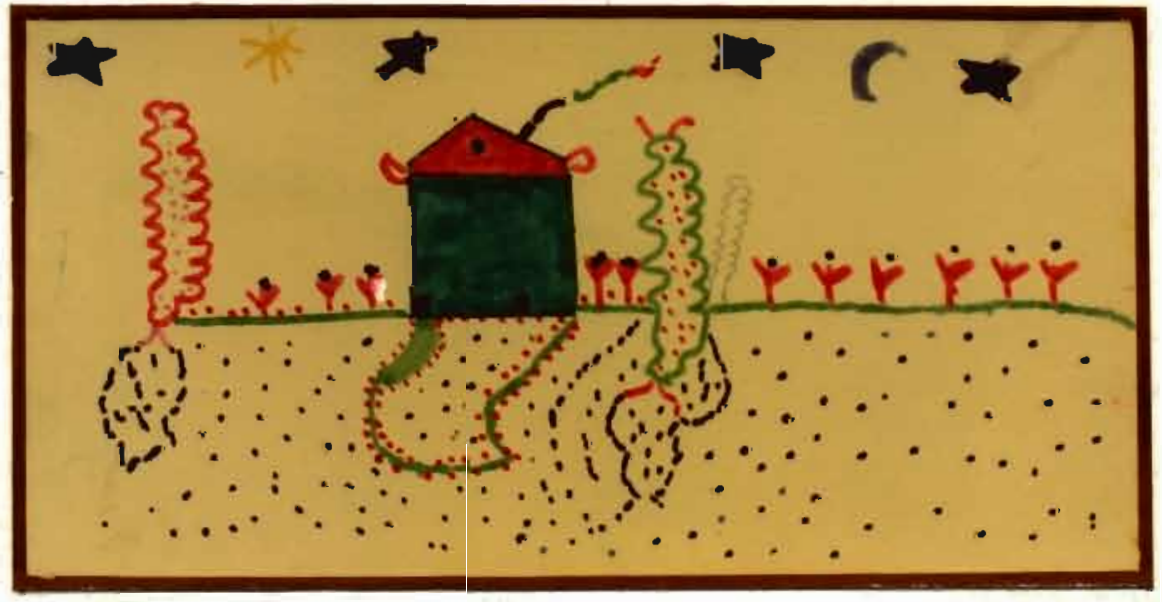

Figure 130. David, marking pen on canvas board, $20.2 \mathrm{~cm} \mathrm{x} 40.5 \mathrm{~cm}$. 


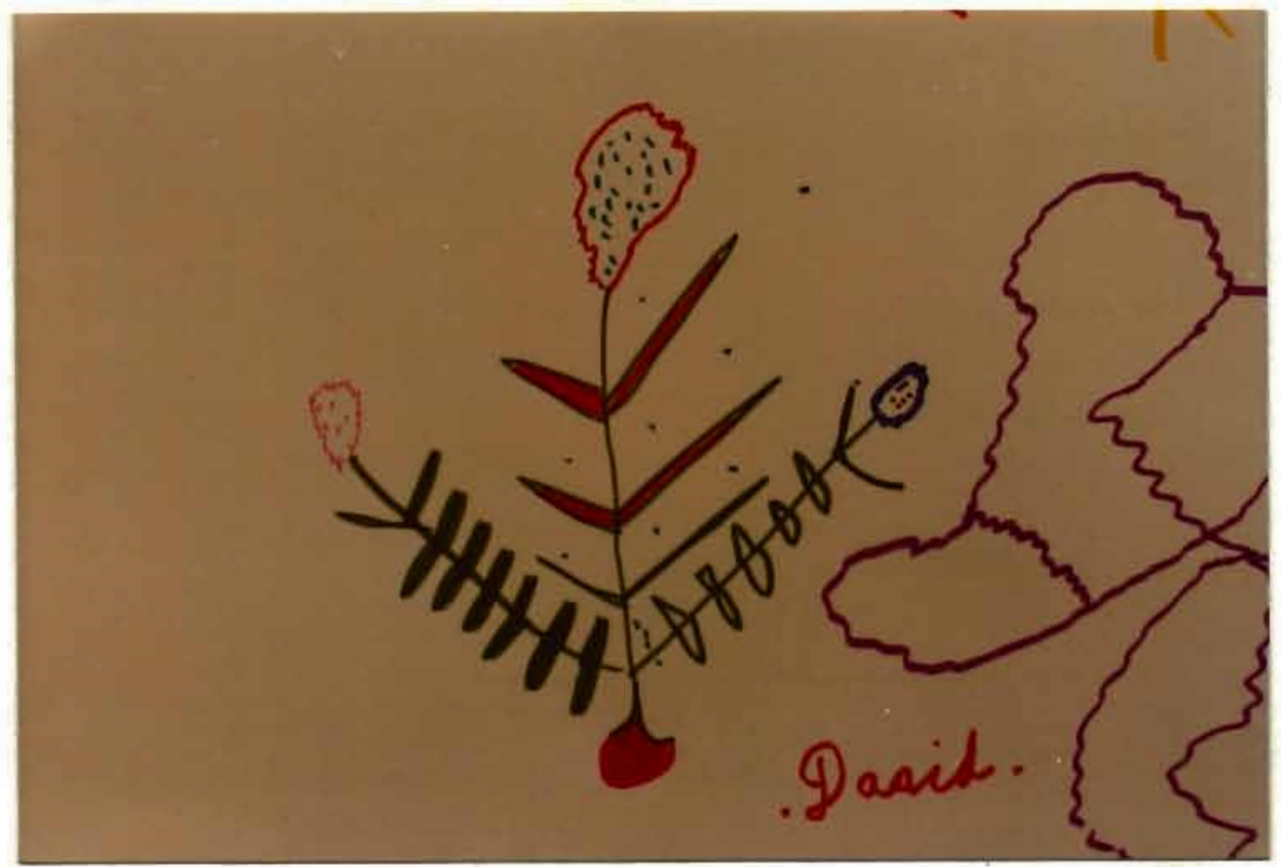

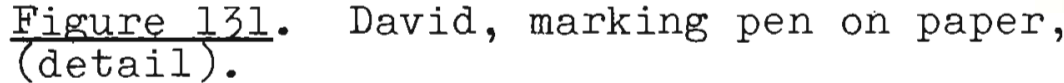

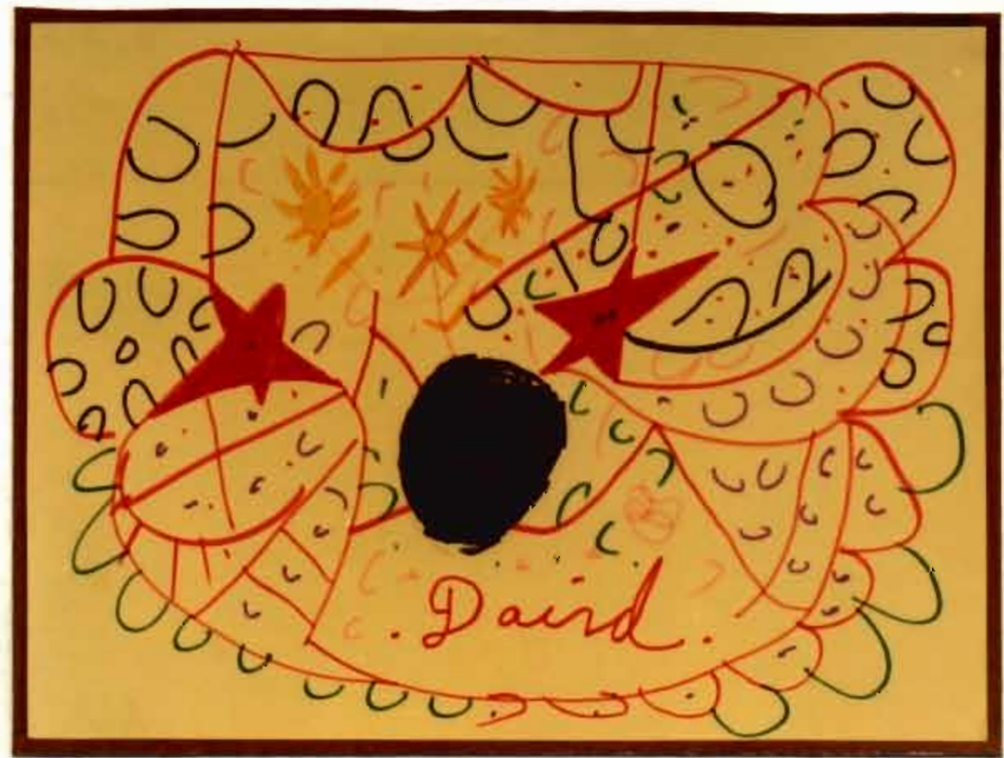

Figure 132. David, marking pen on paper, $45.7 \mathrm{~cm} \times 61.0 \mathrm{~cm}$. 